\title{
Conceptual Design for a High-Temperature Gas Loop Test Facility
}

James B. Kesseli

Thomas L. Wolf

F. Wells Hodous

James S. Nash

Malcom S. Child

Robert S. Cherry

Richard L. Williamson

Ted R. Reed

A. Joseph Palmer

August 2006

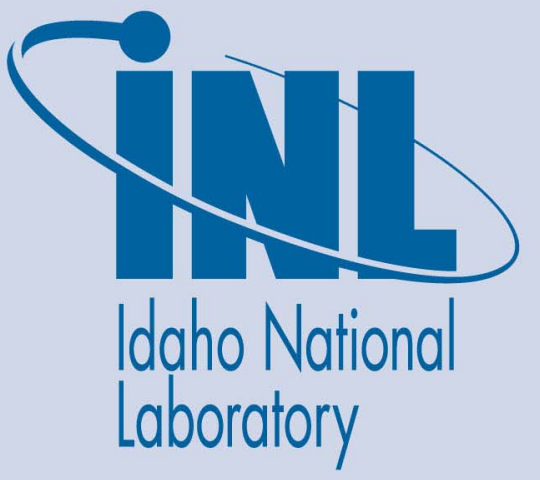

The INL is a U.S. Department of Energy National Laboratory operated by Battelle Energy Alliance 
INL/EXT-06-11648

\section{Conceptual Design for a High-Temperature Gas Loop Test Facility}

${ }^{a}$ Brayton Energy, Inc.

bIdaho National Laboratory
James B. Kesseli ${ }^{\mathrm{a}}$

Thomas L. Wolf ${ }^{a}$

F. Wells Hodous ${ }^{a}$

James S. Nash ${ }^{\mathrm{a}}$

Malcom S. Child ${ }^{a}$

Robert S. Cherry

Richard L. Williamson ${ }^{b}$

Ted R. Reed

A. Joseph Palmer

August 2006

Idaho National Laboratory

Idaho Falls, Idaho 83415

Prepared for the

U.S. Department of Energy

Office of Nuclear Energy

Under DOE Idaho Operations Office

Contract DE-AC07-05ID14517 


\section{EXECUTIVE SUMMARY}

Design of the Next Generation Nuclear Plant (NGNP) must meet strenuous demands imposed by peak temperatures reaching $950^{\circ} \mathrm{C}$, pressures up to $8 \mathrm{MPa}$, and potentially corrosive gases. Foremost among the design challenges is the Intermediate Heat Exchanger (IHX), responsible for transferring heat between the primary (reactor) and secondary (power producing or process heating) streams. A critical requirement for the IHX is survivability under repeated thermal stresses experienced during transient operation.

This document reports on the conceptual design of a test facility capable of simulating the operating conditions for the IHX and other enabling components needed for NGNP development. The specifications adopted for this design were guided by surveys of existing and planned test facilities of similar application, including a visit to the HELITE facility under current development in Cardarache, France. Additionally, an industry survey identified equipment types that could be tested in such a facility, including application to programs other than NGNP. These surveys were instrumental in identifying critical components, among them high-temperature valves and insulation materials. They also informed choice of test scenarios, especially transient maneuvers, establishing a basis for the equipment capabilities and control strategy outlined in this report.

Thermal capacity of the test facility is chosen as $2 \mathrm{MW}$, roughly $1 / 300^{\text {th }}$ that envisioned for a commercial plant. This scale is adequate for testing a full-scale IHX module under representative interface conditions, while remaining small enough to allow for efficient configuration changes as described below. Cost considerations also factored into the determination of system scale.

To provide a range of flexible test scenarios, the facility configuration will feature a single primary loop with a centralized heat source feeding three parallel secondary loops. A conceptual layout drawing identifying the major components associated with the primary (helium) loop, a single secondary loop, and associated support equipment is shown in Figure S-1. Because many of the operating conditions of this unit are near the limit of materials technology, the test loop uses a somewhat revised flow sheet (compared to the NGNP itself) to reduce the demands on materials and equipment while still providing the necessary test conditions. While much of the test system is based on available industrial equipment, several major components will require custom design. A key component in the system design is the 3meter-diameter IHX test vessel. This vessel is sized to accommodate a wide range of test articles and associated instrumentation. The helium and low molecular-weight gas circulators are not standard commercial items and will require some level of customization to meet the functional requirements. The 2 MW electrical heat source and two specialized recuperators will also be custom items although their designs are more conventional. The technological risks of much of this vendor-supplied equipment must be aggressively managed to assure that the supplied hardware is adequately tested and qualified prior to use in the facility.

While a turnkey cost estimate for the facility was not an objective of this study, costs for the major hardware in the primary and one secondary loop were determined. These estimates do not include categories such as equipment for the other secondary loops, detailed engineering and design, construction costs, the cost of the building the unit is installed in (either modifications of an existing building or construction of a new building), additional development costs for novel equipment, or contingency. With these provisos, the estimated procurement cost of the test loop hardware considered in this report is $\$ 4.3$ million. The cost of the completed facility ready for operation will be substantially higher. A rough schedule, which is dependent on funding levels, suggests facility construction beginning in FY-09 with component testing commencing in FY-10. 
Several non-design tasks would strengthen this test loop program. Other NGNP/IHX designers and potential users should be contacted to validate the design requirements and to critique the current effort as it progresses. Beyond that, it would be valuable to develop formal and informal collaborations with researchers at similar facilities in France, Japan, China, and South Africa to facilitate future discussions of design information, test plans, test results, and operational experience. Finally, establishing an R\&D program to develop the advanced instrumentation and measurement techniques needed for strain, thermal imaging, internal displacements, leak rate, and other measurements, on-line and at full test conditions, will be highly valuable in maximizing the quantity, quality, and utility of data produced by this test loop.

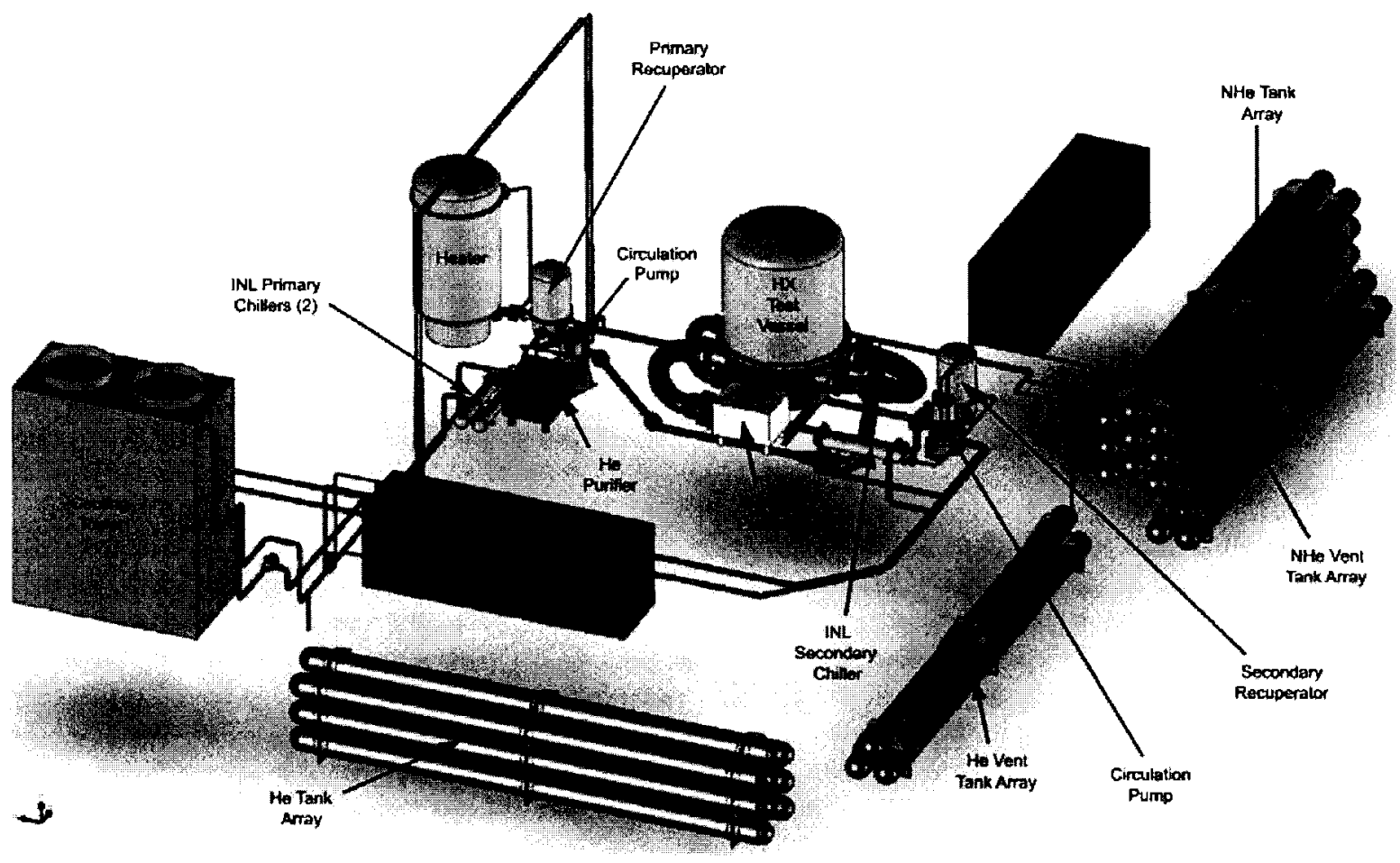

Figure S-1. Conceptual layout drawing of the high temperature gas loop test facility. 


\section{ACKNOWLEDGMENTS}

The authors would like to express gratitude to Guy Laffont (CEA, Caderache, France) for helpful discussions concerning gas circulators, helium purification, and other operational and logistic issues. Gratitude is also expressed to Ed Harvego, Richard Wright, and Kevan Weaver for reviewing this document. 
This page intentionally left blank. 


\section{CONTENTS}

EXECUTIVE SUMMARY ……….............................................................................................ii

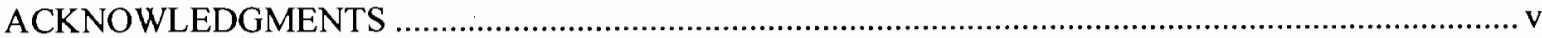

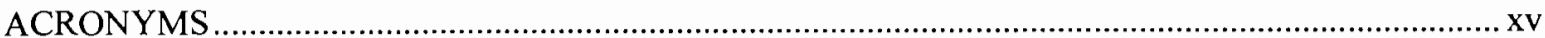

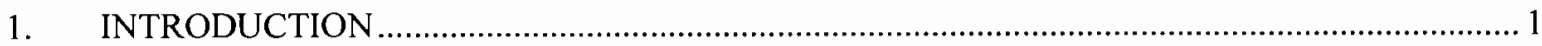

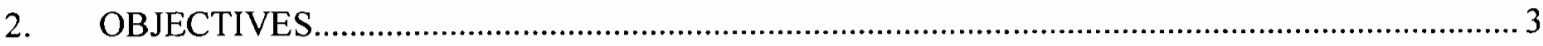

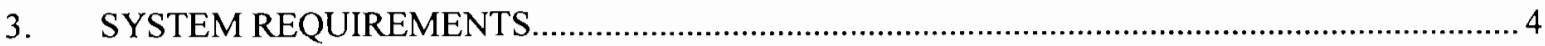

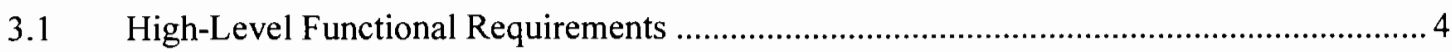

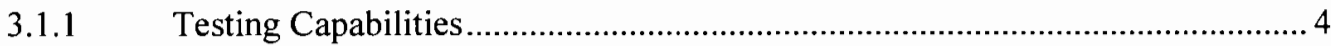

3.1.2 Data Measurement and Operational Control System ......................................... 6

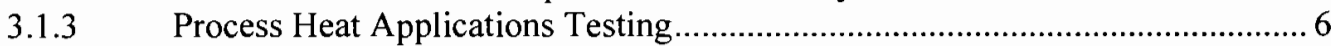

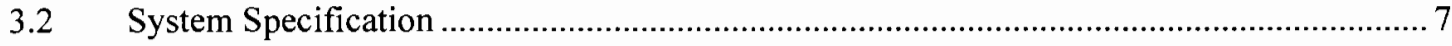

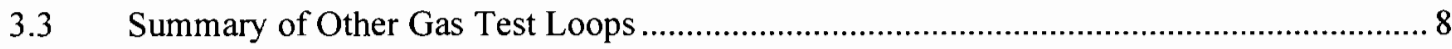

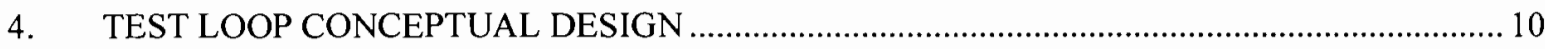

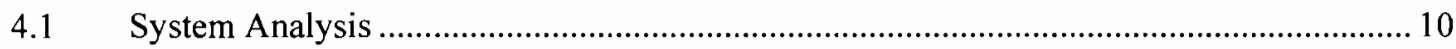

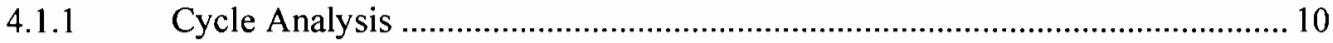

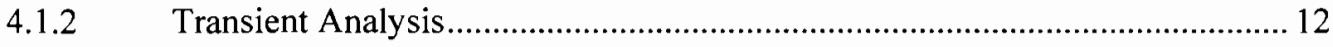

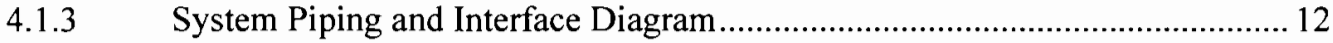

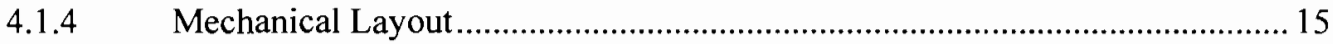

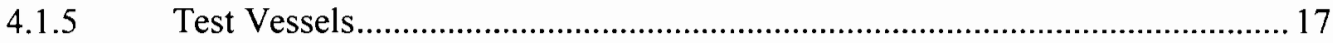

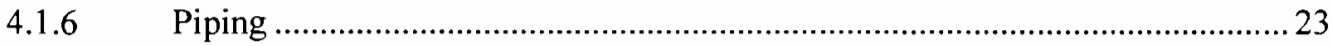

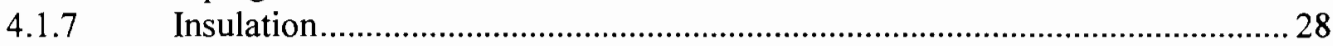

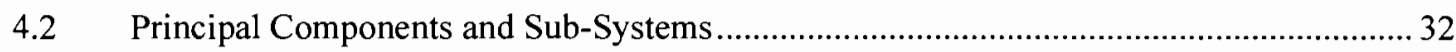

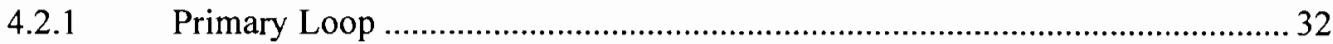

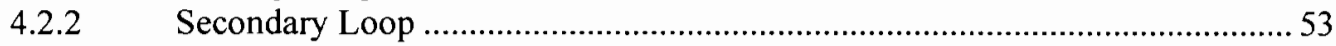

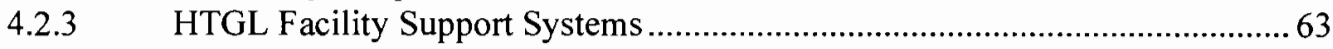

4.2.4 Controls, Instrumentation, and Data Acquisition System ................................ 73

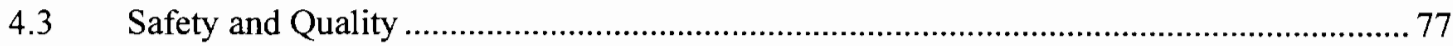

4.3.1 Hazards and Exposure Mechanisms........................................................... 77

4.3.2 Specific Hazard Identification and Mitigation ................................................. 78

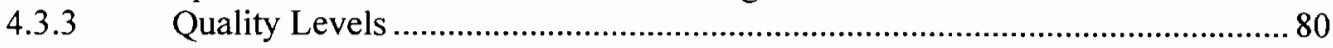

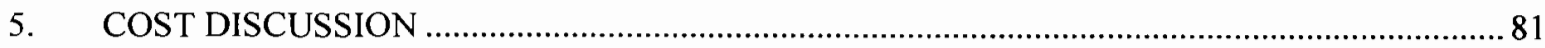




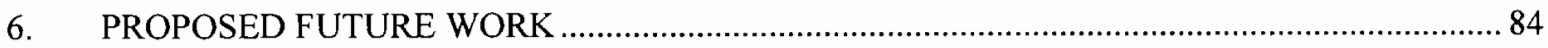

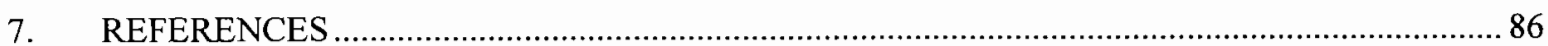

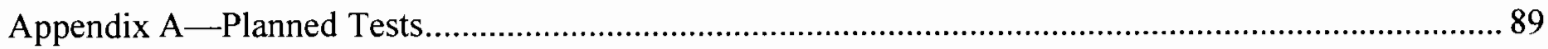

Appendix B-Survey of Existing High-Temperature Gas Loops .................................................... 103

Appendix C—Specifications for System Analysis ......................................................................... 109

Appendix D—Original Specifications for HTGL provided by INL ................................................. 115

Appendix E - Transient Maneuvers — Specification for HTGL ….................................................. 127

Appendix F-Transient Thermal Analysis of Heater-Discharge Duct .................................................. 133

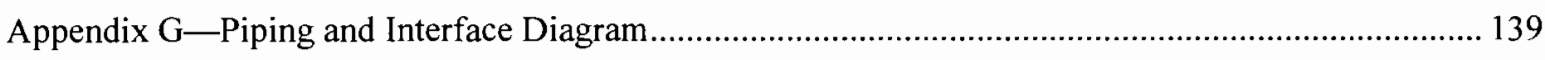

Appendix H-Sulfur-Iodine Equipment Schematic ..................................................................... 145

Appendix I—Pressure Vessel Design and Analysis .................................................................... 149

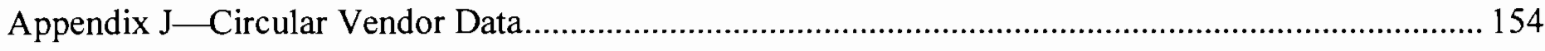

Appendix K-Heat Exchanger Analysis Model Used In Sizing Multi-Pass Cross-Flow Heat

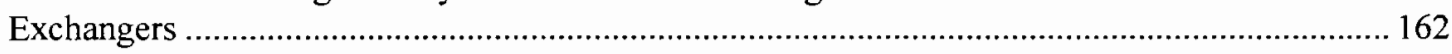

Appendix L—Primary and Secondary Cooler Analysis and Quotations ......................................... 176

Appendix M-Fan-Cooled Radiators - Specifications, Cost Quotes, and Installation Details ............... 184

\section{FIGURES}

Figure S-1. Conceptual layout drawing of the high temperature gas loop test facility. ............... iv

Figure 1. Next Generation Nuclear Plant showing three intermediate heat exchangers. ...............1

Figure 2. Layout of main IHX test vessel (left) and primary heater (right), with two smaller circulators for the primary (red) and secondary (blue) gas loops............................5

Figure 3. Simplified schematic diagram based roughly on indirect gas turbine cycle configuration. Temperatures are representative as discussed in text. ................................10

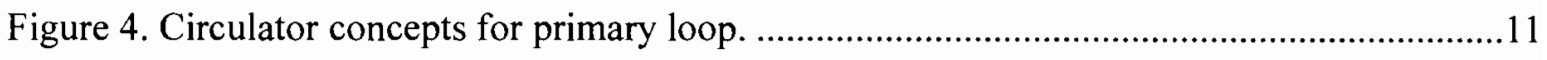

Figure 5. The HTGL facility comprises three test bays arranged in a T-formation. Space is shown in this plan view for a notional expansion to include a sulfur-iodine pilotplant for $\mathrm{H}_{2}$ production. 
Figure 6. A close-up view of the HTGL. Test bays are arranged in a T-formation to minimize the length of pipes conveying hot gas.

Figure 7. Pipes are located in trenches below floor-level. Removable covers (not shown) complete the floor and create ducting to direct ventilation-flow over pipes to maintain wall temperatures at proper levels

Figure 8. Plan view layout of components, piping, and ancillary equipment to support testing of Intermediate Heat Exchangers.

Figure 9. Floating isometric view of the primary and secondary loop equipment and piping for IHX testing, with each major component identified.

Figure 10. Floating view of equipment and vessels supporting an IHX test. Gas supply and vent tanks are shown on the perimeter of the facility.

Figure 11 . The primary loop services the three test bays. Shown are manifolds at the primary heater and recuperator, which can be configured to direct and receive gas from the bay, or bays, in which tests are being conducted.

Figure 12. Overhead cranes are installed in test bays to facilitate the movement of equipment. Fixed equipment is positioned to one side of the bay, leaving space to set the vessel bell while work is performed within.

Figure 13. Bay 1 test vessel annotated to show pass-throughs for instrumentation, as well as flange locations for primary and secondary gas interfaces. A removable bell allows unencumbered access for installation and removal of test equipment. The working volume is 3 -meters in diameter by 3 -meters tall.

Figure 14. Three-meter-diameter IHX test vessel with a compact IHX core installed. Liners direct cooler gases along pressure boundary walls to maintain temperatures within design limits.

Figure 15. Test vessel with a simulated AREVA test article installed. The test article is sized for $2 \mathrm{MW}$ capacity. Mechanical mounting points and fluid-flanges are fixed in space. This provides solid fixity for engineers designing test setups for thermal strain measurements.

Figure 16. Isometric view of internally insulated coaxial pipe construction for hightemperature and high-pressure gas.

Figure 17. Detail of piping features specified to accommodate differences in thermal displacement.

Figure 18. U-pipe assembly provides strain relief for hot pipes between fixed vessels.

Figure 19. Deflection of a U-pipe assembly in response to displacement of a flange in response to thermal lengthening of a pipe between vessels. 
Figure 20. Finite Element Analysis (FEA) plot of a steady-state temperature distribution in a conical coaxial thermal transition with heat transfer boundary conditions provided

Figure 21. Plot of stresses in the peak-stress location for a worst-case, steady-state temperature distribution. .26

Figure 22. Plot of stress in thermal transition due to $6 \mathrm{MPa}$ internal hydrostatic pressure. At $8 \mathrm{MPa}$ pressure case, the membrane stress safety margin is reduced to 0.05 . The safety margin for the membrane-plus-bending is 0.45 . To comply with ASME criteria, the margin must be greater than zero, and increases with pipe wall thickness.

Figure 23. Helicoflex ${ }^{\mathrm{TM}}$ energized seal provides low leakage rate in high-pressure helium sealing applications.

Figure 24. Layered insulation concept and nomenclature. The $\mathrm{Z}$ quantities define thermal resistance between radial locations.

Figure 25. Effective gas conductivity in aerogel pores (for air)............................................30

Figure 26. Sizing study for heater-discharge duct.

Figure 27. Kanthal Heating elements are in the $2 \mathrm{MW}$ HTGL design. The heating element is formed from 4.5-millimeter-diameter resistance wire.

Figure 28. An extended fin surface is used to efficiently transfer the heat to the helium.

The proposed 2-millimeter fin meets thermal performance while incurring tolerable overall pressure loss.

Figure 29. Dimensioned envelope of $2 \mathrm{MW}$ primary gas heater, including ample insulation allowance.

Figure 30. Electric heater layout incorporating 71 Kanthal heating elements and engineering helium heat exchange design.

Figure 31. Integrated heater top end, showing heating element support and electrical termination.

Figure 32. Heating element and fin are free to slide within outer tube shell

Figure 33. Detail of helium flow path through the heating elements. The installation accommodates differential thermal growth between the heating element and the flow guide header plate.

Figure 34. Extended surface fin surrounds the standard Kanthal heating element.

Figure 35 . Heater assembly detail showing top support plate and header plate. 
Figure 36 . Single $28 \mathrm{~kW}$ Kanthal heating element dimensions.

Figure 37. High-speed turbomachinery configurations based on specifications of

Table 12. In all cases, optimum speed for a single-stage centrifugal machine falls within acceptable bounds for current high-speed motors.

Figure 38. Excerpt of P\&ID showing position of primary-side recuperator in process.

Figure 39. Assembly of two recuperator cores, four cells each, specified for duty as a primary-side recuperator.

Figure 40. Flow through the primary-side recuperator. Lower temperature recuperatordischarge gas flows along the pressure boundary to minimize the insulation thickness. The diameter is 1.2-meters, with a cylindrical section 1.1 meters long.

Figure 41. Tube-shell heat exchanger proposed by Basco Industries, in response to the HTGL request-for-quotation. This type of heat exchanger is appropriate for both primary and secondary gas loops.

Figure 42 . Graph showing the influence of downstream bypass flow on secondary gas temperatures.

Figure 43. Graph showing the influence of upstream secondary recuperator bypass on IHX delivery temperatures. The intent of this control strategy is to permit IHX inlet temperature control between 300 and $600^{\circ} \mathrm{C}$

Figure 44. Schematic diagram showing a gas-gap recuperator concept. .59

Figure 45 . The secondary recuperator is a rugged, tube-shell, multi-pass, cross-flow design.

Figure 46. Detail of secondary recuperator designed for $900^{\circ} \mathrm{C}$ gas inlet and to accommodate large differential strains.

Figure 47. The tubes terminate in a tube plate to form the end bell manifold. The tube sheet is modified to form the manifold for the gas-gap mixture of $\mathrm{He} / \mathrm{Ar}$. The diameter is 0.8 -meter (including 150 millimeters of insulation). The nominal length is 3.5 meters

Figure 48. The high-temperature secondary recuperator incorporates a bellows expansion joint on the cold end.

Figure 49. Test bay ventilation draws heated air from ceiling and from ducting, which draws from trenches containing warm gas pipes. .64

Figure 50. Helium Inventory Management Compressor. .........................................................65

Figure 51. Side view of helium inventory management compressor .67 
Figure 52. Gas inventory storage vessel and vent tank, secondary loop. .68

Figure 53. Gas inventory storage skid, offered by FIBA Technologies in Millbury, Massachusetts.

Figure 54. Simplified PSA process description, showing periodic process. 72

Figure 55. Illustration of nested control loops for the six control variables in the primary and secondary circuits.

Figure 56. Simplified flow chart example for each of the six control variables. 75

\section{TABLES}

Table 1. The HTGL will allow testing of all anticipated NGNP categories and processes. 7

Table 2. Basic design conditions for the primary and one secondary loop of the HGTL.............8

Table 3. Survey summary results showing temperature, pressure, and mass flow rate for primary and secondary loops.

Table 4. Nominal design conditions for primary loop subassemblies, based on a typical $400^{\circ} \mathrm{C}$ temperature drop across the IHX test article. The recuperator effectiveness is $83 \%$.

Table 5. Primary loop temperatures for maximum IHX exit temperature conditions, limited by the recuperator inlet temperature. This is expected to be the most severe operating conditions for the components. The recuperator effectiveness is about $82 \%$.

Table 6. General heater design specifications 33

Table 7. A survey of helium heating sources has evaluated combustion, induction, and electrical resistance options.

Table 8. Of the many heating element options, those characteristics listed represent the range recommended for the HTGL heater.

Table 9. Thermal performance design and analysis of the resistance heating system..................36

Table 10. Summary of heater system integration design and analysis. .................................38

Table 11. Preliminary cost assessment for $2 \mathrm{MW}$ heater........................................................44

Table 12. Circulator performance specifications at design conditions. .....................................45

Table 13. Findings corresponding to Figure 37, with preferred single-stage centrifugal design highlighted in red. 
Table 14. Preliminary feedback from candidate circulator suppliers.......................................48

Table 15. Design statepoint for the primary-side recuperator. .............................................49

Table 16. Primary-side thermal design parameters and values............................................51

Table 17. Detailed performance parameters for primary-side recuperator.................................52

Table 18. The general primary cooler specification was submitted to qualified heat exchanger suppliers. Conditions are for an ISO-standard day. The heat exchanger is

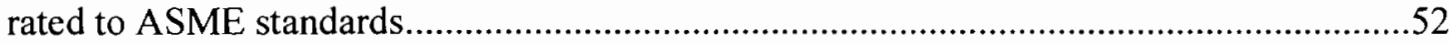

Table 19. The general secondary cooler specification was submitted to qualified heat exchanger suppliers. Conditions are for an ISO-standard day. The heat exchanger is

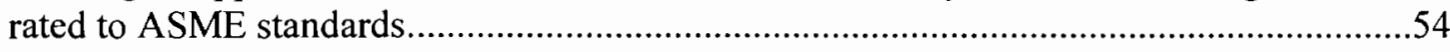

Table 20. Secondary IHX loop design and minimum statepoints.........................................56

Table 21. Comparison of a standard crossflow tube-shell recuperator with pure-argon and pure-helium gas-gap recuperator configurations..............................................................6

Table 22. Summary comparison of secondary recuperator options..........................................63

Table 23. Specifications for gas inventory management................................................66

Table 24. Gas inventory compressor, budgetary pricing. .....................................................66

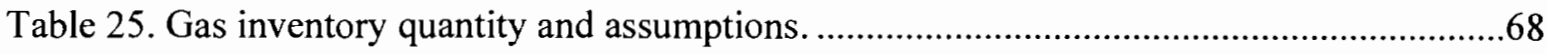

Table 26. Helium Purity and Contaminant Specification (Table obtained from Air

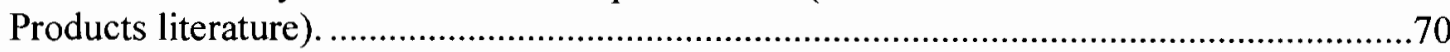

Table 27. The HTGL's six degrees of freedom are used to simulate reactor and secondary

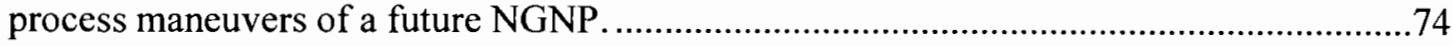

Table 28. General instrument types to be employed in the HTGL.........................................76

Table 29. Capacity and features of data acquisition system for HTGL .................................77

Table 30. Potential Mitigation Methods for Some Hazards Expected in the HTGL...................78

Table 31. Summary equipment costs for the HGTL with one test-bay configured for IHX

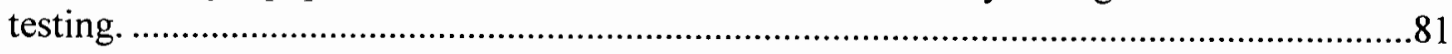




\section{ACRONYMS}

ACHE air-cooled heat exchanger

ADAM (German test facility)

ANSI American National Standards Institute

ASME American Society of Mechanical Engineers

CEA (French Atomic Energy Commission)

EVA (German test facility)

FEA finite element analysis

FMEA Failure Modes and Effects Analysis

FS full scale

HAZOP Hazards and Operability Analysis

HENDEL Helium ENgineering DEmonstration Loop

HELITE HElium Loop for Innovative TEchnology

HTF Helium Test Facility

HTR high-temperature reactor

HTGL High-temperature Gas Loop

HVAC Heating Ventilation and Air Conditioning

HX Heat Exchanger

IHX Intermediate Heat Exchanger

INL Idaho National Laboratory

KAPL Knolls Atomic Power Laboratory

KVA (German test facility)

MHI Mitsubishi Heavy Industries

MTBO mean time between overhauls

MTS materials test sheet

NGNP Next Generation Nuclear (Power) Plant 


$\begin{array}{ll}\text { ODS } & \text { oxide dispersed strengthened } \\ \text { OEM } & \text { original equipment manufacturer } \\ \text { PBMR } & \text { Pebble Bed Modular Reactor } \\ \text { P\&ID } & \text { Piping and Interface Diagram } \\ \text { PSA } & \text { pressure swing adsorption } \\ \text { R\&D } & \text { research and development } \\ \text { RFQ } & \text { Request for Quote } \\ \text { SCF } & \text { standard cubic feet } \\ \text { SI } & \text { Sulfur-Iodine } \\ \text { SNLA } & \text { Sandia National Laboratory Alburquerque } \\ \text { UK } & \text { United Kingdom } \\ \text { UNLV } & \text { University of Nevada Las Vegas } \\ \text { VHTR } & \text { Very High Temperature Reactor }\end{array}$




\section{Conceptual Design for a High-temperature Gas Loop Test Facility}

\section{INTRODUCTION}

The Next Generation Nuclear Plant (NGNP) project involves research, development, design, construction, and operation of a prototype nuclear plant intended for both high-efficiency electricity production and nuclear-assisted hydrogen production. As currently envisioned, the NGNP incorporates the Very High Temperature Reactor (VHTR) technology.

Recently a reference NGNP prototype concept was established based on the lowest risk technology development that will provide an economically competitive nuclear heat source and a hydrogen production capability ${ }^{1}$. The reference NGNP conceptual schematic is shown in Figure 1. The concept includes a helium-cooled, graphite-moderated, thermal neutron spectrum reactor with a once-through fuel cycle. The reactor core will employ either the prismatic block or pebble bed fuel concept. Reactor outlet temperatures will be in the range of 850 to $950^{\circ} \mathrm{C}$, with future capabilities that could reach above $1000^{\circ} \mathrm{C}$.

Advanced high-temperature reactor systems for power generation, such as this, may be classified as direct and indirect cycles. Direct cycles utilize the reactor coolant, helium, as the working fluid of a gas turbine. As shown in Figure 1, the current NGNP concept uses an indirect cycle (judged the lowest risk option) having intermediate heat exchangers (IHXs) to transfer heat from the reactor primary loop to a secondary loop, which drives a gas turbine/electric generator, and to a hydrogen production facility. To isolate the nuclear and hydrogen production facilities from each other for safety reasons, this system includes a second intermediate heat transport loop. Hydrogen will be produced either by a thermochemical process splitting water into hydrogen and oxygen (with sulfur-based processes being the primary candidates) or by thermally-assisted electrolysis of water.

The consensus among industrial power generation developers is that the IHX is the major challenge outside of the nuclear reactor. The power generation equipment, albeit customized for non-standard working fluids, represents very low technical risk. The intermediate heat exchangers must handle the entire heat output from the reactor and do so at reactor outlet temperatures and pressures $\left(950^{\circ} \mathrm{C}\right.$ and

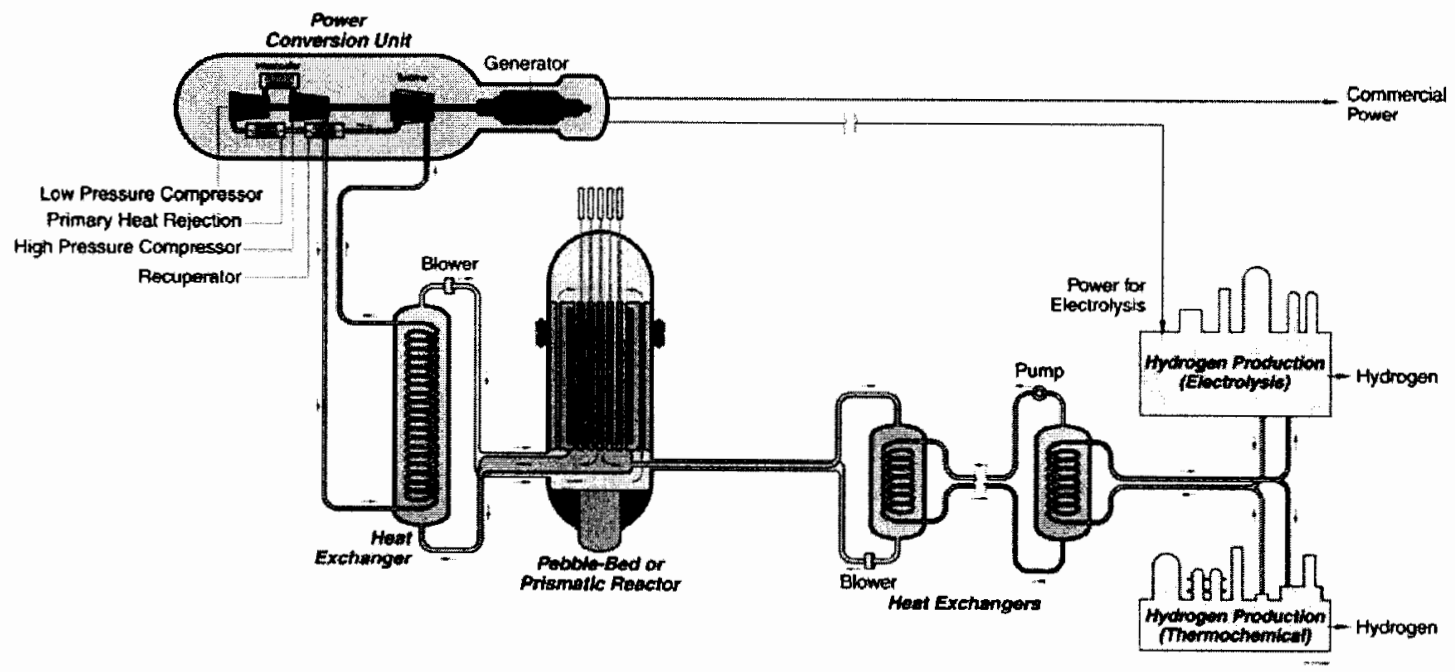

Figure 1. Next Generation Nuclear Plant showing three intermediate heat exchangers. 
$7 \mathrm{MPa}$ ), which are at or near the operating limit for existing materials. Several IHX concepts are being considered, including a variety of innovative compact designs and more traditional tube-in-shell devices. Although bench scale testing of prototypes is ongoing, pilot testing of an appropriate IHX module size at VHTR conditions is not currently feasible. Accordingly, the IHX has been identified as a critical system component with both technological and programmatic risks ${ }^{1}$. In addition, other VHTR components such as gas circulators (and their associated seals, bearings, etc.), high-temperature valves, recuperators, and high-temperature piping are needed for the reactor system but are not well tested at the necessary conditions. Even more fundamentally, materials for these components are not well tested at the temperatures, flow conditions, and impurity levels anticipated for the reactor system.

For these reasons, the NGNP Program Management Plan identifies the need for the design and construction of a reasonably large-scale (on the order of $1 \mathrm{MW}$ ), high-temperature gas test facility for component and materials testing. ${ }^{1}$ The specific high-level objectives identified for this facility are as follows:

- $\quad$ Provide a flexible, well-instrumented environment to evaluate IHX concepts and validate durability and efficiency both for long-term and transient operating conditions

- Include the flexibility to evaluate the performance and durability of other critical high-temperature components, including circulators, valves, recuperators, piping, insulation, and instrumentation

- $\quad$ Provide a controlled-chemistry environment (pure and impure helium) for fundamental materials testing at VHTR temperature and flow conditions

- Include design flexibility such that the primary gas loop can be used as a heat source for future high-temperature demonstration facilities, for example, a large-scale, high-temperature electrolysis process loop. 


\section{OBJECTIVES}

This study had a number of objectives that collectively constitute the development of an early stage conceptual design for a high-temperature gas test loop. The objectives include the following:

- Investigate existing gas test loops to determine their capabilities and how this system might best complement them

- Develop a preliminary test plan to help identify the performance characteristics required of the test unit

- Develop test loop design requirements

- Identify potential test loop locations with an emphasis on characteristics of the building or site rather than on naming a specific location. It was assumed that the test unit would be built at INL and would be operated by INL staff

- Develop a conceptual design including process flow sheet, mechanical layout, and equipment specifications and costs

- Develop a preliminary test loop safety plan.

This report documents the results of these tasks which were primarily accomplished by Brayton Energy, LLC, of Hampton, New Hampshire. INL engineers provided project management, technical guidance and review, and input on tasks requiring knowledge of INL design and operational requirements. 


\section{SYSTEM REQUIREMENTS}

\subsection{High-Level Functional Requirements}

\subsubsection{Testing Capabilities}

The broad requirement is for testing of components to be installed in the primary and secondary coolant loops of a future high-temperature gas reactor. The primary loop operates with helium at $7 \mathrm{MPa}$ (about $1000 \mathrm{psi}$ ) and $950^{\circ} \mathrm{C}$ (about $1740^{\circ} \mathrm{F}$ ). The secondary loop operates with a helium-nitrogen mixture at similar maximum conditions. The leading test priority is for various designs of the IHX. Further test requirements are for isolation valves for emergency shutoff of the primary loop, various construction materials, novel fabrication and joining methods, insulation concepts for the high-temperature piping, and instrumentation strategies including nondestructive evaluation methods for online monitoring of the IHX or valves. A detailed description of anticipated tests is presented in Appendix A, with a general overview given here.

To flexibly provide a broad range of test scenarios, the test loop configuration will feature a single primary loop with a centralized heat source feeding three parallel secondary loops. The primary and secondary test loops will be manually reconfigurable without the use of high-temperature valves which are themselves a target of development. Simplicity of piping changes is a design priority to allow a timely succession of tests, many lasting only hours or days. The design strategy is illustrated in Figure 2, with primary piping shown in red and secondary in blue. The primary heater is housed in the vessel on the right, with the flanged spool pieces at its base allowing flow redirection to any combination of three test bays (only one test bay is shown). Inactive test bays will be isolated from the hot helium supply by disconnecting and capping the piping to them.

The centerpiece test articles will be intermediate heat exchangers, likely one or two full-scale core units (a small fraction of the number required for a commercial system). The primary test issues are heat transfer performance, pressure drop, and internal stresses from thermal expansion. Analysis of performance and durability require the measurement of internal temperature profiles during steady-state and transient operation. Representative fault conditions and transient maneuvers will be simulated, during which potentially damaging stresses may be imposed on the IHX test article. The strategy for core life prediction is to validate finite element computer models against measured thermal and strain profiles, with these models then providing analysis tools covering a range of scenarios beyond those directly simulated.

A few weeks of testing should be sufficient to reproduce the 200 to 400 thermal cycles and transients expected in the NGNP plant over a 20 -year service interval. IHX certification requirements are also anticipated to require, among other things, destructive tests. Therefore, a critical test loop design requirement is to provide containment and assure the safety of the equipment and personnel in the event of IHX failures.

Test and qualification programs for military high-temperature heat exchangers have been reviewed for this report. ${ }^{2}$ The proposed High-Temperature Gas Loop (HTGL) plan builds upon this experience and further recognizes the great potential value of three advanced diagnostic capabilities beyond standard temperature, strain, and pressure measurements. These capabilities are thermal imaging telemetry, in situ precision coordinate measurement for monitoring of dimensional changes, and leak detection online at full-test conditions. These methods, if developed as part of this program, offer the prospects of both better quality data during IHX testing and, in eventual commercial service, ways to monitor IHXs online for early warning of degradation or incipient failure. 


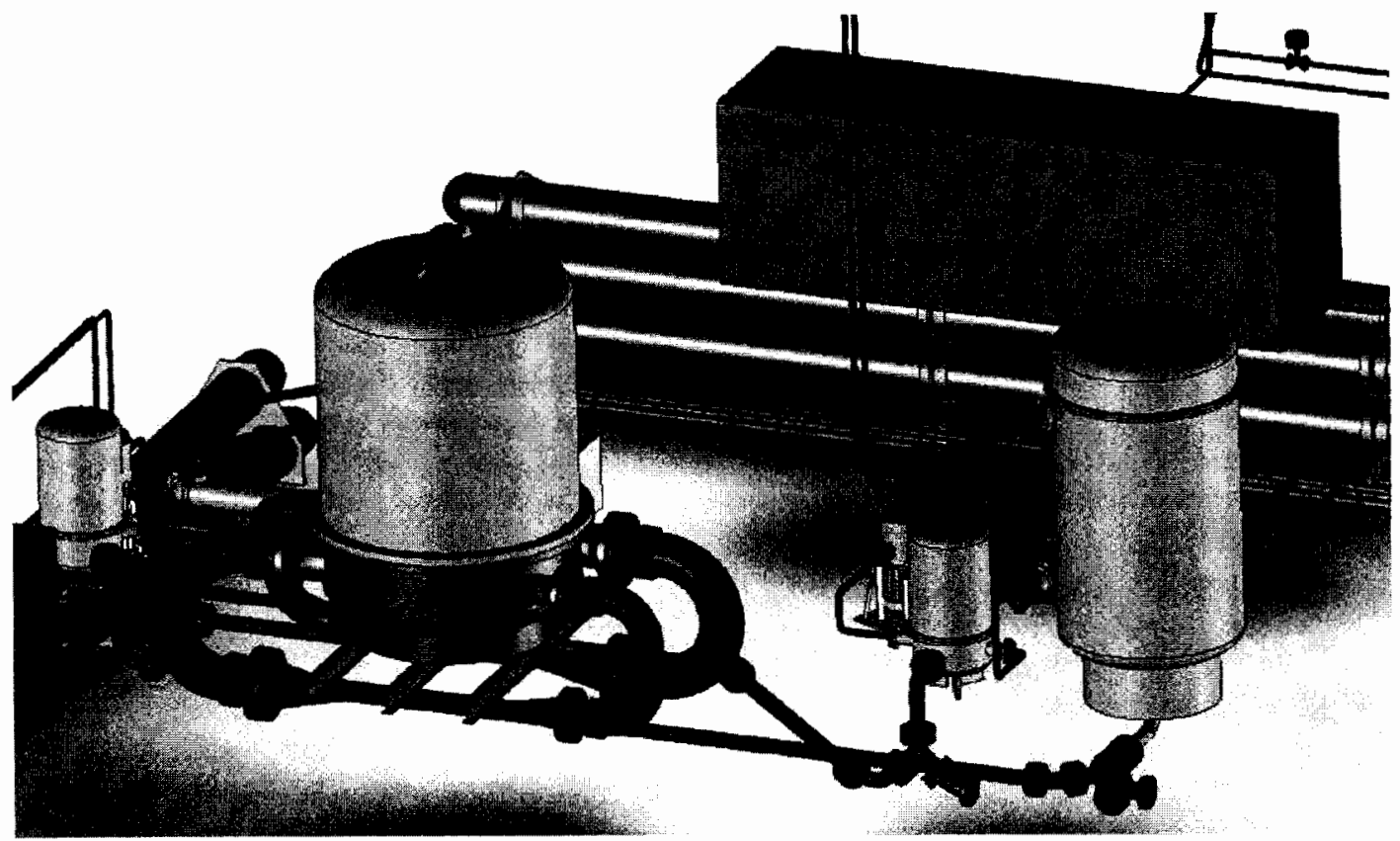

Figure 2. Layout of main IHX test vessel (left) and primary heater (right), with two smaller circulators for the primary (red) and secondary (blue) gas loops.

Testing of isolation valves involves several challenging requirements. A full-scale, hightemperature valve for a NGNP hot piping system is 1 to 2 meters in diameter, requiring special installation and large actuation drives. Each of the three test bays is equipped to handle this scale of equipment. The test objective is primarily to verify sealing while avoiding high-temperature galling. Operation at high temperature and contact pressure in a high-purity helium environment is known to initiate "helium-welding," a form of diffusion bonding between metal parts. The expected test format requires repetitive actuation of the valve under hot flowing conditions with measurement of leakage and valve actuation torque. Some extended dwell periods at high temperature and pressure are also anticipated to fully qualify this equipment. Since the HTGL configuration provides three test bays, extended operation of NGNP valve and IHX tests may run concurrently.

A spectrum of extended endurance tests for materials samples is also planned for investigation of corrosion, fatigue, and creep. These tests will be performed on fabricated parts such as valve bodies, gas turbine engine parts, or on simple weld and braze coupons. Test compartments located in the primary and secondary loops provide exposure to a range of gas velocity and temperature. Tests requiring altered gas compositions-for instance the addition of carbon monoxide, water, or graphite particles-are also planned for a secondary loop to avoid possible damage to the primary loop equipment.

Because the test loop itself operates at conditions equal to or exceeding those of the NGNP system, the loop has many of the same novel design problems. A number of the components in the loop will be new designs, new applications of conventional designs, or use new materials. Though these components will be installed with the expectation that they will perform as needed, they will be undergoing de facto testing of their own. A partial list of examples includes the following:

- Sealing systems for hot, high-pressure helium 
- $\quad$ Pipe design with internal insulation to reduce the temperature at the pressure boundary (This has complications related to insulation performance in pressurized helium, installation of a flow liner that allows the insulation layer to breathe, and insulation mating methods at pipe flanges.)

- Circulators for high-temperature helium.

The French HELITE test loop program recognized this problem and had, as part of its own design effort, a development and testing effort on the equipment that makes up the test loop (as opposed to the IHX test article itself). To address this technical risk, the program plan should include an equipment development program including comprehensive equipment testing at the manufacturer. The system design should include monitoring instruments installed on such assemblies, and a layout that allows relatively simple replacement of such components as alternative concepts for them are developed.

\subsubsection{Data Measurement and Operational Control System}

This system will have significant instrumentation and data collection needs. The basic operation of the test loop requires automated monitoring and control of various flows, temperatures, pressures, and equipment speeds to provide well-regulated test conditions. The control system will be capable of recognizing off-normal conditions and safely shutting down the unit without operator intervention when the conditions warrant. The key control variables will be scanned at relatively high frequency to quickly detect and correct any aberrant behavior.

The test function of the unit calls for comprehensive data collection, online analysis, presentation, and archiving capabilities. In the IHX tests, a large number of temperature and strain data must be collected, perhaps hundreds of channels of data. In the transient IHX tests, these channels must be logged at a rate of about once a second for a number of hours. All three test bays must have similar capability of collecting data from various types of instruments which will be provided as part of the test articles. The data collection system (as well as physical access to the system) must ensure individual security to each test bay because users might require protection of the performance data from their proprietary designs.

Measuring some of the required data will involve more than just installing the proper type of direct sensor. IHX and valve testing will require leak checking, in the first case between the primary and secondary loops while both are hot and pressurized, and in the second case through a closed valve with high pressure behind it and atmospheric pressure downstream. Methods to do this must be conceived and tested as part of the overall project design. One concept for the IHX leak testing is to use gamma-emitting radioactive isotopes of xenon or krypton as inert tracer gases. The radiation from these can be detected with great sensitivity through the system's walls while it is operating. The same leak checking system might be used with valves, or they could use a standard pressure rise test if the necessary piping is installed. Other minor systems will be needed to monitor and control gas composition in the secondary loops for long-term corrosion testing. Trace amounts (2-50 ppm) of gases like $\mathrm{CO}, \mathrm{CO}_{2}, \mathrm{H}_{2} \mathrm{O}, \mathrm{CH}_{4}$, and $\mathrm{H}_{2}$ will be maintained in the secondary gas mixture to simulate the atmosphere generated by reaction of the graphite in a NGNP reactor core. Production of a gas stream containing low levels of suspended graphite particles will also be needed to test for erosion/corrosion. Although both trace gases and graphite particles simulate conditions in the NGNP's primary loop, it is less risky to simulate these conditions in the test system's secondary loops at similar temperature and pressure.

\subsubsection{Process Heat Applications Testing}

A somewhat more involved test program planned for several years in the future covers the interface of the high-temperature gas reactor with the thermochemical sulfur-iodine process for making hydrogen from water. In this process, heat at about $850^{\circ} \mathrm{C}$ is used to decompose sulfuric acid vapor. That process step (which includes vaporization of liquid sulfuric acid, decomposition of the vapor to $\mathrm{SO}_{3}$, and decomposition of that to $\mathrm{SO}_{2}$, all in one vessel) will be validated at pilot scale in this test loop. Since this 
will be a process test rather than just a component test, additional piping, pumps, and chemical storage will be required in the test bay; they will be provided by the test article developers. The test bay, however, must be designed now with space for this equipment and with walls, floors, and ventilation appropriate for acids and toxic gas handling. After the sulfuric acid decomposer unit has been tested-and quite speculatively at this point - the high-temperature test loop might be considered as the thermal energy source for an integrated test of the complete sulfur-iodine process. The significance of this use is simply that, to keep the option open, the test loop should be laid out to allow installation near the primary helium loop of a process system at least as large as the test loop itself.

A similar alternative concept for one of the secondary loop test bays is to characterize the use of molten salt as the working fluid in an intermediate heat transfer loop. Molten salts are potentially advantageous if the heat must be transported over a great physical distance since pumping costs are lower for liquids than for gases. The system to be tested is not well defined at this point, but the requirements for space and spill control should be comparable, though not necessarily identical to, those for the sulfuriodine testing.

\subsection{System Specification}

To develop the specifications for this high-temperature gas loop, the current NGNP and other hightemperature reactor initiatives in the U.S., Japan, China, the Republic of South Africa, France, the Netherlands, and Germany were reviewed. The survey considered three classes of applications outlined in Table 1. Both direct and indirect power conversion systems will use an IHX to provide high-temperature heat for hydrogen or process heating applications. ${ }^{3}$ As it is not predictable which of these applications will advance or fail during research and development, planning must allow for testing each of them.

The basic design conditions for the test loop are listed in Table 2. These were developed after consideration of the critical design parameters for several IHX candidates under development (Table 3 ). In many cases, the candidate processes were not sufficiently advanced to provide detailed specifications. However, a thorough review of the literature and discussions with prominent researchers contributed to the specifications for the INL HTGL. Of the alternative IHXs surveyed, only requirements for the supercritical $\mathrm{CO}_{2}$ reactor fall outside the proposed HTGL specification. The very high pressure for the S$\mathrm{CO}_{2}$ cycle $(20 \mathrm{MPa})$ is well above the $8 \mathrm{MPa}$ peak pressure set for the HTGL. Its operating temperature and differential pressures are, however, achievable. The $\mathrm{S}-\mathrm{CO}_{2} \mathrm{IHX}$ may be rigorously tested at a reduced mean pressure while matching temperatures, transient conditions, and the differential pressure.

Table 1. The HTGL will allow testing of all anticipated NGNP categories and processes.

\begin{tabular}{|c|l|l|c|}
\hline \multicolumn{1}{|c|}{ Cycle } & Secondary fluid & Temperature ${ }^{\circ} \mathrm{C}$ \\
\hline \multicolumn{1}{|c|}{ Power Generation } & & \\
\hline & Steam turbines & Steam & $<650$ \\
\hline & Gas turbines - direct and indirect & $\mathrm{H}_{2}$ & $<900$ \\
\hline & Gas turbines - supercritical $\mathrm{CO}_{2}$ & $\mathrm{CO}_{2}$ & $<700$ \\
\hline & Gas turbine plus steam turbine bottoming cycle & $\mathrm{He}+\mathrm{N}_{2}$ & $<900$ \\
\hline \multicolumn{1}{|c|}{ Hydrogen production } & & $<900$ \\
\hline & Sulfur Iodine & $\mathrm{H}_{2} \mathrm{SO}_{4}+\mathrm{H}_{2} \mathrm{O}$ & $<950$ \\
\hline & High-Temp Electrolysis & $\mathrm{Steam}_{1}$ & $<950$ \\
\hline & Solid Oxide Fuel Cell & $\mathrm{Steam}$ & $<750$ \\
\hline & Calcium-Bromine cycle & $\mathrm{CaBr}+\mathrm{H}_{2} \mathrm{O}$ & $<800$ \\
\hline & Potassium hydroxide & $\mathrm{KOH}+\mathrm{H}_{2} \mathrm{O}$ & \\
\hline \multicolumn{1}{|c|}{ Process heat } & & $<400$ \\
\hline & Heavy oil extraction & Steam & $<950$ \\
\hline
\end{tabular}


Table 2. Basic design conditions for the primary and one secondary loop of the HGTL.

\begin{tabular}{|l|c|}
\hline \multicolumn{1}{|c|}{ Primary Loop } & pure He \\
\hline Composition & $0.80 \mathrm{~kg} / \mathrm{s}$ \\
\hline Mass flow & $950^{\circ} \mathrm{C}$ \\
\hline Supply temperature to IHX & $550^{\circ} \mathrm{C}$ \\
\hline Return temperature from IHX & \\
\hline \multicolumn{1}{|c|}{ Secondary Loop } & $80 \% \mathrm{~N}_{2}, 20 \% \mathrm{He}$ \\
\hline Composition & $2.12 \mathrm{~kg} / \mathrm{s}$ \\
\hline Mass flow & $500^{\circ} \mathrm{C}$ \\
\hline Supply temperature to IHX & $900^{\circ} \mathrm{C}$ \\
\hline Return temperature from IHX & \\
\hline
\end{tabular}

\subsection{Summary of Other Gas Test Loops}

Pioneering research using high-temperature helium test loops was performed about two decades ago in Germany. Other loops are currently operating or under construction in France, Japan, China, and the Republic of South Africa. A summary of those test rigs and their capabilities is provided in Appendix B. Each has a somewhat different focus within the broad range of needs already discussed. The test loop of this report is distinctive in providing a very large test chamber which can accommodate a large IHX test article, potentially including a shell-and-tube type exchanger. This system will also be designed for testing components of the sulfur-iodine process, a capability that only the much smaller Japanese loop also has. Though it is not addressed in detail at this very early stage of design, the INL loop will have the potential to incorporate extensive and sophisticated nondestructive evaluation sensing systems to provide unmatched data about the behavior of the test articles during testing. 


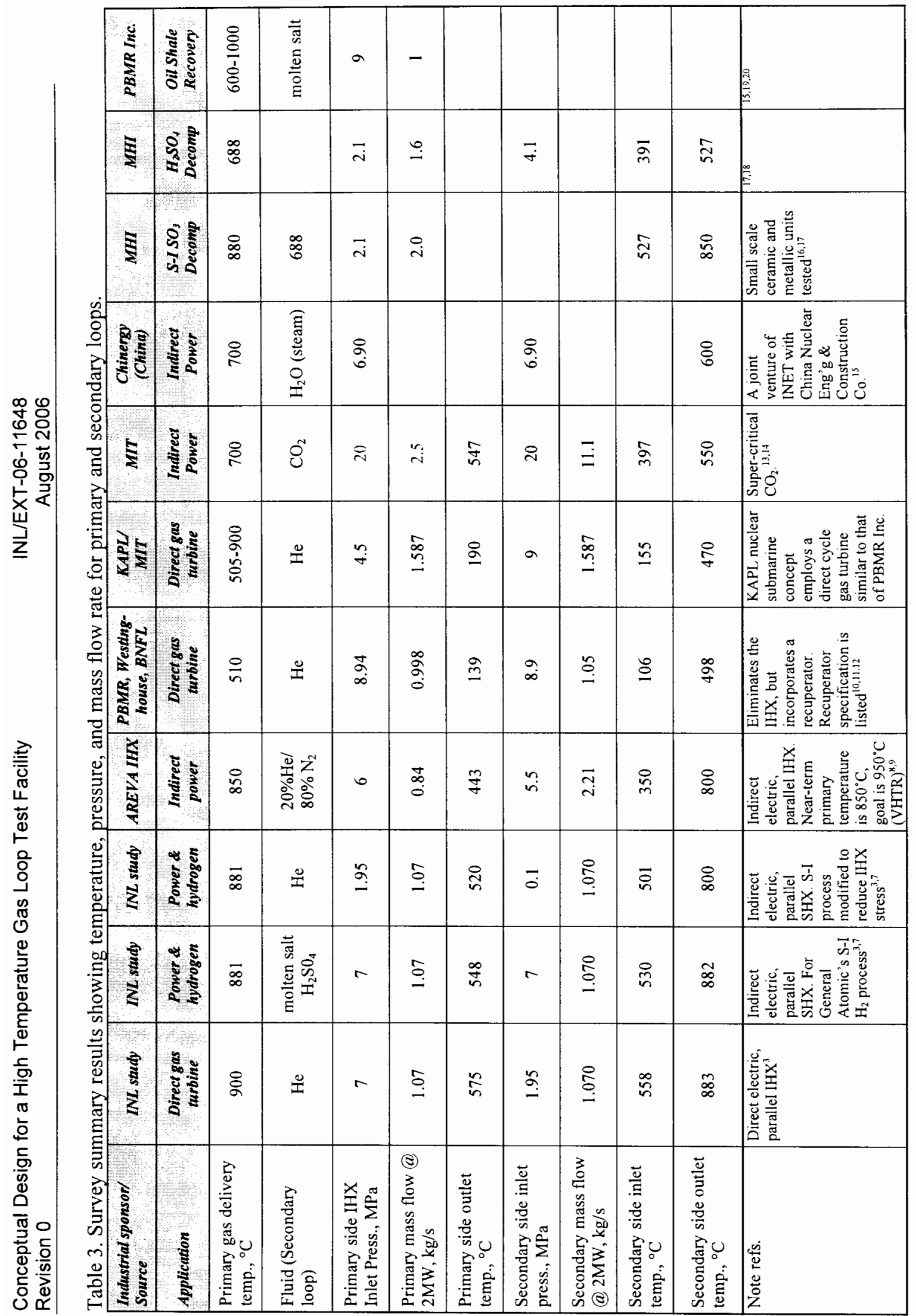




\section{TEST LOOP CONCEPTUAL DESIGN}

\subsection{System Analysis}

\subsubsection{Cycle Analysis}

The primary goals of this analysis are as follows:

- Develop design guidelines for pipe sizing, based on pressure-drop and heat loss budgets

- Create a design specification for the each of the principal HTGL components and subassemblies, including the many heat exchangers and the central heater

- Establish pressure ratio and flow sizing requirements for circulators.

In some cases, cost considerations encountered during the design and quoting of the subassemblies and components dictate changes to the specification; however, at this stage of the design, all components meet the specification with ample margin. A further goal is to compute wall heat transfer for purposes of determining insulation requirements and for analyzing transient thermal performance of selected pipe runs. These subjects are taken up in Sections 4.1.7 and 4.1.2, respectively.

Steady-state analysis has been carried out for the representative configuration illustrated in Figure 3. This configuration is based on the indirect cycle gas turbine power plant. The assumptions and cycle conditions are modeled after information published by AREVA, ${ }^{21,22}$ a leading developer of hightemperature reactor power plants.

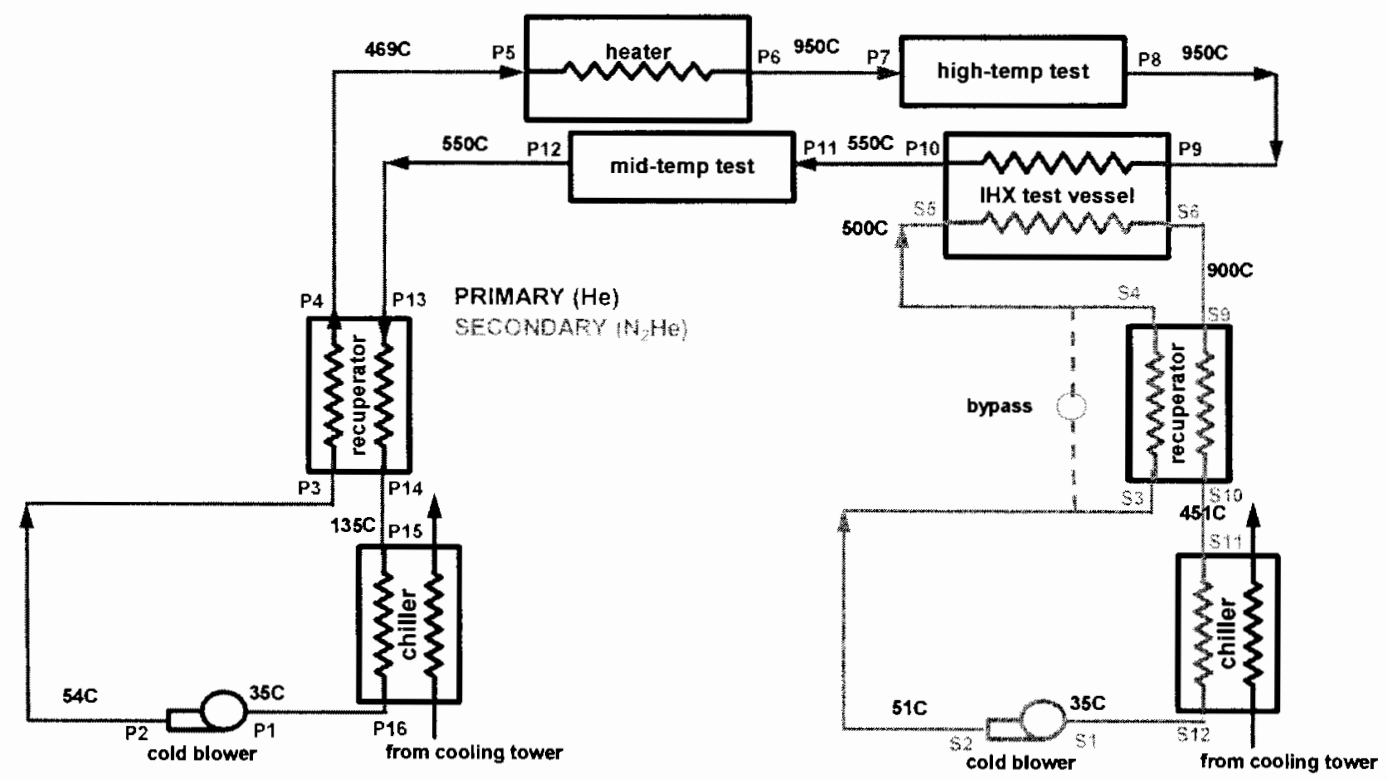

Figure 3. Simplified schematic diagram based roughly on indirect gas turbine cycle configuration. Temperatures are representative as discussed in text. 
Relevant specifications and assumptions are summarized in Appendix C. Temperatures in Figure 3 are displayed for representative purposes and are taken from INL's specification (Appendix D), or derived from a thermodynamic cycle model based on inputs from Appendix $\mathrm{C}$. The values do not correspond directly to AREVA's specification, the increased primary-side peak temperature of $950^{\circ} \mathrm{C}$, a notable difference. This high value is imposed as a test-loop specification in order to cover a broad range of HTGR programs under current development.

Before arriving at the schematic shown in Figure 3, a range of alternative concepts for configuring the primary circulator loop was investigated, as summarized in Figure 4 and discussed below.

A. Hot circulator simple loop. This is thermally the most efficient in that the overboard heat rejection is minimized and is conceptually the simplest approach. The circulator's high operating temperature poses a severe design challenge.

B. Cold circulator/unrecuperated loop. This is thermally the least efficient, as evidenced by the high-temperature rise demanded of the heater. Its attraction relative to Concept $A$ is the use of a cold circulator.

C. Cold circulator/recuperated loop. Heat recovery brings thermal efficiency to levels comparable to that of Concept A, but with the use of a cold circulator. Aside from savings in energy costs, a capital cost advantage over Concept B is also anticipated from reduction in heater capacity and supporting electrical switchgear. This advantage is only partially offset by the cost of the recuperator.

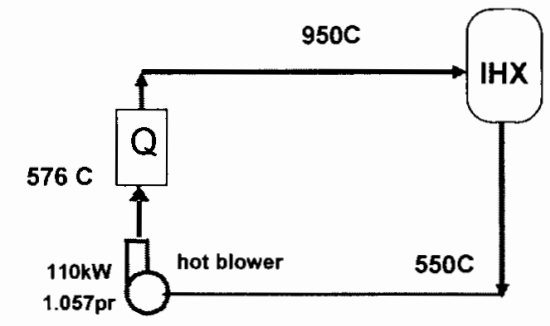

A - Hot circulator simple loop

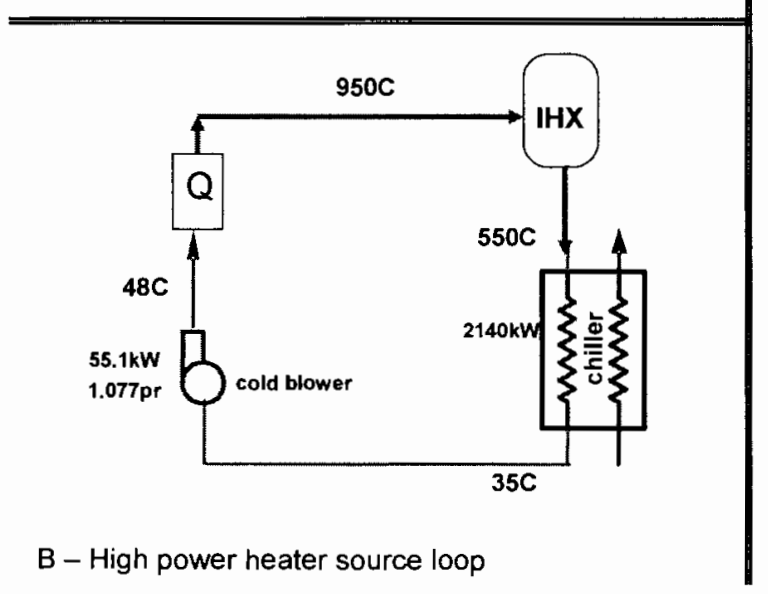

Figure 4. Circulator concepts for primary loop.

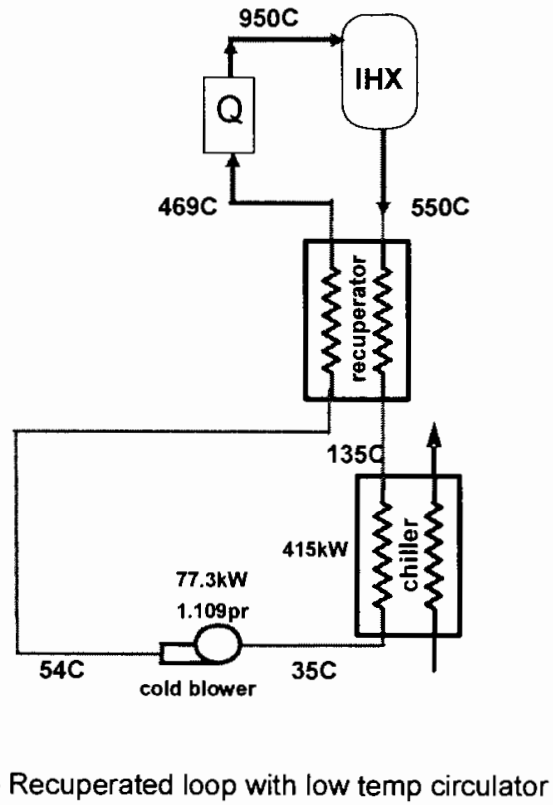

C - Recuperated loop with low temp circulator 
Figure 3 reflects our choice of Concept $\mathrm{C}$. Beyond the reasoning above, this decision is loosely based on preliminary findings regarding circulator pricing (see Section 4.2.1.2). On this basis, we conclude that the circulators will represent a substantial fraction of the overall system budget, so that a proportional reduction in their cost is worth pursuing. Admittedly, more refined studies of system cost are needed before the choice of Concept $\mathrm{C}$ can be made final.

A primary goal of this analysis was to develop design guidelines for pipe sizing based on pressuredrop specifications, which, in turn, will establish head requirements for the circulators. Cost considerations will dictate the eventual specification of system pressure loss, based on the competing trends of piping and circulator cost. Preliminary choices for piping parameters are summarized in Appendix C.

Spreadsheet-based software tools have been developed for the purposes above, customized for application to $\mathrm{N}_{2}-\mathrm{He}$ gas mixtures. Further detail is presented in Appendix C.

\subsubsection{Transient Analysis}

IHX test requirements call for simulation of temperature transients corresponding to various maneuver and failure scenarios. A generic specification for these transients was generated based on NGNP specifications corresponding to indirect gas turbine cycles ${ }^{21,22}$. Details are provided in Appendix E. Relevant time scales for thermal transients are on the order of seconds. It is desirable to minimize thermal lag introduced by test-loop piping, as it represents a potential corrupting influence on these tests.

Transient temperature signatures are of greatest importance at the IHX hot-side inlet. Accordingly, an analysis was performed for piping thermal response between the heater discharge and IHX inlet (stations P6 to P9 of Figure 3), which considered response of the discharge temperature to a step change at the inlet. Details are presented in Appendix F, with relevant findings included below:

- At the pipe discharge, the gas has reached rough thermal equilibrium with the inner wall.

Recognizing this, wall thermal response governs how rapidly gas discharge temperature can react to a change at the inlet.

- The heater-discharge duct, nominally 11-meters long in the HTGL layout, features a thin metal flow liner surrounded by thermal insulation. The thermal diffusivity of the flow liner governs its transient response.

- Analysis of this flow liner reveals that transient response is on the order of 0.2 seconds. Because this value is much shorter than the time scale for imposed thermal transients, the corrupting influence of the nominally 11 -meter heater-discharge pipe defined for the HTGL can safely be ignored.

\subsubsection{System Piping and Interface Diagram}

A detailed piping and interface diagram (P\&ID) has been prepared for the primary loop and one of three candidate secondary loops. The piping and interface diagram provided in Appendix G captures the functional positioning of components, control equipment, and piping needed to accomplish the testing objectives. The test article between the primary and secondary circuits contains an IHX. The piping and support systems planned for the second and third test bays will follow a similar mechanical design approach. 
Whereas it was the intent of this study to utilize industrial solutions or proven purpose-built components where practical, a relatively small fraction of the equipment was found to be readily available from existing industry sources. Only the coolers, employed in both primary and secondary gas loops, could be commercially specified and purchased. The loop has been configured to utilize standard ANSI valves and piping. The HTGL design avoids the use of high-temperature valves $\left(>500^{\circ} \mathrm{C}\right)$.

\subsubsection{P\&ID — Primary Loop Description. The primary loop is composed of the following:}

- Heat Source (electric): providing 2-MW to the helium gas stream, with exit temperature of up to $950^{\circ} \mathrm{C}$

- Recuperator: a helium-to-helium energy savings device, operating at temperatures in the range of $500^{\circ} \mathrm{C}$

- Gas (helium) circulator compressor: to motivate the fluid around the circuit, overcoming the pressure drop of the components and piping

- Cooler: a helium-to-water/glycol heat rejection system, designed to minimize the inlet temperature to the circulator

- Interconnecting piping.

Each of these components and subassemblies has been designed for the specifications and intended duty of the HTGL, as detailed in Section 4.2. Ancillary support equipment and controls are discussed in Section 4.1.3.3.

4.1.3.2 P\&ID - Secondary Loop. Three secondary loop test bays are proposed for the HTGL installation. At this stage of the design, only one of the three has been analyzed and is shown in detail in the P\&ID. A principal objective of the HTGL test plan is to configure the test loop to permit simultaneous operation of one, two, or all three secondary loops. Simultaneous tests will share the $2 \mathrm{MW}$ heat addition capability. The primary loop will deliver helium to each test bay with independent control over mass flow, but a common delivery temperature and pressure. The three secondary loops are individually controlled. In this arrangement each loop contains a minimum of the following:

- Containment and support structure for the test article: Typically a pressure vessel for IHX testing.

- A recuperator: Receives the exhaust heat from the test article, and controls and maintains the desired level of preheat of the secondary return temperature to the test article.

- A circulator: A controllable compressor that pumps the secondary fluid around the circuit to overcome pressure losses in the piping and gas path components.

- A cooler: A secondary fluid-to-water/glycol heat exchanger designed to reject heat and minimize the inlet temperature the circulator inlet.

As there are several candidate fluids under consideration for the secondary loops, additional support equipment may be necessary. For this study, detailed consideration was directed to the wellresearched high-temperature reactor design promoted by AREVA ${ }^{21,22}$ and others. This system uses a secondary fluid mixture of helium and nitrogen as the working fluid for a gas turbine engine. 
The secondary circuit for the He- $\mathrm{N}_{2}$ test bay has been analyzed in detail, with most mechanical details provided in this report. This test loop is designed to focus on life and performance testing of the IHX, operating at temperatures up to $950^{\circ} \mathrm{C}$. A critical feature of this secondary loop design is the ability of the circuit to control temperatures, mass flows, and pressures of both loops to simulate maneuvers anticipated during reactor and power plant faults. This is discussed in more detail in Appendix A, which describes test plans.

4.1.3.3 P\&ID Ancillary Equipment. Several subsystems are specified to service the test loops, indicated as follows:

- Gas storage tanks, nominally at pressures above mean operating pressures during test, can be vented to their respective loop or valved and pumped back after a test.

- Gas purification equipment is required to support both primary (helium) and secondary circuits. This system circulates a small fraction of the net flow continuously. Likely, the load on this system will be greatest during commissioning of the HTGL, prior to initiating hot testing.

- A network of vacuum pumps, including roughing, diffusion and holding, are employed in both secondary and primary loops to evacuate and clean piping and system components.

- Gas charging system, a high-pressure compressor station capable of filling the test loops to the prescribed pressures, is also used to decommission each experiment, with the intent of pumping out each test loop, thereby maximizing the recovery of gases. The P\&ID indicates a gas charge compressor for both primary and secondary loops; however, it appears that with some secondary fluids, such as $\mathrm{He}-\mathrm{N}_{2}$ mixes, a common compressor may be used to serve both circuits.

- To allow rapid depressurization in a test vessel, piping is provided to a high capacity bank of tanks. These tanks are maintained at low pressure during the experiment and may be activated by a solenoid-actuated valve or a proportional control valve. As shown in the P\&ID and proceeding layouts, the vent tank is the same volume as the test loop and allows for a rapid 2:1 pressure variation.

4.1.3.4 Starting and Operating the HTGL. Preparing for a test, primary and secondary loops are pumped down to a vacuum and stabilized. This removes air from the system and rids it of contaminants and off-gases from within the circuit. Stabilization of the vacuum level at $10^{-6}$ torr indicates that a loop is ready for filling.

Typically, it is critical to control the differential pressure on the IHX test article, hence the primary and secondary loops are charged simultaneously. The primary loop receives a charge of industrial-grade helium (see Section 4.2.3.3), while the secondary loop may receive any number of candidate gas mixtures. A substantial gas inventory capacity is provided by external storage tanks. Both primary and secondary circuits are serviced by dedicated high-pressure piston compressors. Once filled to the specified cold charge pressure, circulators are activated and gases flow through the loops. During this period, gas purity is monitored and gas-purifying systems are active to achieve purity levels specified by the test requirements. Once gas purity levels are established, the primary heater and the coolers on both loops are activated. As the temperature rises in the loop, the increasing pressure is monitored and the inventory of helium may be adjusted to achieve the target pressure. Inventory control is achieved by the bleed-down circuit and the charge compressor.

The HTGL is equipped with a six-degree-of-freedom control system and the associated actuators to achieve the desired test conditions and perform simulated transient maneuvers (section 4.1.2). In 
summary, the power to the electric heater is controlled to acquire and hold a prescribed set-point. Similarly, the primary and secondary gas circulator speeds are controlled to achieve the specified flow rates. The secondary flow inlet temperature to the IHX test article is controlled by a bypass circuit and a novel recuperator thermal control mechanism (Section 4.2.2.2). Coolers on each loop are configured to minimize the gas inlet temperature for circulators. Heat rejection from the coolers is provided by fancooled radiators outside the walls of the facility.

\subsubsection{Mechanical Layout}

Three test bays are planned for the HTGL to support testing of various components for the NGNP. They are arranged in a $T$-formation with the primary-side equipment at the intersection. The single primary loop supports all three test bays, while secondary loops, each potentially handling different media (helium, helium-nitrogen mix, sulfur-iodine, molten salt, etc) are dedicated to specific test bays. By centering the primary loop equipment at the intersection of the $T$-formation, the length of pipes conveying hot gases to and from the test bays is kept short. Frictional pressure loss and heat loss are thereby minimized as practical given space requirements for equipment, reducing the demand on the primary circulator and the HVAC system respectively. Figure 5 provides a plan view of the HTGL with orientation of the three test bays to the primary loop equipment and the piping between each. A large area off one bay is shown as a notional site for a sulfur-iodine pilot-plant for hydrogen production. The HTGL is seen as a ready source of heat needed for that future demonstration.

A close-up view of the HTGL (Figure 6) shows details of the central primary loop and a complete secondary gas loop in Test Bay 1, to the left. Test Bays 2 and 3 are also served by the central primary loop and heater. Test Bays 2 and 3, located adjacent the space-claim for the future sulfur-iodine experiment and the primary loop, are sized to accommodate a range of possible secondary loops, including molten salts, steam, $\mathrm{CO}_{2}$, sulfur-iodine (SI) constituents and other candidates for the NGNP. A schematic of one possible SI process is shown in Appendix H.

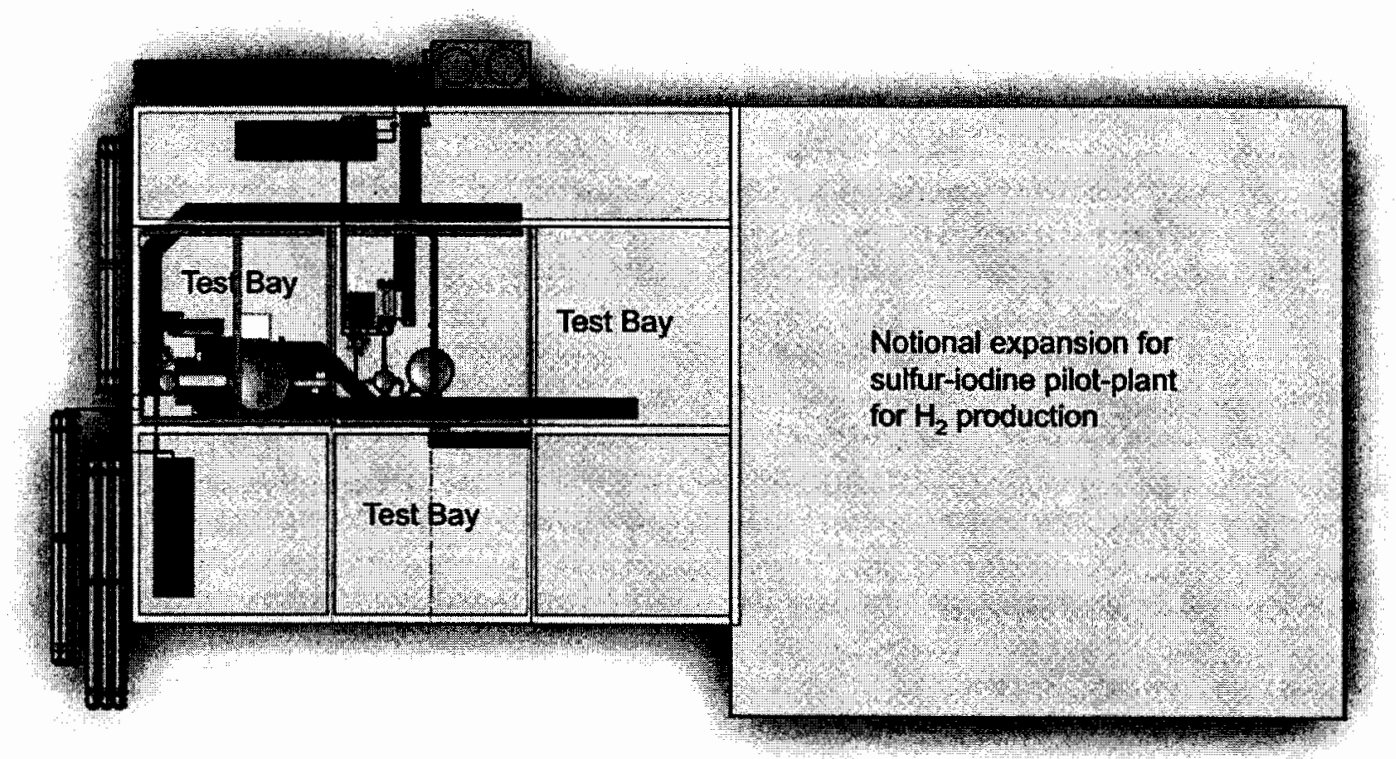

Figure 5. The HTGL facility comprises three test bays arranged in a T-formation. Space is shown in this plan view for a notional expansion to include a sulfur-iodine pilot-plant for $\mathrm{H}_{2}$ production. 


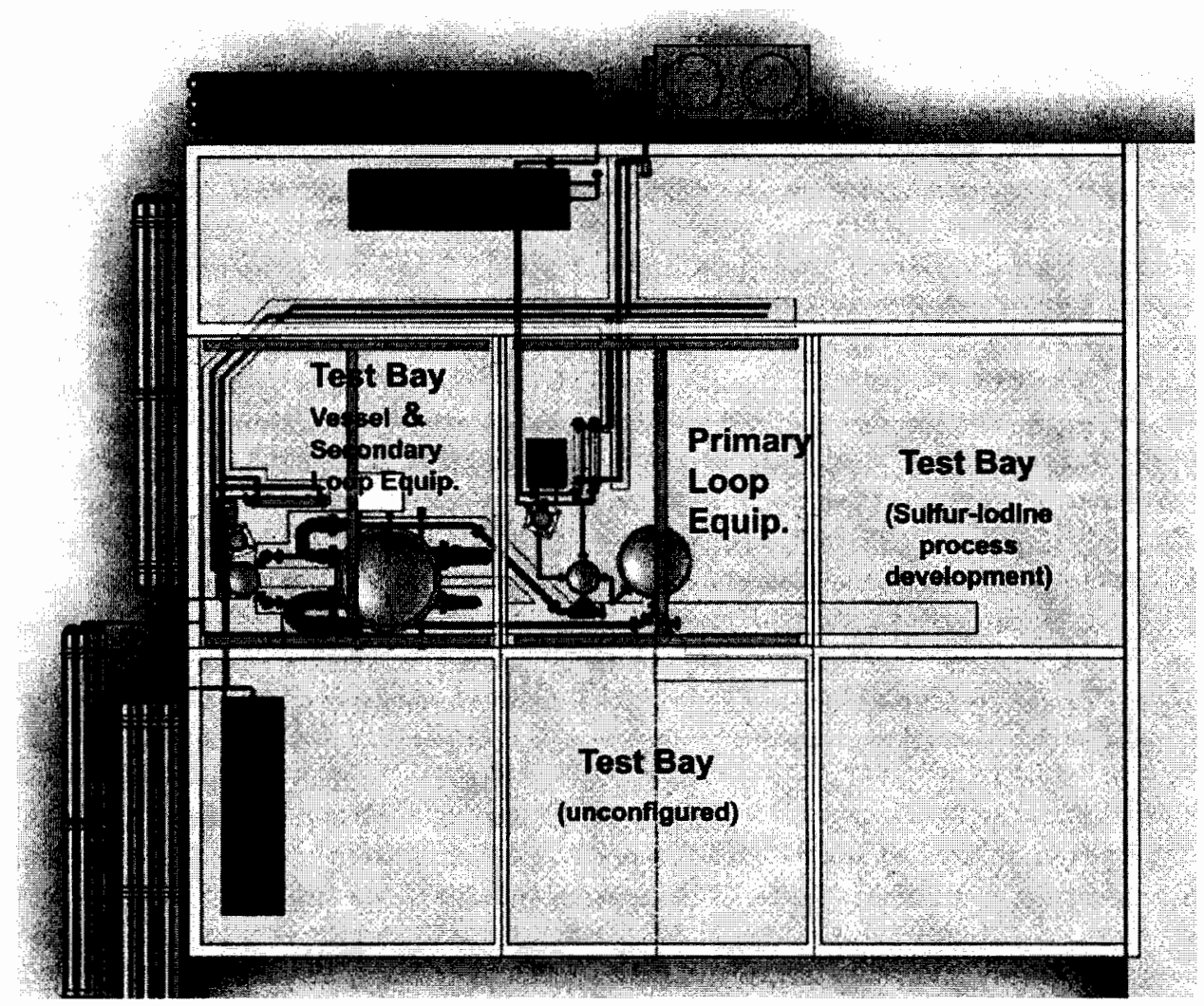

Figure 6. A close-up view of the HTGL. Test bays are arranged in a T-formation to minimize the length of pipes conveying hot gas.

Lateral runs of piping are below floor-level in covered trenches. This is done to protect staff and visitors from pipes that may be above safe touch temperatures, as well as to allow free space for operations. These trenches can be seen in Figure 7, occupied by their respective pipe runs. Pipes above floor-level appear larger. Extra internal insulation lowers the outer surface of these to safe temperatures. Not shown in Figure 7 are covers over the pipe trenches. These serve a dual purpose, as they effectively create a duct for directing air over pipe surfaces at a prescribed velocity for cooling (see Section 4.1 .7 for further details regarding pipe temperature control and Section 4.2.3.2 describing ventilation) and complete the facility floor.

The laboratory set-up for IHX testing is shown in plan-view in Figure 8. Here, relative sizes and location of equipment can be seen. The primary loop heater, recuperator, coolers, circulator, and helium purification system are clustered near the center within their bay (not shown) with the cooling tower, helium compressor, and helium storage tanks above. The IHX vessel is prominent, to the left of the primary equipment, with the secondary-loop equipment, including recuperator, cooler, circulator, and gas purification, in close proximity. To the left of the test vessel and secondary equipment is an array of tanks for venting the primary-side of the test vessel to simulate sudden depressurization events. Below these are the nitrogen-helium-mix tanks and the secondary vent tank. 


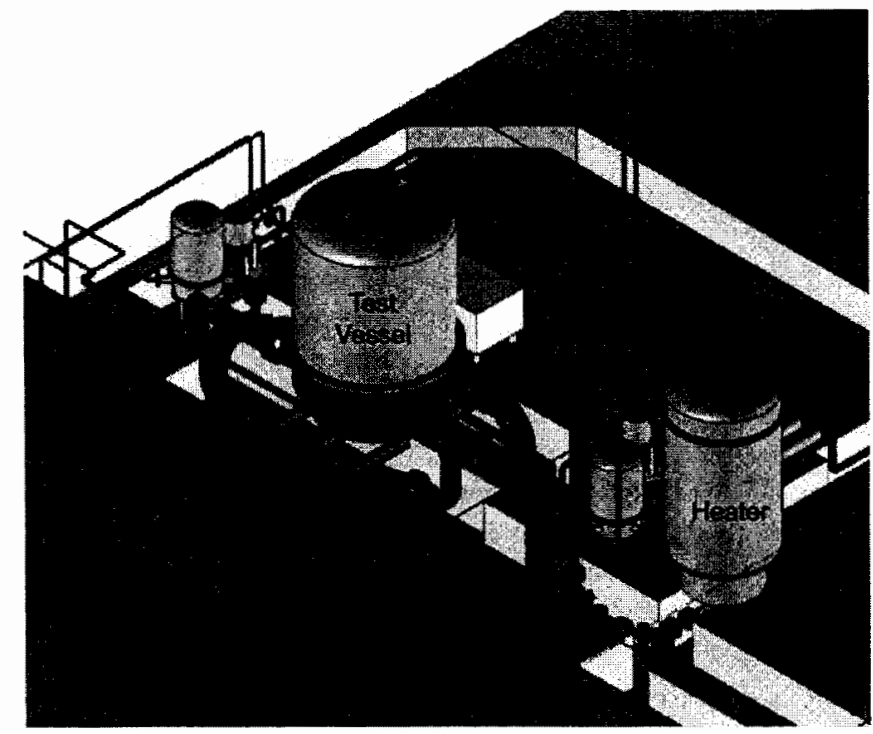

Figure 7. Pipes are located in trenches below floor-level. Removable covers (not shown) complete the floor and create ducting to direct ventilation-flow over pipes to maintain wall temperatures at proper levels.

Gas storage and vent tank bundles are outside the walls of the facility. This facilitates delivery by avoiding potentially dangerous handling of high-pressure vessels. The proposed arrangement of gas storage is shown in Figure 8. Also shown are preliminary layouts for gas purification systems and a fancooled radiator for heat-rejection from coolers used to condition gas approaching primary and secondary circulators. Additional views of the HTGL are shown in Figures 9-11.

Layout of test bays is planned to allow movement of equipment and access for assembly and maintenance. Left, right, and vertical lift capability is provided by an overhead crane, the structure for which is shown in Figure 12. Equipment is placed generally to the side of the bay, leaving space for forklift access and an area to place the vessel-bell while test setup or removal activities are ongoing.

\subsubsection{Test Vessels}

Several large custom pressure vessels are specified in the HTGL and are required to house the IHX test articles, the electric heater, and the two recuperators. Each is internally insulated and shielded by a cooling liner to isolate the vessel from the elevated internal gas temperatures. High-performance silica micropore insulation is used to line the interior of the vessels. This class of insulation is analyzed in Section 4.1.7. Conformance with American Society of Mechanical Engineers (ASME) Boiler and Pressure Vessel Codes $^{23}$ is a requirement for all pressure vessels used in the HTGL.

4.1.5.1 Test Article Pressure Vessel. The 3-meter-diameter IHX pressure vessel, shown in Figure 13, is the largest of all vessels proposed for the HTGL. Its size is intended to accommodate a wide range of heat exchanger test articles and provide access for the experimental team. The design provides a mounting ring (not shown) and four upward-facing flanges connecting the inlets and outlets for the primary and secondary loops. The upper portion of the vessel bell is intended to retract vertically from the lower head to provide unobstructed access to the test article. Note that there are no penetrations in the upper head and that all instrumentation leads will be routed through penetrations in the lower head. Hemispherical heads are specified to minimize wall thickness and manufacturing cost of the vessel. 


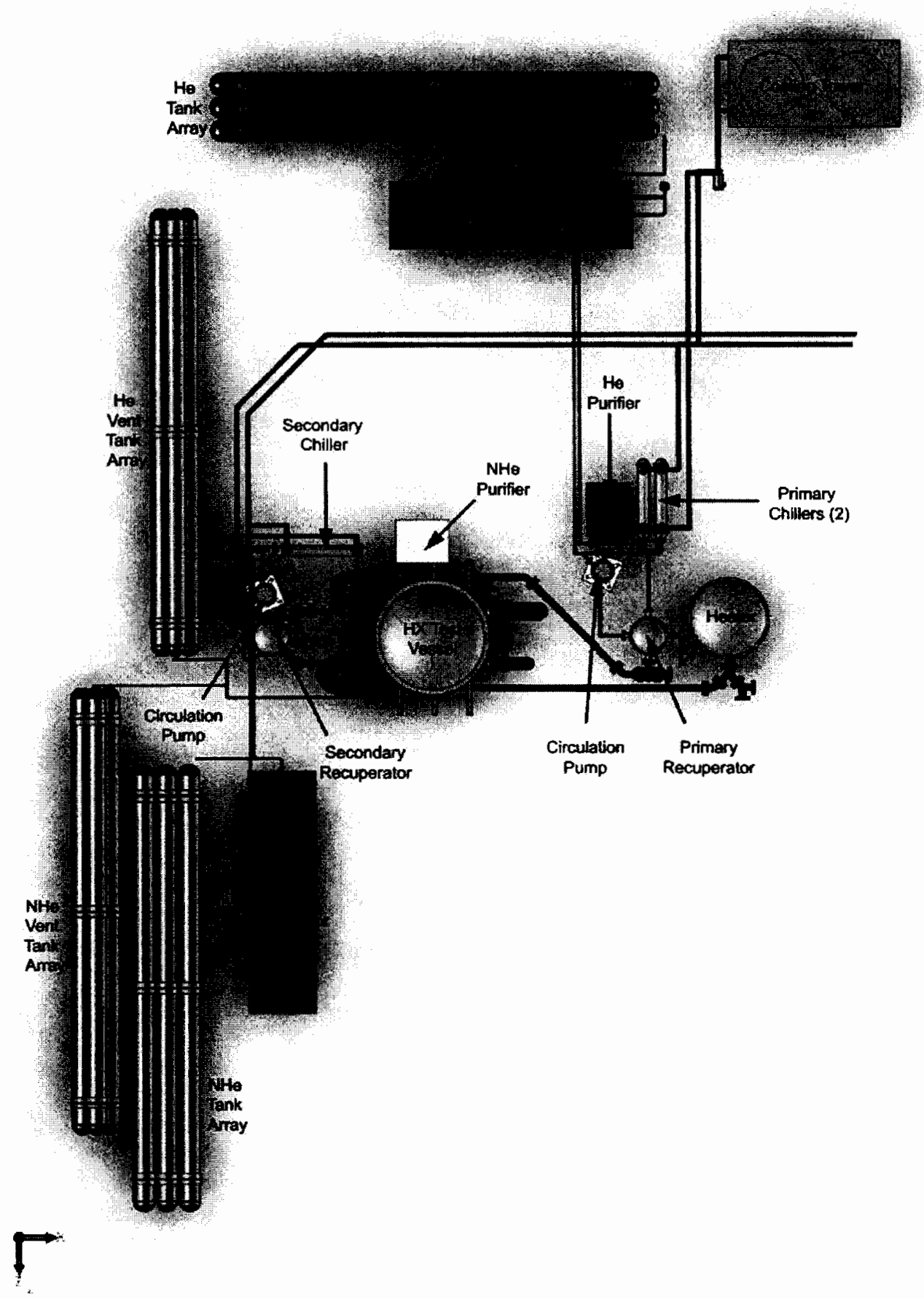

Figure 8. Plan view layout of components, piping, and ancillary equipment to support testing of Intermediate Heat Exchangers. 


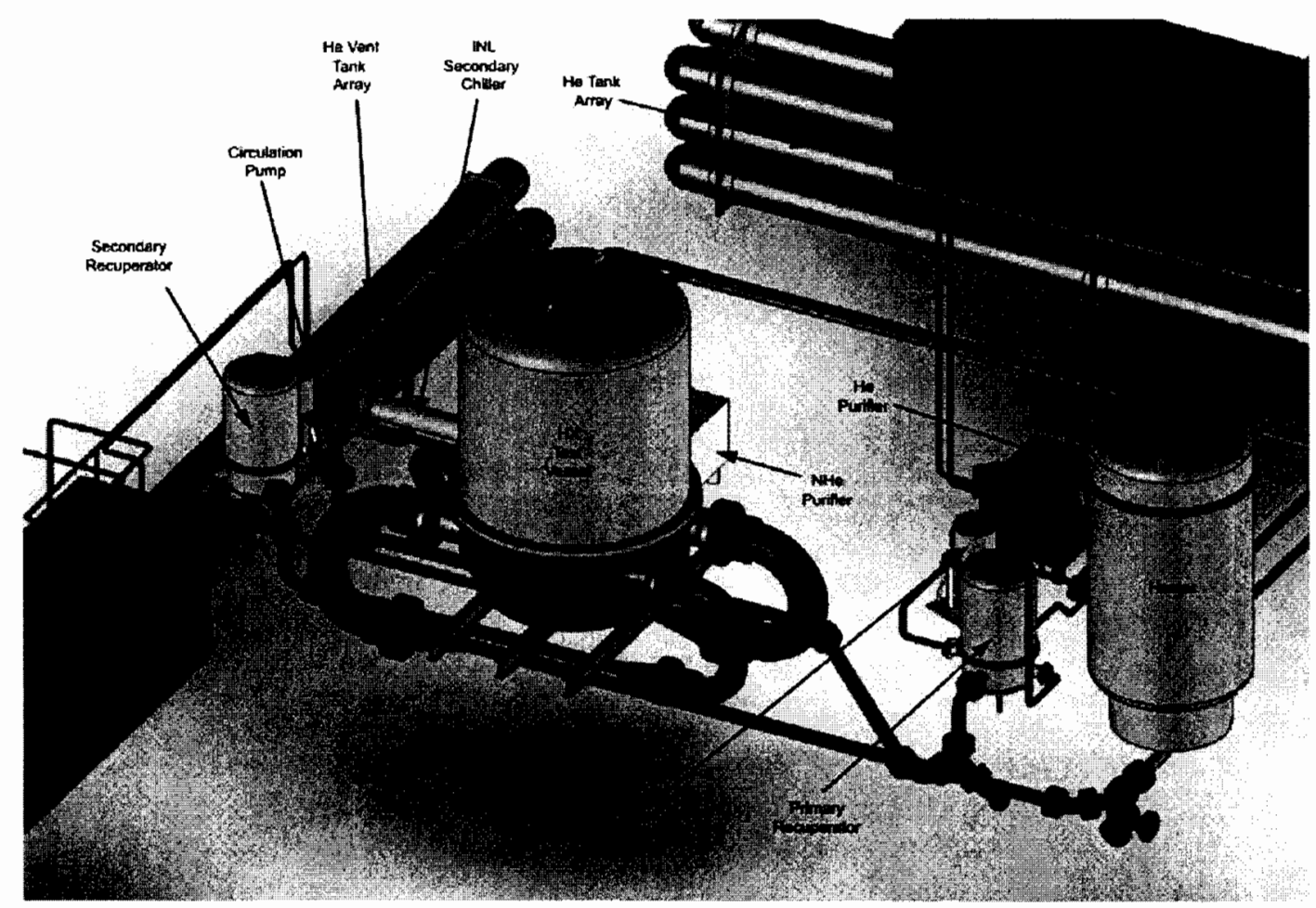

Figure 9. Floating isometric view of the primary and secondary loop equipment and piping for IHX testing, with each major component identified.

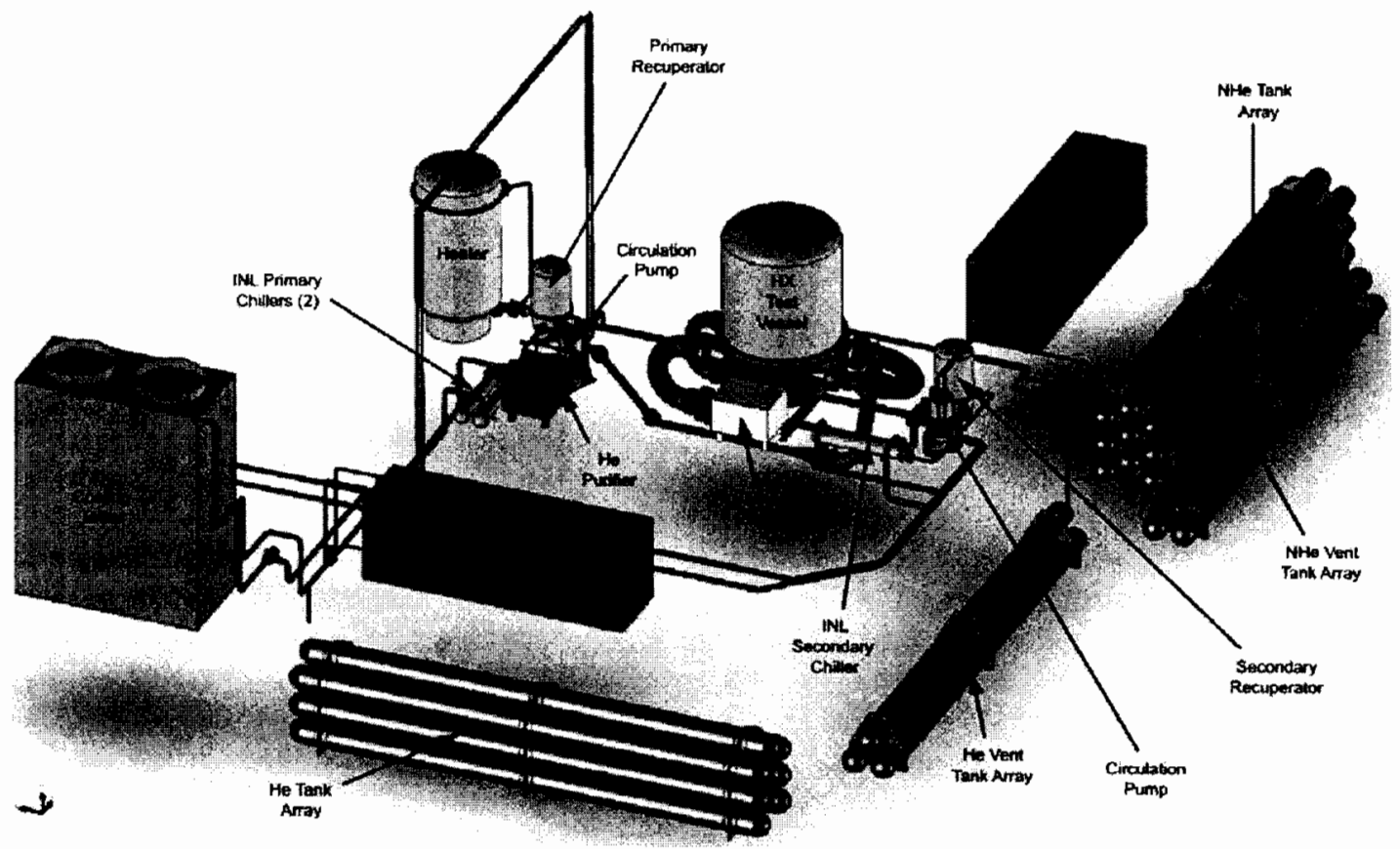

Figure 10. Floating view of equipment and vessels supporting an IHX test. Gas supply and vent tanks are shown on the perimeter of the facility. 


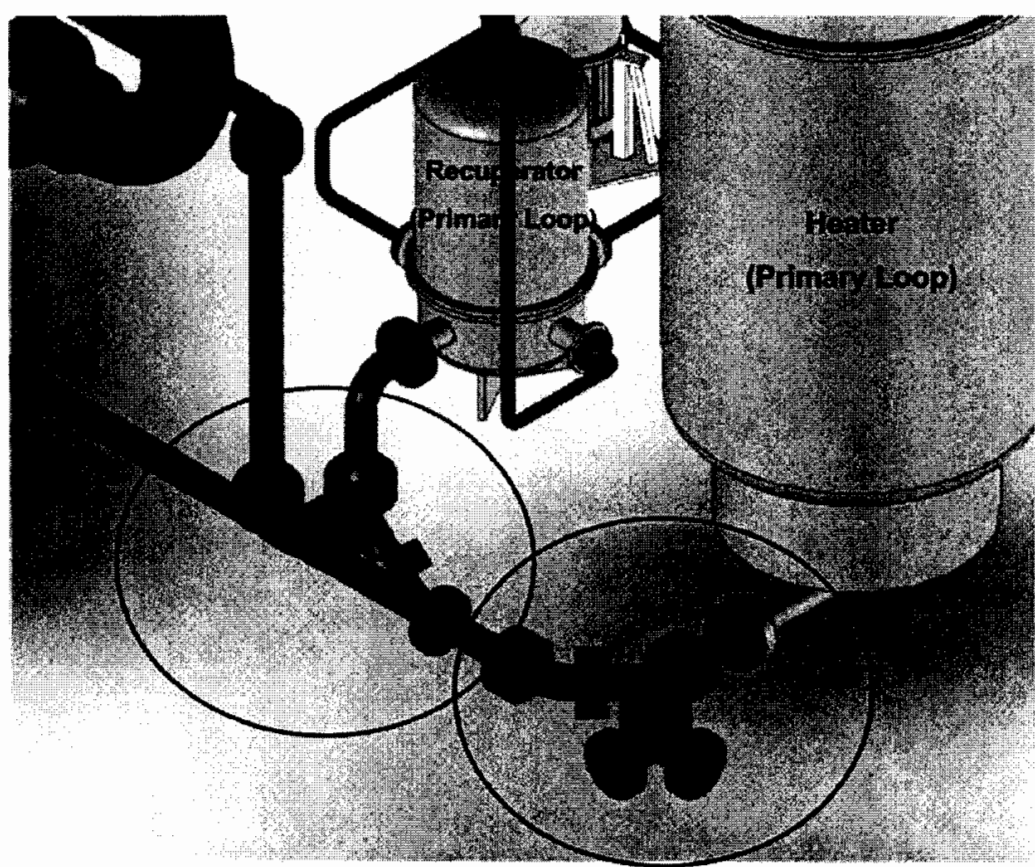

Figure 11. The primary loop services the three test bays. Shown are manifolds at the primary heater and recuperator, which can be configured to direct and receive gas from the bay, or bays, in which tests are being conducted.

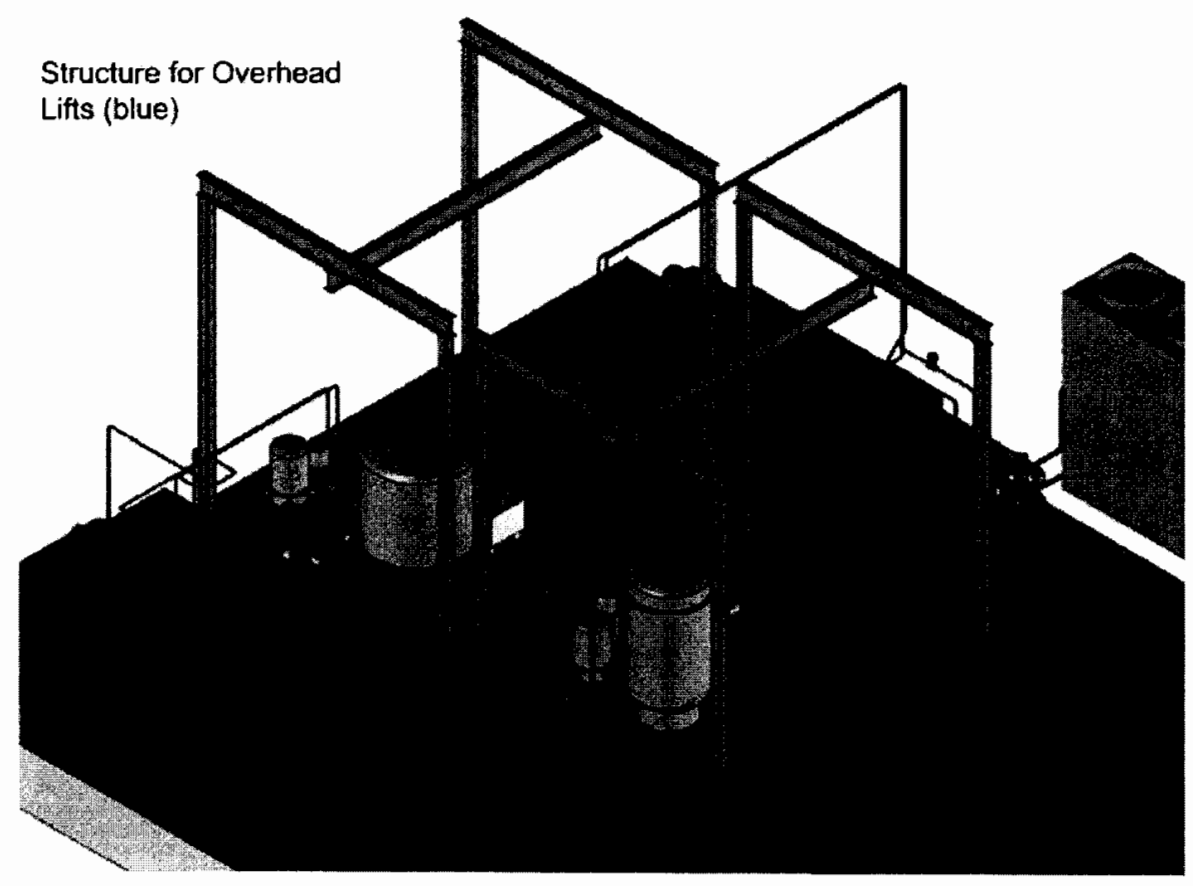

Figure 12. Overhead cranes are installed in test bays to facilitate the movement of equipment. Fixed equipment is positioned to one side of the bay, leaving space to set the vessel bell while work is performed within. 
The pressure vessel, described in this section, serves the primary function of providing a flexible test-bed for all known industry IHX test articles. Other primary functional requirements are ease of access for installation and instrumentation, inspection and service, and access ports data cabling. The primary vessel for Test Bay 1 is designed to accommodate full-sized IHX cores, such as those described by AREVA $^{21,22}$ and General Atomics. ${ }^{7}$ Heat exchanger candidates include plate-fin, chemically-etched plate, and tube-shell designs. The detailed design and component costs for the IHX test vessel are provided in Appendix I.

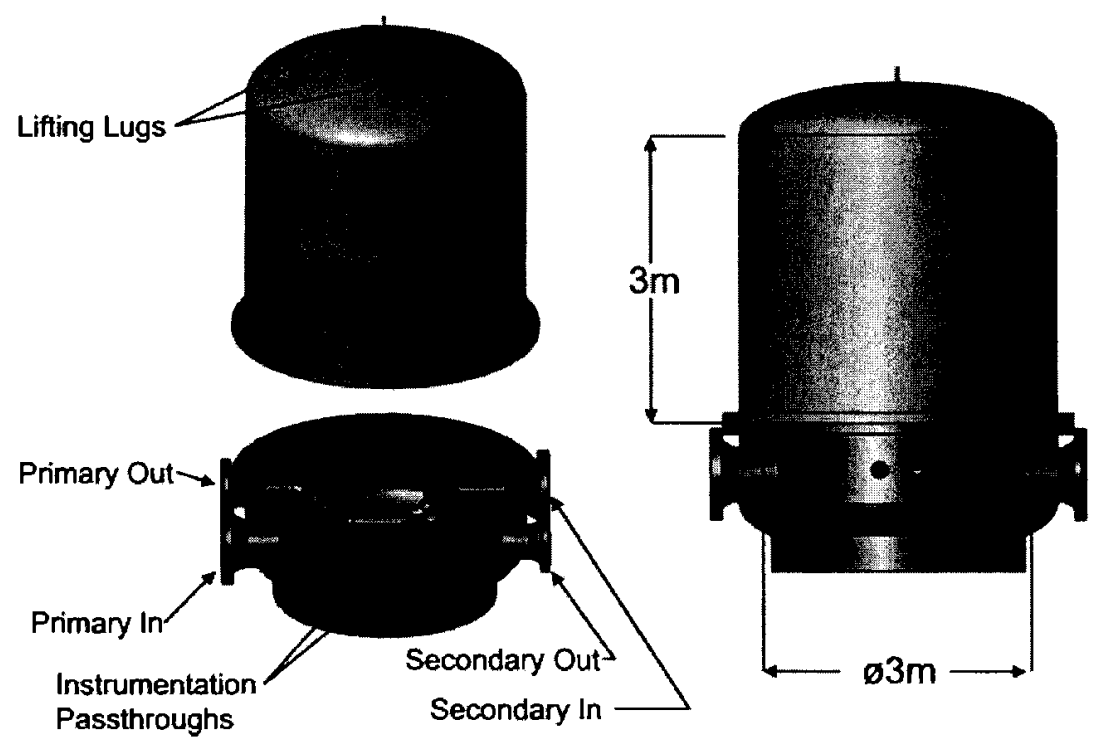

Figure 13. Bay 1 test vessel annotated to show pass-throughs for instrumentation, as well as flange locations for primary and secondary gas interfaces. A removable bell allows unencumbered access for installation and removal of test equipment. The working volume is 3 -meters in diameter by 3 -meters tall.

An installation example of the test vessel with an intermediate heat exchanger for indirect cycle gas turbines is shown in Figure 14 and Figure 15. This heat exchanger, designed by Brayton Energy, LLC, is a candidate for the AREVA IHX. ${ }^{21}$ This two-core arrangement, sized for the 2-MW HTGL capacity, occupies a relatively small portion of the large test envelope.

IHX core modules are contemplated in many sizes and shapes. Whereas it is critical to test the entire IHX core and attachments to perform life testing, the large test volume is a unique advantage of this facility. 


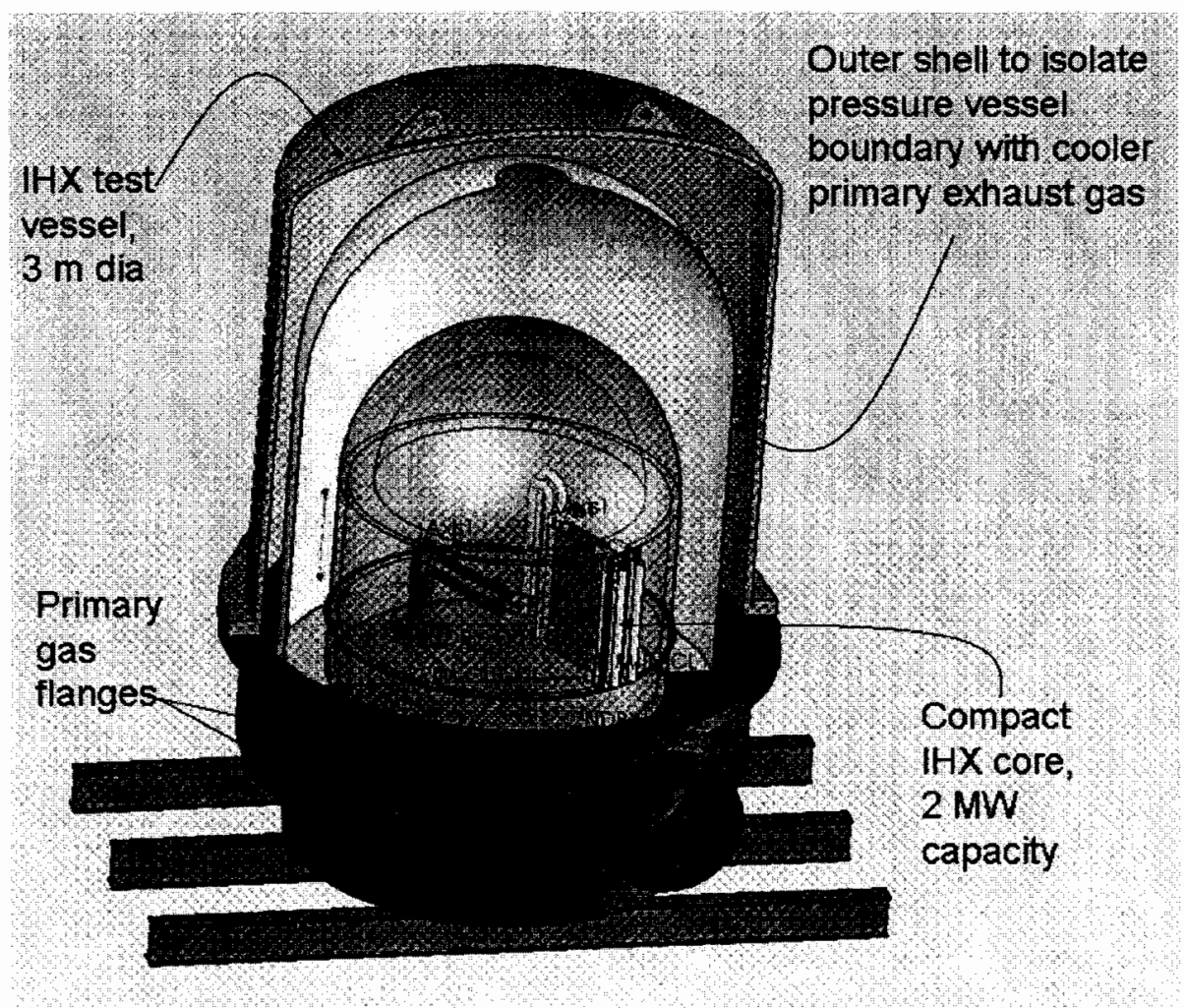

Figure 14. Three-meter-diameter IHX test vessel with a compact IHX core installed. Liners direct cooler gases along pressure boundary walls to maintain temperatures within design limits.

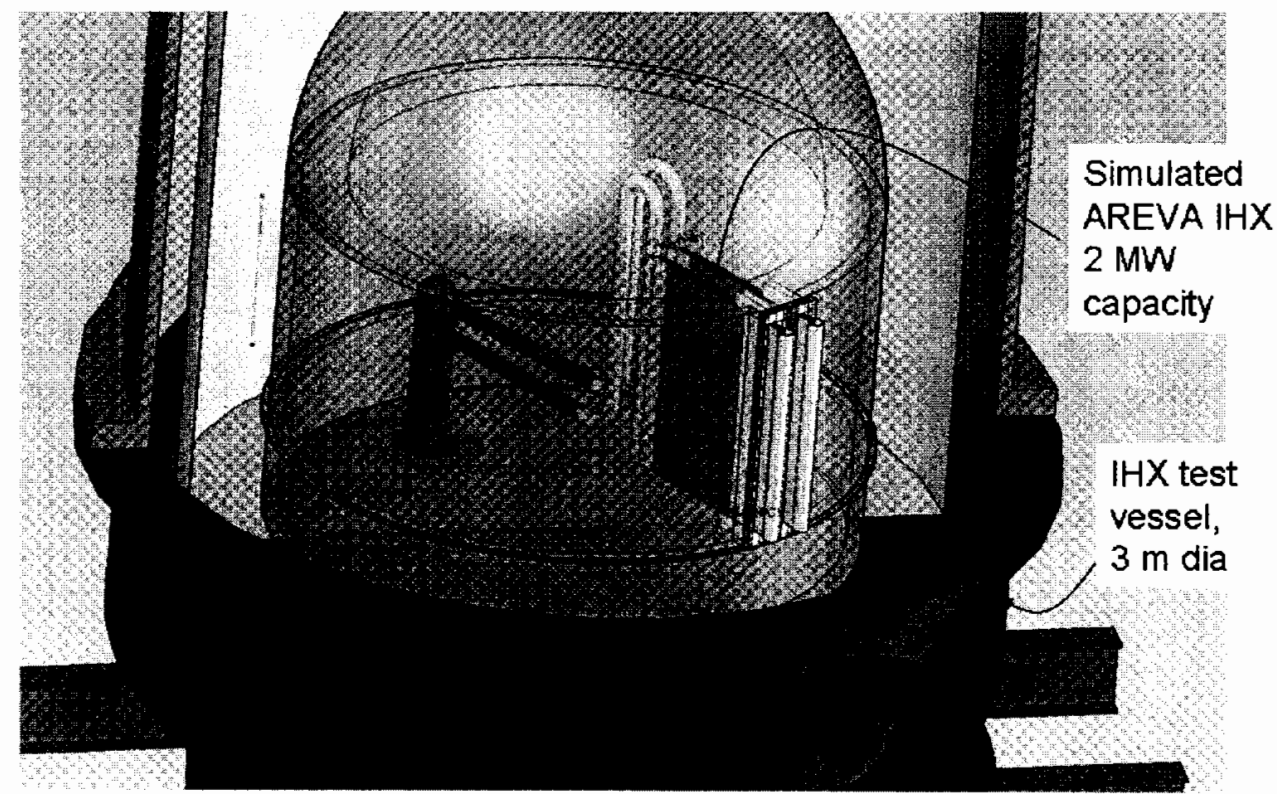

Figure 15. Test vessel with a simulated AREVA test article installed. The test article is sized for $2 \mathrm{MW}$ capacity. Mechanical mounting points and fluid-flanges are fixed in space. This provides solid fixity for engineers designing test setups for thermal strain measurements. 


\subsubsection{Piping}

Piping in the test loop conveys various gases at elevated temperatures between the components in the primary and secondary circuits. In the high-temperature piping runs $\left(800\right.$ to $\left.950^{\circ} \mathrm{C}\right)$, few options comply with ASME Power Piping codes. ${ }^{23}$ To comply with the code and avoid extensive use of expensive super-alloys, high-temperature piping runs are internally insulated. The heat load on the facility, size, and general accessibility are also important criteria that have been applied to this design.

A coaxial pipe configuration, shown in Figure 16, is specified for all high-temperature pipe runs. The inner tube is a light gauge, corrosion resistant, high-strength nickel superalloy, and serves as the flow liner. This layer prevents erosion and contamination of the insulation and provides a smooth, low-friction fluid boundary. Alloy 625 (14-gauge) has been selected for this duty. The pressure boundary, Type 304 stainless steel pipe, is isolated from the flow liner by a high-performance thermal insulation such as aerogel. Performance of this insulation in high-pressure, high-temperature helium differs substantially from manufacturer's data for performance in barometric-pressure air. As discussed in Section 4.1.7, the conductivity of aerogel insulation may approach the continuum conductivity of the helium with which it is saturated at test conditions.

The inner diameter is sized to keep frictional pressure losses within a budget dictated by the headrise capabilities of circulators and by the expected losses in test articles and other system components.

With cool vessel walls in fixed positions, piping pressure boundaries at elevated temperatures, and pipe liners at very high temperatures, differential thermal growth must be addressed to avoid potentially damaging strain. Relative thermal displacements include the thermal expansion of pipes and the relative diametral expansion rates of pipes and cooler flanges. Both are addressed in the specified design strategy within the detail seen in Figure 17. A U-pipe with hinged expansion joints, a conical thermal transition, and telescoping inner liners are the respective solutions to these potential sources of thermal strain.

For the 6-inch-diameter pipe specified in the hottest piping runs, lengthwise displacements may be as high as 32-millimeters, end-to-end. U-pipe assemblies with hinged expansion joints at each end, as shown in Figure 18, provide strain relief for deflections of this magnitude with ample margin ${ }^{\mathrm{a}}$. The asinstalled and deflected states are shown kinematically in Figure 19 as a rotation of the U-portion of the assembly, while the hinges articulate with only rotational freedom about the axes of the hinge pins. These assemblies are of a larger diameter to accommodate insulation that maintains their pressure boundaries at temperatures close to those of the adjoining vessels. Thermal analysis indicates that there is no appreciable temperature difference between the vessel and $U$-pipe assemblies, as what potential exists is leveled by thermal conduction.

Thermal transitions are prescribed at the ends of the piping runs and serve to join the elevatedtemperature pipes to the cooler U-pipe assemblies with stress magnitudes that will not limit durability. To create the transition, a cone is welded between the nominal pipe diameter and the enlarged diameter of the mating U-pipe. More insulation is allowed in the radial space between the constant-diameter liner as the cone expands with distance from the pipe-end flange. This naturally controls the temperature distribution along the conical transition, as seen in Figure 20.

a. They have been sized by the manufacturer, Senior Flexonics Pathway, to accommodate as much as 4-inches of pipe extension for 5,000 cycles. 
An analysis has been performed at pressures and temperatures typical of an indirect gas turbine, applying ASME Section B31.3 safety criteria. The results of the finite element analysis indicate that the thermal stress associated with the temperature gradient (Figure 20,21) is quite low for the proposed configuration. In the test case, shown in Figure 22, the membrane stress associated with the internal pressure dominates, and dictates the required wall thickness. At the $6 \mathrm{MPa}$ conditions analyzed, the required wall thickness for the 18.5 inch $(470 \mathrm{~mm})$ internal diameter pipe was determined to be 0.75 inches $(19 \mathrm{~mm})$. This geometry also complies with the ASME codes at the maximum rated pressure of 8 $\mathrm{MPa}$.

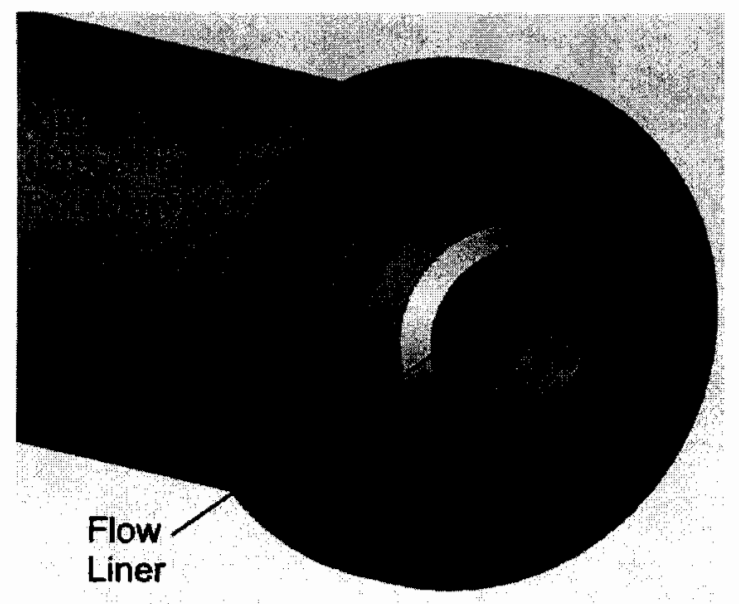

Figure 16. Isometric view of internally insulated coaxial pipe construction for high-temperature and highpressure gas.

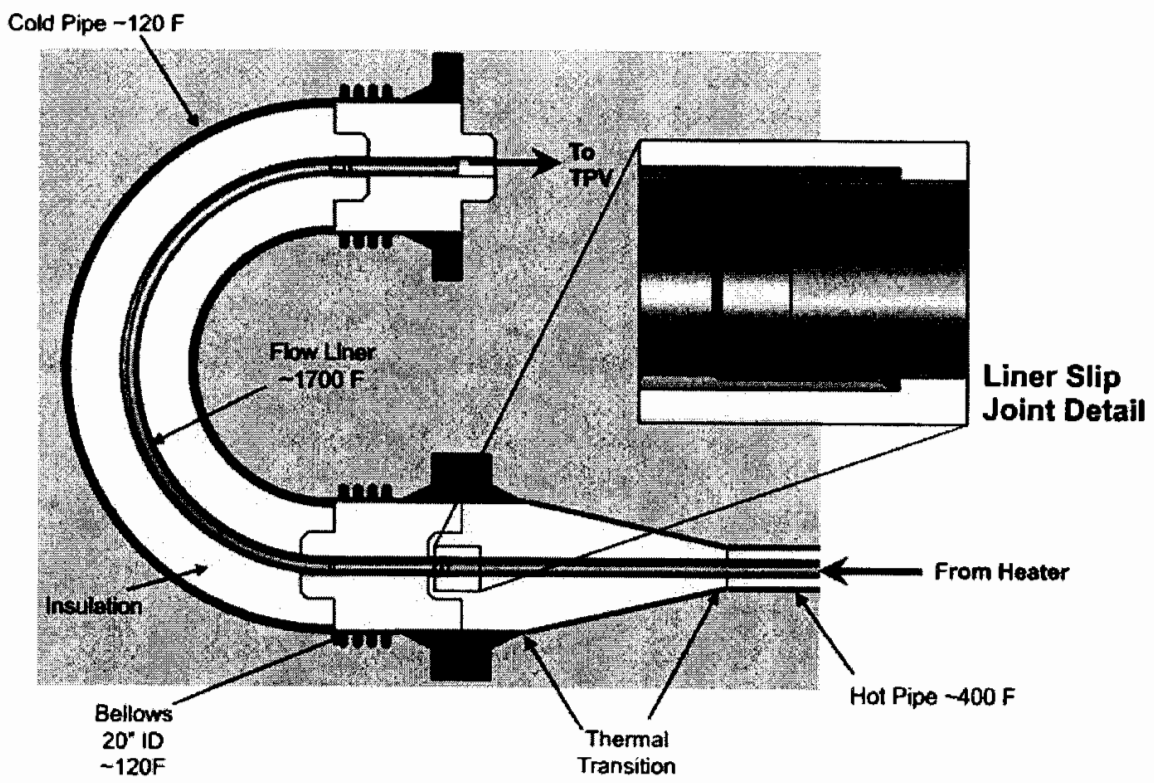

Figure 17. Detail of piping features specified to accommodate differences in thermal displacement. 


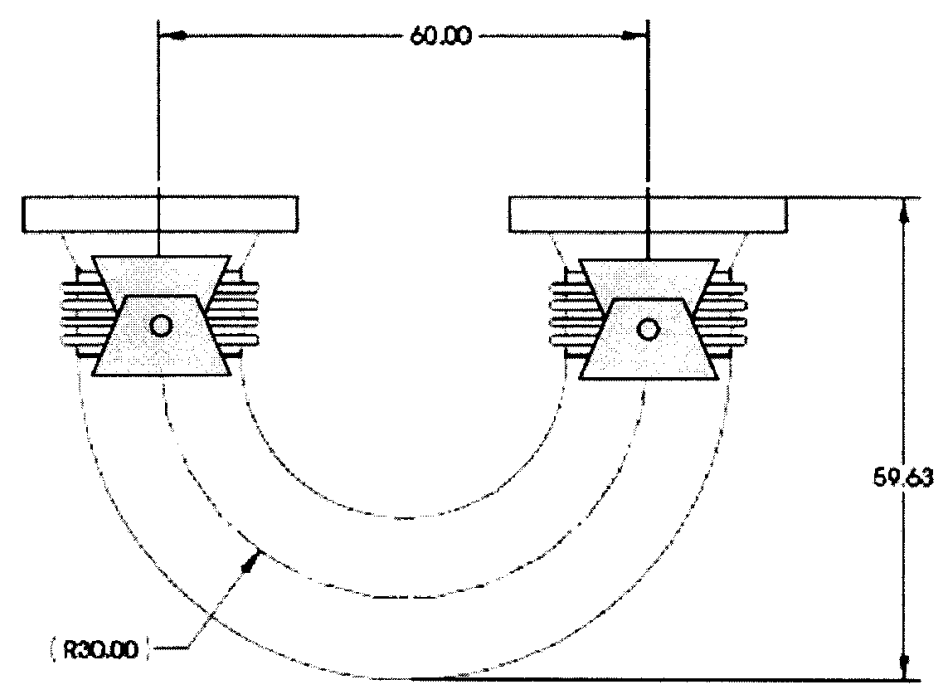

Figure 18. U-pipe assembly provides strain relief for hot pipes between fixed vessels.
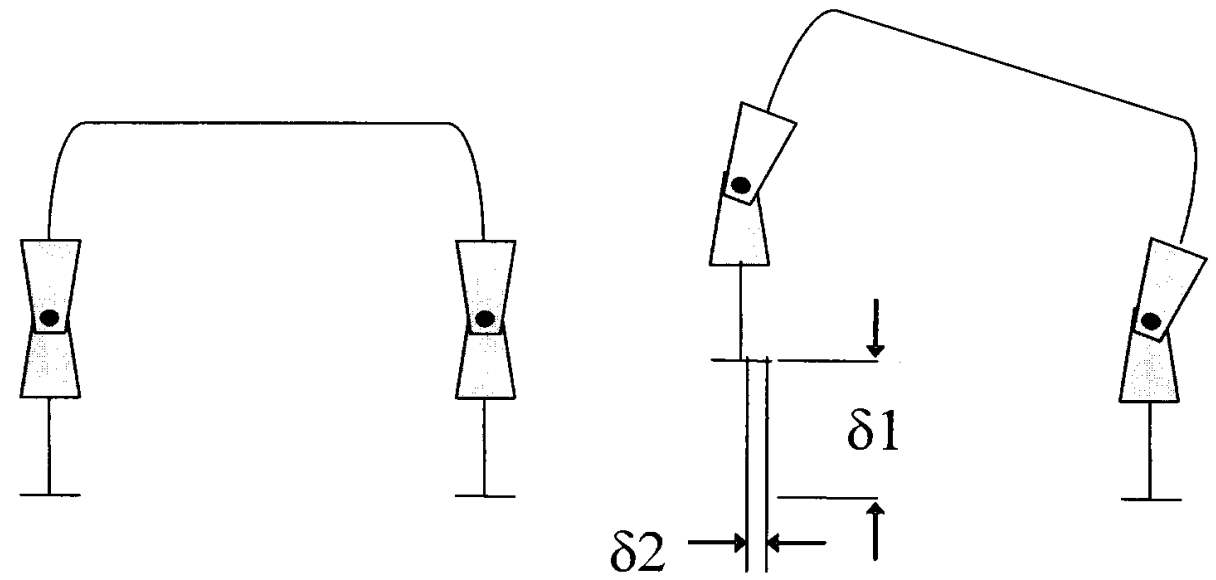

Figure 19. Deflection of a U-pipe assembly in response to displacement of a flange in response to thermal lengthening of a pipe between vessels. 


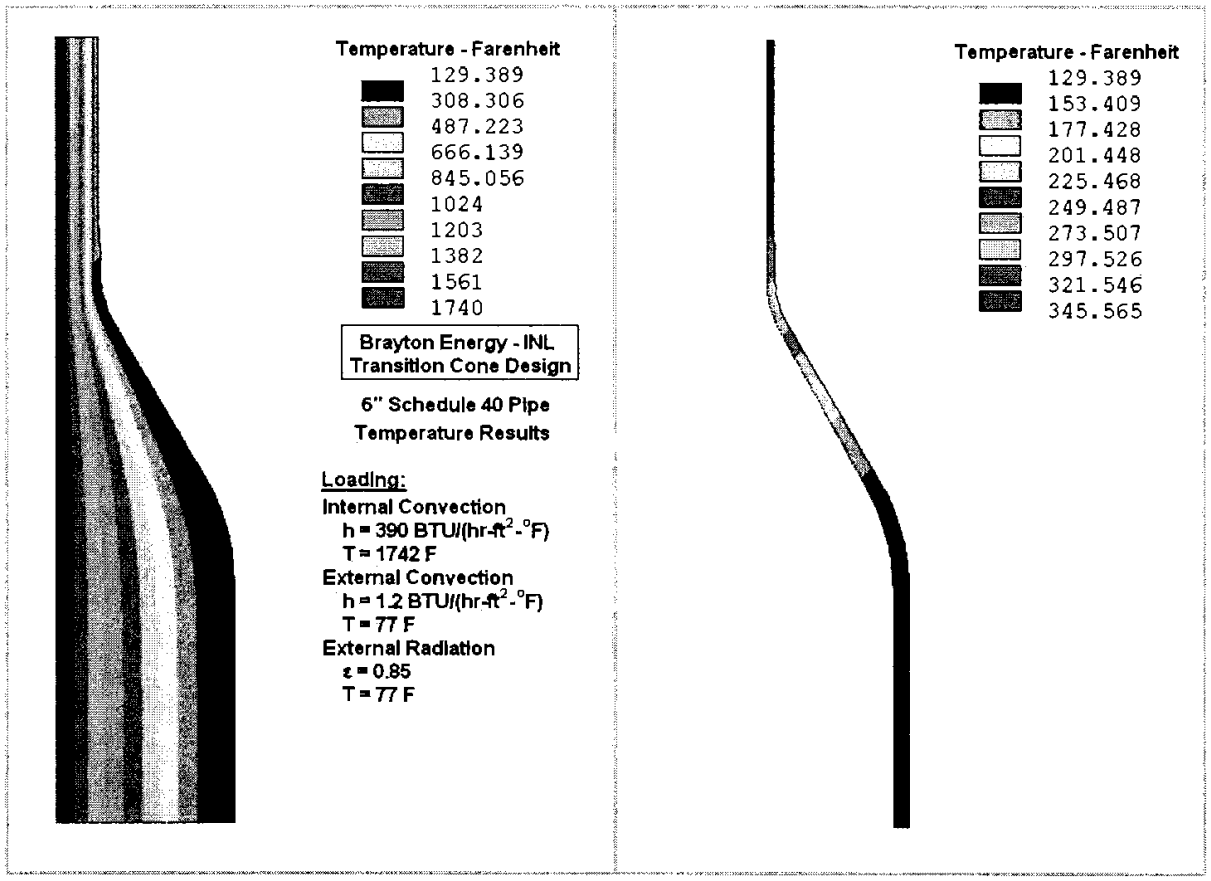

Figure 20. Finite Element Analysis (FEA) plot of a steady-state temperature distribution in a conical coaxial thermal transition with heat transfer boundary conditions provided.
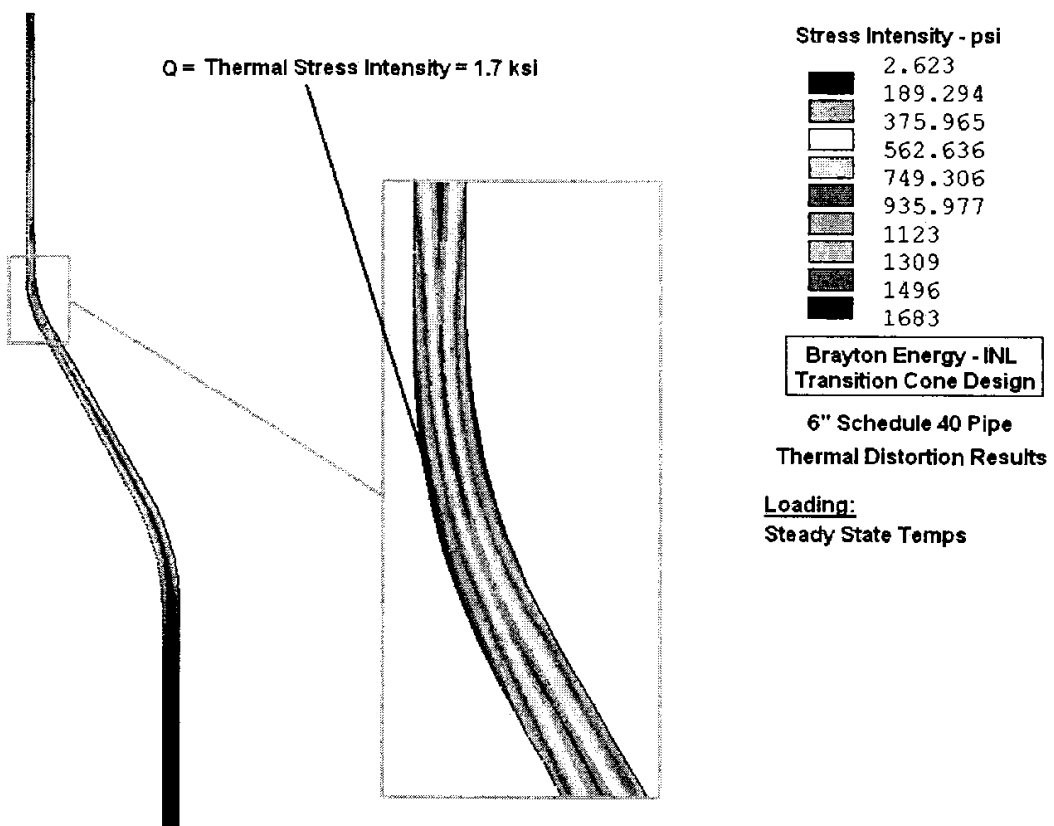

Figure 21. Plot of stresses in the peak-stress location for a worst-case, steady-state temperature distribution. 

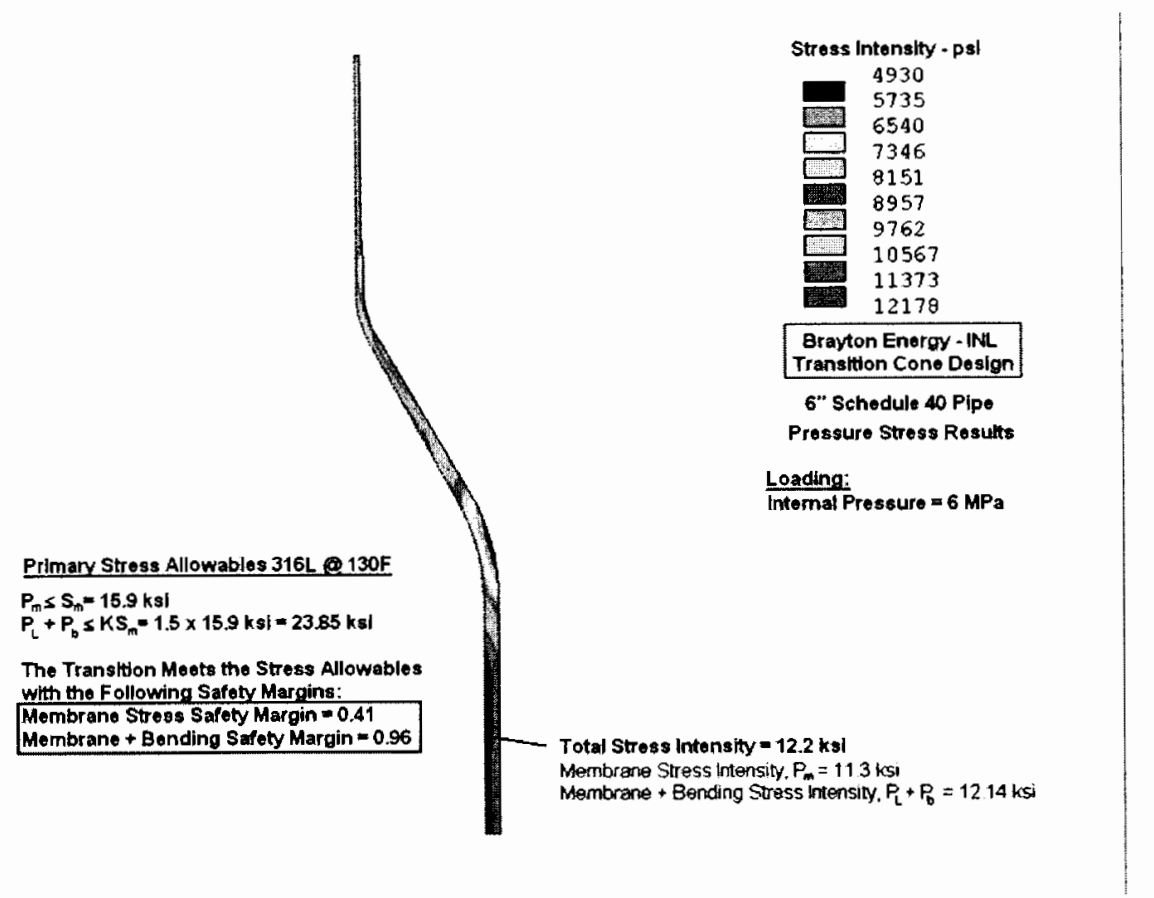

Figure 22. Plot of stress in thermal transition due to $6 \mathrm{MPa}$ internal hydrostatic pressure. At $8 \mathrm{MPa}$ pressure case, the membrane stress safety margin is reduced to 0.05 . The safety margin for the membraneplus-bending is 0.45 . To comply with ASME criteria, the margin must be greater than zero, and increases with pipe wall thickness.

Since insulation resides between the flow-liner and the pressure boundary, gas within is pressurized as well. To avoid pressure-stresses on the flow-liner during changes in the mean pressure, ventilation is required between insulation and the flow-liners. As of this writing, a specific configuration has not been established for ventilation but has been accomplished successfully in similar piping designs with periodic aft-facing louvers and fine-mesh screen covering the opening to prevent infiltration of insulation fibers into the flow-path. A similar scheme is envisioned for the piping system and will be assessed with respect to fluid pressure losses and stress on the liner.

The inner liner expands considerably with respect to the pressure boundary. Between the roomtemperature isothermal state and the hottest operating state, this differential expansion amounts to 12 millimeters per meter of pipe length. Because the heater-to-test vessel piping is over 11 meters in length, a total of 132 millimeters of liner extension must be absorbed. By dividing the liner into telescoping sections, this differential expansion can be accommodated by relative sliding. Though a detailed-design has not been established for the liner segments, this is a proven scheme that has been used in similar applications. To avoid galling of adjacent sections, a ceramic coating will be specified for contacting surfaces.

Several options exist for sealing of helium pipe flanges. However, due to the elevated temperature and pressure that will be experienced by the gaskets $\left(200^{\circ} \mathrm{C}, 8 \mathrm{MPa}\right)$ standard metal O-ring or spiral wound gasket arrangements could exceed leakage allowables. An energized O-ring seated in a grooved mating flange will provide the tightest seal with the least leakage. The specialized O-ring type that is recommended for He applications uses a jacketed helical spring to maintain contact with the flange mating faces. High-pressure helium leak rates better than $1.0 \times 10^{-8} \mathrm{cc} / \mathrm{s}$ (equivalent to $1 \mathrm{cc}$ every three years) have been achieved using these seals. 


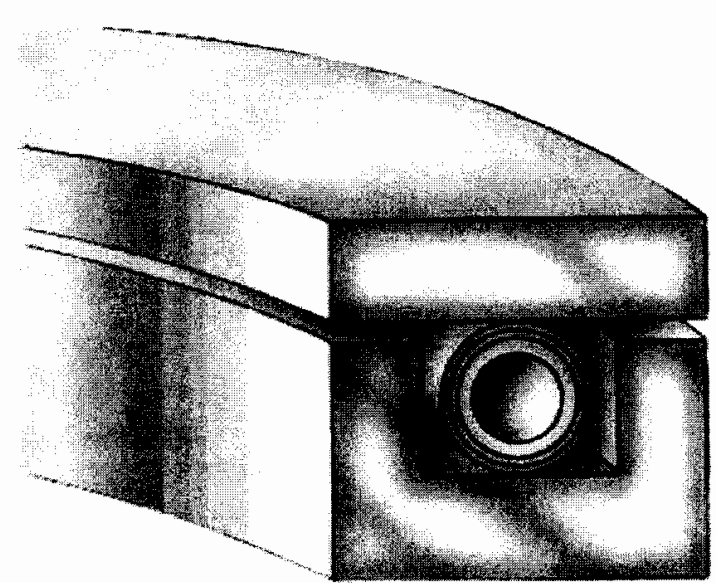

Free State

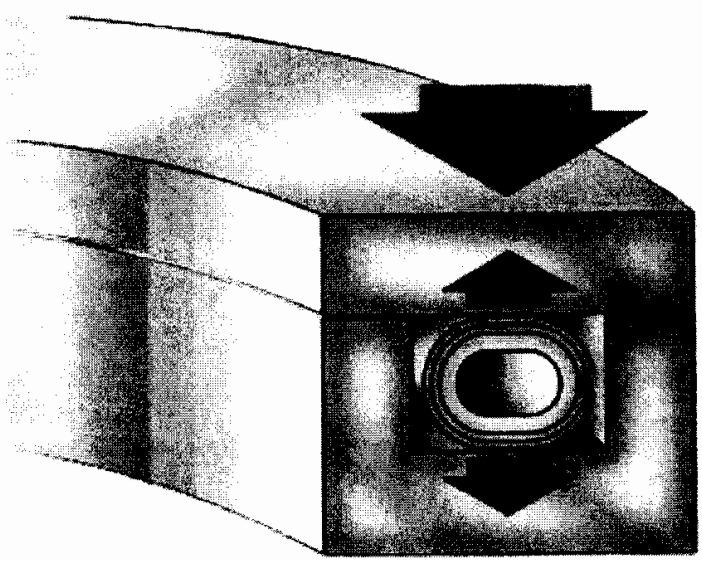

In Compression

Figure 23. Helicoflex ${ }^{\mathrm{TM}}$ energized seal provides low leakage rate in high-pressure helium sealing applications.

\subsubsection{Insulation}

This section describes trade studies aimed at developing a practical strategy for pipe insulation and summarizes preliminary design recommendations. Numerical findings will focus on the heater-discharge pipe, which presents a formidable design challenge because of its high temperature and overall length. The same design methodology will be applied to other hot piping runs in the system.

A range of competing objectives was considered in developing an insulation strategy, namely:

- $\quad$ Stress in the pressure vessel must fall within ASME allowables.

- $\quad$ Surface temperatures are to be minimized to the extent practical. Although a safe touch temperature is ideal, this turns out to be unworkable as shown below.

- Heat loss is generally to be minimized, although more from the standpoint of limiting HVAC demands than for energy efficiency. For the heater-discharge pipe, where a challenging discharge temperature $\left(950^{\circ} \mathrm{C}\right)$ must be achieved, a further incentive to control heat loss is to minimize temperature drop because of the need for a compensating increase in inlet temperature.

- External diameters are generally to be minimized in an effort to promote access and serviceability.

- $\quad$ Adoption of inexpensive low-temperature alloys is preferred.

Trade studies have been carried out within the framework of the goals above, based on the proposed multi-layer insulation concept shown in Figure 24. The purpose of each concentric layer is as follows: 
- Flow Liner (1 to 2). Thin sheet-metal shell that provides a smooth surface for gas flow and containment for the internal insulation. It cannot support a pressure differential and must be vented in order to allow for pressure equilibration during transients. In numerical trade studies, thickness was prescribed as a constant 1.6-millimeters, with thermal conductivity values for stainless steel.

- Internal Insulation (2 to 3). Minimum requirement is to reduce the temperature of the pressure pipe ( 3 to 4 ) to levels allowable at the prescribed wall stress. Added internal insulation may also be warranted for purposes of reducing surface temperature. Because the flow liner is gas permeable, internal insulation will be saturated with pressurized gas, carrying implications for its insulating properties as discussed below.

- $\quad$ Pressure pipe (3 to 4). Carries the pressure load. Can be fabricated from an inexpensive alloy, because of the role of internal insulation in reducing its temperature substantially below that of the gas. Thermal conductivity equal to stainless steel is applied in numerical studies.

- External insulation (4 to 5). Optional. Purpose is to reduce surface temperature, alternatively achievable with added internal insulation. In numerical studies, a high-temperature ceramic material (Gemcolite 2600) was assumed for purposes of specifying thermal conductivity, applying curves from the manufacturer based on temperature.
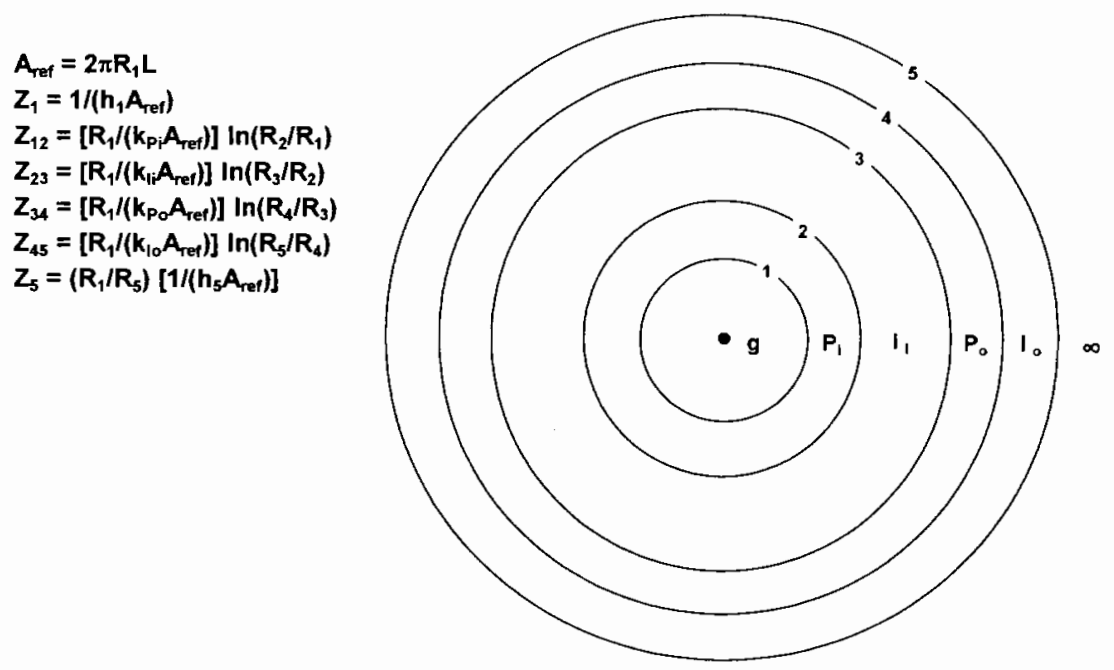

Figure 24. Layered insulation concept and nomenclature. The $\mathrm{Z}$ quantities define thermal resistance between radial locations.

Internal insulation will be permeated by the pressurized gas, as stated above. As a rough approximation in numerical studies for the heater-discharge pipe (carrying helium), internal insulation conductivity is assigned equal to that of helium, based on justification below.

Internal insulation material is of 'aerogel' class ${ }^{24}$ as manufactured by Microtherm (among other suppliers). These materials are characterized by extremely small pores, on the order of $30-\mathrm{nm}$, for Microtherm's product. In typical low-pressure applications where pore dimension is smaller than molecular mean free path, motion of gas molecules departs from the usual 'continuum' rules. Exceptionally low thermal conductivity is attained at a level far below that for the gas in the continuum limit. 
The insulating property of aerogels is diminished at high pressure because of the reduction in molecular mean free path, eventually reaching the continuum limit (mean free path is much smaller than pore size). An empirical expression governing the conductivity of air in aerogel pores is given $\mathrm{as}^{24}$,

$$
k_{g}=\frac{k_{g}^{o}}{I+\alpha k_{n}},
$$

where $k_{g}{ }^{0}$ is air conductivity in the continuum limit, $\alpha \approx 2$ for air, and the Knudsen number $k_{n}$ is the ratio of mean free path to pore size. This expression is evaluated in Figure 25, showing the rise in effective air conductivity with pressure, with the continuum limit nearly reached at a pressure of $10 \mathrm{MPa}$.

For gases other than air, a preliminary literature review yielded no results comparable to that above. On the justification that the underlying physics will be comparable for other gases, the highpressure continuum limit is applied by setting insulation conductivity equal to that of helium. Referring to Figure 25, at a pressure of $6 \mathrm{MPa}$ this is probably conservative with respect to gas conductivity alone, though the influence of radiation (neglected here) will be to elevate insulation conductivity above that of the gas in the pores.

A further assumption applied in numerical studies for the heater-discharge pipe, consistent with mechanical layouts developed in Section 4.1.4, is the presence of a surrounding enclosure carrying a longitudinal flow of cooling air at ambient temperature. Taking the velocity of the cooling flow as $3 \mathrm{~m} / \mathrm{s}$, the surface convection coefficient is estimated at $2.1 \mathrm{~W} /\left(\mathrm{m}^{2} \cdot \mathrm{K}\right)$. Additional surface heat transfer is applied in the form of radiation to surroundings at ambient temperature, with a surface emissivity of 0.85 prescribed.

Effective Gas Conductivity in Micropores

(for air)

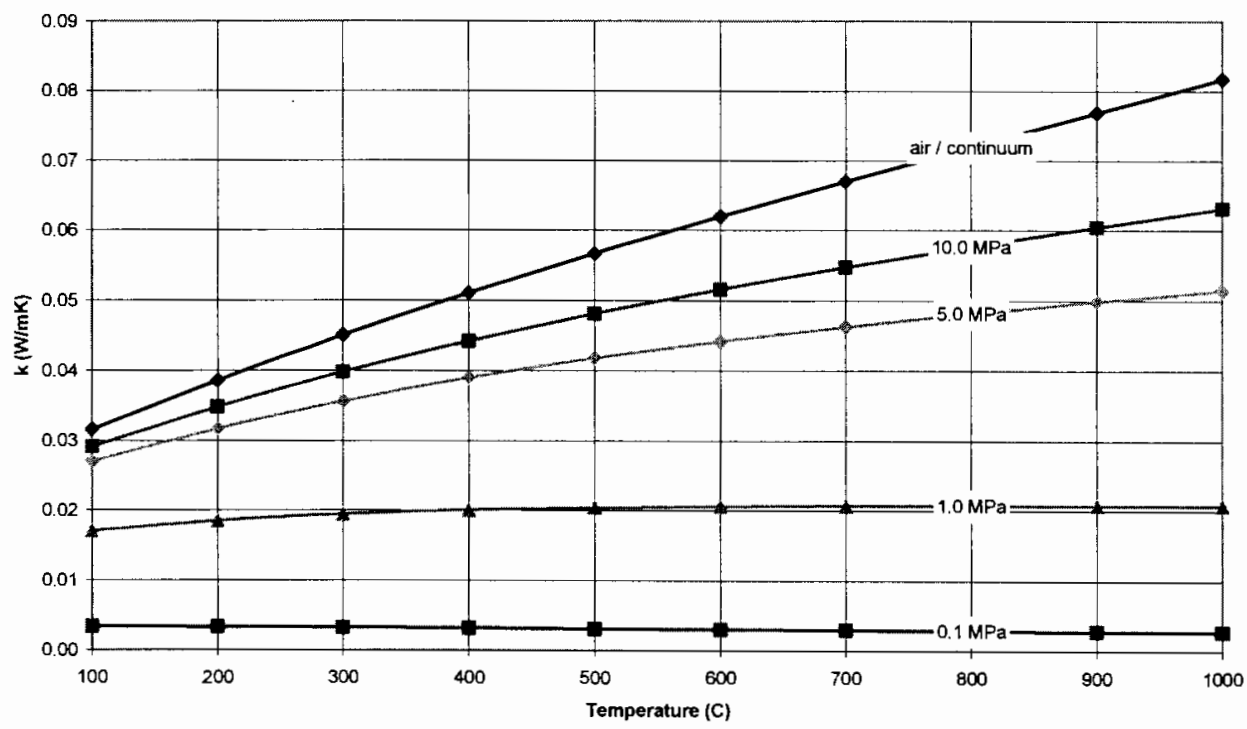

Figure 25. Effective gas conductivity in aerogel pores (for air). 
Numerical findings for the heater-discharge duct are summarized in Figure 26, for the case of pressure pipe stress and temperature fixed at allowable levels for a low-grade stainless alloy (86.2 $\mathrm{MPa} \&$ $538^{\circ} \mathrm{C}$ ). The following observations can be made:

- Reduction of surface temperature to a 'touchable' $49^{\circ} \mathrm{C}\left(120^{\circ} \mathrm{F}\right)$ makes for an unmanageable design. External diameter is roughly 610 -millimeters ( 24 inches) with the pressure pipe very large and costly.

- Allowing surface temperature to climb to $538^{\circ} \mathrm{C}\left(1000^{\circ} \mathrm{F}\right)$ makes for a much smaller envelope, with overall diameter below 100 millimeters ( 4 inches). In this limit the external insulation has disappeared, and the surface temperature is equal to the prescribed $538^{\circ} \mathrm{C}\left(1000^{\circ} \mathrm{F}\right)$ for the pressure pipe.

- In the $538^{\circ} \mathrm{C}\left(1000^{\circ} \mathrm{F}\right)$ 'bare-pipe' limit above, heat loss $(94 \mathrm{~kW})$ will impose a significant HVAC burden, and temperature drop $\left(23^{\circ} \mathrm{C}\right)$ will push inlet temperature to challenging levels.

With drawbacks as described above at the extremes of the envelope, a compromise solution is indicated. For example, an external diameter of 150 millimeters ( 6 inches) gives a surface temperature near $218^{\circ} \mathrm{C}\left(425^{\circ} \mathrm{F}\right)$, with pressure pipe diameter and wall thickness of 140 millimeters ( 5.5 inches) and 4.6 millimeters $\left(0.18\right.$ inch) respectively. At $23 \mathrm{~kW}$ and $5.6^{\circ} \mathrm{C}$, heat loss and $\Delta \mathrm{T}$ appear manageable.

Also under consideration as a design simplification is the 'bare-pipe' approach, but allowing a larger diameter than corresponds to the $538^{\circ} \mathrm{C}\left(1000^{\circ} \mathrm{F}\right)$ surface temperature above. An external diameter of 150 millimeters (6 inches) yields a surface temperature of $254^{\circ} \mathrm{C}\left(490^{\circ} \mathrm{F}\right)$ with pressure pipe wall thickness of 5 millimeters (0.2 inches). Heat loss and $\Delta \mathrm{T}$ increase to $31 \mathrm{~kW}$ and $7.4^{\circ} \mathrm{C}$.

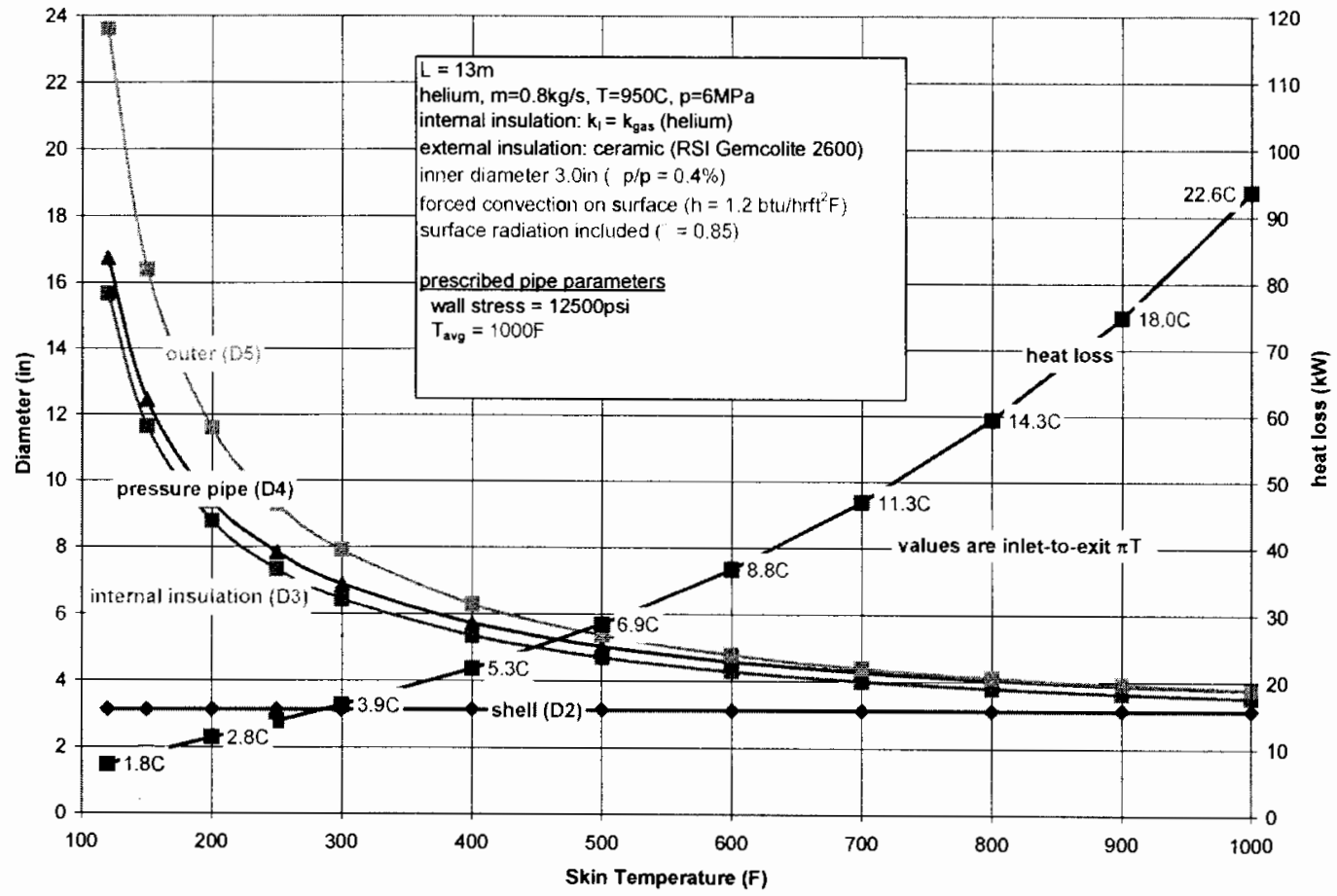

Figure 26. Sizing study for heater-discharge duct. 
Work remains before converging on an eventual design values for the heater-discharge pipe (and other hot pipe runs). For rough layout purposes, the findings of this study suggest external diameters in the vicinity of 150 millimeters ( 6 inches), this value having been adopted in the preliminary designs developed in Section 4.1.4.

\subsection{Principal Components and Sub-Systems}

\subsubsection{Primary Loop}

The primary loop is designed to deliver helium to the IHX test section at temperatures up to $950^{\circ}$ C. The performance analysis and circulator assumptions presented in section 4.1.1 are based on nominal conditions typical of indirect gas turbines ${ }^{3,21,22}$. Given the range of uncertainty in the IHX test requirements, a broader specification for the primary components is required. The nominal and most extreme cases are summarized in Table 4 and Table 5. Energy balances of the principal subassemblies do not account for the piping heat losses. The following sub-sections describe the preliminary analysis and sizing of the primary components.

4.2.1.1 Primary Electric Heater. The heat source for the HTGL has been designed for the conditions outlined in Table 6. These conditions meet the specifications set forth for a range of test programs supporting the NGNP initiatives. The following section discusses trade studies performed to select a practical configuration, as well as the mechanical design and cost of the final design.

Table 4. Nominal design conditions for primary loop subassemblies, based on a typical $400^{\circ} \mathrm{C}$ temperature drop across the IHX test article. The recuperator effectiveness is $83 \%$.

\begin{tabular}{|l|c|c|c|c|c|c|}
\hline & Heater & Recup, Hot Side & Recup, Cold Side & Cooler & Circulator & IHX \\
\hline $\mathrm{M}, \mathrm{kg} / \mathrm{s}$ & 0.8 & 0.8 & 0.8 & 0.8 & 0.8 & 0.8 \\
\hline Tin, C & 469 & 550 & 65 & 146 & 35 & 950 \\
\hline Tout, C & 950 & 146 & 469 & 35 & 65 & 550 \\
\hline Q, kW & 2,000 & $-1,681$ & 1,681 & -462 & 125 & $-1,664$ \\
\hline
\end{tabular}

Table 5. Primary loop temperatures for maximum IHX exit temperature conditions, limited by the recuperator inlet temperature. This is expected to be the most severe operating conditions for the components. The recuperator effectiveness is about $82 \%$.

\begin{tabular}{|l|c|c|c|c|c|c|}
\hline & Heater & Recup, Hot Side & Recup, Cold Side & Cooler & Circulator & IHX \\
\hline $\mathrm{M}, \mathrm{kg} / \mathrm{s}$ & 0.950 & 0.950 & 0.950 & 0.950 & 0.950 & 0.950 \\
\hline Tin, C & 545 & 650 & 65 & 170 & 35 & 950 \\
\hline Tout, C & 950 & 170 & 545 & 35 & 65 & 650 \\
\hline Q, kW & 2,000 & $-2,521$ & 2,521 & -709 & 158 & $-1,576$ \\
\hline
\end{tabular}


Table 6. General heater design specifications.

\begin{tabular}{|l|c|}
\hline \multicolumn{1}{|c|}{ Specification } & Design value \\
\hline Max outlet temperature, ${ }^{\circ} \mathrm{C}$ & 950 \\
\hline Nominal inlet temperature, ${ }^{\circ} \mathrm{C}$ & 545 \\
\hline Power, $\mathrm{kW}$ & 2000 \\
\hline Gas & Helium \\
\hline Maximum pressure, $\mathrm{MPa}$ & 8.0 \\
\hline Pressure drop, $\Delta \mathrm{P} / \mathrm{P}$ & 0.01 \\
\hline Number of cycles per year & 200 \\
\hline Life, heating elements, hrs & $>10,000$ \\
\hline
\end{tabular}

4.2.1.1.1 Heating Source Design - The evaluation of heating systems initially considered both combustion and electrical sources. Though the combustion source was used effectively with some of the earlier German simulators, ${ }^{25}$ operational complexity, as well as corrosion and oxidation, detract from its feasibility. Due to the limited operating temperature of the indirect combustion gas/helium heat exchanger, the German approach was to operate an electrical resistance-heating element as a topping stage to achieve a $950^{\circ} \mathrm{C}$ delivery temperature. Though the combustion operating costs may be favorable, the capital cost of the system is estimated to be substantially higher than that of the all-electrical system.

An induction heating system was also considered for the application. This apparatus would employ an inductive coil to heat a receptor. The receptor must incorporate the heat exchange features to transfer the energy to the helium by convection. A feasible arrangement could be engineered for this application; however, there are several drawbacks which precluded further effort on this study. Some of the initial concerns are summarized below:

- The induction coil requires water cooling during operation. With the water loop inside the pressure boundary, the system may have serious single-point failure scenarios dependent on the operation of the water coolant loop and support systems.

- Coolant leakage could seriously compromise ongoing tests by causing rapid corrosion.

- Electro-magnetic interference from the induction coil may compromise thermocouple and other instrumentation accuracy.

- The receptor heat exchanger appears more complex than those envisioned for electrical resistance heaters.

In terms of controllability, safety, and capital cost, an electrical resistance heating system demonstrates many advantages over combustion and inductive heat sources. As controlled thermal ramping and rapid shutdown are critical requirements of the high-temperature test loop, the electric resistance-heating element is well suited for this duty. Several electrical heating system candidates have been evaluated. Various heating elements may be used to achieve the required temperature range, with the durability as a key discriminator. 
Table 7 outlines several candidate heating element candidates surveyed for the HTGL. The design of the helium heat exchanger requires an ample temperature differential between the heating element and the gas. The three typical industrial choices are shown in Table 7. The refractory alloys (tantalum, tungsten, and molybdenum) permit operating temperatures well above those of the gas temperature specification, thus enabling good design flexibility with the helium heat exchange. These heating elements are commonly used in vacuum heat treating or brazing furnaces. The principal limitation of tantalum, tungsten, or molybdenum heating elements is their intolerance to contaminants. Nickel-chrome resistance heating elements are a common choice for lower temperature, lower cost industrial heating systems. More durable, higher temperature heating elements are made from oxide dispersed strengthened alloys (iron-chrome-aluminum). These materials have excellent scale resistance and creep strength at high temperature. One such product is the Kanthal APM heating element. General design features of the Kanthal heating elements are provided in Table 8.

Table 7. A survey of helium heating sources has evaluated combustion, induction, and electrical resistance options.

\begin{tabular}{|c|c|c|c|c|c|c|}
\hline Source & Combustion & $\begin{array}{c}\text { Induction } \\
\text { heater }\end{array}$ & $\begin{array}{l}\text { Tantalum, } \\
\text { tungsten, or } \\
\text { molybdenum } \\
\text { resistance } \\
\text { elements }\end{array}$ & $\begin{array}{l}\text { Ni-chrome } \\
\text { resistance } \\
\text { elements }\end{array}$ & $\begin{array}{c}\text { Oxide } \\
\text { dispersed } \\
\text { strengthened } \\
\text { (ODS) } \\
\text { resistance } \\
\text { elements }\end{array}$ & Notes \\
\hline $\begin{array}{l}\text { Temperature } \\
\text { limits }\end{array}$ & $<950^{\circ} \mathrm{C}$ & $<1350^{\circ} \mathrm{C}$ & $>1500^{\circ} \mathrm{C}$ & $<1100^{\circ} \mathrm{C}$ & $<1350^{\circ} \mathrm{C}$ & $\begin{array}{l}\text { System } \\
\text { durability and } \\
\text { compactness } \\
\text { improve with } \\
\text { higher rating } \\
\text { temp }\end{array}$ \\
\hline $\begin{array}{l}\text { Tolerance to } \\
\text { contaminants }\end{array}$ & & $\begin{array}{l}\text { Use resistant } \\
\text { alloy for } \\
\text { receptor }\end{array}$ & $\begin{array}{l}\text { Very low } \\
\text { tolerance to } \mathrm{O}_{2} \text {, } \\
\mathrm{H}_{2} \mathrm{O}, \mathrm{N}_{2}\end{array}$ & $\begin{array}{l}\text { Will tolerate } \\
\text { trace } \mathrm{O}_{2}, \mathrm{H}_{2} \mathrm{O}, \\
\mathrm{N}_{2}\end{array}$ & $\begin{array}{l}\text { Excellent } \\
\text { resistance to } \\
\mathrm{O}_{2}, \mathrm{H}_{2} \mathrm{O}, \mathrm{N}_{2}\end{array}$ & $\begin{array}{l}\text { Trace } \\
\text { contaminants are } \\
\text { inevitable }\end{array}$ \\
\hline Capital Cost & Highest & competitive & $\begin{array}{l}\text { Highest among } \\
\text { resistors }\end{array}$ & $\begin{array}{l}\text { Lowest } \\
\text { among } \\
\text { resistors }\end{array}$ & $\begin{array}{l}\text { Slightly more } \\
\text { than NiCr, but } \\
\text { half that of } \\
\text { Moly }\end{array}$ & $\begin{array}{l}\text { ODS heating } \\
\text { elements } \\
\text { budgetary cost of } \\
\$ 120,000 / 2 \mathrm{MW}\end{array}$ \\
\hline $\begin{array}{l}\text { Overall } \\
\text { durability }\end{array}$ & $\begin{array}{l}\text { Complexities } \\
\text { associated } \\
\text { with high } \\
\text { temp heat } \\
\text { exchanger, } \\
\text { combustion } \\
\text { control } \\
\end{array}$ & Excellent & $\begin{array}{l}\text { Limited due to } \\
\text { likely } \\
\text { contamination }\end{array}$ & $\begin{array}{l}\text { Nominally } \\
8000-12,000 \\
\text { hour MTBO }\end{array}$ & $\begin{array}{l}\text { Nominally } \\
20,000- \\
40,000 \mathrm{hr} \\
\text { MTBO }\end{array}$ & \\
\hline Other & $\begin{array}{l}\text { Used in the } \\
\text { German } \\
\text { project up to } \\
700^{\circ} \mathrm{C} \text { with } \\
\text { topping } \\
\text { electric to } \\
\text { achieve } \\
900^{\circ} \mathrm{C} \text {. }\end{array}$ & $\begin{array}{l}\text { Several } \\
\text { single point } \\
\text { failure } \\
\text { concerns in } \\
\text { coolant loops } \\
\text { and support } \\
\text { system }\end{array}$ & $\begin{array}{l}\text { Best for high } \\
\text { temp vacuum } \\
\text { braze and heat- } \\
\text { treating. Not } \\
\text { practical choice } \\
\text { for large test } \\
\text { loop due to } \\
\text { likely } \\
\text { corrosion. }\end{array}$ & $\begin{array}{l}\text { Lower temp } \\
\text { threshold } \\
\text { requires more } \\
\text { careful } \\
\text { management } \\
\text { of He coolant. }\end{array}$ & $\begin{array}{l}\text { Acceptable } \\
\text { temp range and } \\
\text { excellent } \\
\text { corrosion } \\
\text { resistance, } \\
\text { make this the } \\
\text { most } \\
\text { economical } \\
\text { choice }\end{array}$ & \\
\hline
\end{tabular}


Table 8. Of the many heating element options, those characteristics listed represent the range recommended for the HTGL heater.

\begin{tabular}{|l|c|}
\hline \multicolumn{1}{|c|}{ Design parameter } & $\begin{array}{c}\text { Kathal APM Heating-Element } \\
\text { Specification }\end{array}$ \\
\hline Life, hours & 16,000 to 24,000 \\
\hline Element surface temperature, $\mathrm{C}$ & $<1200$ \\
\hline Element type & Straight wire \\
\hline Wire diameter & $4.5 \mathrm{~mm}$ \\
\hline Number of wires per heating elements & $12(6 \mathrm{pairs})$ \\
\hline Heating element diameter, mm & 68 and 80 \\
\hline Available heating element length., meter & 1 to 9 \\
\hline Power per element, $\mathrm{kW}$ & 5 to 80 \\
\hline Voltage per element, VAC & 240 to 1440 as required \\
\hline Wire resistance change from room temp to operating temp & Nominally $5 \%$ \\
\hline Budgetary cost, $\$ \mathrm{~kW}$ & 69 \\
\hline
\end{tabular}

A photograph of the standard Kanthal heating element is shown in Figure 27. This element forms the basis of the proposed 2-MW HTGL heater. The thermal design and integration of these elements into the 2-MW subassembly is discussed in the following sections.

4.2.1.1.2 Thermal Analysis - Based on durability, adequate service temperature, and economics, the Kanthal heating elements were selected for the preliminary design of the heating system. The manufacturer offers the heating elements in many dimensional configurations and provides engineering customization support such as will be required in the HTGL. The critical design challenge of the helium heater is to configure the geometry to achieve uniform and high convection around the radiation source. The coupled requirement to achieve a compact arrangement requires that the tubular heating elements are bundled into the smallest possible diameter. To manage the extremely high temperatures $\left(950^{\circ} \mathrm{C}\right)$, the surrounding pressure vessel is heavily insulated on the interior.

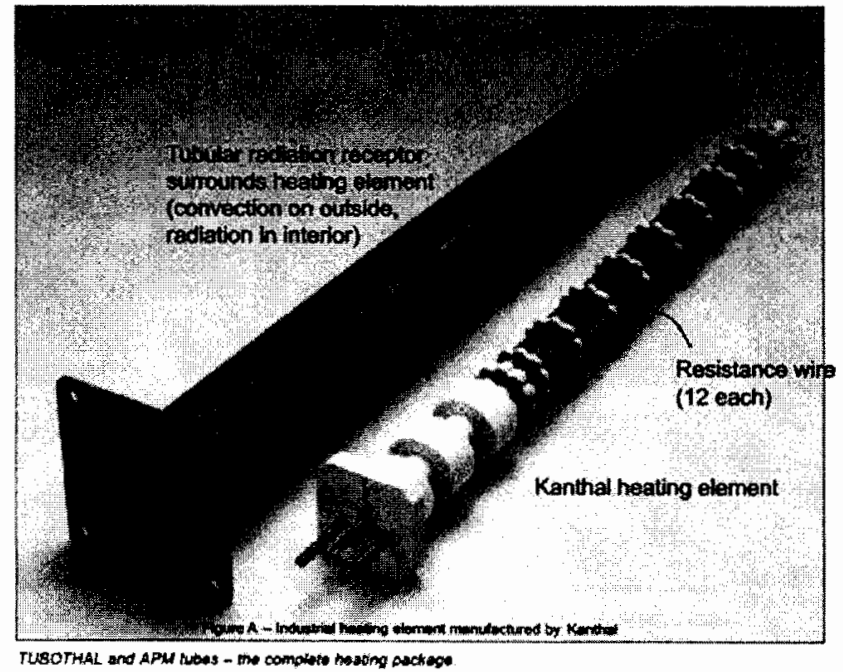

Figure 27. Kanthal Heating elements are in the 2 MW HTGL design. The heating element is formed from 4.5-millimeter-diameter resistance wire. 
A standard heating element has been configured for the proposed HTGL. The element surface flux and temperature limitations represent important design criteria for the heating system. As the flux and radiant temperature increase, the radial temperature drop through the resistance wire is limited by the melting point $\left(1450^{\circ} \mathrm{C}\right)$ of the alloy. Table 9 contains the general design specifications defined to achieve reliable performance from the selected heating element.

Table 9. Thermal performance design and analysis of the resistance heating system.

\begin{tabular}{|c|c|c|}
\hline $\begin{array}{l}\text { Heating Rod Geometry and } \\
\text { Specifications } \\
\end{array}$ & $\begin{array}{l}\text { Baseline } \\
\text { Design }\end{array}$ & Notes \\
\hline Total $\mathrm{Q}, \mathrm{kW}$ & 2,000 & Specification \\
\hline Tube inside diameter, $\mathrm{mm}$ & 83 & Selected receptor diameter, with clearance \\
\hline Heating element $\mathrm{OD}, \mathrm{mm}$ & 80 & Standard Kanthal Heating element \\
\hline Tube length, mm & 3,412 & Recommended by Kanthal, 480 VAC, 4.5 -mm elements \\
\hline Area/tube $\mathrm{cm}^{2}$ & 8,575 & \\
\hline Power/tube kW & 28.3 & \\
\hline Tube flux, $\mathrm{W} / \mathrm{cm}^{2}$ & 3.18 & Conservative selection, recommended by Kanthal \\
\hline No. Tubes & 70.7 & Analysis result \\
\hline \multicolumn{3}{|l|}{ Flow and Geometry } \\
\hline Total mass flow, $\mathrm{kg} / \mathrm{s}$ & 0.8000 & Specification \\
\hline Mass flow $/ \mathrm{rod} \mathrm{kg} / \mathrm{s}$ & 0.0113 & Specification \\
\hline FPI, (fins per in.) & 16.0 & Selection \\
\hline Fin thickness, $\mathrm{mm}$ & 0.15 & Selection \\
\hline Finned annulus area, $\mathrm{mm}^{2}$ & 515.2 & \\
\hline Number of fins, & 158.3 & \\
\hline Fin blockage, $\mathrm{mm}^{2}$ & 85.19 & \\
\hline Gap or fin height, mm & 2.00 & Selection \\
\hline Ax flow area, $\mathrm{mm}^{2}$ & 215.0 & \\
\hline Fin spacing, $\mathrm{mm}$ & 1.6 & Equivalent to 16 fins per in. \\
\hline $\mathrm{V}, \mathrm{m} / \mathrm{s}$ & 13.44 & Analysis result \\
\hline \multicolumn{3}{|l|}{ Heat transfer } \\
\hline Gas in Temp, $\mathrm{K}$ & 742.0 & Specification \\
\hline Gas out Temp, K & $1,223.0$ & Specification \\
\hline $\mathrm{Re}$ & 2141 & Reynolds number \\
\hline $\operatorname{Pr}$ & 0.665 & Prandtl number \\
\hline $\begin{array}{l}\text { Channel aspect ratio } \\
\text { (laminar) }\end{array}$ & 0.81 & \\
\hline $\begin{array}{l}\text { NU, laminar, rectangular } \\
\text { channel }\end{array}$ & 2.92 & Nusselt number, laminar, rectangular passage \\
\hline $\mathrm{D}_{\mathrm{h}}=4 \mathrm{~A} / \mathrm{P}, \mathrm{mm}$ & 1.79 & Hydraulic diameter \\
\hline $\mathrm{h}, \mathrm{W} /\left(\mathrm{m}^{2} \cdot \mathrm{K}\right)$ & 562.1 & Convective heat transfer coef. \\
\hline $\begin{array}{l}\text { Surface area in gap (fin } \\
\text { area), } \mathrm{m}^{2}\end{array}$ & 1.938 & \\
\hline
\end{tabular}


Table 9. (continued).

\begin{tabular}{|c|c|c|}
\hline $\begin{array}{l}\text { Heating Rod Geometry and } \\
\text { Specifications } \\
\end{array}$ & $\begin{array}{l}\text { Baseline } \\
\text { Design }\end{array}$ & Notes \\
\hline $\begin{array}{l}\text { LMTD, Log mean temp } \\
\text { differential }\end{array}$ & 25.90 & \\
\hline $\mathrm{D}_{\mathrm{Ta}}$, inlet end, $\mathrm{K}$ & 31.5 & Inlet end \\
\hline $\mathrm{D}_{\mathrm{Tb}}$, exit end, $\mathrm{K}$ & 21.0 & Exit end \\
\hline $\begin{array}{l}\text { Exit end tube receptor temp, } \\
\mathrm{K}\end{array}$ & $1,251.0$ & Worst case, hot end \\
\hline Exit end element temp, $\mathrm{K}$ & $1,331.9$ & Worst case, hot end \\
\hline $\begin{array}{l}\text { T_element, Max allowable, } \\
\text { K }\end{array}$ & $1,473.0$ & Recommended allowable \\
\hline $\mathrm{Q}=\mathrm{hA} \Delta \mathrm{T}$, convection, $\mathrm{W}$ & 28,210 & Energy balance confirmation \\
\hline $\mathrm{Q}=\mathrm{mdot} \cdot \mathrm{cp} \cdot \Delta \mathrm{T}=\mathrm{h} \cdot \mathrm{A} \cdot \Delta \mathrm{T}, \mathrm{W}$ & 28,314 & Energy balance confirmation \\
\hline Flux convection, $\mathrm{W} / \mathrm{cm}^{2}$ & 3.17 & Iteration parameter \\
\hline \multicolumn{3}{|l|}{ Radiation } \\
\hline Emissivity & 0.8 & Selection \\
\hline Fin tube ID temp, exit end, $K$ & 1,251 & Tube has fin brazed to OD, high rad on ID \\
\hline Outer wall $\Delta \mathrm{T}, \mathrm{K}$-deg below & 80.9 & Temp drop between resistor wire and receptor \\
\hline $\begin{array}{l}\mathrm{Q}_{\mathrm{rad}}, \mathrm{W} / \mathrm{cm}^{2} \text { (at outer wall } \\
\text { temp) }\end{array}$ & 3.16 & For energy conservation \\
\hline $\mathrm{Q}_{\mathrm{rad}}$ to outer wall, W & 30,657 & For energy conservation. w/ losses \\
\hline \multicolumn{3}{|l|}{ Pressure drop } \\
\hline$\rho$, mean, $\mathrm{kg} / \mathrm{m} 3$ & 2.9379 & Gas properties \\
\hline $\mathrm{P}_{\text {Dynamic }},\left(\rho \mathrm{V}^{2} / 2\right), \mathrm{MPa}$ & 0.000265 & \\
\hline f, fanning, turbulent & 0.011614 & \\
\hline f, fanning, laminar & 0.026866 & \\
\hline Pressure drop, $\mathrm{MPa}$ & 0.054220 & \\
\hline $\mathrm{DP} / \mathrm{P}$ (laminar) & $0.904 \%$ & Analysis result (vs $1.5 \%$ spec) \\
\hline
\end{tabular}

The selected geometry employs an extended surface fin wrap around each heating element tube. The 2-millimeter $(0.08$ inch) fin is formed around the element and enclosed by an outer tube. Figure 28 shows a similar arrangement. The folded fin is brazed to the inner tube forming an annular-fin flow passage between the tubes. The fin geometry both extends the convective area and creates a small hydraulic diameter, favorable to convective heat transfer. The objective of the design process is to accomplish the following:

1. Derive the heating element temperature that matches the convective and thermal radiation fluxes along the axial length of the tube. The heating element and receptor temperatures must be below the alloy rating.

2. Minimization of the heating element and receptor temperatures, to extend life and provide safety margin on achieving the specifications. 
3. Define a passage geometry that meets criteria $1 \& 2$ without exceeding the component pressure drop.

The preceding analysis was performed at the nominal pressure of $6 \mathrm{MPa}$. Since the design summarized in Table 9 achieves the desired result with helium in the laminar regime, the heat exchange parameters are only weakly a function of pressure. At elevated pressure, the thermal performance will not change, while the pressure drop decreases. At a lower mean pressure of $4 \mathrm{MPa}$, the performance remains constant, while the pressure drop rises to an acceptable level of $2 \%$.

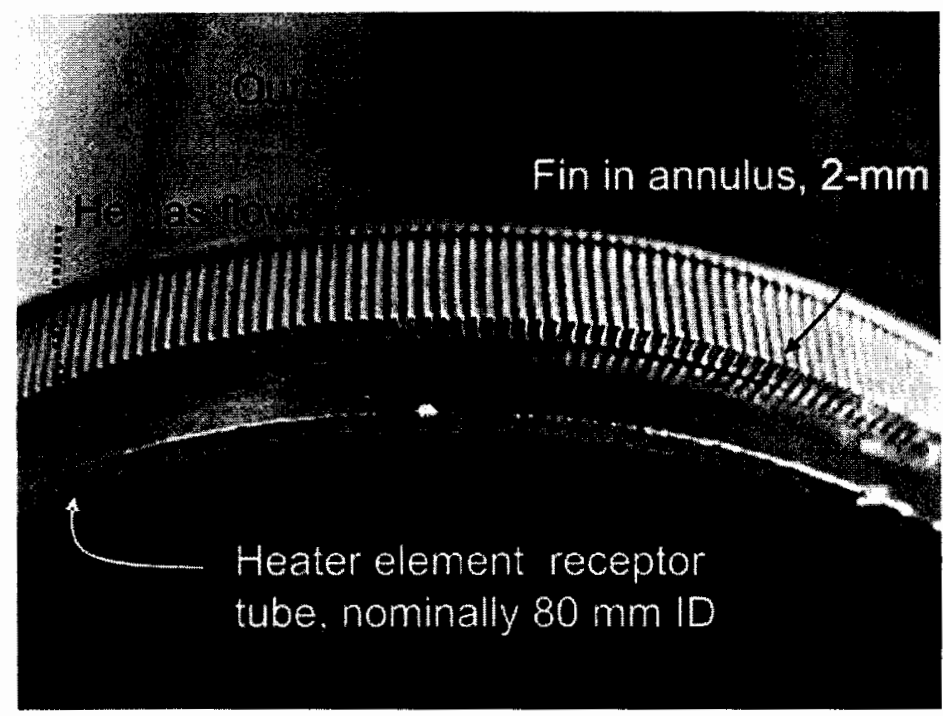

Figure 28. An extended fin surface is used to efficiently transfer the heat to the helium. The proposed 2millimeter fin meets thermal performance while incurring tolerable overall pressure loss.

4.2.1.1.3 Mechanical and Insulation Design - A summary of the recommended heater geometry is provided in Table 10. The 71 heating tubes are bundled into a close pack hexagonal array.

Table 10. Summary of heater system integration design and analysis.

\begin{tabular}{|l|c|l|}
\hline \multicolumn{1}{|c|}{$\begin{array}{c}\text { Heater Geometry and } \\
\text { Specifications }\end{array}$} & $\begin{array}{c}\text { Baseline } \\
\text { Design }\end{array}$ & Notes \\
\hline $\begin{array}{l}\text { Number of tubular heating } \\
\text { elements }\end{array}$ & 71 & For $2000 \mathrm{~kW}$ requirement (as defined in previous table) \\
\hline $\begin{array}{l}\text { Tube length, mm } \\
\text { Half space between } \\
\text { tubes+wall thickness, mm }\end{array}$ & 1.0 & Geometry selection \\
\hline Dia. Of bundle, mm & 750 & \\
\hline $\begin{array}{l}\text { Containment vessel wall } \\
\text { thickness }\end{array}$ & & \\
\hline $\begin{array}{l}\text { ASME Allowable wall stress, } \\
\text { MPa }\end{array}$ & 124.1 & Selected \\
\hline Nominal vessel wall thickness, & 78.6 & Analysis result \\
\hline
\end{tabular}


Table 10. (continued).

\begin{tabular}{|l|c|l|}
\hline \multicolumn{1}{|c|}{$\begin{array}{c}\text { Heater Geometry and } \\
\text { Specifications }\end{array}$} & $\begin{array}{c}\text { Baseline } \\
\text { Design }\end{array}$ & \\
\hline $\mathrm{mm}$ & & \\
\hline Insulate containment vessel & & Notes \\
\hline $\mathrm{k}$, insulation, $\mathrm{W} /(\mathrm{cm} \cdot \mathrm{K})$ & $0.00345 \mathrm{l}$ & Based on mean temp of helium \\
\hline $\mathrm{h}$, outside, $\mathrm{W} /\left(\mathrm{cm}^{2} \cdot \mathrm{K}\right)$ & 0.000584 & Natural convection, exterior \\
\hline $\mathrm{h}$ inside, $\mathrm{W} /\left(\mathrm{cm}^{2} \cdot \mathrm{K}\right)$ & $0.00562 \mathrm{l}$ & Natural convection, interior \\
\hline $\mathrm{R} 2, \mathrm{~mm}$ & 975 & Vessel outer radius \\
\hline Thickness, $\mathrm{mm}$ & 600 & selected to achieve permissible touch temp \\
\hline $\mathrm{R} 1, \mathrm{~mm}$ & 375 & \\
\hline $\mathrm{U} 1, \mathrm{~W} /\left(\mathrm{cm}^{2} \cdot \mathrm{K}\right.$ & $8.91052 \mathrm{E}-$ & \\
\hline $\mathrm{Q}, \mathrm{W}=\mathrm{UA} \Delta \mathrm{T}$ & 05 & \\
\hline Touch temp $($ wall Temp $){ }^{\circ} \mathrm{F}$ & 168.2 & May want to reassess insulation thickness \\
\hline
\end{tabular}

The mechanical integration of the 71 Kanthal heating elements into a functional system has involved the following tasks:

- Sealing the heating rods to force helium flow through the intended passages

- Management of differential thermal expansion between heating elements, the support structure, sealing system, and electrical termination

- Isolating the pressure vessel from the extreme interior temperatures

- $\quad$ Porting the piping inlets and exits through the cool pressure boundary

- Thermal isolation of the electrical service for series and parallel heating element arrangements

- $\quad$ Providing a means of delivering the current through the pressure boundary.

The design analyzed in the previous section incorporates standard industrial heating elements, shown in Figure 27. The overall dimensions of the integrated package are shown in Figure 29. Though the subject of a permissible surface touch temperature remains open, the envelope shown allows for ample insulation of 600 millimeters to insure a low surface temperature. Roughly 500 millimeters of radial insulation might be removed from the interior, reducing the vessel diameter accordingly. Under such conditions, the surface temperature would increase to about $200^{\circ} \mathrm{C}\left(400^{\circ} \mathrm{F}\right)$, still a safe margin for the coded pressure vessel. Heat loss increases to approximately $1 \%$ with 100 millimeters insulation selection.

The preliminary design of the $2 \mathrm{MW}$ heater is shown in the following series of Figures 30 through Figure 36. The heating elements are suspended from the top support plate. The lower plate serves as the manifold for the flow guide tubes, welded to the tube-sheet. The plenum formed between the two plates is filled with the inlet helium at temperatures ranging from 450 to $550^{\circ} \mathrm{C}$. The enclosed element, with surrounded fin, passes through the lower manifold plate and flow tubes, forming the enhanced flow passages. The flow tube guide and the fin-wrapped heating element are separate surfaces intended to 
accommodate differential movement during transients. Figure 31 shows the electrical termination concept where the electrical terminals of the heating elements are tied to a common bus-plate. This plate rests on insulation at the top of the vessel. Though the details have not been finalized, the design will strive for serviceability, permitting individual heater elements to be removed from a top access port. The electrical service will incorporate standard industrial feed-throughs. To manage the significant amperage (nominally 4200 ) at $480 \mathrm{VAC}$, multiple feed-through ports may be employed. Typical vacuum and retort furnaces draw 3000 to 4000-ampere through water-cooled furnace ports. Advanced Vacuum Systems Inc., a furnace manufacturer, has offered to adapt a version of their power management system to the project.

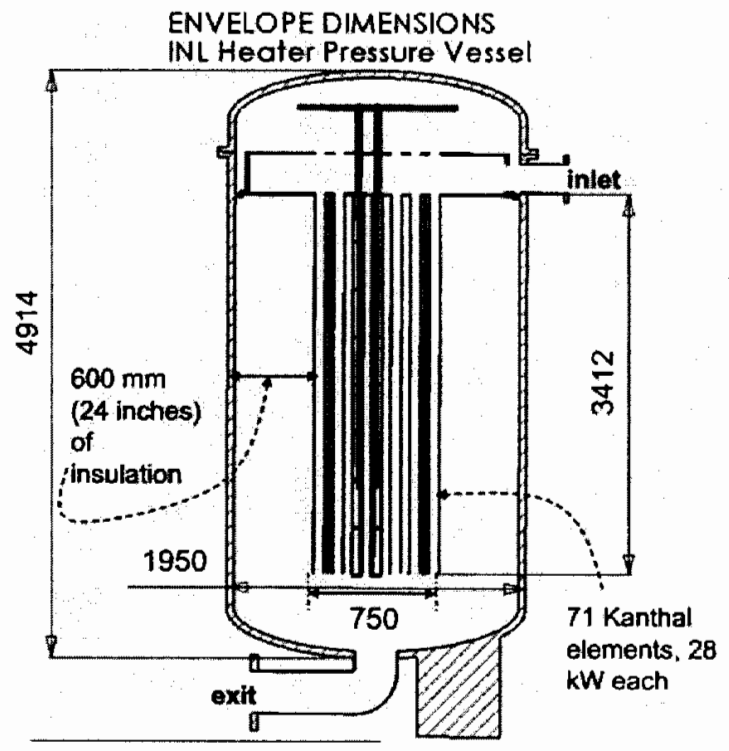

Figure 29. Dimensioned envelope of $2 \mathrm{MW}$ primary gas heater, including ample insulation allowance. 


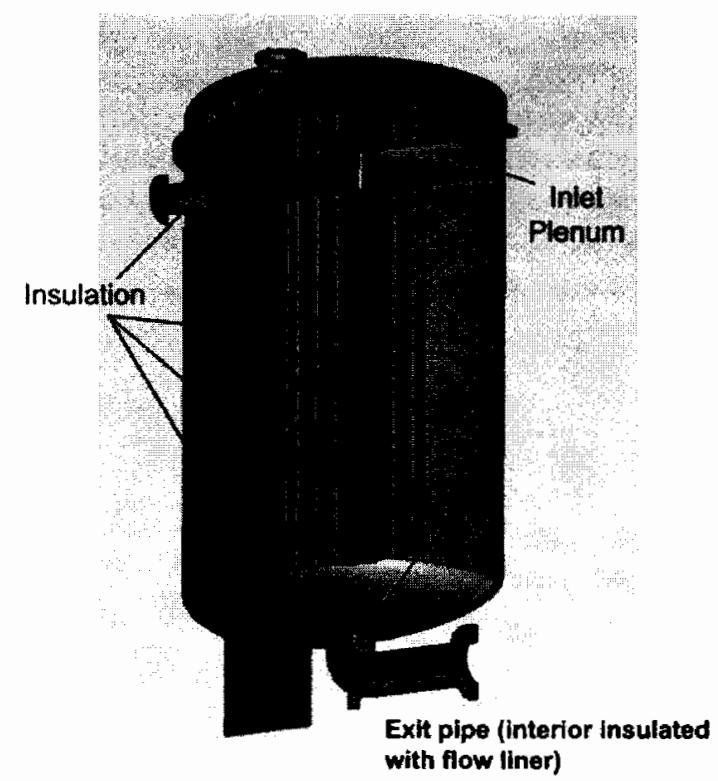

Figure 30. Electric heater layout incorporating 71 Kanthal heating elements and engineering helium heat exchange design.

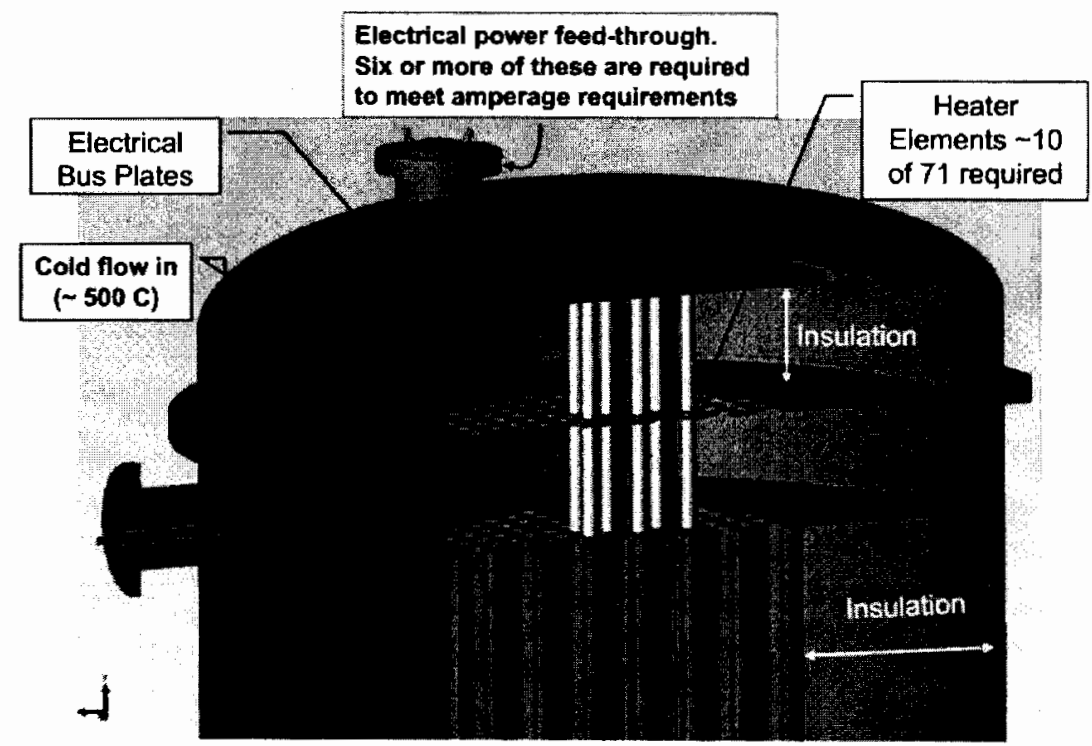

Figure 31. Integrated heater top end, showing heating element support and electrical termination. 


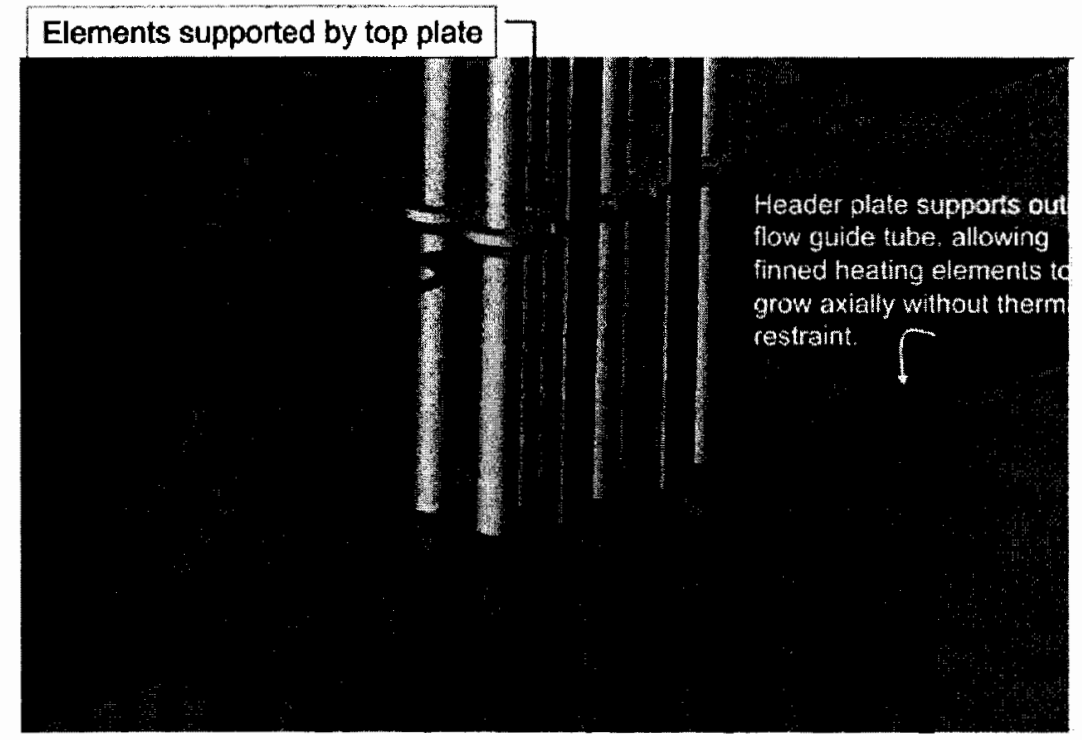

Figure 32. Heating element and fin are free to slide within outer tube shell.

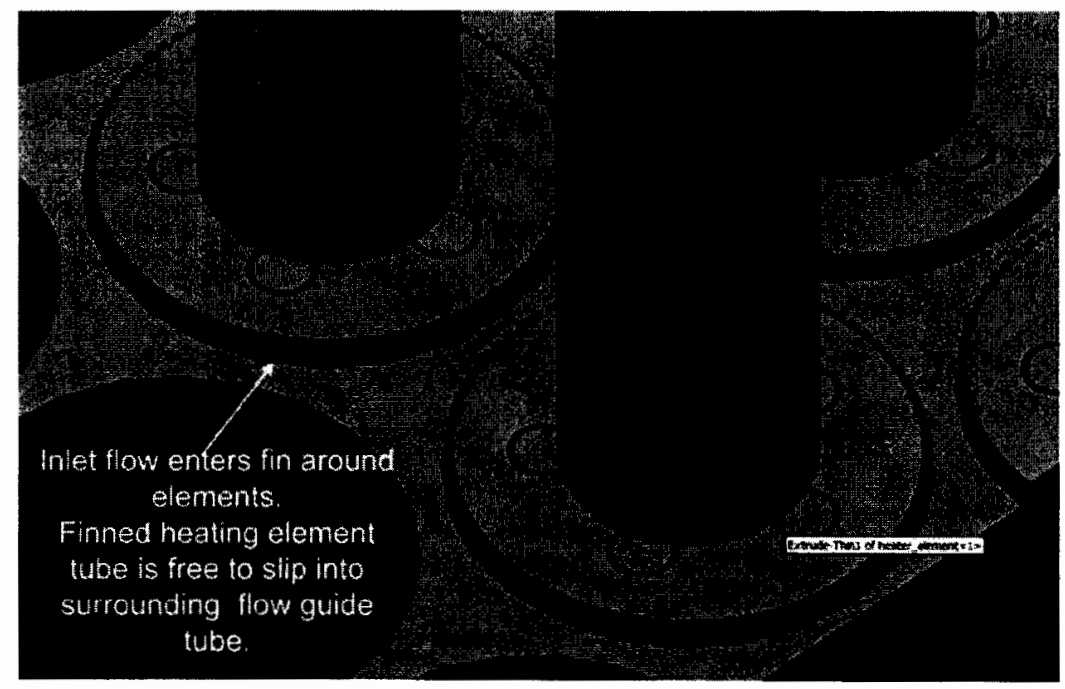

Figure 33. Detail of helium flow path through the heating elements. The installation accommodates differential thermal growth between the heating element and the flow guide header plate. 


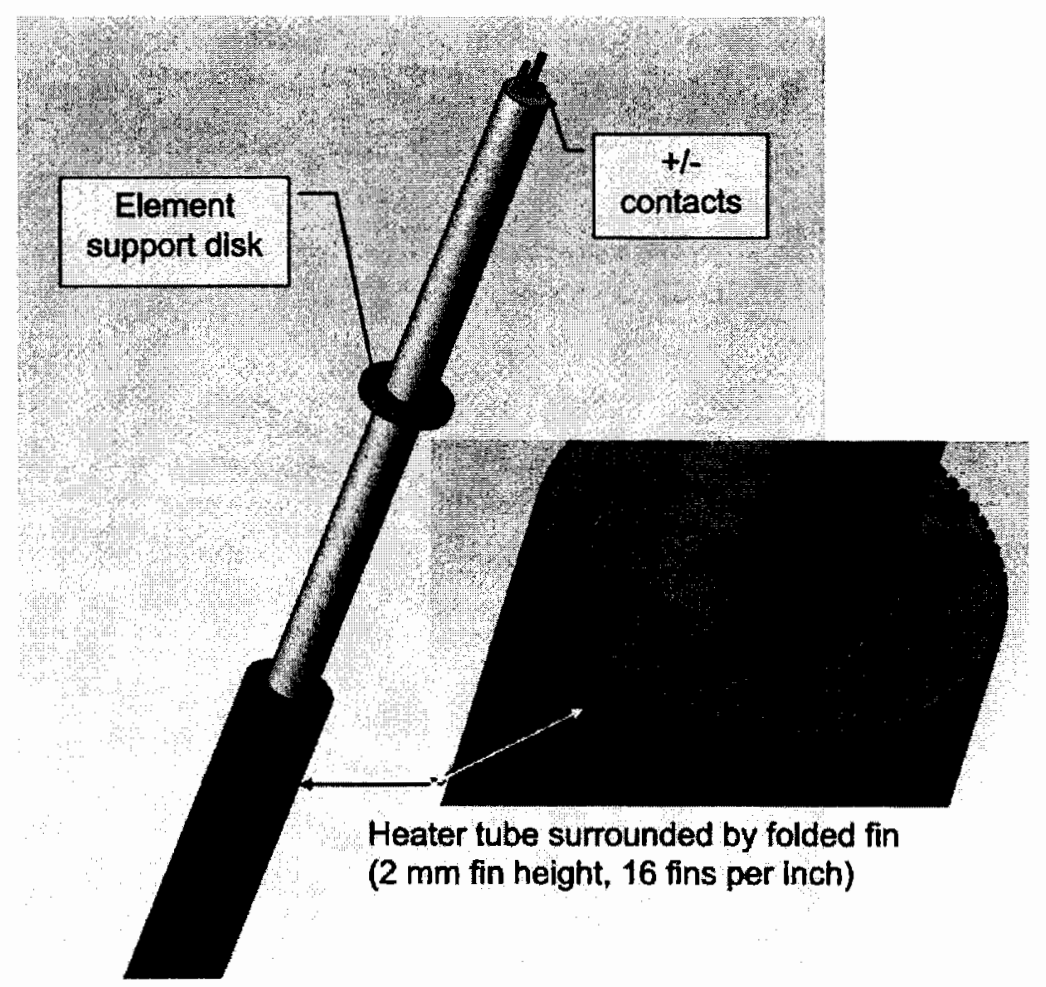

Figure 34. Extended surface fin surrounds the standard Kanthal heating element.

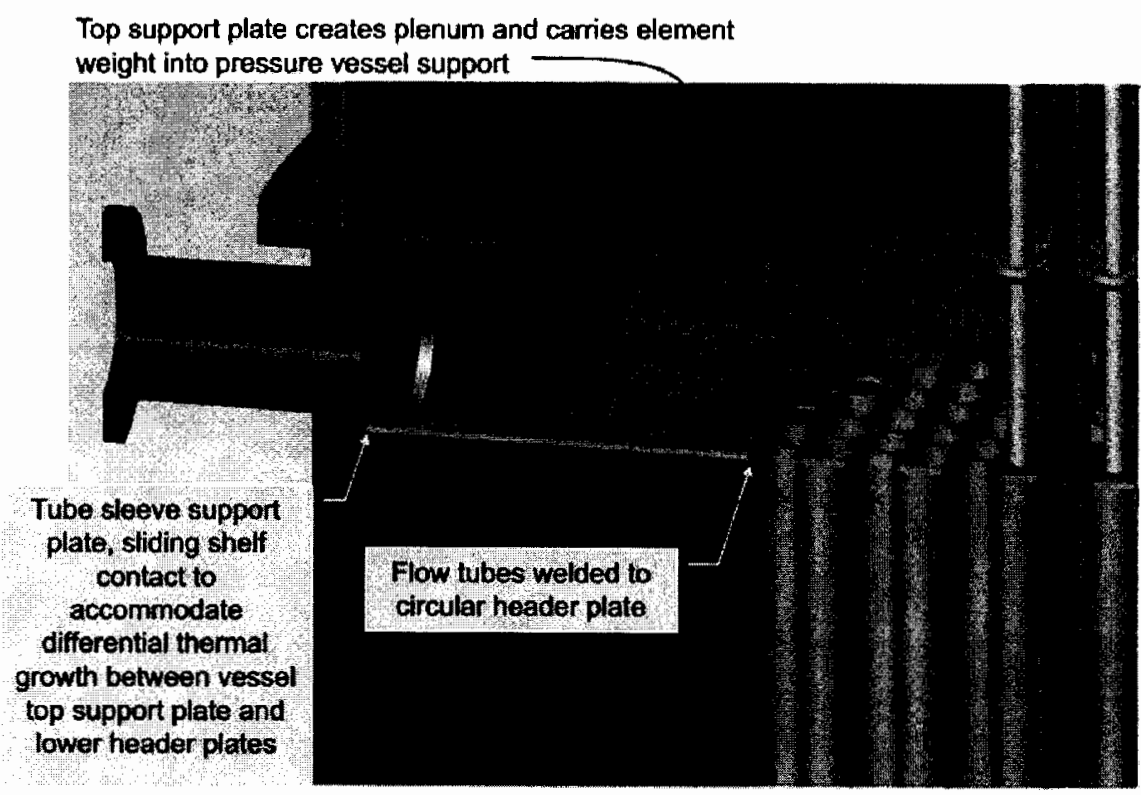

Figure 35 . Heater assembly detail showing top support plate and header plate. 


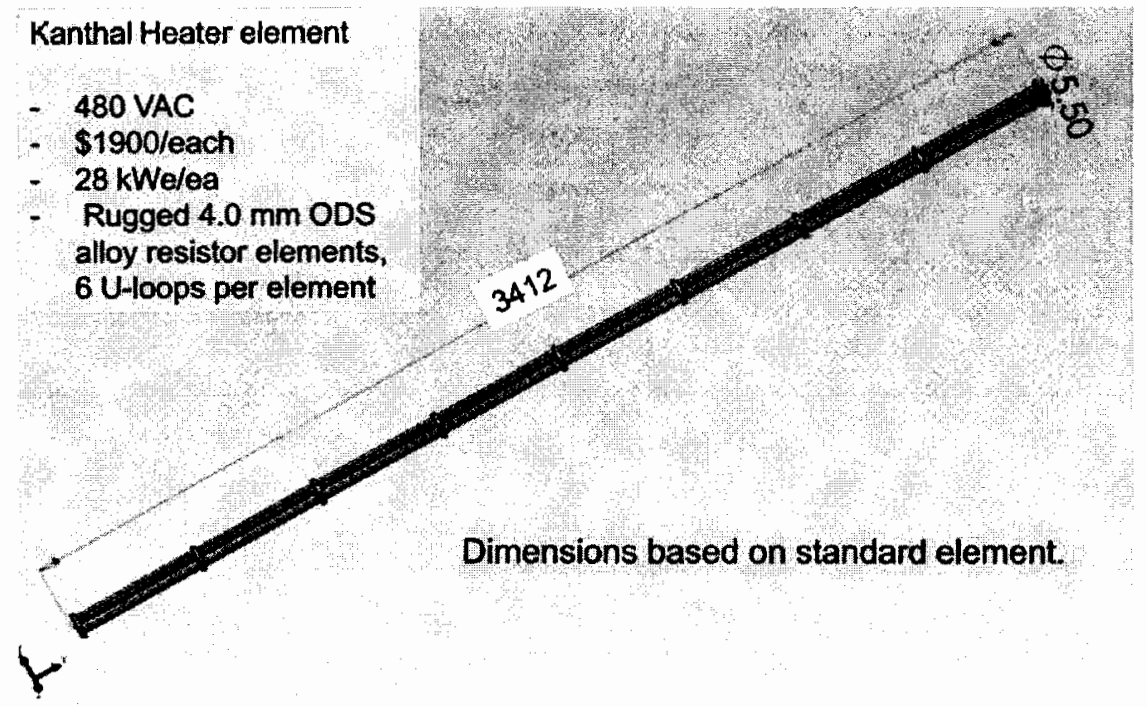

Figure 36. Single $28 \mathrm{~kW}$ Kanthal heating element dimensions.

4.2.1.1.4 Heater System Costs - The capital costs for the 2-MW heater have been estimated from the preliminary design and are given in Table 11. As the heating elements are engineered to order, a firm budgetary quotation was received. Costs for all other elements of the package are engineering estimates. The preliminary nature of this highly engineered system warrants the inclusion of a sizable contingency factor in the pricing analysis. The enclosing pressure vessel and associated end heads, (evaluated in Section 4.1.5) are not included in this cost estimate, but are assessed in Appendix I.

Table 11. Preliminary cost assessment for $2 \mathrm{MW}$ heater.

\begin{tabular}{|l|c|c|c|c|}
\hline & $\begin{array}{c}\text { Nominal } \\
\text { weight, } \mathrm{kg}\end{array}$ & $\begin{array}{c}\text { Unit Cost } \\
\$\end{array}$ & Quantity & Extended Cost \\
\hline Quoted cost/element & & $\$ 1,900$ & 71 & $\$ 134,900$ \\
\hline Fin segment unit cost & 14.12 & 373 & 71 & $\$ 26,506$ \\
\hline Inner tube (receptor) & 11.3 & 372 & 71 & $\$ 26,404$ \\
\hline Outer tube, flow tube & 11.7 & 386 & 71 & $\$ 27,394$ \\
\hline Processing, welding & & 100 & 71 & $\$ 7,100$ \\
\hline Top support plate & 1684 & 40,809 & 1 & $\$ 40,809$ \\
\hline Tube plate & 1404 & 37,099 & 1 & $\$ 37,099$ \\
\hline Electrical bus plate & 421 & 1,855 & 2 & $\$ 3,710$ \\
\hline Electrical feed-throughs & & 2,500 & 4 & $\$ 10,000$ \\
\hline Insulation & & 3,000 & 1 & $\$ 3,000$ \\
\hline Assembly & & 30,000 & 1 & $\$ 30,000$ \\
\hline Exit transition cone & 69 & 1,835 & 1 & $\$ 1,835$ \\
\hline Inlet pipe liner assembly & 2 & 510 & 1 & $\$ 510$ \\
\hline Contingency & & & $80 \%$ & $\$ 171,494$ \\
\hline Total & & & & $\$ \mathbf{5 2 0 , 7 6 1}$ \\
\hline
\end{tabular}


4.2.1.2 Gas Circulators. Development of custom hardware will be needed for gas circulators on both primary and secondary loops, and these components will represent a significant portion of system cost. The selection process for the circulators is admittedly at a very preliminary stage, and no clear favorite has emerged among the competing design strategies. This section identifies various hardware options and summarizes limited information solicited thus far from prospective vendors.

As discussed in Section 4.1.1, choice of circulator inlet temperature will have a fundamental impact on the hardware. For purposes of preliminary loop design, a 'cold' circulator approach is advocated above, based on a combined strategy of recuperation and overboard heat rejection for reducing circulator inlet temperature roughly to ambient. Still under consideration for the primary loop is an alternative 'hot' circulator strategy, which reduces overall complexity and is thermally more efficient. Our preliminary strategy was driven by cost concerns over development of a custom 'hot' circulator, but no firm decision can be reached until the design process is farther advanced.

For the secondary loop only a 'cold' circulator is considered, because overboard heat rejection is mandatory. The sensible strategy is to reject this heat upstream of the circulator. Broad specifications for primary and secondary circulators are shown in Table 12.

With fewer components in the primary loop, lower pressure ratio is demanded under the hot circulator strategy, but power demand is higher because of the increased inlet temperature. It is noted that power levels above are based on an assumed $70 \%$ component efficiency, a realistic figure for properlydesigned centrifugal turbomachinery running at 'optimum' speed. Much lower efficiency is projected under some strategies, carrying proportional increases in power demand. The following broad hardware classifications are under consideration for both primary and secondary circulators:

- Option 1 - High-speed rotating turbomachinery. Given freedom to choose shaft speed based on optimum turbomachinery efficiency, each specification above can be met using a single centrifugal stage (see below).

- Option 2 - Low-speed rotating turbomachinery. Limitations on shaft speed can be met with additional turbomachinery stages and/or compromises in stage efficiency from operation at low 'specific speed' (see below).

- Option 3 - Reciprocating (piston) compressors. Despite special design challenges posed by high operating pressure, this strategy deserves serious consideration.

Table 12. Circulator performance specifications at design conditions.

\begin{tabular}{|l|l|l|l|c|c|c|c|}
\hline & & Composition & Massflow & $\begin{array}{c}\text { Inlet } \\
\text { Pressure }\end{array}$ & $\begin{array}{c}\text { Inlet } \\
\text { Temp }\end{array}$ & $\begin{array}{c}\text { Pressure } \\
\text { Ratio }\end{array}$ & $\begin{array}{c}\mathrm{W}_{\text {SHAFT }} \\
(@ 70 \% \text { effy }\end{array}$ \\
\hline Primary & Cold & $\mathrm{He}$ & $0.80 \mathrm{~kg} / \mathrm{s}$ & $6.0 \mathrm{MPa}$ & $35^{\circ} \mathrm{C}$ & 1.11 & $77 \mathrm{~kW}$ \\
\hline & Hot & $\mathrm{He}$ & $0.80 \mathrm{~kg} / \mathrm{s}$ & $6.0 \mathrm{MPa}$ & $550^{\circ} \mathrm{C}$ & 1.06 & $110 \mathrm{~kW}$ \\
\hline Secondary & Cold & $\mathrm{N}_{2}-\mathrm{He}(80: 20)$ & $2.12 \mathrm{~kg} / \mathrm{s}$ & $5.5 \mathrm{MPa}$ & $35^{\circ} \mathrm{C}$ & 1.11 & $63 \mathrm{~kW}$ \\
\hline
\end{tabular}


Considering the first option above, attainment of good efficiency for a single turbomachinery stage hinges on the 'specific-speed' parameter ${ }^{26}$ for which an optimum value can be identified for a given class of machine. For a multi-stage compressor with inlet conditions, flow, and overall pressure ratio prescribed, specific speed for a given stage may be raised through increased shaft speed and/or increased stage count. With sufficient headroom on shaft speed, optimum specific speed is achievable in a single stage, generally preferred from the standpoint of simplicity.

The preferred drive configuration for the current application is direct coupling to a permanentmagnet motor, accepting that shaft-speed limitations imposed by the motor must be respected. A rough envelope of permissible alternator speed is shown as the blue curve in Figure 37, obtained from a curve fit of commercially available hardware. Speed-power combinations on or below the curve may be considered attainable using current technology.

Findings from a preliminary study investigating Option 1 above are summarized in Figure 37 and Table 13. For preliminary estimating purposes, 'optimum' specific speed was prescribed as 0.6 for a centrifugal stage and 1.5 for an axial stage. For axial compressors especially, there is wide latitude in these numbers, but not sufficient to change the broad conclusions of the study, namely:

- The specifications of Table 12 can be met in all cases using a single centrifugal stage, running at optimum speed using current motor technology.

- Various axial configurations are also possible, including single-stage designs (noting flexibility in specific-speed choice). However, single-stage centrifugal designs are generally preferred for cost reasons.

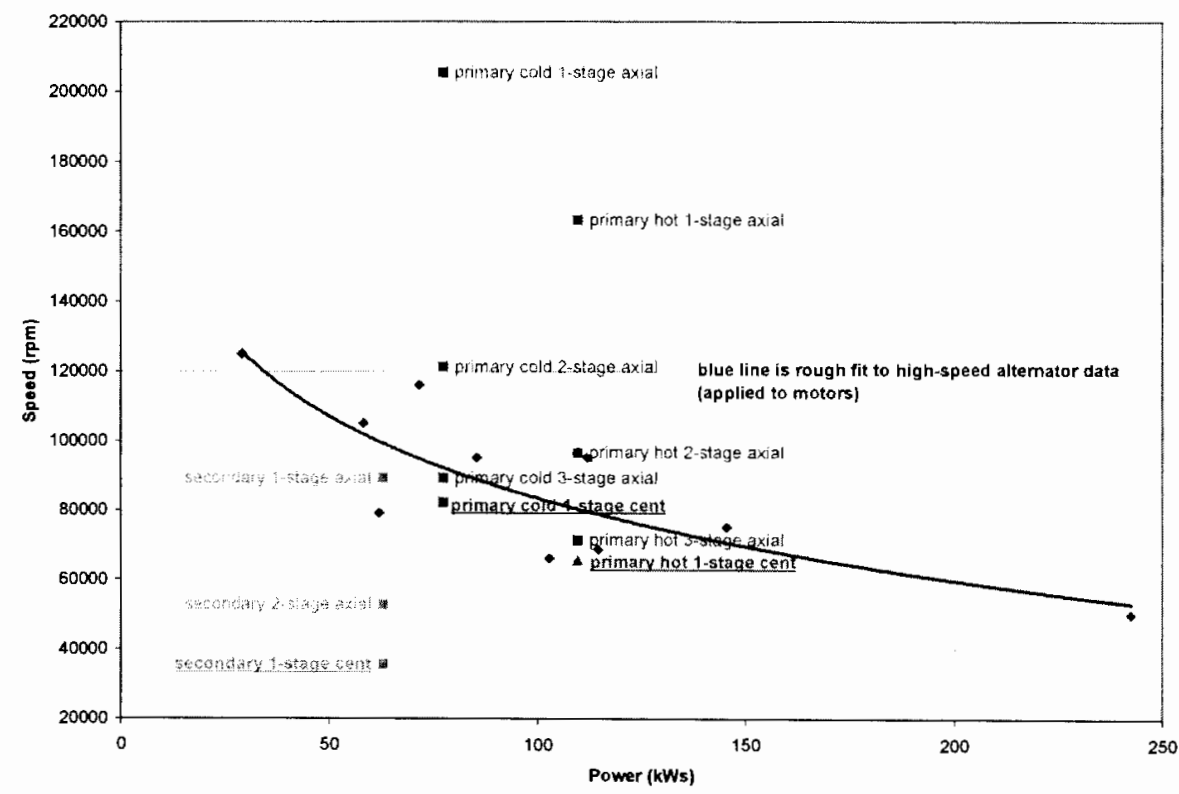

Figure 37. High-speed turbomachinery configurations based on specifications of Table 12. In all cases, optimum speed for a single-stage centrifugal machine falls within acceptable bounds for current highspeed motors. 
Table 13. Findings corresponding to Figure 37, with preferred single-stage centrifugal design highlighted in red.

AXIAL

\begin{tabular}{|l|l|c|c|c|c|c|c|c|c|c|}
\hline \multirow{2}{*}{} & \multicolumn{3}{|c|}{} & \multicolumn{3}{|c|}{ 1-Stage } & \multicolumn{3}{c|}{ 2-Stage } & \multicolumn{3}{c|}{ 3-Stage } \\
\cline { 2 - 12 } & $\begin{array}{c}\text { Dia } \\
(\mathrm{mm})\end{array}$ & $\begin{array}{c}\text { Speed } \\
(\mathrm{rpm})\end{array}$ & $\begin{array}{c}\text { Utip } \\
(\mathrm{m} / \mathrm{s})\end{array}$ & $\begin{array}{c}\text { Dia } \\
(\mathrm{mm})\end{array}$ & $\begin{array}{c}\text { Speed } \\
(\mathrm{rpm})\end{array}$ & $\begin{array}{c}\text { Utip } \\
(\mathrm{m} / \mathrm{s})\end{array}$ & $\begin{array}{c}\text { Dia } \\
(\mathrm{mm})\end{array}$ & $\begin{array}{c}\text { Speed } \\
(\mathrm{rpm})\end{array}$ & $\begin{array}{c}\text { Utip } \\
(\mathrm{m} / \mathrm{s})\end{array}$ \\
\hline Primary & Cold & 51 & 205,586 & 553 & 61 & 121,292 & 389 & 68 & 89,256 & 317 \\
\hline & Hot & 77 & 163,414 & 659 & 92 & 96,762 & 465 & 102 & 71,291 & 379 \\
\hline Secondary & Cold & 66 & 89,219 & 307 & 78 & 52,697 & 216 & 87 & 38,793 & 176 \\
\hline
\end{tabular}

\section{CENTRIFUGAL}

\begin{tabular}{|l|l|c|c|c|}
\hline \multicolumn{2}{|c|}{} & \multicolumn{3}{|c|}{ 1-Stage } \\
\cline { 3 - 5 } \multicolumn{2}{|c|}{} & $\begin{array}{c}\text { Dia } \\
(\mathrm{mm})\end{array}$ & $\begin{array}{c}\text { Speed } \\
(\mathrm{rpm})\end{array}$ & $\begin{array}{c}\text { Utip } \\
(\mathrm{m} / \mathrm{s})\end{array}$ \\
\hline Primary & Cold & 78 & 82.234 & 335 \\
\hline & Hot & 117 & 65.365 & 399 \\
\hline Secondary & Cold & 100 & 35.688 & 186 \\
\hline
\end{tabular}

Regarding Option 2, low-speed turbomachinery, optimum stage specific-speed can in principle be achieved through increased stage-count. However, because the speed of drive hardware contemplated (e.g. synchronous AC motors) is dramatically lower than described above, this is not a practical alternative. Instead, aerodynamic design is optimized for low specific speed and applied in a design having relatively few stages. Several compressor classes are candidates for this low-speed application (e.g. regenerative, side-channel, and roots blowers).

It is noted that these low-speed machines will be of compromised efficiency compared to Option 1, the $70 \%$ figure above no longer applicable. For example, the quoted efficiency for the side-channel blower offered by Air Technologies is in the range of $30 \%$. Because power consumption is of minor concern for this application, low efficiency is likely permissible. However, the impact on capital cost, for example, the need for larger motors and switchgear, is a possible source of concern.

Regarding Option 3, piston compressors, the principal challenge for this application is that associated with high mean pressure, removing any possibility of capitalizing directly on stock hardware. These machines are customarily configured with drive components at ambient pressure, with pressure containment for the piston/cylinder accomplished with a sliding seal. Chief concerns are overboard gas leakage past the seal and high steady loads on mechanical components. According to a commercial supplier of this equipment (RIX Industries), the latter issue could be overcome through specialized design, in that projected loads do not dramatically exceed those for purpose-built machines in current operation.

A proposed solution for the overboard leakage problem is to surround the compressor with a lowpressure containment vessel purged with helium, with leaked gas replenished by means of a low-capacity scavenge compressor designed for high-pressure ratio $(\sim 80)$. Such hardware is already a system requirement for purposes of system charging and sequestering of gas during maintenance. 
Also briefly considered was the aiternative of surrounding the entire compressor/drive assembly with a hermetic high-pressure enclosure. Based largely on concerns related to the lubrication system, the commercial supplier above suggests that this would require a substantial redesign effort.

Effort is underway to solicit budgetary quotations for gas circulator hardware, with preliminary findings summarized in Table 14.

Supporting literature for the suppliers above is provided in Appendix J.

Table 14. Preliminary feedback from candidate circulator suppliers.

\begin{tabular}{|c|c|c|c|c|c|}
\hline Vendor & Classification & Type & Application & SUnit & Comments \\
\hline Howden & $\begin{array}{l}\text { High-Speed } \\
\text { Turbo }\end{array}$ & $\begin{array}{l}\text { 1-Stage } \\
\text { Centrifugal }\end{array}$ & $\begin{array}{l}\text { Primary/hot } \\
\text { Secondary }\end{array}$ & $\$ 4.6 \mathrm{M}$ & $\begin{array}{l}\text { Shockingly high quotation, } \\
\text { probably not worth a closer } \\
\text { look. }\end{array}$ \\
\hline $\begin{array}{l}\text { Barber } \\
\text { Nichols }\end{array}$ & $\begin{array}{l}\text { Low-Speed } \\
\text { Turbo }\end{array}$ & $\begin{array}{l}\text { 2-Stage } \\
\text { Centrifugal }\end{array}$ & $\begin{array}{l}\text { Primary } / \text { cold } \\
\text { Primary/hot } \\
\text { Secondary }\end{array}$ & $\begin{array}{l}\$ 160 \mathrm{~K} \\
220 \mathrm{~K} \\
140 \mathrm{~K}\end{array}$ & $\begin{array}{l}\text { Credible vendor. Should } \\
\text { proceed to next level. } \\
\text { Puzzled by low shaft speed. }\end{array}$ \\
\hline $\begin{array}{l}\text { Air } \\
\text { Technologies }\end{array}$ & $\begin{array}{l}\text { Low-Speed } \\
\text { Turbo }\end{array}$ & $\begin{array}{l}\text { 4-Stage } \\
\text { Side- } \\
\text { Channel } \\
\text { Blower }\end{array}$ & $\begin{array}{l}\text { Primary/cold } \\
\text { Secondary }\end{array}$ & $\$ 768 \mathrm{~K}$ & $\begin{array}{l}\text { Developed under AREVA } \\
\text { program so should be closest } \\
\text { thing to 'ready'solution. } \\
\text { Low efficiency } \sim 30 \% \text {. } \\
\text { Sufficient flow capacity at } \\
\text { rated speed, but } 80 \mathrm{~K} W \\
\text { motor insufficient at this } \\
\text { efficiency level. Should } \\
\text { investigate possibility of } \\
\text { fitting larger motor. }\end{array}$ \\
\hline $\begin{array}{l}\text { RIX } \\
\text { Industries }\end{array}$ & Piston & $\begin{array}{l}\text { Double- } \\
\text { Acting }\end{array}$ & $\begin{array}{l}\text { Primary } / \text { cold } \\
\text { Secondary }\end{array}$ & & $\begin{array}{l}\text { Vendor experienced in } \\
\text { helium compression at high } \\
\text { inlet pressure (but well short } \\
\text { of our application). Provided } \\
\text { preliminary sizing study (see } \\
\text { attached). }\end{array}$ \\
\hline
\end{tabular}

4.2.1.3 Primary Recuperator. A recuperator is specified to reduce gas temperatures approaching the cooler and circulator and to recover a substantial portion of that temperature to preheat gas approaching the heater. The recuperators used in the primary and secondary loops reduce the energy demand for heating and cooling gas while providing conditions for efficient operation of gas circulators. An excerpt from the P\&ID is provided in Figure 38 to show where the primary-side recuperator resides with respect to the heater, IHX vessel, circulator, and cooler with which it communicates via piping. 


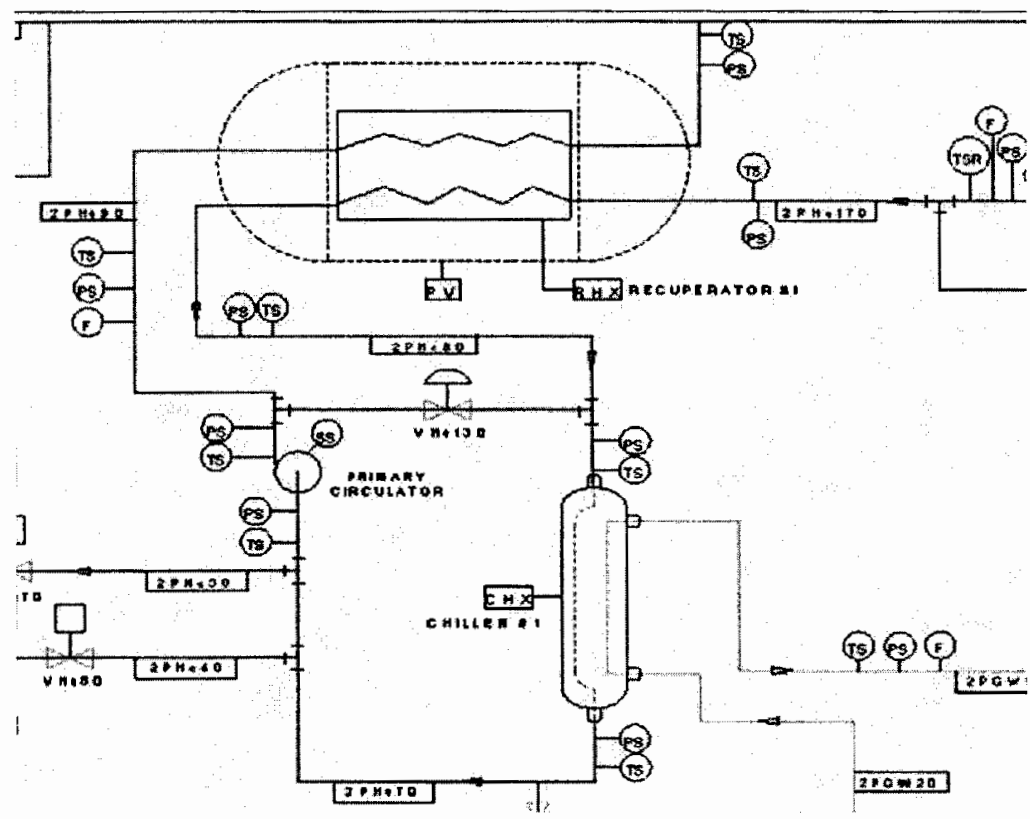

Figure 38. Excerpt of P\&ID showing position of primary-side recuperator in process.

4.2.1.3.1 Design Statepoint for Primary Recuperator - The design statepoint for the primaryside recuperator is given in Table 15.

Table 15. Design statepoint for the primary-side recuperator.

\begin{tabular}{|l|c|}
\hline \multicolumn{1}{|c|}{ Parameter } & Magnitude \\
\hline Hot-Side Inlet Temperature, maximum & $650^{\circ} \mathrm{C}$ \\
\hline Cold-Side Inlet Temperature & $100^{\circ} \mathrm{C}$ \\
\hline Mean Pressure & $8-\mathrm{MPa}$ \\
\hline Differential Pressure, Cold-Side-Hot-Side & $0.5-\mathrm{MPa}$ \\
\hline Massflow & $0.8-\mathrm{kg} / \mathrm{s}$ \\
\hline
\end{tabular}

4.2.1.3.2 Primary-Side Recuperator Mechanical Design - The operating requirements of the recuperator are typical of those commercially supplied to the gas turbine industry. ${ }^{27}$ An example of one designed by Brayton Energy, LLC for NGNP applications is shown in Figure 39. A detailed performance analysis of the recuperator has been performed. The counterflow plate-fin design is exceptionally compact and effective. A summary of the specific thermal design parameters is provided in Table 16.

The assembly shown in Figure 40 is the basis for the primary-side recuperator for the test loop. It is packaged in a lined pressure vessel and employs design features for sealing. The assembly is strain-relief designed and analyzed for a full-sized recuperator. To minimize the size of the pressure vessel, the cooled IHX exhaust gas, shown as to cooler in Figure 40, is arranged to flow in shells along the inner surfaces of the pressure boundary. The complete flow circulation is shown in Figure 40.

This recuperator has been designed to accommodate the significant differential thermal expansion and cyclic operation. The U-shaped exit pipes are designed to absorb the differential thermal expansion of the core and piping, without the use of bellows or other expansion joints. 


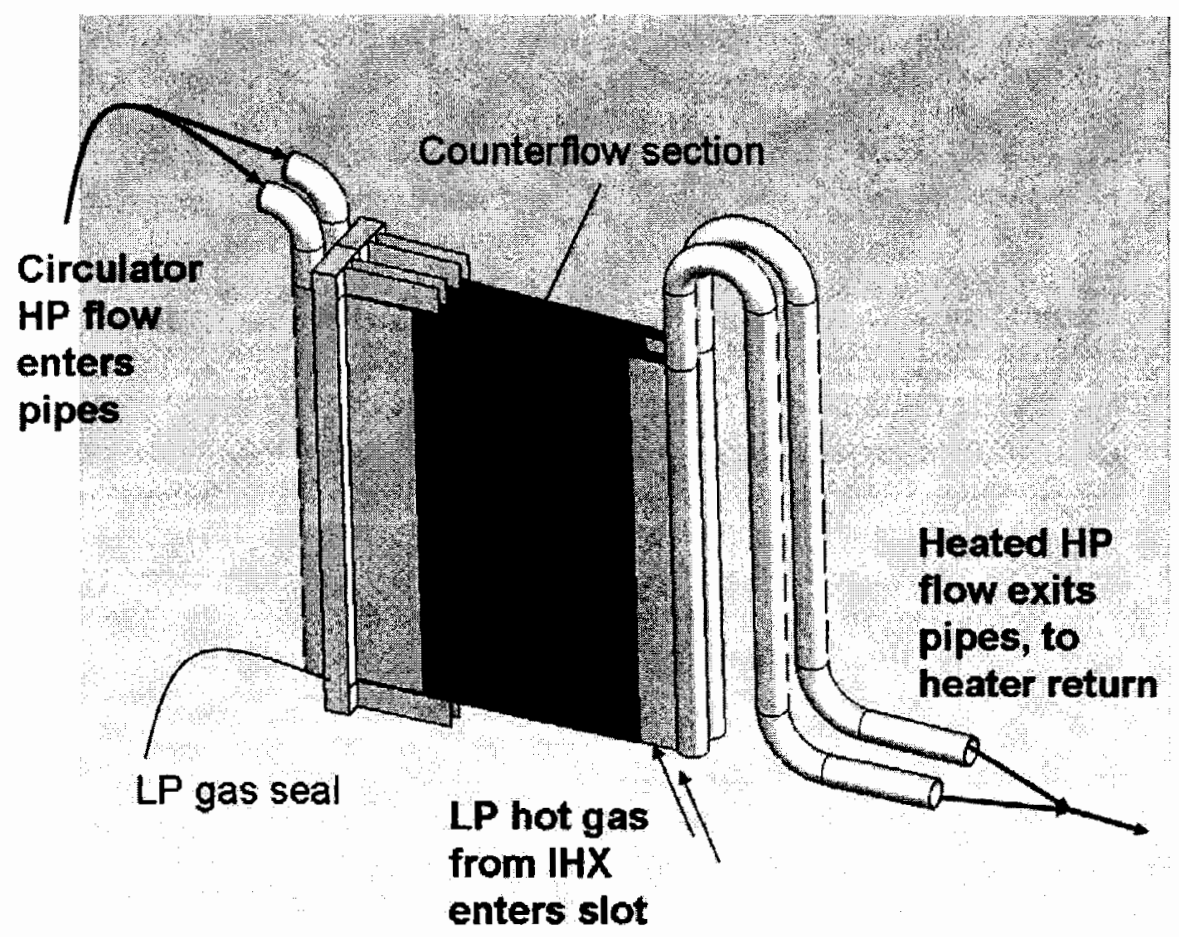

Figure 39. Assembly of two recuperator cores, four cells each, specified for duty as a primary-side recuperator.

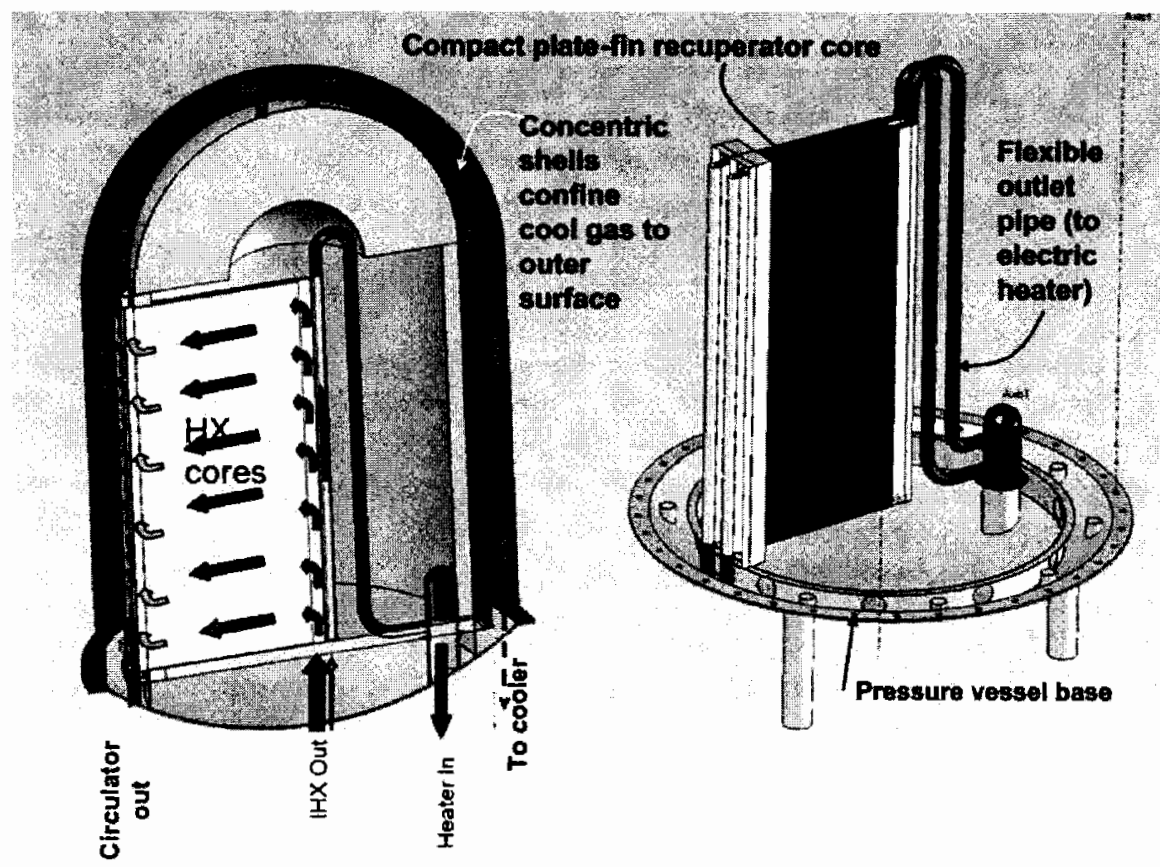

Figure 40. Flow through the primary-side recuperator. Lower temperature recuperator-discharge gas flows along the pressure boundary to minimize the insulation thickness. The diameter is 1.2-meters, with a cylindrical section 1.1 meters long. 
4.2.1.3.3 Primary Recuperator Performance - At the conditions provided in Table 15 , the recuperator has a thermal effectiveness of $94.9 \%$ and a net pressure loss totaling $2.1 \%$ of the inlet absolute pressure. The detailed performance parameters accounting for these net performance parameters are provided in Table 17.

4.2.1.4 Primary Cooler. Heat rejection from the primary circuit occurs immediately upstream from the circulator, and the cooler-inlet gas temperature must be minimized to enable the circulator to function properly. A conventional multi-pass cross-flow tube-shell heat exchanger using a water/glycol mixture is appropriate to cool the gas mixture exiting from the primary recuperator.

The selected cooler is conservatively designed to account for the wide range of possible recuperator gas exit conditions. In the event of a by-pass failure in the IHX, the primary cooler may receive elevated temperatures. Fortunately, a class of heat exchangers serving the air compressor intercooler industry is appropriate for this duty. Such gas compression equipment is rated to pressures well above the HTGL's 8-MPa requirement. Also, owing to the superior thermal conductivity and viscosity of helium, the performance rating is not challenging.

The recommended commercially available heat exchangers are of tube-shell construction. Highpressure gas is specified to be internal to the tubes. Independent analyses were performed with reputable suppliers, Basco, and API. The specification for the preliminary sizing analysis is shown in Table 18 .

Table 16. Primary-side thermal design parameters and values.

\begin{tabular}{|l|c|c|l|c|c|}
\hline \multicolumn{4}{|c|}{ Cooled-Side } & \multicolumn{4}{c|}{ Heated-Side } \\
\hline Parameter & Value & Units & \multicolumn{1}{|c|}{ Parameter } & Value & Units \\
\hline Matrix Width & 1.067 & $\mathrm{~m}$ & Matrix Width & 1.067 & $\mathrm{~m}$ \\
\hline Matrix Flow Length & 0.48 & $\mathrm{~m}$ & Matrix Flow Length & 0.48 & $\mathrm{~m}$ \\
\hline Fin Density & 1,772 & $\mathrm{~m}^{-1}$ & Fin Density & 1772 & $\mathrm{~m}^{-1}$ \\
\hline Surface Type & Wavy & - & Surface Type & $\begin{array}{l}\text { Transverse } \\
\text { Folded Screen }\end{array}$ & - \\
\hline Fin Height & 1.1 & $\mathrm{~mm}$ & Fin Height & 3.0 & $\mathrm{~mm}^{-1}$ \\
\hline Flow Area & .00107 & $\mathrm{~m}^{2}$ & Flow Area & 0.00640 & $\mathrm{~m}^{2}$ \\
\hline Heat Transfer Area & 2.67 & $\mathrm{~m}^{2}$ & Heat Transfer Area & 40.35 & $\mathrm{~m}^{2}$ \\
\hline Hydraulic Diameter & 0.56 & $\mathrm{~mm}$ & Hydraulic Diameter & 0.28 & $\mathrm{~mm}$ \\
\hline
\end{tabular}


Table 17. Detailed performance parameters for primary-side recuperator.

\begin{tabular}{|l|c|c|c|}
\hline \multicolumn{2}{|c|}{ Cooled-Side Performance } & \multicolumn{2}{c|}{ Heated-Side Performance } \\
\hline Reynolds Number & 1730 & Reynolds Number & 138 \\
\hline Convection Coefficient & $5,812 \mathrm{~W} / \mathrm{m}^{2}-\mathrm{K}$ & Convection Coefficient & $17,819 \mathrm{~W} / \mathrm{m}^{2}-\mathrm{K}$ \\
\hline Fin Efficiency & $59 \%$ & Fin Efficiency & $5 \%$ \\
\hline Pressure Loss & $1.41 \%$ & Pressure Loss & $0.60 \%$ \\
\hline & & & $54.9 \%$ \\
\hline Thermal Effectiveness & \multicolumn{2}{|c|}{ Overall Performance } & \\
\hline
\end{tabular}

Table 18. The general primary cooler specification was submitted to qualified heat exchanger suppliers. Conditions are for an ISO-standard day. The heat exchanger is rated to ASME standards.

\begin{tabular}{|c|c|}
\hline Application & $\begin{array}{c}\mathrm{HX}-\# 1 \\
\text { (Primary) }\end{array}$ \\
\hline Gas type & $\mathrm{He}$ \\
\hline Coolant & water/glycol \\
\hline Glycol fraction & 0.38 \\
\hline Gas flow rate, $\mathrm{kg} / \mathrm{s}$ & 1 \\
\hline Gas inlet temp, ${ }^{\circ} \mathrm{C}$ & 135 \\
\hline Gas out temp & 35 \\
\hline Gas in pressure, $\mathrm{MPa}$ (normal rating) & 6 \\
\hline Gas max rated pressure, $\mathrm{MPa}$ & 8 \\
\hline Coolant flow rate, $\mathrm{kg} / \mathrm{hr}$ & 13,426 \\
\hline Coolant in temp, ${ }^{\circ} \mathrm{C}$ & 25 \\
\hline Coolant out Temp, ${ }^{\circ} \mathrm{C}$ & 58 \\
\hline Heat rejected, $\mathrm{kW}$ & 520 \\
\hline Coolant pressure, mm Hg (Idaho barometric pressure) & 24.53 \\
\hline \multicolumn{2}{|l|}{ Gas properties } \\
\hline Gas specific heat, $\mathbf{J} /(\mathrm{kg} \cdot \mathrm{K})$ & 5200.0 \\
\hline Gas viscosity, $\mathrm{Pa}^{*} \mathrm{~s}$ & $2.067 \mathrm{E}-05$ \\
\hline Gas Thermal conductivity, $\mathrm{W} /(\mathrm{m} \cdot \mathrm{K})$ & $1.618 \mathrm{E}-01$ \\
\hline
\end{tabular}


A performance analysis of the general multi-pass tube shell heat exchanger was performed for the conditions listed in Table 18. The results of the analysis are shown in Appendix K. This solution was used to size the heat exchanger portrayed in the integrated system layout. As stated earlier, several commercial heat exchangers can be specified to meet this requirement.

4.2.1.4.1 Primary Cooler Mechanical Configuration - In response to the request-for-quotation, Basco Industries has offered a durable tube-shell heat exchanger. With this construction, the bell-end header and the tube sheet are designed to operate at 8-MPa pressure. The shell around the tubes is designed for typical facility water pressures of under $100 \mathrm{psi}(0.7 \mathrm{MPa})$. Figure 41 shows the Basco design.

4.2.1.4.2 Primary Cooler and Heat Rejection Cost Summary - Detailed cost and performance information for the primary cooler has been received from one qualified supplier. These details are provided in Appendix L. The cost is quoted at $\$ 19,160$.

\subsubsection{Secondary Loop}

Three secondary loops are anticipated for the proposed HTGL. The following general guidelines have been established for the three circuits:

- Non corrosive gas mixtures - such as helium-nitrogen

- Helium

- $\quad$ Steam, molten salts, thermochemical process fluids.

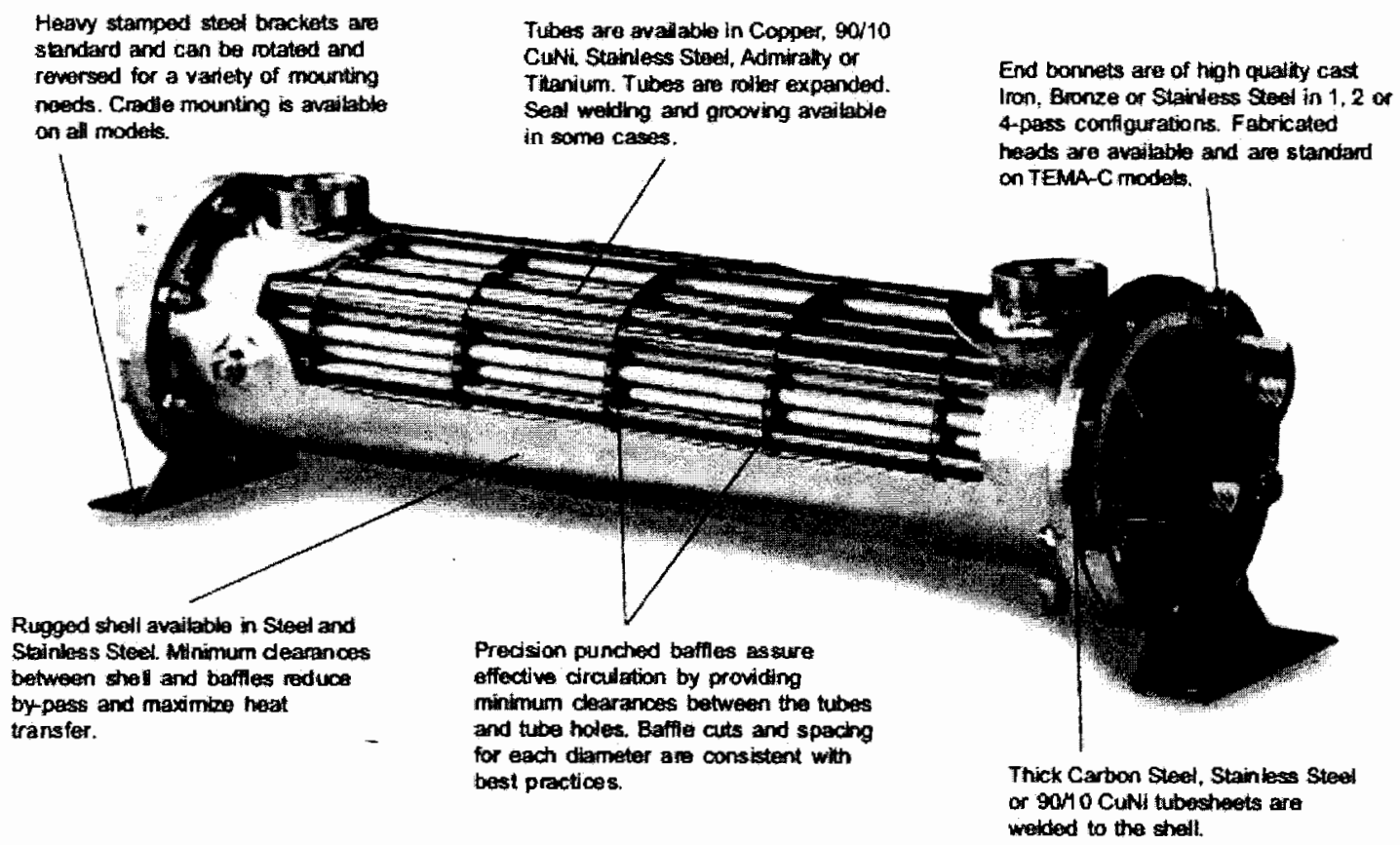

Figure 41. Tube-shell heat exchanger proposed by Basco Industries, in response to the HTGL request-forquotation. This type of heat exchanger is appropriate for both primary and secondary gas loops. 
4.2.2.1 Secondary Cooler Design. Heat is rejected from the secondary circuit immediately upstream of the circulator in order for the circulator to function properly. A water/glycol mixture is appropriate to cool the gas mixture exiting from the secondary recuperator.

The secondary cooler must be conservatively designed to account for the wide range of possible recuperator gas exit conditions. Since the heat removal from the upstream recuperator is a control variable to enable independent control over the IHX inlet temperature, a wide range of cooler gas inlet conditions are anticipated. As for the primary cooler (Section 4.2.1.4), an industrial tube-shell heat exchanger is appropriate for this task.

A specification for the preliminary sizing analysis is shown in Table 19. An independent analysis was performed to confirm the dimensional choices and guide and check the results of the venders.

A performance analysis of the general multi-pass tube shell heat exchanger was performed for the conditions listed in Table 19. The results of the analysis are shown in Appendix $\mathrm{L}$ along with the analysis provided by a qualified supplier. In this assessment, the vendor recommended a single module, identical to that of the primary loop. While the module meets thermal performance for the secondary side, its pressure drop exceeds the specification. This is confirmed by the independent analysis, also provided in Appendix L. The recommended solution incorporated into the HTGL system layout is to install a pair of the units proposed by the supplier. This decision serves to lower pressure drop and adds margin on heat rejection. The pressure drop for the pair of secondary units operating in parallel is projected to be, nominally, $0.7 \%$, and is in conformance with the overall circuit pressure-loss budget.

Table 19. The general secondary cooler specification was submitted to qualified heat exchanger suppliers. Conditions are for an ISO-standard day. The heat exchanger is rated to ASME standards.

\begin{tabular}{|l|c|}
\hline \multicolumn{1}{|c|}{ Application } & $\mathrm{HX}-\mathrm{H} 2$ \\
\hline Gas type & $20 \% \mathrm{He}, 80 \% \mathrm{~N}_{2}$ \\
\hline Coolant & water $/ \mathrm{glycol}$ \\
\hline Glycol fraction & 0.38 \\
\hline Gas flow rate, $\mathrm{kg} / \mathrm{s}$ & 2.7 \\
\hline Gas inlet temp, ${ }^{\circ} \mathrm{C}$ & 451 \\
\hline Gas out temp & 35 \\
\hline Gas in pressure, $\mathrm{MPa}$ (normal rating) & 5.5 \\
\hline Gas max rated pressure, $\mathrm{MPa}$ & 8 \\
\hline Coolant flow rate, $\mathrm{kg} / \mathrm{hr}$ & 54,725 \\
\hline Coolant in temp, ${ }^{\circ} \mathrm{C}$ & 25 \\
\hline Coolant out Temp, ${ }^{\circ} \mathrm{C}$ & 58 \\
\hline Heat rejected, $\mathrm{kW}$ & $2,119.5$ \\
\hline Coolant pressure, $\mathrm{mm}$ Hg (Idaho barometric pressure) & 24.53 \\
\hline Gas Properties & \\
\hline Gas specific heat, $\mathrm{J} /(\mathrm{kg} \cdot \mathrm{K})$ & $1,887.0$ \\
\hline Gas viscosity, $\mathrm{Pa} \cdot \mathrm{s}$ & $2.873 \mathrm{E}-05$ \\
\hline Gas Thermal conductivity, W/(m-K) & $1.238 \mathrm{E}-01$ \\
\hline
\end{tabular}


4.2.2.1.1 Secondary Mechanical Configuration and Cost Summary - In response to the request-for-quotation, Basco Industries has offered a durable tube-shell heat exchanger. With this construction, the bell-end header and the tube sheet is rated to ASME standards for $10 \mathrm{MPa}$ pressure. The shell around the tubes is designed for typical facility water pressures of under $690-\mathrm{kPa}$. Figure 41 , in the primary cooler section 4.2.1.4, shows the Basco design. Two of these units are incorporated into the HTGL package, with parallel gas piping. Installation details are provided in Appendix L.

Detailed cost and performance information for the primary cooler has been received from one qualified supplier. These details are provided in Appendix L. The cost is quoted at $\$ 19,160$ for each of two units, totaling to $\$ 38,320$.

4.2.2.2 Secondary Loop Recuperator. As with the primary-side, a recuperator continuously precools gas flowing between the IHX test-vessel and the cooler/circulator and pre-heats gas flowing away from the circulator to the heater. In performing this duty, it moderates the demand on coolers and heaters in the secondary loop. The secondary recuperator has a more strenuous duty than the primary recuperator because it receives IHX exhaust, approaching temperatures of $900^{\circ} \mathrm{C}$. Its second function is to provide control over the IHX secondary inlet gas temperature. A required thermal effectiveness in the vicinity of $60 \%$ for the secondary recuperator provides some design relief. These requirements differentiate the secondary recuperator from other IHX and primary heat exchangers.

To impose the prescribed transient maneuvers on the IHX test article, the IHX inlet temperature (equal to the secondary recuperator exit) must be controllable. Table 20 describes the secondary IHX loop design and minimum statepoints.

Four system design options have been evaluated to provide this functionality:

- Option 1 - Down stream liquid heat exchanger (high temp cooler)

- Option 2 - Down stream bypass (hot side dilution)

- $\quad$ Option 3 - Upstream bypass (cold side)

- Option 4 - Gas-gap thermal control recuperator construction. 
Table 20. Secondary IHX loop design and minimum statepoints.

\begin{tabular}{|l|c|c|}
\hline Statepoint & $\begin{array}{c}\text { Reference } \\
\text { Design }\end{array}$ & $\begin{array}{c}\text { Minimum IHX } \\
\text { Inlet } \\
\text { Temperature }\end{array}$ \\
\hline $\mathrm{M}_{9-10}, \mathrm{~kg} / \mathrm{s}$ & 2.1 & 2.1 \\
\hline $\mathrm{M}_{3-4}, \mathrm{~kg} / \mathrm{s}$ & 2.1 & 2.1 \\
\hline $\mathrm{T}_{9},{ }^{\circ} \mathrm{C}$ & 900 & 900 \\
\hline $\mathrm{T}_{10}{ }^{\circ} \mathrm{C}$ & 373.8 & 373.8 \\
\hline $\mathrm{T}_{3},{ }^{\circ} \mathrm{C}$ & 65 & 65 \\
\hline $\mathrm{T}_{4},{ }^{\circ} \mathrm{C}$ & 600 & 600 \\
\hline $\mathrm{T}_{4-\mathrm{Mix}},{ }^{\circ} \mathrm{C}$ & $\mathbf{6 0 0}$ & 300 \\
\hline$\varepsilon_{\text {cold }}$ & 0.641 & 0.641 \\
\hline $\mathrm{Q}_{3-4},{ }^{\prime} \mathrm{W}$ & $2,166,815$ & $2,166,815$ \\
\hline $\mathrm{N}_{\mathrm{TU}}{ }^{11}$ & 1.78 & 1.78 \\
\hline $\mathrm{C}_{\min } / \mathrm{C}_{\mathrm{Max}}$ & 0.984 & 0.984 \\
\hline
\end{tabular}

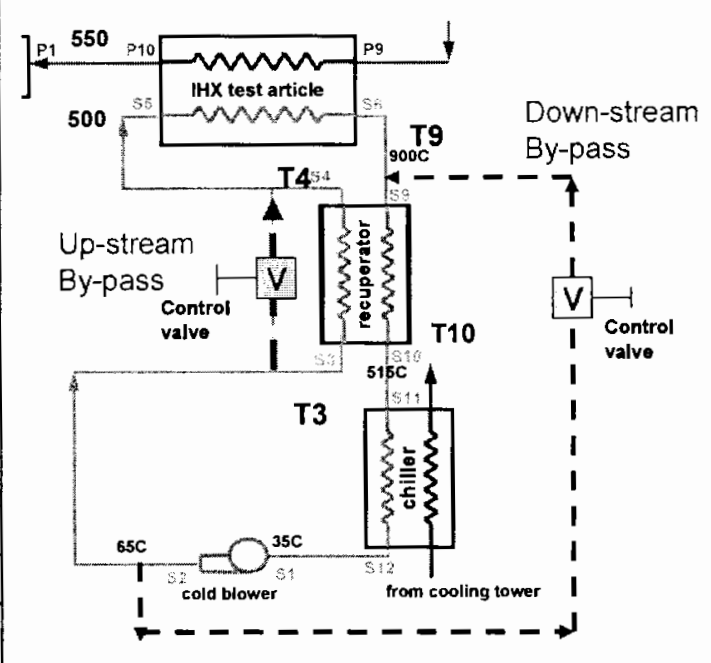

4.2.2.2.1 Option 1- Downstream High-Temperature Cooler-Temperature Control - The initial design approach was to use a water-cooled gas cooler upstream of the recuperator to lower the gas temperature to the extent that a compact design, as specified for the primary loop, could be used with low risk. However, cooling $900^{\circ} \mathrm{C}$ gas with a water cooler appeared fraught with issues such as boiling and corrosion. Further diminishing its appeal is a lack of sufficient turndown as controlling the water flowrate has a limited influence on the IHX return temperature. Finally, a larger recuperator would be needed to gain the thermal effectiveness required to achieve the minimum IHX temperature statepoint.

4.2.2.2.2 Option 2- Downstream-Bypass Temperature Control - The downstream bypass approach is shown in the figure inset of Table 20. Cool gas exiting the circulator is bled into, and mixed with, gas approaching the inlet of the secondary recuperator. As with the upstream bypass option, a mixed-out temperature is adjusted by a cool control valve. In this case, however, the hot gas exiting the IHX is diluted with cool gas exiting the circulator prior to entering the recuperator. With a cooler temperature and greater capacity on the cooled side of the recuperator, the heated side exits at a lower temperature. As seen in Figure 42 , to achieve the $300^{\circ} \mathrm{C}$ target temperature to the IHX, the circulator flow capacity increases by an additional 1.4-times the nominal flow. This would require that the blower be scaled upward by 2.8 -times to $4.4-\mathrm{kg} / \mathrm{s}$. Further, in order to not increase the head requirement, additional flow area would be required for the cooled-side of the recuperator and the cooler. With the input variable applied to the opposite side of the recuperator from the control variable, a relatively slow response is predicted. The advantages are a reduced peak temperature into the recuperator and the low temperature of the control valve. 


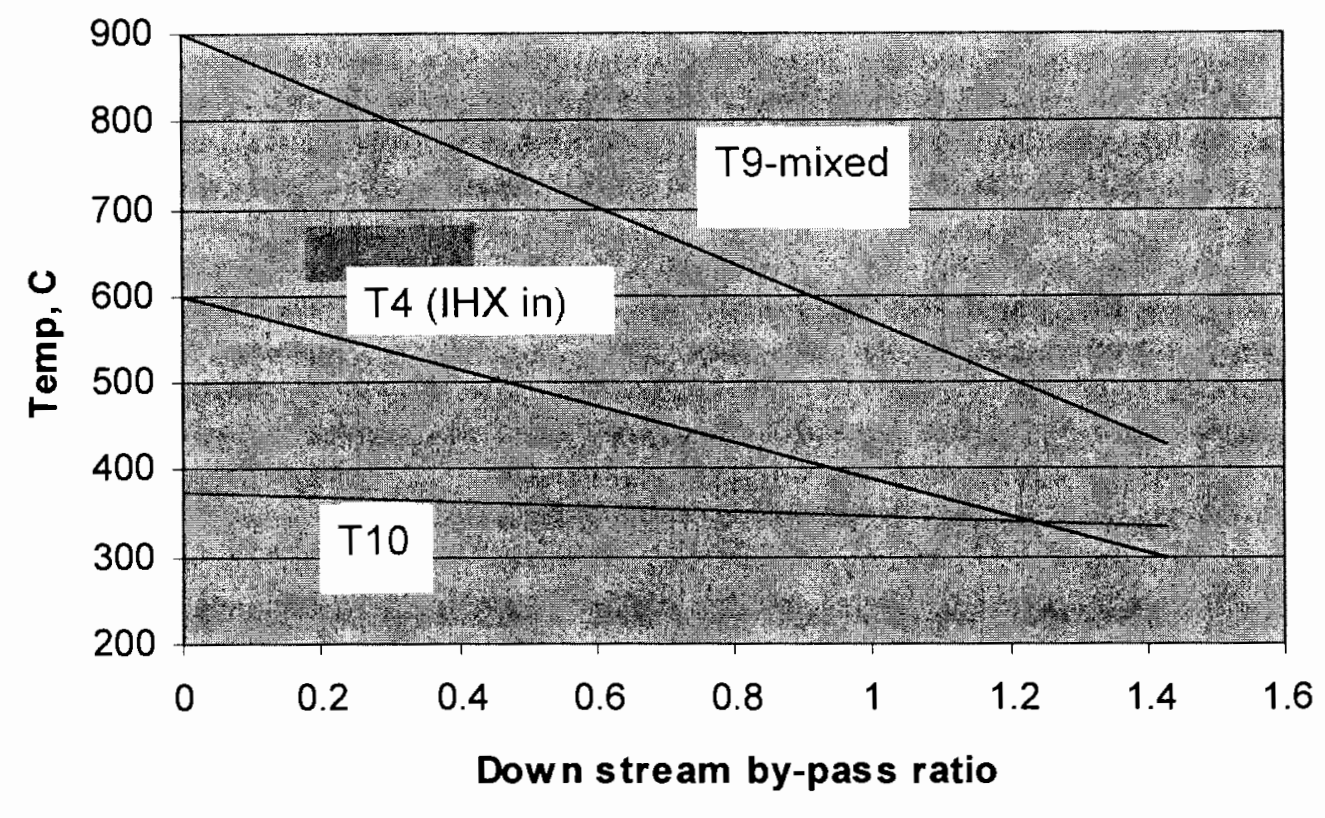

Figure 42. Graph showing the influence of downstream bypass flow on secondary gas temperatures.

4.2.2.2.3 Upstream-Bypass Temperature Control - The upstream bypass diverts a portion of the cold-circulator flow discharge gas around the secondary recuperator, where it mixes with the parallel stream of gas heated in the recuperator. This is shown in the figure inset of Table 20. Reducing the flow on one side of the recuperator creates a lower relative conductance and therefore higher temperature effectiveness on that side. This is not a strong function, however, and so a constant NTU (number of transfer units) assumption is used by observing that convection coefficients will be confined to a narrow range. The net effect, with a perfectly mixed flow, is shown in Figure 43 with the mix temperature declining faster with increased bypass than the recuperator discharge. Shunting $60 \%$ of the cold-blower discharge flow around the recuperator achieves the target mixed-out gas temperature of $300^{\circ} \mathrm{C}$ at the IHX inlet.

The upstream bypass strategy does not require excess blower capacity to achieve the target temperature; it has a strong positive response on the IHX inlet temperature, and it uses a relatively cold control valve with lower cost and higher inherent reliability. Less attractive features are higher thermal loading on the cooler between the recuperator and the circulator, and possible flow distribution anomalies and related thermo-mechanical strains associated with a lowered mass flow and attendant pressure loss on the heating side of the recuperator. The cooler's capability to take the added load is seen mainly as a sizing issue. Possible flow anomalies can be addressed by analysis and refinement. Overall, this option appears to be the best technical and economic balance of those analyzed. 


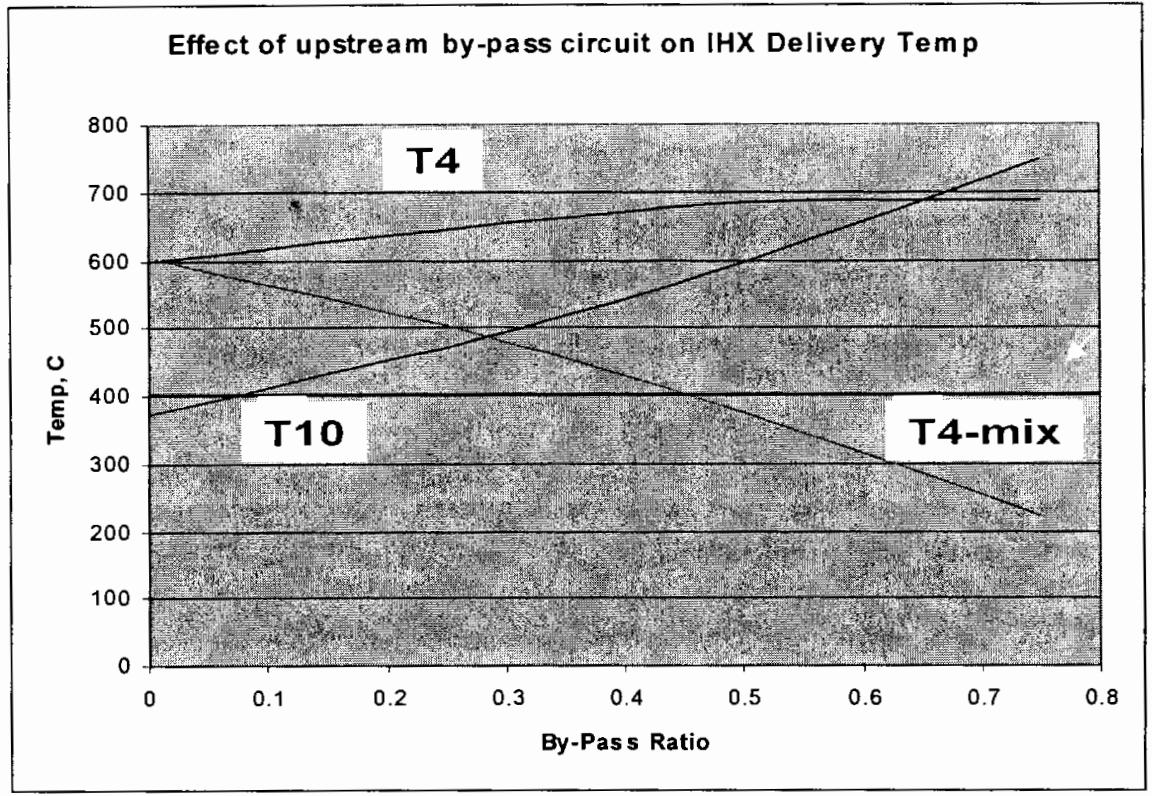

Figure 43. Graph showing the influence of upstream secondary recuperator bypass on IHX delivery temperatures. The intent of this control strategy is to permit IHX inlet temperature control between 300 and $600^{\circ} \mathrm{C}$.

4.2.2.2.4 Gas-Gap Recuperator - A gas-gap calorimeter is a well-developed method for controlling heat flux through a boundary separating two fluids. A gap, or annulus in the case of a tubular element, is filled with a gas mixture. Varying the composition of the mixture affects the bulk thermal conductivity. The common mixture of helium and argon enables a wide range of thermal conductivity, about 10:1. Alternatively, helium and nitrogen may be mixed to yield a 5.5:1 variation in gap conductance.

The principle of a gas-gap calorimeter has been extended to the secondary recuperator to provide the required thermal control. A gas-gap recuperator, composed of coaxial tubes, separated by a variable thermal-conductivity gas mixture, is perhaps the least conventional concept analyzed for secondary-loop temperature control. By adjusting the mixture of helium and argon in the annular gap around the tube, the thermal effectiveness of the recuperator may be changed from $65 \%$ to $28 \%$, thereby allowing the IHX return temperature to be varied from the maximum of 600 to the minimum of $300^{\circ} \mathrm{C}$. This concept is shown schematically in Figure 44. The performance analysis is summarized in Table 21.

The design evaluated uses finned tubes in cross-flow for the outer tube and a plain inner tube. With an array of 120 tubes, each 3,353-millimeters long, and with 12 cross-flow passes, thermal effectiveness ranging from 27.7 to $64.9 \%$ can be achieved. The gas-gap recuperator is significantly larger by nature of the additional thermal impedance. The analysis results summarized in Table 21 show the roughly doubling effect on heat exchanger size required to employ the gas-gap.

The gas-gap recuperator is a viable option for the secondary recuperator for the IHX test loop. It has desirable performance characteristics and promises to respond quickly to input, as thermal mass has less influence on response. It also avoids bypass loops and valving. It is, however, a non-standard design and thus is seen as a backup to the upstream bypass option. 


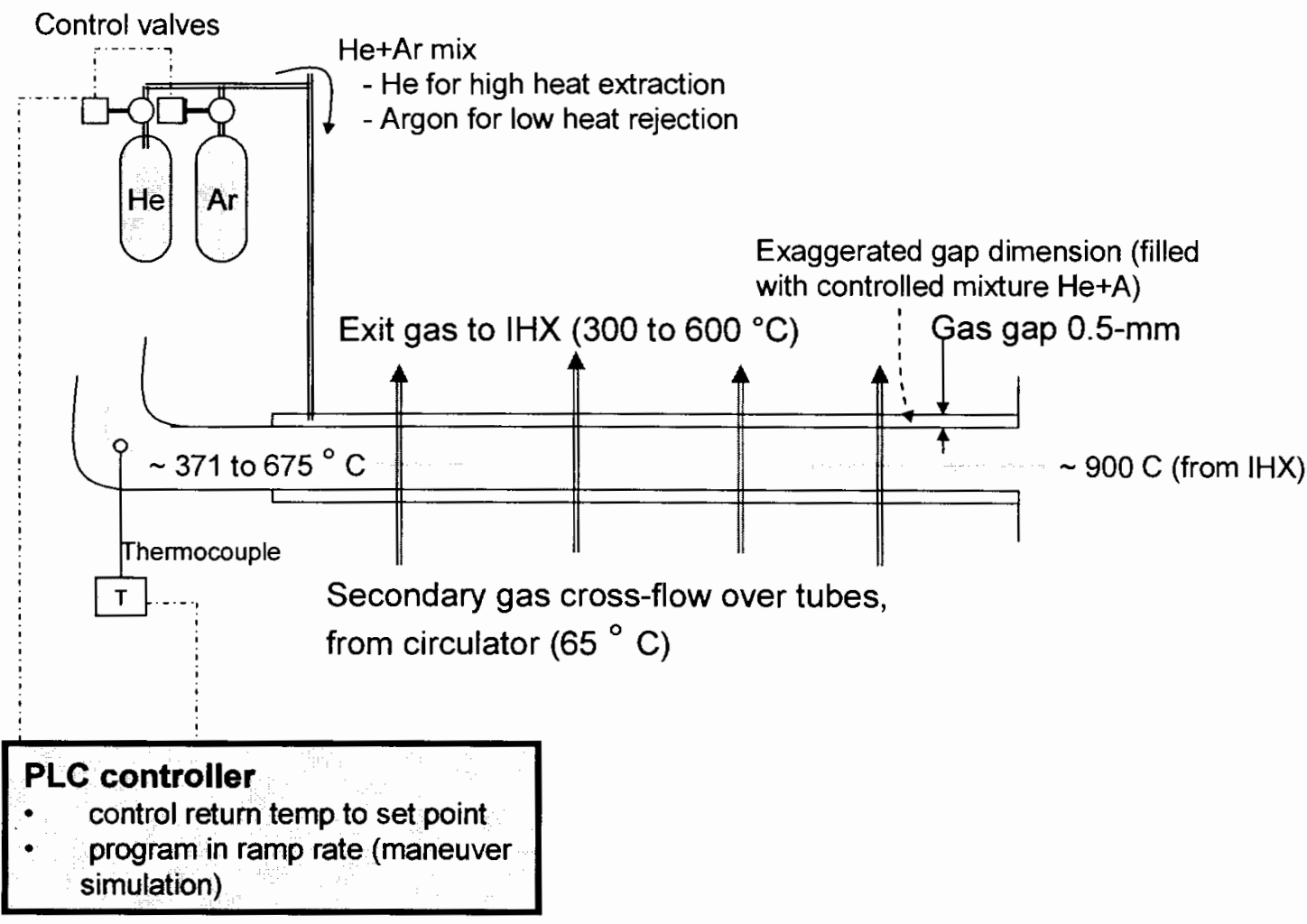

Figure 44. Schematic diagram showing a gas-gap recuperator concept. 
Table 21. Comparison of a standard crossflow tube-shell recuperator with pure-argon and pure-helium gas-gap recuperator configurations.

\begin{tabular}{|l|c|c|c|c|}
\hline & Units & Standard Crossflow & $\begin{array}{c}\text { Gas-gap } \\
\text { (He) }\end{array}$ & $\begin{array}{c}\text { Gas-gap } \\
\text { (Ar) }\end{array}$ \\
\hline Massflow & $\mathrm{kg} / \mathrm{s}$ & 2.1 & 2.1 & 2.1 \\
\hline $\mathrm{T}-$ from IHX (external) & ${ }^{\circ} \mathrm{C}$ & 900 & 900 & 900 \\
\hline Temperature external inlet & ${ }^{\circ} \mathrm{C}$ & 65 & 65 & 65 \\
\hline Pressure & $\mathrm{MPa}$ & 5.5 & 5.5 & 5.5 \\
\hline Tube ID & $\mathrm{mm}$ & 9.525 & 9.525 & 9.525 \\
\hline Number of tubes & & 110 & 120 & 120 \\
\hline Tube Length & $\mathrm{mm}$ & 1829 & 3353 & 3353 \\
\hline Fin type & & $\mathrm{CF} 7.34$ & $\mathrm{CF} 7.34$ & $\mathrm{CF7.34}$ \\
\hline Array Dia & $\mathrm{mm}$ & 330 & 330 & 330 \\
\hline $\mathrm{N}_{\text {passes }}$ & & 8 & 12 & 12 \\
\hline$\varepsilon_{\text {multipass }}$ & {$[\%]$} & 63.8 & 64.9 & 27.7 \\
\hline $\mathrm{P}_{\text {loss_internal }}$ & {$[\%]$} & 1.90 & 1.99 & 2.14 \\
\hline $\mathrm{P}_{\text {loss_external }}$ & $\%$ & 0.03 & 0.04 & 0.04 \\
\hline $\mathrm{T}_{\text {intermal_outlet }}$ & ${ }^{\circ} \mathrm{C}$ & 383 & 371 & 675 \\
\hline $\mathrm{T}_{\text {IHX delivery }}$ & ${ }^{\circ} \mathrm{C}$ & 598 & 607 & 296 \\
\hline
\end{tabular}

4.2.2.2.5 Secondary Recuperator Mechanical Design - The preliminary design for the secondary recuperator has selected the tube-shell configuration as the most reliable. Since the required thermal effectiveness is quite low, $<65 \%$, the design's lack of compactness and high weight are not significant drawbacks. Also, since the tube and shell fluids are the same, leakage between the two sides is inconsequential. Based upon the reported performance analysis, the required $1203 / 8$-inch tubes are connected to a tube sheet at both ends. A series of axial baffles partitions the axial length, forcing the shell flow through a multi-cross flow path. This geometry is shown in Figures 45 to 48 . The mechanical design employs ample insulation to isolate the $900^{\circ} \mathrm{C}$ incoming gas from the pressure vessel and piping boundaries. Inside the inlet header plenum, the hot gas is exposed to a floating sheet metal liner and the multiple ports of the tube sheet. The tube sheet is free to expand, employing a simple pressure activated sliding gasket seal to minimize leakage of the cooler shell fluid into the plenum. The elevated shell fluid pressure provides clamping force on the gasket, providing adequate sealing of the two fluid paths. The cooler end tube sheet is configured in the same manner, while incorporating a bellows expansion joint to take-up axial growth. 


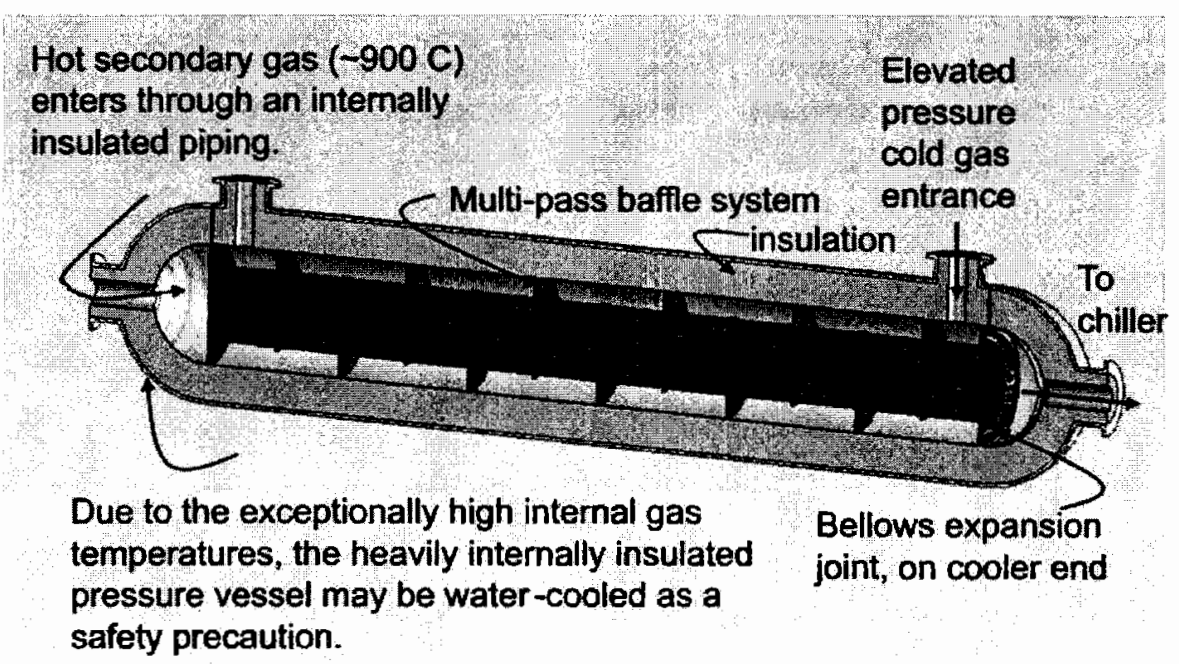

Figure 45 . The secondary recuperator is a rugged, tube-shell, multi-pass, cross-flow design.

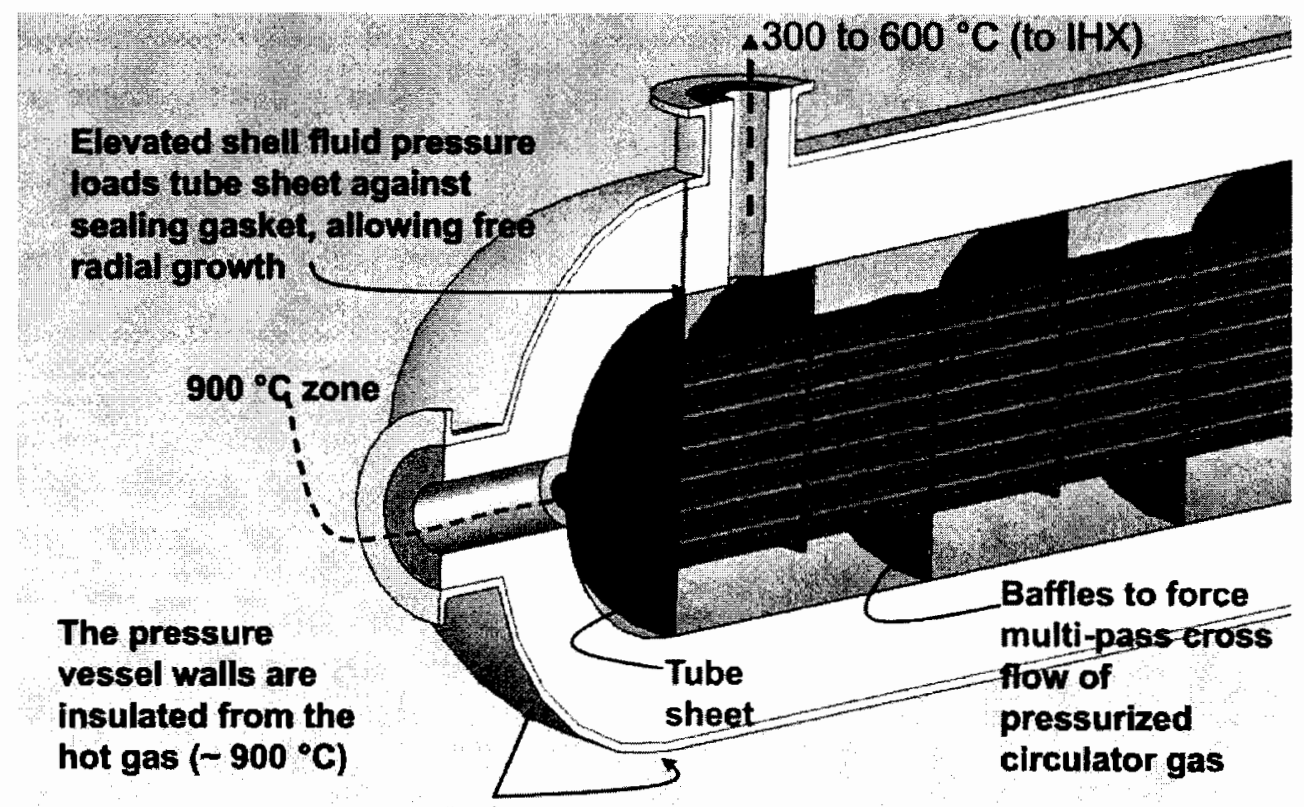

This hot end of the vessel may be water cooled as a precaution

Figure 46. Detail of secondary recuperator designed for $900^{\circ} \mathrm{C}$ gas inlet and to accommodate large differential strains. 


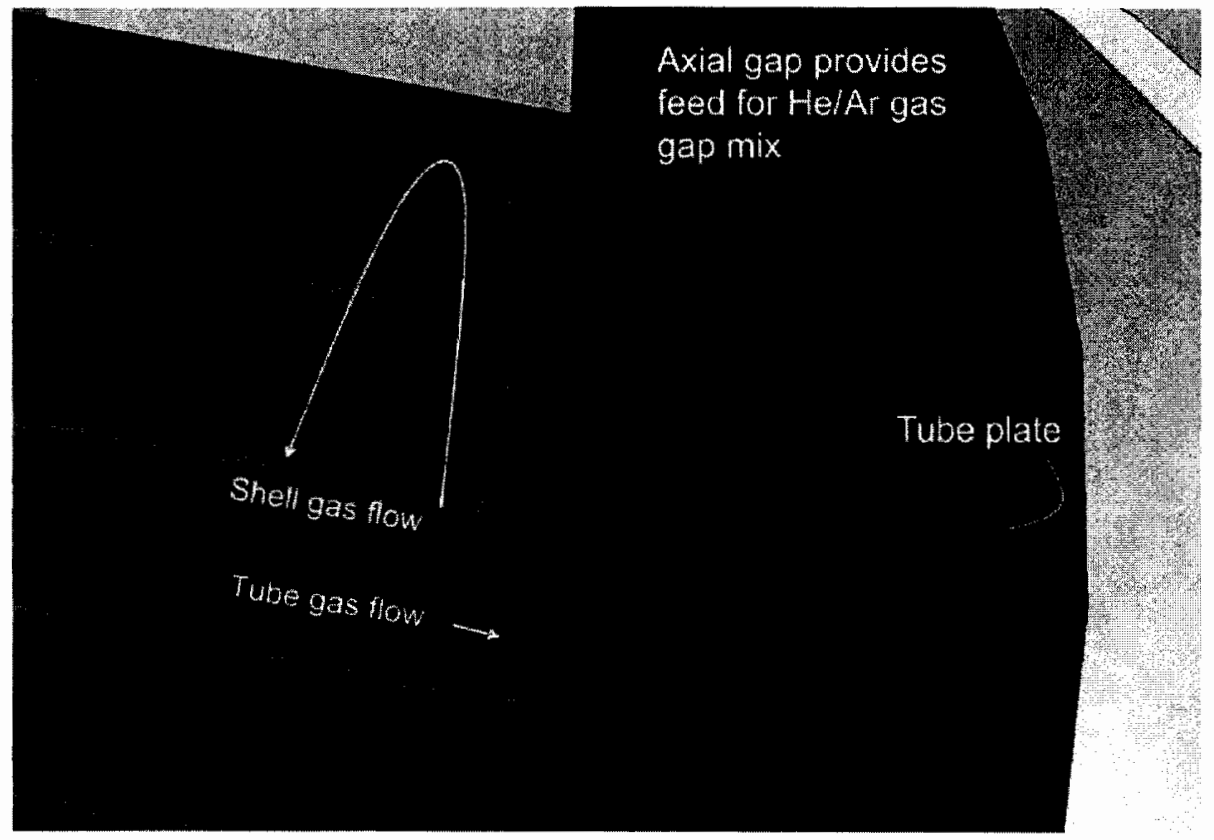

Figure 47. The tubes terminate in a tube plate to form the end bell manifold. The tube sheet is modified to form the manifold for the gas-gap mixture of He/Ar. The diameter is 0.8 -meter (including 150 millimeters of insulation). The nominal length is 3.5 meters.

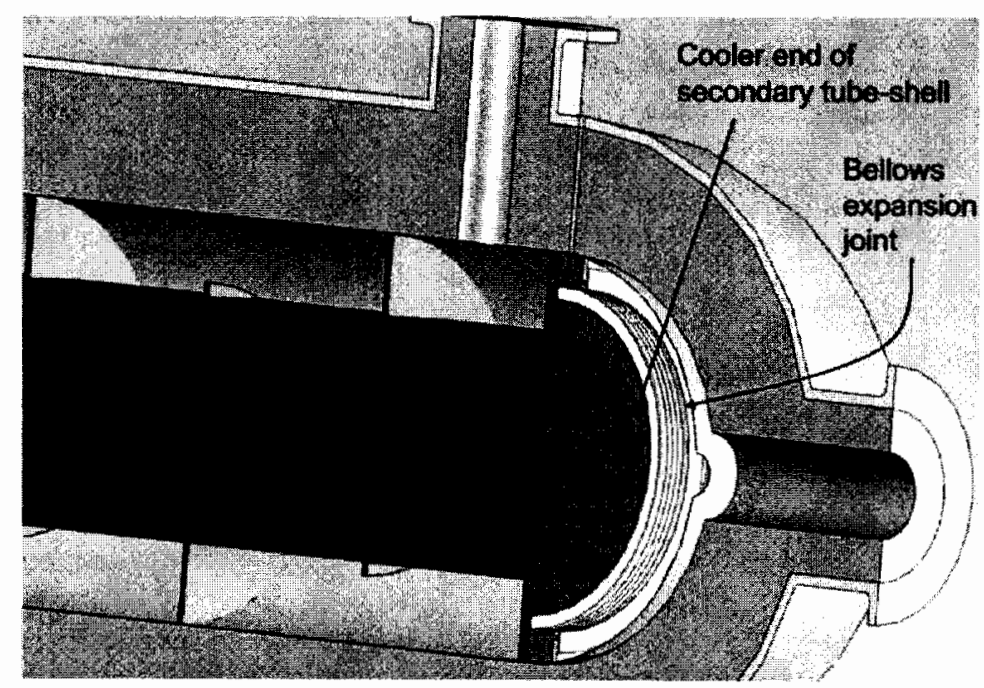

Figure 48. The high-temperature secondary recuperator incorporates a bellows expansion joint on the cold end. 


\subsection{Secondary Recuperator Summary - Table}

Table 22. Summary comparison of secondary recuperator options.

\begin{tabular}{|l|l|l|}
\hline \multicolumn{1}{|c|}{ Design Option } & \multicolumn{1}{|c|}{ Advantages } & \multicolumn{1}{c|}{ Liabilities } \\
\hline $\begin{array}{l}\text { Option-1, Down stream } \\
\text { tempid heat exchanger (high }\end{array}$ & \multicolumn{1}{|c|}{$\begin{array}{l}\text { a) Likely boiling and corrosion due to } \\
\text { water cooling } 900^{\circ} \mathrm{C} \text { gas. } \\
\text { b) Insufficient turndown with water } \\
\text { flow variation } \\
\text { c) Increases size of recuperator to meet } \\
\text { temperature requirements }\end{array}$} \\
\hline $\begin{array}{l}\text { Option-2, Down stream by- } \\
\text { pass (hot side dilution) }\end{array}$ & $\begin{array}{l}\text { a) Reduced temp recup in } \\
\text { b) Cold control valve }\end{array}$ & $\begin{array}{l}\text { a) Excess circulator capacity (240\%) to } \\
\text { meet target range (\$200K to \$600K). } \\
\text { b) Recup is way over flow and DP/P } \\
\text { spec and must be enlarged. } \\
\text { c) Large thermal inertia between DOF } \\
\text { and control parameter. }\end{array}$ \\
\hline $\begin{array}{l}\text { Option-3, Upstream by- } \\
\text { pass (cold side) }\end{array}$ & $\begin{array}{l}\text { a) Doesn't require excess } \\
\text { circulator capacity } \\
\text { b) Positive response of input } \\
\text { on control parameter } \\
\text { c) Cold control valve }\end{array}$ & $\begin{array}{l}\text { a) Temps on heat exchanger become } \\
\text { slightly more challenging in part load } \\
\text { b) Low cooling flow to recup may } \\
\text { result in local over-heating/ problems } \\
\text { not yet foreseen }\end{array}$ \\
\hline $\begin{array}{l}\text { Option-4, Gas-gap thermal } \\
\text { control recuperator } \\
\text { construction }\end{array}$ & $\begin{array}{l}\text { a) Wide turndown range } \\
\text { b) Fast response } \\
\text { c) Avoids bypass loop } \\
\text { d) Smooth transition with } \\
\text { fine temp control }\end{array}$ & $\begin{array}{l}\text { a) Non-standard technology } \\
\text { b) Challenging headering for control- } \\
\text { gas }\end{array}$ \\
\hline
\end{tabular}

4.2.2.3 Secondary Circulator. The subject of gas circulator compressors for low molecular weight gas has been analyzed in Section 4.2.1.2. For secondary gas mixtures, such as the He- $\mathrm{N}_{2}$, the compressor technology will be similar. Circulators for fluids, other than $\mathrm{He}$ and $\mathrm{He}-\mathrm{N}_{2}$ mixtures, have not been analyzed.

\subsubsection{HTGL Facility Support Systems}

The equipment described in this section is common or shared by both primary and secondary loops.

4.2.3.1 Heat Rejection - Fan Cooled Radiator. The fan-cooled radiator and associated glycol loops remove and dissipate heat rejected from the primary and secondary loops, the cooler, and gas-gap heat exchangers, as required to maintain circulator temperatures below $50^{\circ} \mathrm{C}$. Wet and dry approaches have been considered for removing heat from the primary and secondary sides of the test loop. Given the maintenance costs associated with maintaining a wet cooling tower against freezing and fouling, a dry, fan-cooled radiator approach has been selected.

The radiator inlet conditions are based on outlet conditions from the primary and secondary coolers. Radiator outlet conditions are based on a $30^{\circ} \mathrm{C}$ day, and a barometric pressure of 24.8 millimeters-Hg (Idaho Falls). A glycol/water mixture of $38 \%$ has also been selected, with a freeze 
temperature of below $-25^{\circ} \mathrm{C}$. The parameters used to obtain preliminary radiator sizing and cost are given in Table 18 and Table 19.

A quotation has been obtained from SPX Cooling Technologies for a bundled, air-cooled heat exchanger that combines primary and secondary glycol loops into a single unit. The estimated cost is $\$ 88,100$. As this equipment represents no engineering risk and is of competitive cost, further work in this task has been deferred. Alternative arrangements and redundancy will be analyzed in the later phase of this program. Cost and installation information is provided in Appendix M.

4.2.3.2 Ventilation System. The HTGL piping and components introduce a significant heat load on the test facility. The two principal heat source categories are as follows:

1. Incidental heat loss from test loop components and vessels will elevate the room temperature, particularly near the ceiling due to buoyant convection. It is desirable to remove this heat through a drafting duct at or near the ceiling.

2. Hot piping (supply and return) running in floor trenches will transfer heat through radiation and convection to the trench airspace and the trench covers. In order to mitigate this heating effect, forced convective cooling is proposed, which will utilize the covered trenches as cooling air ducts.

Both removal systems could be powered by the same fan station, located at an outside wall adjacent to the building. A common duct trunk will be run through the wall into each room at ceiling elevation, with dampered vents for heat removal from near the ceiling. Additionally, vertical ducts will be dropped from the ceiling trunk in each test bay and connected to flanged pick-up points at the "exhaust ends" of the trenches. At the "inlet ends" of the trenches, floor grating will allow air to be drawn from the room, into the trenches, along the length of the covered trenches, and then up the vertical ducting to the main fan duct at the ceiling. Figure 49 shows the general layout and airflow.

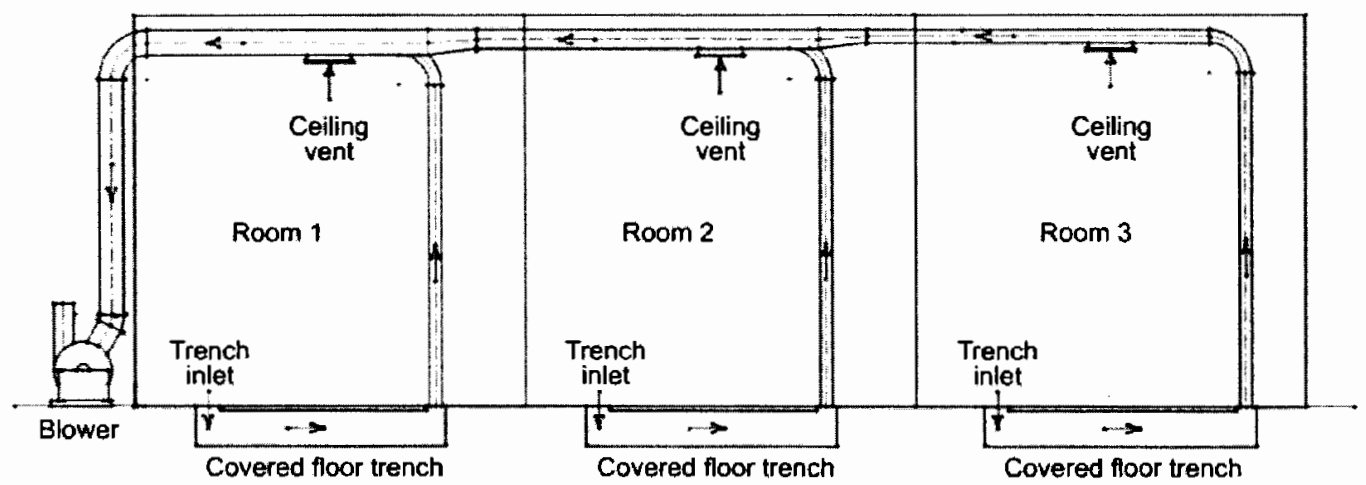

Figure 49. Test bay ventilation draws heated air from ceiling and from ducting, which draws from trenches containing warm gas pipes.

System balancing would be achieved through manually operated dampers, giving capability to adjust the amount of air being drawn from ceiling or trench in each room, and also from room to room. To provide redundancy, the fan station should contain three fan units, all operating with a minimum of $33 \%$ excess capacity. A simple manually operated duct gate would allow changeover to the redundant blower in the event of a primary blower failure. 


\subsubsection{Helium Handling.}

4.2.3.3.1 Gas Inventory Compressor - A compressor in both the primary and secondary loops is prescribed for managing the gas inventories. Though one helium unit may serve both gas systems, system isolation and flexibility has been favored over economics in this case. The primary side compressor, as placed in the system P\&ID is shown below in Figure 50; the secondary system is configured similarly. The compressors perform the following functions:

- $\quad$ Filling of on-site gas storage vessels from a delivery vessel

- Charging the test loop

- Discharging the test loop

- Re-pressurization of gas after purification

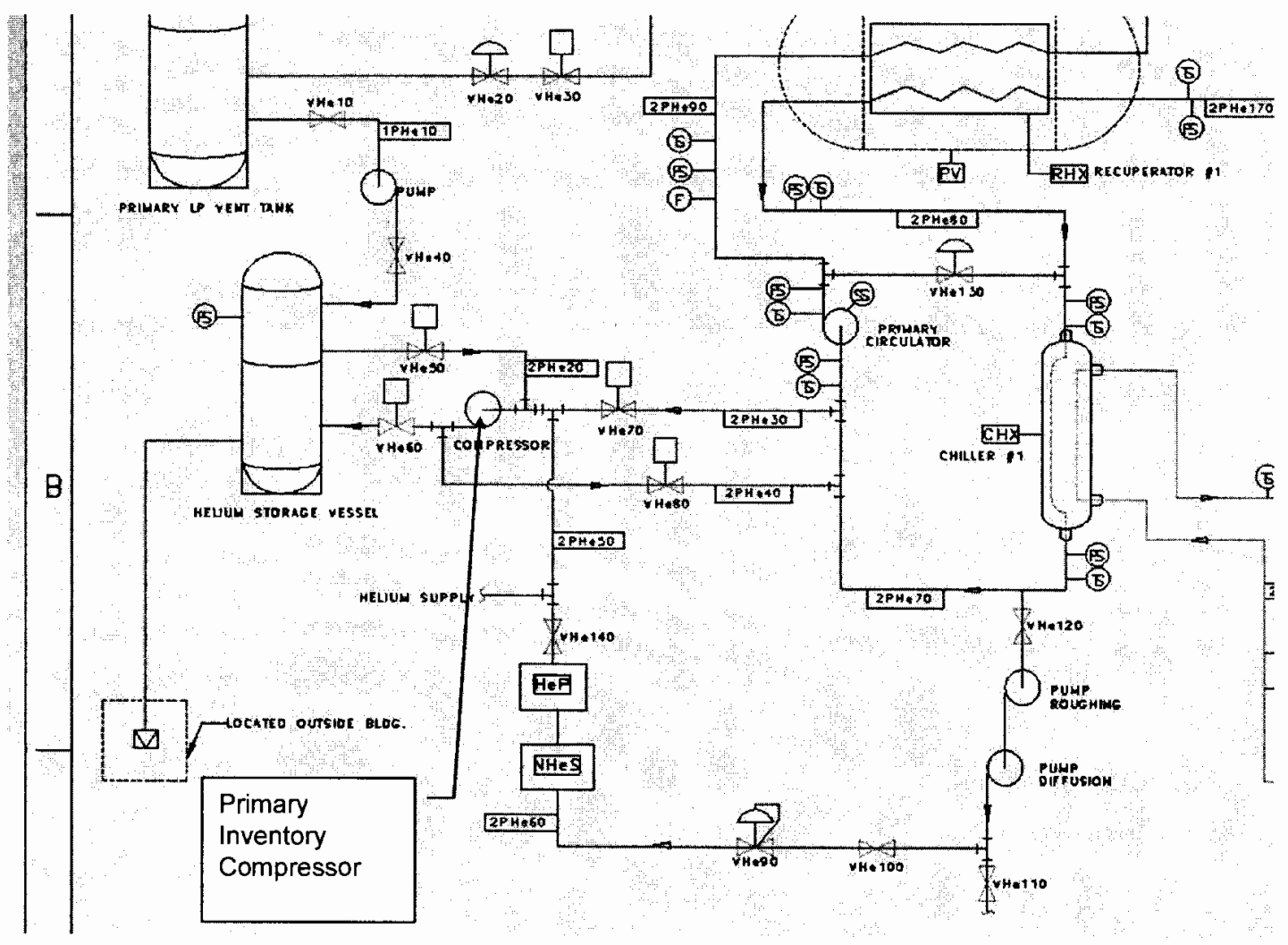

Figure 50. Helium Inventory Management Compressor.

Table 23 provides the specifications used to obtain sizing and price information for the gas inventory management compressors. 
Table 23. Specifications for gas inventory management.

\begin{tabular}{|l|c|}
\hline \multicolumn{1}{|c|}{ Parameter } & Value \\
\hline Max. compressor inlet temperature & $40^{\circ} \mathrm{C}$ \\
\hline Pump inlet pressure (regulated) & 1 -bar \\
\hline Max. required pressure & $17-\mathrm{MPa}$ \\
\hline Compression rate $^{\mathrm{b}}$ & $10.3-\mathrm{m}^{3} / \mathrm{min}$ for a total charge time $\sim 3$ hours \\
\hline
\end{tabular}

A budgetary quotation obtained from Norwalk Compressors is presented below in Table 24. A new smaller model, capable of charging the system in about six hours, is estimated at $\$ 210 \mathrm{~K}$. Refurbished machines are available for roughly $30 \%$ lower cost.

Table 24. Gas inventory compressor, budgetary pricing.

\begin{tabular}{|l|c|c|}
\hline \multicolumn{1}{|c|}{ Description } & $\begin{array}{c}\text { Compression Rate } \\
\left(\mathrm{m}^{3} / \mathrm{min}\right)\end{array}$ & Cost $(\$)$ \\
\hline TDR-S5T, new, oil lubrication & 10.3 & 300,000 \\
\hline TDR-S5T, used, oil lubrication & 10.3 & 210,000 \\
\hline Unit two sizes smaller than TDR-S5T, new, oil lubrication & 5.1 & 210,000 \\
\hline S5T -Oil-less lubrication, new & 10.3 & $>300,000$ \\
\hline
\end{tabular}

Reciprocating compressors from Norwalk require pressure regulation on the inlet side to approximately one bar. The oil-less machine also requires a pressure-regulated inlet, with a five-stage unit requiring an inlet pressure of 4-bar. The TDR-S5T has mass of 13,666-kilograms and has a power requirement of $149-\mathrm{KW}$. The service interval for the oil-lubricated machines is 6,000 -hours. The service interval for the oil-less machines is 2000 -hours.

A side view of the compressor is shown in Figure 51. Envelope dimensions for the unit are 7112 millimeters-long by 1905 -millimeters-wide by 2260 -millimeters tall. An additional 2,030-millimeters must be added to the right of the view below as a maintenance area.

\footnotetext{
${ }^{b}$ The compression rate specification is based on compression of one-half of the total gas inventory (65,000 SCF) to $17 \mathrm{MPa}$ in 3 hours time.
} 


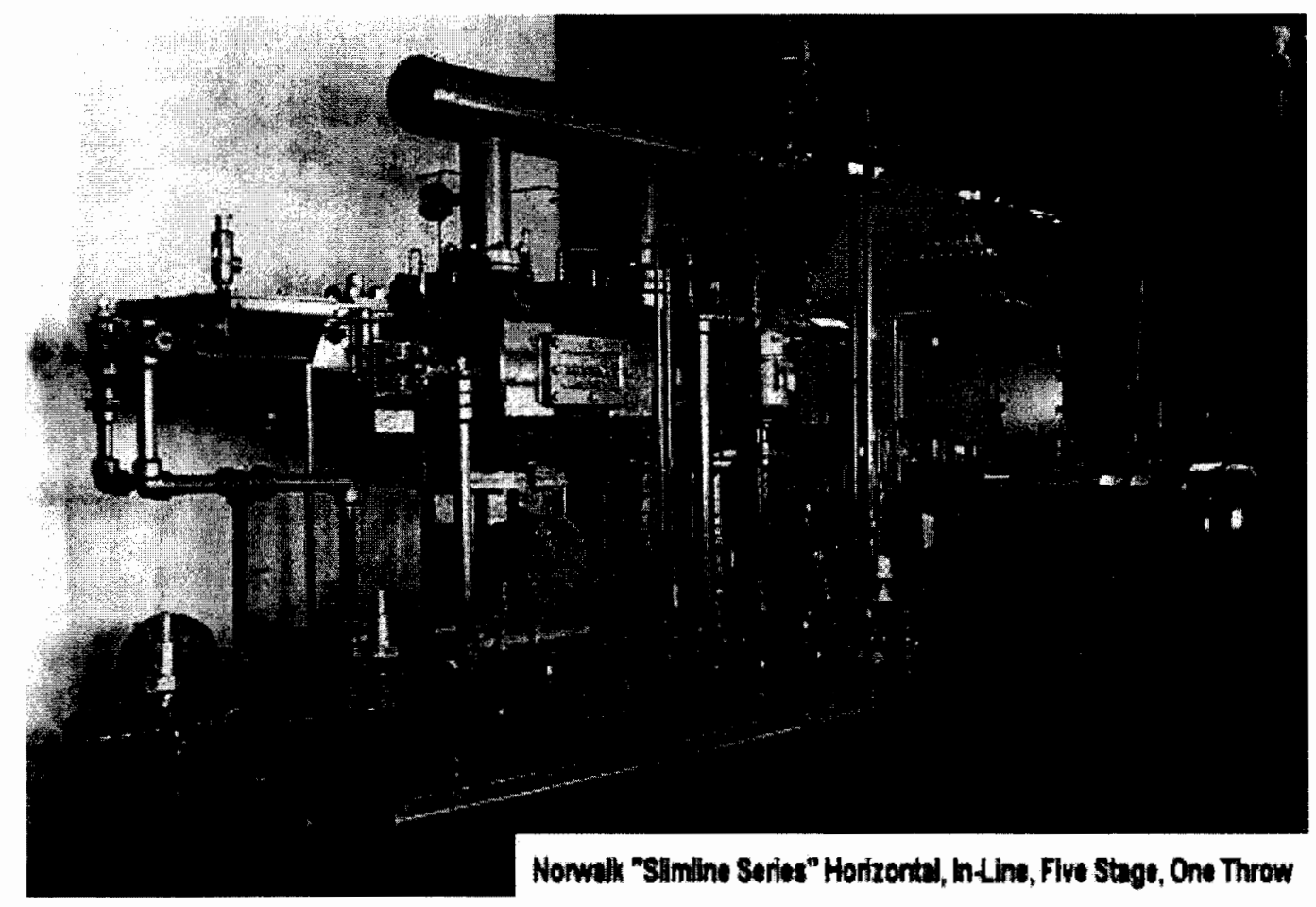

Figure 51. Side view of helium inventory management compressor.

4.2.3.3.2 Gas Inventory Storage Vessel and Vent Tank - Gas inventory is stored on-site, for both the primary and secondary loops, in a quantity to provide for test requirements, and for intentional and unintentional gas loss. An estimate of the total gas inventory requiring storage has been established based on system volume. The estimated total quantity requiring on-site storage is 3,709-standard-cubicmeters per loop. This amount represents twice that required to charge the loop for a test at the maximum conditions of $8-\mathrm{MPa}$ and $950^{\circ} \mathrm{C}$. The surplus gas is available to cover that lost during loop evacuation, unintentional leakage, and expansion of the test loop volume if additional test bays are added. Placement of the secondary loop storage vessel and vent tank in the P\&ID is shown in Figure 52. The layout for the primary loop is similar.

Gas inventory requirements are tabulated with assumptions used to determine an estimated inventory quantity in Table 25.

A budgetary quotation was obtained from FIBA Technologies in Millbury, Massachusetts, for two nine-tube skids as shown in Figure 53. The price for each skid is $\$ 200,000$. The tubes are designed to DOT standards and measure 559-millimeters outer-diameter by 12.1-meters-long. Each tube holds up to 425-standard-cubic-meters of gas at a storage pressure of 16.6-17.2-MPa. Custom piping is possible within individual skids allowing the tubes to also serve as vent tanks as shown on the P\&ID in Figure 52. 


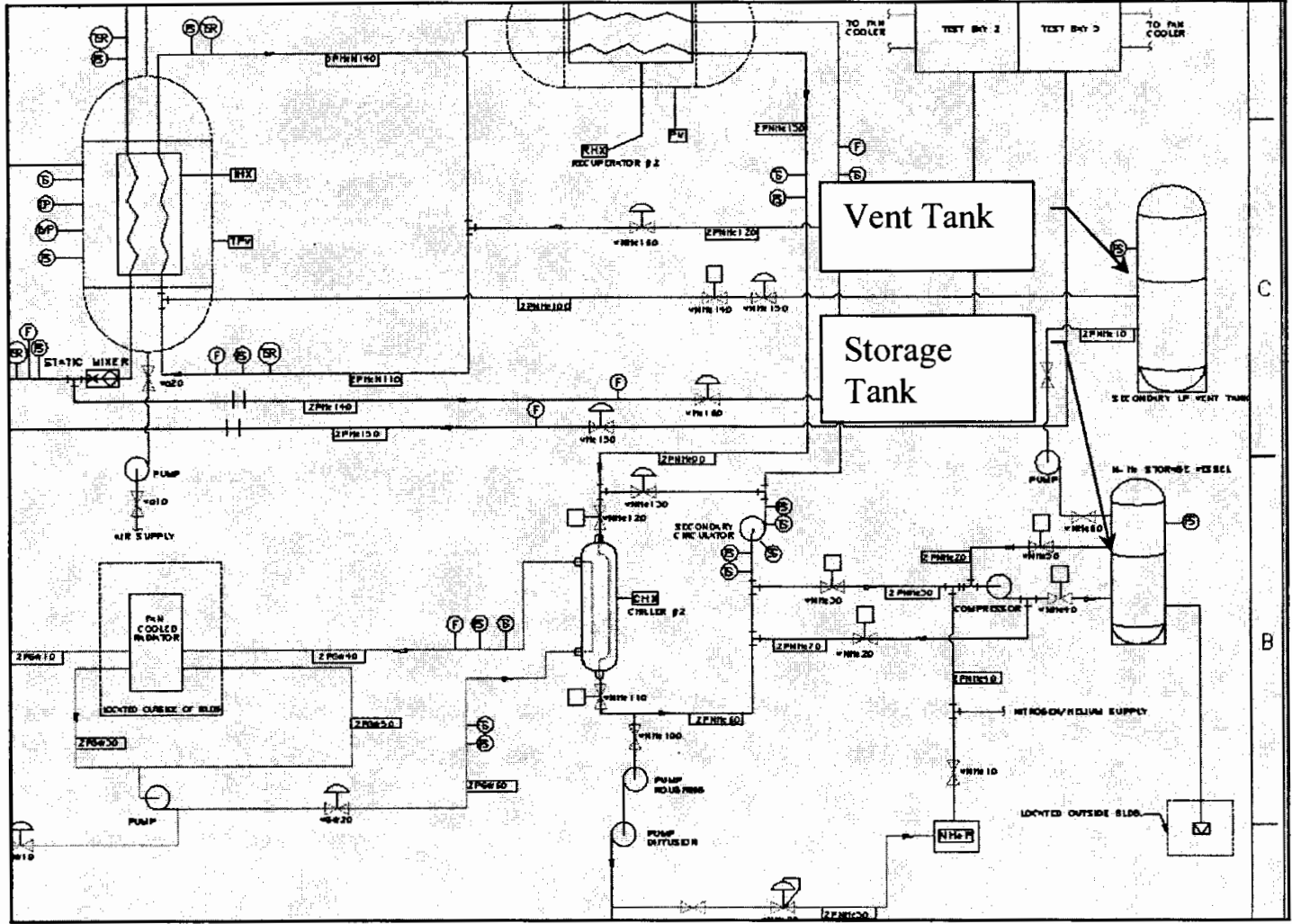

Figure 52. Gas inventory storage vessel and vent tank, secondary loop.

Table 25. Gas inventory quantity and assumptions.

\begin{tabular}{|l|l|c|c|c|c|}
\hline $\begin{array}{c}\text { Loop } \\
\text { Description }\end{array}$ & \multicolumn{1}{|c|}{ Inventory Description } & $\begin{array}{c}\text { Press. } \\
(\mathrm{MPa})\end{array}$ & $\begin{array}{c}\text { Temp. } \\
\left({ }^{\circ} \mathrm{C}\right)\end{array}$ & $\begin{array}{c}\text { Mass } \\
(\mathrm{kg})\end{array}$ & $\begin{array}{c}\text { Volume } \\
\left(\mathrm{m}^{3}\right)\end{array}$ \\
\hline \multirow{3}{*}{$\begin{array}{l}\text { Primary } \\
\text { (pure He) }\end{array}$} & Max. condition component test & 8.0 & 950 & 302 & 92 \\
\cline { 2 - 6 } & Total inventory & 0.1 & 20 & 605 & - \\
\cline { 2 - 6 } & Storage conditions & 17.2 & 20 & 605 & 22 \\
\hline \multirow{2}{*}{$\begin{array}{l}\text { Secondary } \\
\left(80-20 \mathrm{~N}_{2}-\mathrm{He}\right)\end{array}$} & Max. condition component test & 8.0 & 950 & 921 & 92 \\
\cline { 2 - 6 } & Total inventory & 1.0 & 20 & 1842 & - \\
\cline { 2 - 7 } & Storage conditions & 17.2 & 20 & 1843 & 22.1 \\
\hline $\begin{array}{l}\text { Assumptions: } \\
\text { Primary-side volume is three times the test vessel volume or } 3 \times 30.6 \mathrm{~m}^{3}=92.0 \mathrm{~m}^{3} \\
\text { Primary-side volume equals secondary-side volume } \\
\text { Total inventory is twice that required for max. condition component test }\end{array}$ & & & \\
\hline
\end{tabular}




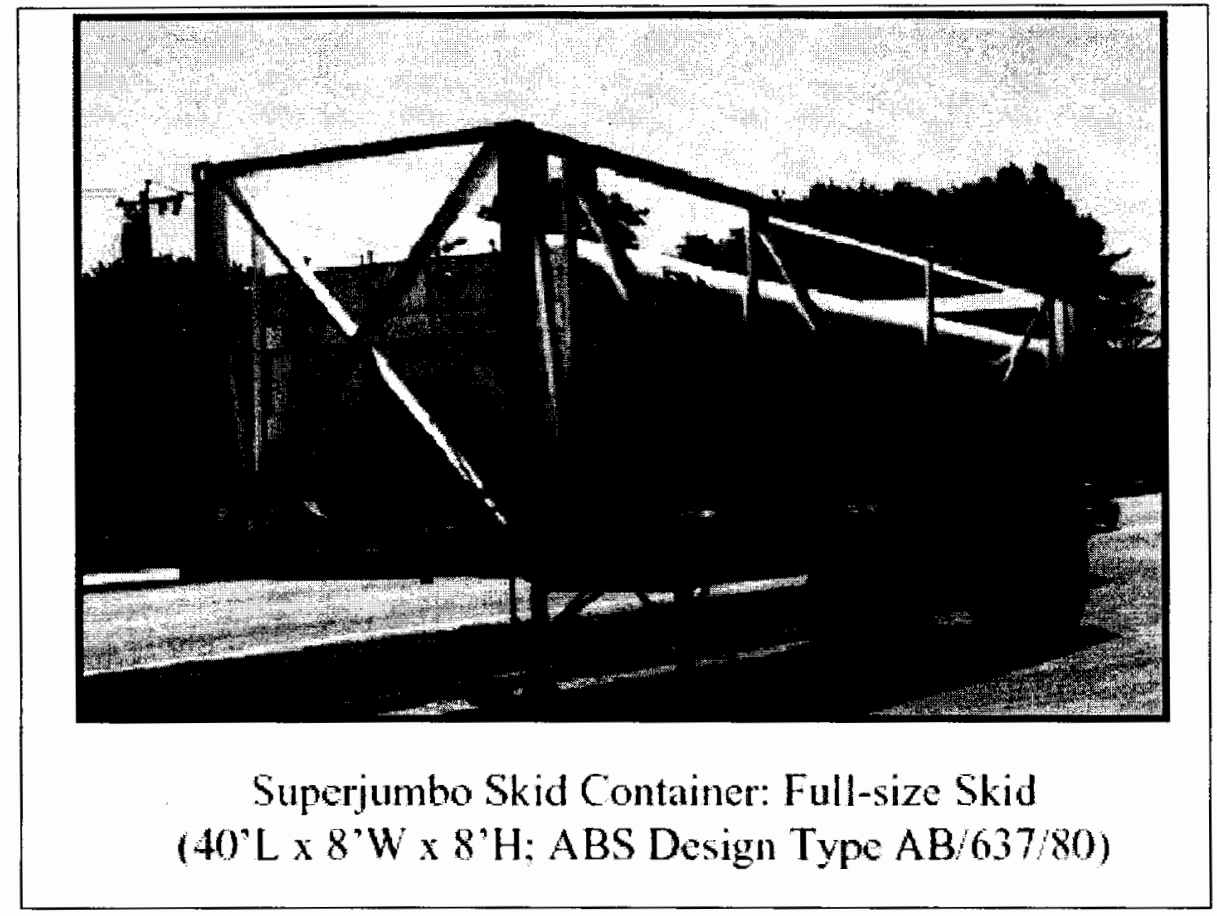

Figure 53. Gas inventory storage skid, offered by FIBA Technologies in Millbury, Massachusetts.

4.2.3.4 Gas Purification System - Contaminants are introduced as part of the gas inventory, from residual oils and other volatiles present at rig commissioning and introduced during multiple test setups and breakdowns. At this stage of the project, a specification for gas purity has not been decided. Consequently, the objective of this study is to gather relevant information to provide a basis for a future economic assessment.

Helium purity grades and associated contaminant amounts are shown below in Table 26; industrial grade equates to 'High Purity Grade' are shown in the far right. The impurities such as air, argon, nitrogen, water, methane, and particulates are expected in both the primary and secondary loops. Most of the free and volatile gases will be removed from the test loops by persistent hard pumping at $10^{-6}$ torr, provided by the vacuum pumps. Post installation cleaning and preparation procedures such as those employed by the vacuum brazing industry should be adopted. 
Table 26. Helium Purity and Contaminant Specification (Table obtained from Air Products literature).

\section{Helium Specifications}

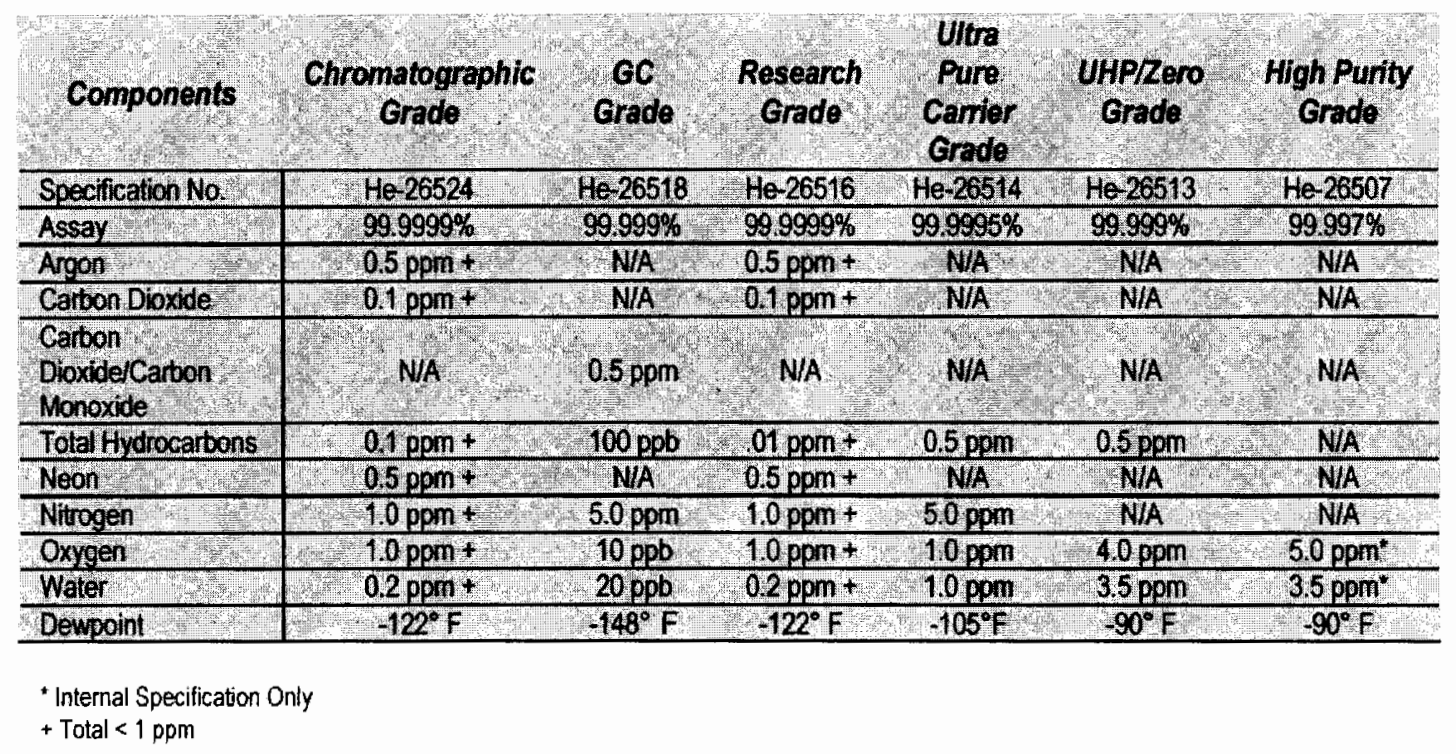

Two strategies for purifying gas inventories on-site have been explored. One approach entails replacing contaminated helium with each test, at an estimated cost of $\$ 13,000$ for the primary side and $\$ 6,100$ for the secondary side. This is consistent with a U.S. Geological Survey, which found that most high-volume helium applications in the U.S. do not recycle. Primary and secondary stream cleanliness specification is achieved by a combination of media-type filtration for particulates, and vacuum purging techniques similar to those employed in the vacuum brazing industry. The alternative approach involves the purchase or lease of helium purification equipment utilizing helium separation by diffusion through a membrane, or absorption of contaminants by a molecular sieve. Purchase of this equipment is anticipated in the neighborhood of $\$ 100,000$. Leasing this equipment is possible, and may be competitive with 'replacement' approach in a cost trade analysis.

Purification cannot be used to economically recover helium from the secondary $\mathrm{He}^{-} \mathrm{N}_{2}$ circuit. The high nitrogen content would quickly load the filtration membrane and sieve, returning only a small percentage of helium. It is recommended by a supplier that the most economical way to obtain the 80/20 nitrogen-helium mixture is to mix on-site.

Technical elements of the replacement approach include the following:

- The purity of industrial grade gas, delivered by the two suppliers cited, is $99.997 \%$ ( $30 \mathrm{ppm})$. As shown above in Table 26, higher purity levels are available. The purity obtainable from an on-site membrane and PSA purification system is $99.7 \%$ and $99.997 \%$ respectively.

- Clean all materials in contact with gas stream, using conventional cartridge-type filtration (10-40 $\mu \mathrm{m})$ in conjunction with standard gas drying equipment. 
- Vent used helium to atmosphere and purchase replacement helium charge with each test or when gas analysis shows unacceptable contaminant levels.

- Maintain a clean inventory of twice that required for test charge to cover unintentional leakage and test loop expansion.

Elements to the purification approach include:

- As shown on the conceptual P\&ID, the purification system is a series arrangement of equipment. An arrangement yielding maximum purity entails directing flow through a cartridge filter, a membrane system, and finally, a molecular sieve.

- The molecular-sieve system would also act as a helium-nitrogen separator to remove any nitrogen influx from the secondary side. The molecular-sieve system utilizes up to four pressure vessels requiring cold inlet flow regulated to $690-\mathrm{kPa}$.

- Bulk helium, obtained by suppliers from natural gas fields as one source, is purified cryogenically. Inclusion of this equipment in the HTGL requires further investigation of equipment suppliers and cost.

- Helium filtration systems, on similar volume high-temperature helium test facilities, indicate that filtration rates of $I 5$ to $20 \mathrm{~kg} / \mathrm{hr}$ are sufficient. ${ }^{28}$ The system employed is a low temperature absorption system similar to that described above. At this rate, the primary side helium charge would be filtered in approximately 20 hours.

4.2.3.4.1 Helium Purification Equipment and Methods - On-site purification of helium, to high degree of purity, can be accomplished with either a pressure swing adsorption (PSA) purification system or a cryogenic bed system. Depending on the initial purity, both systems can be operated in conjunction with a particulate filter and a membrane filter.

Cryogenic separators utilize an adsorption bed sustained at temperatures appropriate to separate impurities. Most of the gases in Table 26 and likely contaminants of concern are condensed at nominally $70^{\circ} \mathrm{K}$, just below the boiling point of nitrogen. Like the PSA system, the bed must be operated in a periodic manner to purge the system. Elevating the bed temperature is effective in purging accumulated contaminants. A recuperator or regenerator is typically incorporated into the system to conserve energy.

In the PSA system, the helium is purified by selective adsorption of contaminants in a molecular sieve. Helium is subsequently separated from contaminants and the adsorptive bed through a co-current depressurization process. Contaminants are removed from the bed by counter-current depressurization. A schematic of a representative system is shown below in Figure 54. 

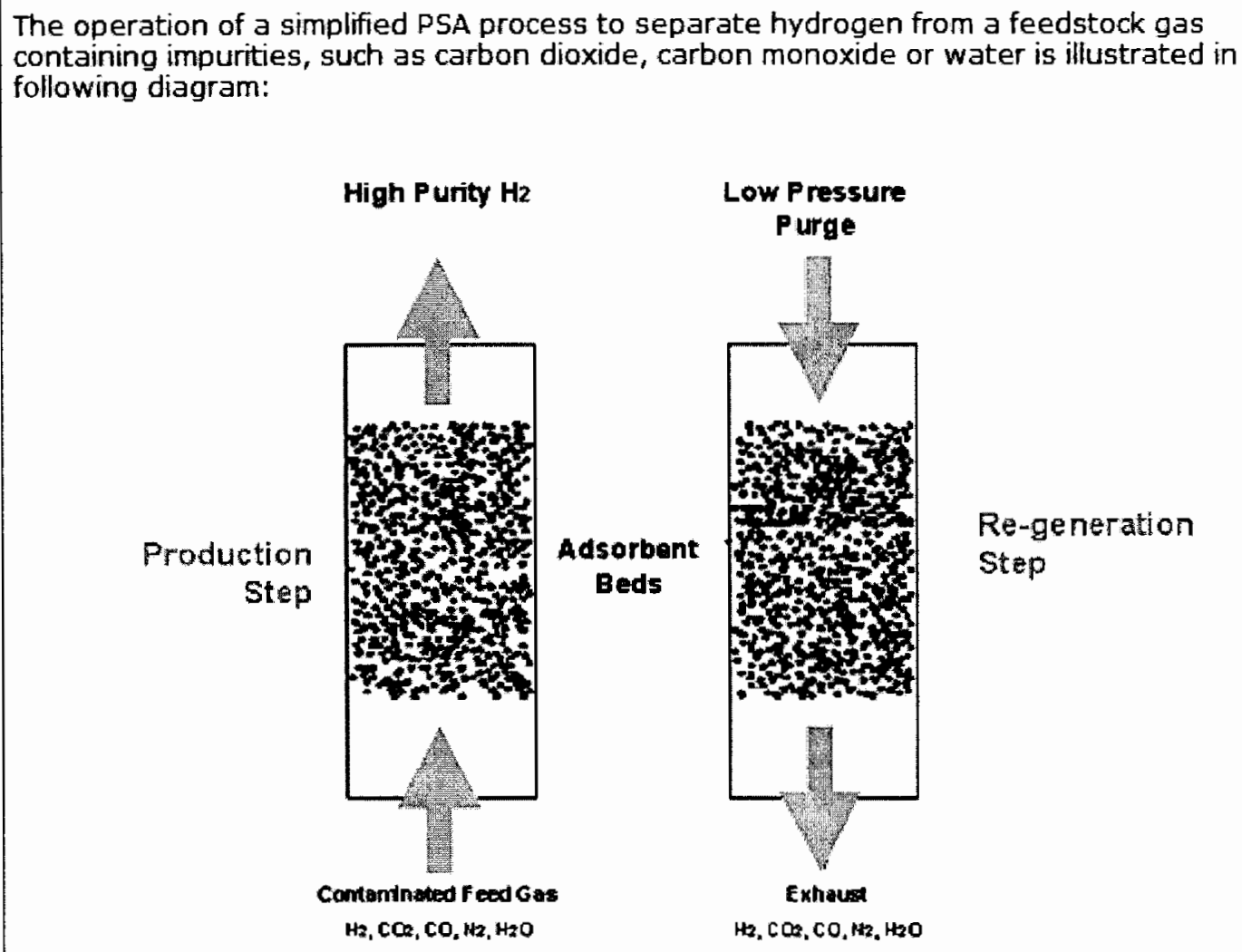

Figure 54. Simplified PSA process description, showing periodic process.

4.2.3.4.2 Component Specifications and Sizing Parameters - Parameters and assumptions used to for preliminary sizing and cost estimate are listed below:

1. Purification rate of 15 to $30 \mathrm{~kg} / \mathrm{hr}$

2. Purity level obtainable by system of 99.997 percent ( $30 \mathrm{ppm}$ total remaining impurities)

3. Helium stream requiring purification is 70 percent pure or greater

4. Gas volume requiring purification is one-half of total inventory or $65,000 \mathrm{SCF}$.

The use of a PSA system on the secondary-side is not likely economical if the nitrogen fraction is above about $30 \%$.

4.2.3.4.3 Vendor Identification, Budgetary Cost Estimate - A budgetary quote of $\$ 400-500 \mathrm{~K}$ was provided by Air Products, for a PSA system meeting the requirements listed above. This price included engineering, on-site gas analyses equipment, and assembly. Not covered by this price is ancillary equipment which primarily includes a compressor. Maintenance costs of $\$ 10-20 \mathrm{~K}$ are expected every two years. As an alternative, Praxair would consider leasing PSA equipment if a commitment to buy all gas from them was in place. 
The cryogenic system of an appropriate size was not located by the submission date of this report; however, this may present a more economical approach, particularly if there is some flexibility with the purification period and acceptable contaminant levels.

\subsubsection{Controls, Instrumentation, and Data Acquisition System}

An integrated controls and data center will be incorporated into the HTGL facility. While details of the experiments are lacking in many areas, the same principals of testing gas turbine recuperators to milstandards ${ }^{29}$ have been adopted for this assessment.

4.2.4.1 Controls. Endurance testing and finite element analysis validation are key features of the proposed HTGL. This testing requires accurate time-dependent control over the temperature, pressure, and flow of the test loop. The HTGL has been designed to perform prescribed maneuvers to simulate NGNP and other high-temperature reactor operating and safety scenarios. A maneuver is a portion of a cycle wherein all state points (temperature, pressure, flow) start and end at the same point. The maneuver portion of the cycle is typically initiated by one of four conditions:

- $\quad$ Start-up command

- Normal shut-down command

- Normal load-change command

- Failure or safety sequence trip, which includes

- $\quad$ Primary circulator fault/failure or

- $\quad$ Secondary fault (engine or $\mathrm{H}_{2}$-generation process shutdown).

For the purpose of characterizing cumulative damage, a cycle begins with a normal start sequence and ends with a series of shutdown sequences. Likewise, power maneuvers begin at a steady-state power setting, transition to a new load step, then return to the pressure, flow, and temperature of the original load. Simulated maneuvers for these scenarios have been formulated to serve as a basis for developing the HTGL specifications. To gauge the required response rates of the HTGL equipment, the two NGNP failure scenarios have been examined. The proposed "mock maneuvers" for a power generation cycle are shown in Appendix E.

The HTGL has been designed with a six-degree-of-freedom control system with a response rate capable of simulating the mock maneuvers. These six degrees of freedom are listed in Table 27.

The control system will employ nested control loops to operate the actuators and control devices described in Table 27. It should be noted that the proposed HTGL is equipped to ramp temperature and flow up or down, while gas pressure can only be ramped downward. Pressure increases are relatively slow and limited by the size of the gas charging system. At this point of the design, no NGNP maneuvers have been identified wherein either primary or secondary pressure must be ramped up. If needed this might be accommodated by an additional high-pressure gas storage vessel. 
Table 27. The HTGL's six degrees of freedom are used to simulate reactor and secondary process maneuvers of a future NGNP.

\begin{tabular}{|l|l|l|}
\hline & Degree of Freedom & \multicolumn{1}{c|}{ Control device } \\
\hline Primary Circuit & & \\
\hline DOF-1 & IHX inlet temperature & Electrical power regulation to the heater \\
\hline DOF-2 & IHX inlet pressure & Helium bleed-down valve, transferring inventory to storage vessels \\
\hline DOF-3 & mass flow & Circulator speed and/or bypass valve \\
\hline Secondary & & \\
\hline DOF-4 & IHX inlet temperature & Gas-gap fluid regulation and/or upstream by-pass \\
\hline DOF-5 & IHX inlet pressure & Gas bleed-down, transferring inventory to storage vessels \\
\hline DOF-6 & mass flow & Circulator speed and/or bypass valve \\
\hline
\end{tabular}

Each experiment planned for the HTGL will have a test plan that provides detailed algorithms for the maneuver simulations as described in Appendix E. The control system requires a coordinated control over the six degrees of freedom. A nested control-loop software architecture is proposed for both primary and secondary circuits. Typically, the faster responding feedback loop serves as the inner loop and the slower responding conditions form the outer control loops. Figure 55 illustrates this hierarchy, wherein the more rapid flow and pressure variables are checked and updated on a faster time scale, while gas temperature, subject to the thermal inertia of several heat exchangers, is updated at the slowest clock speed.

Software for each of the six control loops shown in Figure 55 may be written in a common process control software platform, such as LabView-RT. This software is easily configurable for the unique simulated maneuver algorithms for each test program. A simplified example of the flow chart is provided in Figure 56.

Secondary Nested Control Loops

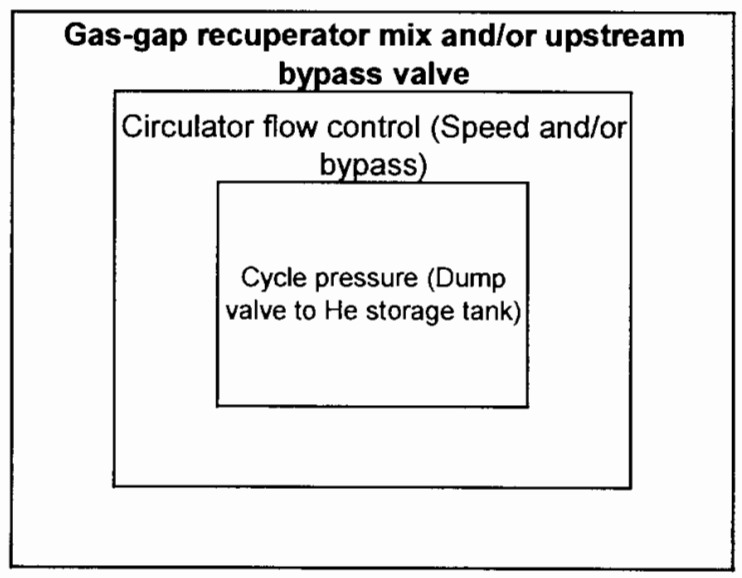

\section{Primary Nested Control Loops}

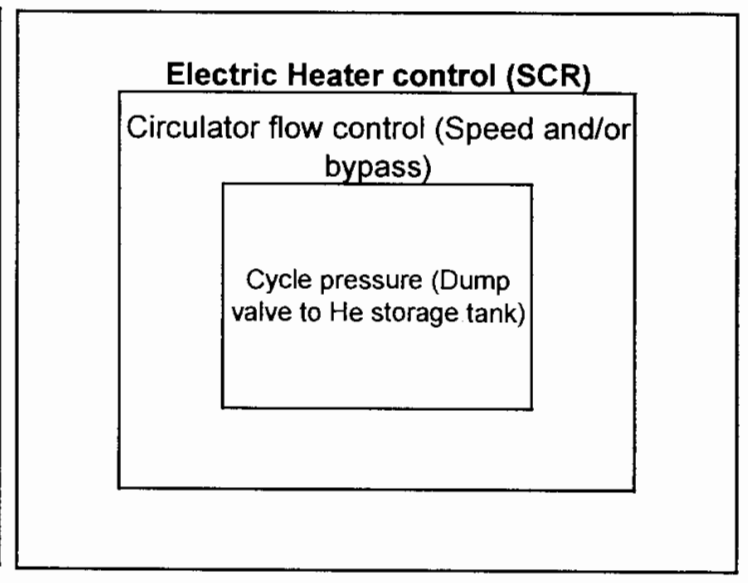

Figure 55. Illustration of nested control loops for the six control variables in the primary and secondary circuits. 


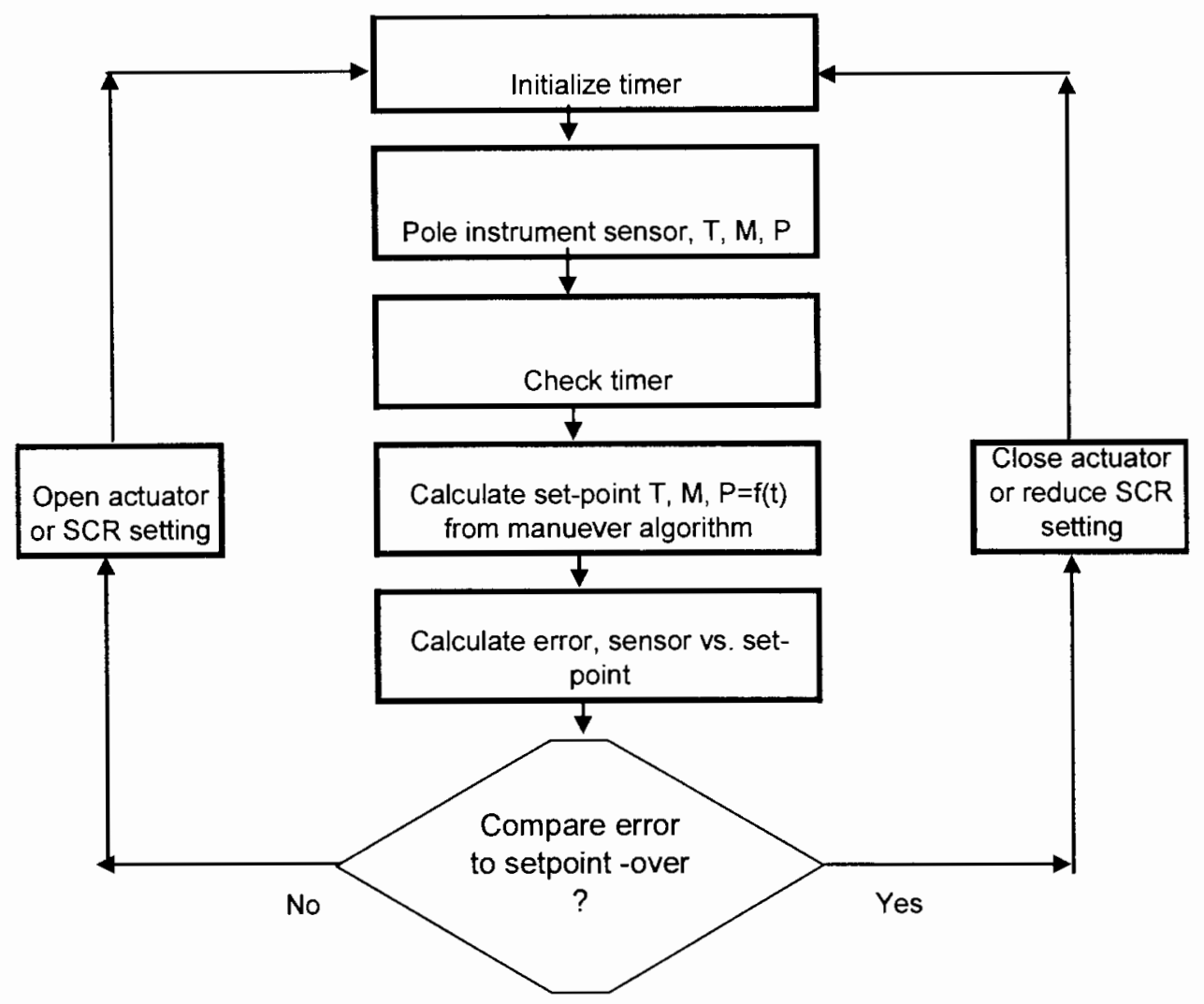

Figure 56. Simplified flow chart example for each of the six control variables.

4.2.4.2 Instrumentation. The instrumentation and data acquisition system of the HTGL is designed to receive steady-state performance data as well as transient data acquired during the transient simulations discussed in Section 4.1.2. Critical instrumentation has been identified on the Piping and Interface Diagram (PID), Section 4.1.3. The general categories of instrumentation are summarized in Table 28. The HTGL will incorporate a range of insertable probes and non-intrusive measurement techniques. The detailed list, indicated on the piping and instrument diagram (P\&ID), is provided in Appendix G. This partial list designates approximately 70 critical instrumentation locations. In addition to the instrumentation described in the PID, the HTGL will support calibration equipment for each sensor and device.

Three advanced real-time testing procedures are proposed for the INL HTGL, distinguishing this facility from other state-of-the-art heat exchanger test facilities:

1. Primary-secondary leakage measurements, employing radio isotope tracers. ${ }^{30}$

- $\quad$ IHX leak testing using gamma-emitting radioactive isotopes of xenon or krypton as inert tracer gases. These can be detected with great sensitivity through the system's walls while it is operating. This system enables the measurement of trace levels of leakage, typically from the higher-pressure primary gas to the secondary gas. 
2. Real-time high precision dimensional changes in the core (coordinate measurement).

- $\quad$ This equipment employs optical methods coupled through fiber optic ports to monitor the thermal growth of the test article during operation, including transient maneuvers.

Displacement measurement, referenced to a datum structure provides key information for FEA model validation and invaluable insights into the behavior of the heat exchanger.

3. Non-intrusive, high-resolution thermal imaging and monitoring of the IHX core.

- Thermal imaging equipment, employing fiber optic telemetry, can be arranged to view and monitor a wide area of the IHX test article, providing coverage and resolution not practical with thermocouples. Thermocouples will provide redundant validation of thermal images, as well as access to internal passages not accessible by line of sight.

Table 28. General instrument types to be employed in the HTGL.

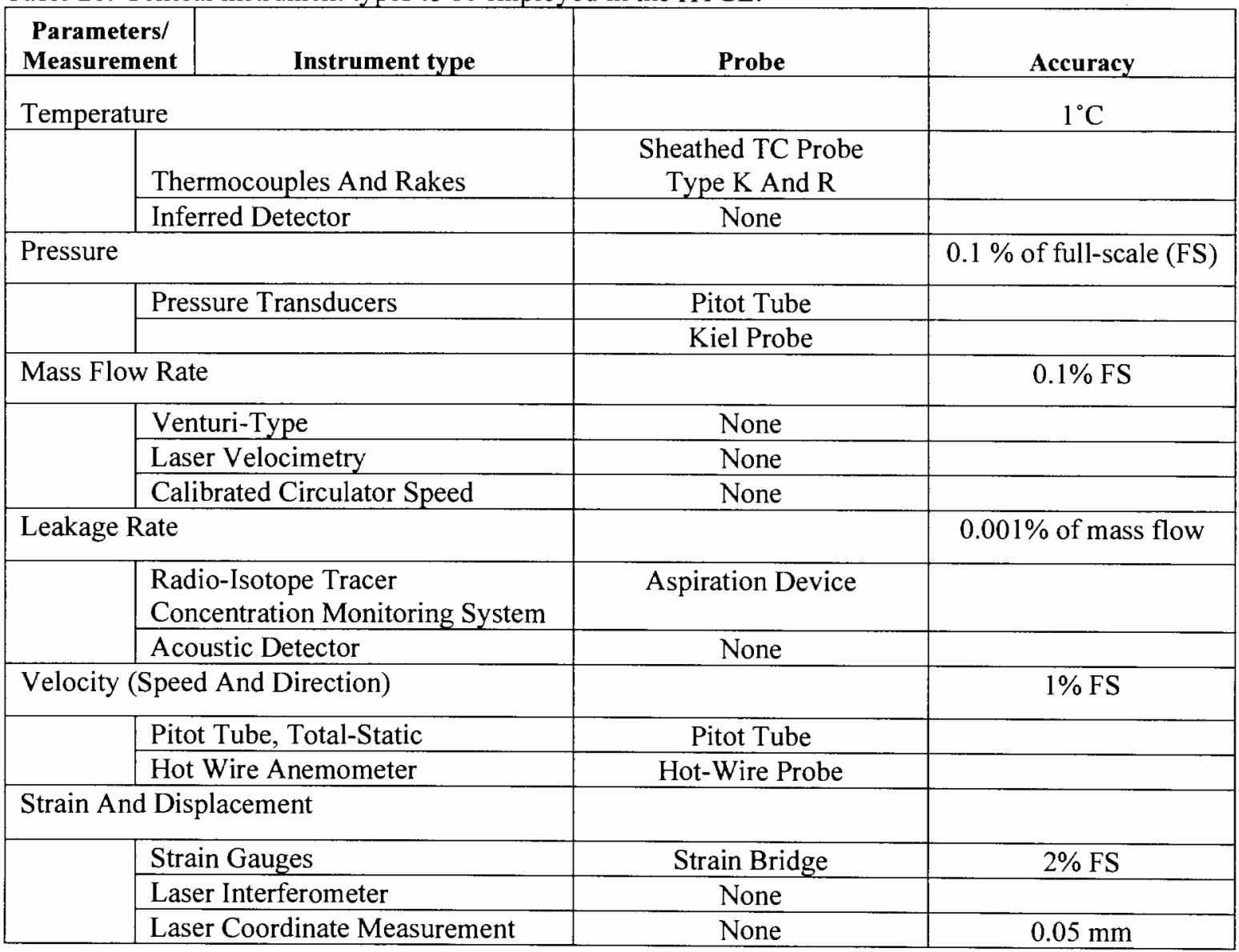

4.2.4.3 Data Acquisition. Data acquisition and controls requirements shall be coordinated into a central control and data center. An integrated system is warranted to assure that the data is properly timestamped and logged for eventual reduction and analysis. The anticipated requirements are stated in Table 29. 
Table 29. Capacity and features of data acquisition system for HTGL.

\begin{tabular}{|l|c|}
\hline \multicolumn{1}{|c|}{ Feature } & Requirement \\
\hline Scan rate & $10 /$ second \\
\hline Analog pressure transducer channels & 100 \\
\hline Analog thermocouple channels & 300 \\
\hline Analog mass flow & 4 \\
\hline Discrete pressure switches and alarms & 100 \\
\hline Discrete temperature switches and alarms & 100 \\
\hline Vibration sensors & 2 \\
\hline
\end{tabular}

\subsection{Safety and Quality}

\subsubsection{Hazards and Exposure Mechanisms}

While a detailed analysis of safety issues and their mitigation must wait until the preliminary design is complete, it is clear that this system presents a number of hazards. Some are directly related to the extreme operating conditions. These include high temperatures, which can lead to personnel burns or ignition of fires; high pressure, which can lead to jets of very hot leaking gas or to shrapnel from failed equipment; potential exposure to hazardous chemicals such as carbon monoxide or sulfuric acid which will be used in corrosion tests; and a significant asphyxiation hazard from accidental release of the large inventory of helium in the system and its holding tanks. Other hazards derive from the hardware and the way it will be operated, including electrical hazards from the $2 \mathrm{MW}$ of heating system and the power control circuitry; hoisting/rigging and elevated work hazards from the large scale of the equipment, some of which will be moved in the course of setting up experiments; and heat stress on the operators if the planned large heat loss from the piping, expected to be on the order of $100 \mathrm{~kW}$, raises room temperature significantly. Another potential hazard that cannot be assessed until the particular equipment items are tested is high noise levels from the gas circulators or helium compressors.

These hazards present a danger to personnel only if there is an exposure pathway. Most of these hazards will be addressed by engineering controls such as guards or isolation systems on hot surfaces to prevent direct contact, or high capacity room ventilation to limit the buildup of helium, heat, and toxic gases. Others will be addressed with administrative controls such as warning signs and written procedures for critical operations. Nonetheless, the expected mode of operation of this test facility presents several challenges to any planned controls. Equipment failure from the extreme conditions is one mechanism that must be considered in the more detailed stages of design; this includes not only the articles being tested, but also the test loop's equipment, such as the circulators. A second challenge originates with the wide variety of test articles and test conditions that will be used. Frequent changes present opportunities for miscommunication or failure to recognize that something is not correct. A third problem, related to the variety of test articles, is that an ever-changing variety of personnel for each new test are likely to be around the unit. Though they will not be operating the test loop itself, they will have to be made aware of the hazards around them. In addition, if the test loop runs for several years, the INL staff actually operating the unit likely will have turnover and those new people will have to be well trained. Fourth, the extreme temperature and pressure in the test loop create the possibility of heavy maintenance demands on the system, for instance for instrument recalibration or frequent seal replacement on the rotating equipment. The high level of personnel involvement in maintenance work, in turn, creates a higher 
probability of exposure to the mechanical and thermal hazards of the unit unless good controls are in place and personal awareness is high.

\subsubsection{Specific Hazard Identification and Mitigation}

Developing controls for these hazards requires that all of them be identified. A variety of hazard analysis methods exists which can be applied to this system when the design is mature enough to provide the detail needed for the analyses. Two methods that seem well suited as Failure Modes and Effects Analysis (FMEA) to identify the consequences of particular hardware failures, and Hazards and Operability (HAZOP) analysis which is better suited to analysis of process perturbations. The choice of these or other methods will be made during preliminary design when a proposed building location is known. The INL safety review procedures in place at that time will be used to help select the review methods. Some form of formalized safety review will be done during preliminary design so that if significant changes are required, they can be addressed during the final design phase. This does not preclude the possibility of additional types of safety reviews, particularly concerning operations, later in design or just before startup.

To address the identified hazards and potential operating problems, a variety of mitigations will be applied. Key general items are that unnecessary personnel will not be allowed into the unit while it is operating, and those in the unit while it is pressurized will wear safety glasses. Training on recognizing and responding to the hazards will be provided to the operating staff and visitors who enter the operating area. Other more specific actions or hardware are described in Table 30. Because the characteristics of the hazards cannot be fully described at this stage of design, these controls are only representative of those that might be used.

Table 30. Potential Mitigation Methods for Some Hazards Expected in the HTGL.

\begin{tabular}{|c|c|c|}
\hline Hazard & Engineering Controls & Administrative controls \\
\hline High temperatures & $\begin{array}{l}\text { - Insulate exposed surfaces } \\
\text { - Install extremely hot piping in } \\
\text { covered trenches } \\
\text { - Locate hot objects away from } \\
\text { walkways }\end{array}$ & $\begin{array}{l}\text { - } \quad \text { Post warning signs } \\
\text { - Require gloves when } \\
\text { working near hot objects }\end{array}$ \\
\hline High pressure gas leak & $\begin{array}{l}\text { - Install potential leak sources away } \\
\text { from walkways } \\
\text { - } \quad \begin{array}{l}\text { Provide rupture disks or relief } \\
\text { valves to prevent overpressures }\end{array}\end{array}$ & \\
\hline Equipment failure - shrapnel & $\begin{array}{l}\text { - Provide shields or walls around } \\
\text { test articles } \\
\text { - Require that problematic tests } \\
\text { provide their own additional } \\
\text { containment }\end{array}$ & $\begin{array}{l}\text { Do not allow any } \\
\text { personnel entry during } \\
\text { tests with greater } \\
\text { likelihood of equipment } \\
\text { failure }\end{array}$ \\
\hline
\end{tabular}


Table 30. (continued).

\begin{tabular}{|c|c|c|}
\hline Hazard & Engineering Controls & Administrative controls \\
\hline Asphyxiation & $\begin{array}{l}\text { - Install a high capacity air handling } \\
\text { system to vent the room } \\
\text { - Install oxygen monitors in helium- } \\
\text { containing rooms } \\
\text { - Vent pressure relief devices to an } \\
\text { external stack }\end{array}$ & $\begin{array}{l}\text { - Have written procedures } \\
\text { for helium transfer } \\
\text { operations } \\
\text { - Require lockout of helium } \\
\text { tanks when working on } \\
\text { that system }\end{array}$ \\
\hline Electrical shock & $\begin{array}{l}\text { Provide necessary insulation and } \\
\text { grounding per design codes }\end{array}$ & $\begin{array}{l}\text { - Require lockout of power } \\
\text { when working on that } \\
\text { system }\end{array}$ \\
\hline Hoisting and rigging & $\begin{array}{l}\text { Provide integral lifting points on } \\
\text { equipment likely to be moved } \\
\text { - Keep lifting paths open in the } \\
\text { layout }\end{array}$ & \\
\hline Elevated work & $\begin{array}{l}\text { - Provide fixed ladders, platforms, } \\
\text { and railings where needed }\end{array}$ & $\begin{array}{l}\text { - Require hard hats in areas } \\
\text { with overhead work }\end{array}$ \\
\hline $\begin{array}{l}\text { Hazardous chemicals }(\mathrm{CO}, \\
\left.\mathrm{H}_{2} \mathrm{SO}_{4} \text {. others }\right)\end{array}$ & $\begin{array}{l}\text { - Store gases outside } \\
\text { - Provide high capacity air handling } \\
\text { to vent where they are used } \\
\text { - Provide gas monitors where the } \\
\text { gases are stored or used } \\
\text { - } \begin{array}{l}\text { Provide safety showers and } \\
\text { eyewash stations }\end{array} \\
\end{array}$ & - Post warning signs \\
\hline High noise levels & - Install acoustic barriers if needed & $\begin{array}{l}\text { - Measure actual noise } \\
\text { levels when in operation } \\
\text { - Post signs about required } \\
\text { hearing protection if } \\
\text { needed }\end{array}$ \\
\hline Heat stress & $\begin{array}{l}\text { - Provide high capacity room } \\
\text { ventilation to remove hot air } \\
\text { - Monitor the room temperature } \\
\text { - } \quad \text { Provide a cooled rest area }\end{array}$ & $\begin{array}{l}\text { - Address heat stress in } \\
\text { procedures requiring long } \\
\text { times in the operating } \\
\text { areas }\end{array}$ \\
\hline
\end{tabular}




\subsubsection{Quality Levels}

INL procedures require that the quality level for design and operations must be specified. The level is determined from the scale of damage consequences if there is an accident and from the necessary integrity of the data produced by a system. The INL quality program is certified under ASME NQA-1, which has a section for R\&D activities and allows a graded approach for such activities. The INL currently ${ }^{c}$ has four quality (or "safety class") grades. The two highest levels are typically applied to nuclear facilities. The lowest two are currently designated "Low Safety Class" and "Consumer Grade." Because of its high temperature and pressure, certain components of the HTGL may be classified Low Safety Class, but the majority of the components can likely be classified Consumer Grade. Certain instruments or data collection systems might require a higher-than-minimum level of quality assurance to ensure accuracy, precision, or traceability of the results generated by the test loop.

The assigned quality level has cost and schedule implications both during initial design and construction and also later during operations, maintenance, and modification of the system. One of the major impacts is on procurement of parts or components. Consumer Grade permits project personnel to purchase parts directly from their choice of suppliers; this allows, for example, the use of parts from a local hardware store for quick repairs. At Low Safety Grade, purchasing of such parts must be done through the INL Procurement Department to assure that the proper grade of authentic (not counterfeit) hardware is provided by the vendor.

Similar considerations apply to configuration control of the test apparatus. Configuration control refers to the process by which the test apparatus may be modified after a baseline design has been established. Although the HTGL is an R\&D project and changes are expected, a measure of configuration control must be applied to those components that perform a safety function or are designed and certified to a design code, such as the ASME pressure vessels. During the construction, startup, and testing phases, a Consumer Grade quality level allows expeditious modifications to non-critical system components with the approval of the cognizant engineer. A higher quality level requires more documentation, review, and signatures before such changes can be implemented, and this can affect a project's schedule.

The HTGL project's approach to quality level assignments, data quality, and configuration control must be documented prior to commencing detailed design. At INL such project policies are typically set forth in a Project Management Plan which is reviewed and signed by all the project stakeholders, including INL line management, INL quality and safety representatives, the INL design team, and any external partners. The Project Management Plan establishes important policies at the start to avoid costly delays and rework during the design and construction phases.

\footnotetext{
' The INL is in the process of revising its system for classifying quality levels. It is expected that the classification descriptions discussed here will remain valid although the quality level names will change.
} 


\section{COST DISCUSSION}

While a complete cost estimate was not an objective of this conceptual design, it was possible to define some of the costs for the major hardware items in the primary helium loop and the Bay 1 secondary loop. These estimates do not include categories such as equipment for the other two secondary loops, detailed engineering and design, construction costs, the cost of the building the unit is installed in (either modifications of an existing building or construction of a new building), additional development costs for novel equipment, or contingency. The test articles themselves such as IHXs or isolation valves as well as their support equipment or instrumentation will be purchased and provided by others. With these provisos, the estimated procurement cost of the test loop hardware considered in this report is $\$ 4.3$ million. The cost of the completed facility ready for operation will be substantially higher.

The conceptual design includes components ranging from those readily available from suppliers to others that are unique. For standard items, vendor quotations serve as the basis for estimation. Where the components are more developmental, discussions were held with candidate engineering concerns to reasonably bracket the cost. Some components, such as the electrical heat source for the loop, are completely new items. Costs for these components are prepared using a specially prepared bottom-up cost model grounded in commodity pricing and experience with like constructions. For several equipment items such as the gas purification system, pricing was not available or not obtained. Budgets for these have been assigned using engineering judgment. Table 31 shows a breakdown of equipment costs for the HGTL, with Bay 1 configured for IHX testing.

Table 31. Summary equipment costs for the HGTL with one test-bay configured for IHX testing.

\begin{tabular}{|l|c|l|}
\hline \multicolumn{1}{|c|}{ Description } & Estimated Cost & \multicolumn{1}{c|}{ Basis } \\
\hline Primary Loop Equipment & & \multicolumn{1}{|c|}{} \\
\hline Electric Resistance Heater & $\$ 640,000$ & Quotation, Kanthal plus cost model \\
\hline Recuperator & $\$ 52,000$ & Cost model (Brayton Energy) \\
\hline Cooler & $\$ 22,000$ & Quotation, API \\
\hline Circulator & $\$ 300,000$ & $\begin{array}{l}\text { Budget from } \$ 150-700 \mathrm{~K} \text { range, various } \\
\text { solutions }\end{array}$ \\
\hline Piping & $\$ 42,500$ & Schedule 4, 5, 6-inch, AISI 316 \\
\hline Valves & $\$ 147,000$ & Quotation \\
\hline Vent Tank & $\$ 140,000$ & Cost Model \\
\hline Bay 1 Test Vessel & $\$ 570,000$ & $\begin{array}{l}\text { Cost model calibrated to quotations, } \\
\text { Steel-Pro, Edmonton Exchanger }\end{array}$ \\
\hline Bay 1 Secondary Loop Equipment & & \\
\hline Recuperator & $\$ 52,000$ & Cost model (Brayton Energy) \\
\hline Cooler & $\$ 38,000$ & Quotation, API \\
\hline Circulator & $\$ 300,000$ & Average of two quotes \\
\hline Piping & $\$ 36,000$ & Schedule 4, 5, 6 inch, AISI 316 \\
\hline Valves & $\$ 158,000$ & Quotation \\
\hline Vent Tank & $\$ 100,000$ & Cost Model \\
\hline
\end{tabular}


Table 31. (continued).

\begin{tabular}{|l|c|l|}
\hline \multicolumn{1}{|c|}{ Description } & Estimated Cost & \multicolumn{1}{|c|}{ Basis } \\
\hline Support Equipment & & \\
\hline Gas Purification System & $\$ 300,000$ & Budget from Prax-Air \\
\hline Evacuation pump, LP Vent tank & $\$ 5,000$ & Estimate \\
\hline Roughing pump (2 required) & $\$ 10,000$ & Estimate \\
\hline Diffusion pump (2 required) & $\$ 10,000$ & Estimate \\
\hline Gas Inventory Management System & & \\
\hline Gas separator & $\$ 50,000$ & Praxair \\
\hline Inventory control compressor & $\$ 300,000$ & Norwalk \\
\hline Primary He storage vessel & $\$ 200,000$ & FIBA Technologies \\
\hline Evacuation pump, LP Vent tank & $\$ 5,000$ & Estimate \\
\hline $\begin{array}{l}\text { Inventory control compressor, } \\
\text { secondary }\end{array}$ & $\$ 300,000$ & \\
\hline Secondary gas storage vessel & $\$ 100,000$ & FIBA Technologies \\
\hline Cooling Tower & $\$ 88,000$ & Quotation, SPX Cooling Technologies \\
\hline Piping & $\$ 15,000$ & Cost Model \\
\hline Controls and Data & $\$ 120,000$ & Budget \\
\hline Electronic Control System & $\$ 50,000$ & Budget \\
\hline Instruments, sensors, probes & $\$ 100,000$ & Budget \\
\hline Wiring and harnesses & $\$ 4,300,500$ & \\
\hline Data Acquisition System & $\$ 50,000$ & Budget \\
\hline Total Equipment Cost & $\$ 120$ \\
\hline
\end{tabular}

The two circulators have been budgeted at $\$ 300,000$ each after reviewing available technologies. There is still uncertainty about the best system to meet the technical requirements. Options range from a two-stage centrifugal blower, estimated at $\$ 150,000$, to the side-channel axial blower selected for the French HELITE test-loop, estimated to cost $\$ 700,000$. This equipment and the associated budget require significant further definition during preliminary design.

Cost models were prepared for the vessel and piping estimates. The vessel model calculates the mass of the vessel based on its inside dimensions and maximum operating conditions at the pressure boundary. Cost per unit mass was verified through quotation. A cost ratio deduced from quotations on two completed vessels was used to scale the material costs as part of the price estimate. Subjective complexity factors, as compared to a quoted configuration, were assigned to the vessel configurations being priced. The Bay 1 test vessel, recuperators, and heater were priced using this model. 
As with the vessel cost model, the piping model is based on a calculated mass for the pressure boundary, flanges, and liners. Pressure boundaries are all assumed to be standard schedule-40 300-series stainless steel pipe at a cost of $\$ 4$ per $\mathrm{kg}$, while liners are 1.6-millimeters thick nickel alloy at $\$ 40$ per $\mathrm{kg}$. Masses for 900 psi flanges were provided by a supplier. Flame-sprayed, telescoping, liner ends are estimated at $\$ 150$ each. A 1:1 ratio of labor to material is assumed along with a $20 \%$ margin overall. This model was used to price all pipes configured for IHX testing plus an additional 300 meters of 2.5 inchdiameter uninsulated pipe for support systems. Articulating U-pipe assemblies were estimated separately on the basis of direct experience with similar fabrications. The cooler (smaller) assemblies are estimated at $\$ 10,000$ each, while the larger ones are estimated to be $\$ 15,000$ each. 


\section{PROPOSED FUTURE WORK}

The conceptual design documented in this early report is only the first step in establishing a hightemperature gas loop test facility at INL. This system will present a number of challenges in design and procurement, and likely during operations as well. This section recommends several activities to complement the normal next steps of preliminary and detailed design. It closes with a discussion of a tentative schedule for loop design, construction, and qualification.

\section{Validate design requirements and assumptions}

The initial activity in the conceptual design was to establish design requirements and develop a preliminary test plan for the facility by surveying proposed high-temperature gas reactor designs as well as other existing and proposed test loops. A valuable step now would be to communicate the results of the conceptual design task to other researchers and potential users of the facility (e.g., IHX and other component manufacturers, reactor system designers, material researchers, international collaborators, etc.) both to communicate progress on the facility and to receive a constructive critique. Any feedback on system configuration or testing capabilities that leads to design alterations can be easily and inexpensively accommodated at this stage of design. Because such feedback could disclose sensitive or proprietary information about users' or vendors' plans, individual visits rather than an open workshop might be more productive. Site visits to selected other researchers and key potential users are recommended for early in FY-07.

\section{Develop ties to other test loop programs}

High-temperature test loops are currently operating or under construction in France, Japan, China, and the Republic of South Africa. A focused effort to establish international collaborative research with these groups is recommended, either individually or to the extent possible as a consortium. Obvious benefits include avoiding unproductive overlap of test loop capabilities while not addressing the full range of needs, sharing of loop design information and operating experience, cross-validating test methods, and, ultimately, sharing test results. Meetings with potential international collaborators are recommended for the near future, both for technical exchange and to discuss formal collaborative agreements. Based on expressions of interest in such collaboration in March 2006, ${ }^{31}$ a joint U.S./French meeting at INL has been tentatively scheduled to address these topics.

\section{Establish an instrumentation $R \& D$ program}

Advanced nondestructive evaluation techniques exist, at least at the lab scale, but have not been incorporated in the thinking about high-temperature heat exchanger testing. Many of these methods have been conceived for use in nuclear reactors and are consequently fairly readily adaptable to IHX or other component testing, but they might require recognition early in the test loop design to assure that they can be incorporated into the hardware. Aside from generating data about test component performance, these methods could themselves be incorporated into full-scale IHXs to monitor their condition on-line. Consequently, creating a methods development program to run in parallel with test loop design would be valuable to the test program and to the ultimate technology commercialization. Some of the techniques that appear valuable are thermal imaging of heat exchanger surfaces, on-line opto-acoustic monitoring at full temperature and pressure of internal displacements and strain, and detection and quantification of small leaks between the primary and secondary sides using radioisotopic tracers. 
Aggressively manage equipment design and procurement risks

Some of the equipment in the test loop, particularly the circulators, heater, and high-temperature piping, must operate at what are severe and unusual conditions compared to normal industrial practice. To minimize the consequent technical risk, consideration should be given to tracking the progress of the vendor's design of these custom items and requiring formal testing and qualification of them prior to delivery or installation in the test facility. Such testing was done by the French, providing valuable experience and test data as their overall loop design evolved. This testing could potentially be done at the component manufacturer's facility, at existing test facilities via subcontract, or at INL. Appropriate test procedures would have to be identified and the procurement schedule should allow time for vendors to address possible initial failures to pass the acceptance tests.

Prospective schedule

A proposed schedule for loop design, construction, and qualification follows, based on the expectation that component testing will begin in 2010 . Given sufficient resources, the effort could likely be accelerated. Development and testing of custom-made, long-lead mechanical equipment is likely to be a major part of the critical path to completion. A much more detailed schedule should be produced as an early part of preliminary design.

FY-06 Complete conceptual design

FY-07 Complete preliminary design and enter final design stage

FY-08 Complete final design and procure long lead-time components

FY-09 Construct loop construction and begin initial qualification

FY-10 Complete loop qualification and begin component/materials testing 


\section{REFERENCES}

1. Next Generation Nuclear Plant Project Preliminary Project Management Plan, INL/EXT-05-00952 Rev. 1, March 2006.

2. Nash, J., 2006, Materials Characterization for Brazed Plate Fin Heat Exchangers, IR Energy Systems, June 8, 2005.

3. Harvego, E.A., 2006, Evaluation of Next Generation Nuclear Power Intermediate Heat Exchanger Operating Conditions, INL/EXT-06-11109, April 2006.

4. Forsberg, C., Joliot, F., and Han, O., 2004, Reactors and Molten Salts-Options and Missions, Summer School on Nuclear Reactors, Cardarache, France, August 25, 2004.

5. High-Temperature Reactors for In-Situ Recovery of Oil from Oil Shale, Proceedings of the ICAPP '06, Reno NV, USA, Paper 6104, June 4, 2006.

6. Tennenbaum, J., 2006, South Africa's PBMR: World's Most Versatile Nuclear System, EIR Science \& Technology, pp. 34-47, February 10, 2006.

7. General Atomic, 2006, Pre-Conceptual Design Report: SI-Based Plant, US DoE Contract No. DEFG03-02sF22609/A000, Nuclear Energy Research Initiative, April 2006.

8. Gauthier, J.C., Brinkmann, G., Copsey, B., and Lecomte, M., 2004, Antares: The HTR/VHTR project at Framatome ANP, $2^{\text {nd }}$ International Topical Meeting of High Temperature Reactor Technology, Paper A10, pp. 1-13, Beijing, China, September 22-24, 2004.

9. Gauthier, J.C., Lecomte, M. Dr., and Billot, P. Dr., 2005, The Framatome-ANP Near Term HTR Concept and its Longer Term Development Perspective, 13th International Conference on Nuclear Engineering, ICONE 13 - 50387, Beijing, China, May 16-20, 2005.

10. Mitchell, M.N., Smit, K., Fechter, M., and Fazluddin, S., Design and Materials Aspects of the PBMR.

11. PBMR Design Status \& Technology Development Plan Summary, For NGNP Materials R\&D Update, Pages 1-21, May 2006.

12. Slabber, J., 2006, Technical Description of the PBMR Demonstration Power Plant, Document Number 016956, Revision 4, February 2, 2006.

13. Hejzlar, P., Driscoll, M.J., Dostal, V., Wang, J., Gong, Y., Guenette, G., and Carstens, N.A., Supercritical $\mathrm{CO}^{2}$ cycle for Gen-IV Reactors Overview of MIT work, MIT, Cambridge, MA, November 2005.

14. Hejzlar, P., Dostal, V., and Driscoll, M.J., 2005, Proceedings of ICAPP '05, Soeul Korea, May 1519, Paper 5090, 2005.

15. Kadak, A.C., Ph.D., 2004, A Future For Nuclear Energy - Pebble Bed Reactors, MIT, Cambridge, MA, April 25, 2004. 
16. McHugh, K., (Principal Contributor), 2005, Hydrogen Production Methods, Prepared for MPR Associates, Inc., February 2005.

17. Minatsuki, I, et. al, 2006, A Comparison of Design Characteristics Between Plate-Type and Cylinder-Type Configurations of Ceramic Heat Exchangers for Hydrogen Production, Mitsubishi Heavy Industries, Ltd, Proceedings of the HTR $20063^{\text {rd }}$ International Topical Meeting on High Temperature Reactor Technology, Johannesburg, South Africa, Oct 4, 2006.

18. Kunitomi, K., Ph.D., Notes, Japan, 2006.

19. Harding, J., 2005, Pebble Bed Modular Reactors- Status and Prospects, Olympia, WA, February 2005.

20. Wilson, D., 2005, Materials Issues for High Temperature Containment of Fluoride Salts, Oak Ridge National Laboratory, Liquid Salt Technical Working Group Meeting, Canoga Park, CA, October 28, 2005.

21. Development of the Intermediate Heat Exchanger (IHX) for Antares, Proceedings of ICAPP, Paper 6457, Reno NV, June 4-8, 2006.

22. Lecomte, M., 2005, The Areva Near Term HTR Concept and Its Longer Term Development Perspective, ICONE13-50387, May 16-202005.

23. ASME Boiler and Pressure Vessel Code, Section VIII Division III.

24. Zeng, S.Q., Hunt, A., and Greif, R., 1995, Transport Properties of Gas in Silica Aerogel, Journal of Non-Crystalline Solids 186, 264-270.

25. Harth, R., Jansing, W., and Teubner, H., 1990, Experienced Gained from the EVA II and KVK Operation, 1989, Nuclear Engineering and Design 121, pp. 173-182, North Holland, 1990.

26. Dixon, S.L., 1978, Fluid Mechanics, Thermodynamics of Turbomachinery, $3^{\text {rd }}$ edition, Pergamon Press, 1978.

27. Kesseli, J., Wolf, T., and Nash, J., Micro Industrial and Advanced Gas Turbines Employing Recuperators, Proceedings of ASME Turbo Expo, GT2003-38938, Atlanta, Georgia, June 16 - 19 2003.

28. Stolzl, D.L., Twenty-FiveYears of Brown Boveri Experience in Development, Design, and Fabrication of Circulators for HTGR.

29. Nash, J., Analysis and Testing of Ingersoll-Rand Recuperator for WR21 ICR Engine, Presented at the American Society of Metals, St. Louis, MO, October 2000.

30. Cherry, Robert, INL, 2006, Memo on the use of Radio-Isotope Tracers to Detect Leakage in High Temperature Heat Exchanger Testing, May 2006.

31. US/French Collaborative Efforts on Large Scale Gas Test Loops, Meeting, pp. 1-5, CEA - Saclay, February 28, 2006. 


\section{Appendix A}

\section{Planned Tests}




\section{Appendix A}

\section{Planned Tests}

\section{A-1. INTRODUCTION}

Test objectives and methodologies for the High-Temperature Gas Test Loop (HTGL) have been examined from the perspective of the IHX developer. The Test Loop is designed to accommodate a wide range of High-Temperature Reactor (HTR) and NGNP test articles, many of which are not currently well defined. Test requirements associated with the direct and indirect gas turbine power generation cycles are reasonably well defined, and as such their test objectives tend to have the greatest influence on the HTGL planning during the conceptual design phase. Testing for the IHX of a power generation cycle, such as that described by AREVA ${ }^{1,2}$ and PBMR Inc. ${ }^{3}$ should also be appropriate for other $\mathrm{H}_{2}$-generation processes employing secondary gases.

The HTGL is equipped with features to allow rigorous simulation of anticipated NGNP thermal and pressure transients. Six degrees of freedom are required to accomplish the transient maneuvers. This important capability of the rig is described in Section 4.2.4 of the main body of the report, under Controls, Instrumentation, and Data Acquisition.

\section{A-2. TEST OBJECTIVES AND METHODOLOGY FOR GAS-COOLED INTERMEDIATE HEAT EXCHANGERS (IHX)}

Five principal test objective categories are presented in Tables A-1 through A-5. The IHX tests are based on procedures and methodology employed on military gas turbine recuperators, such as the advanced WR-21 engine developed by the U.S. and UK navies, ${ }^{4}$ and include Stress and Life Model Validation, Durability Testing, Performance Validation, Materials Testing, and Other HTR Component Qualification Tests. 


\section{A-2.1 Intermediate Heat Exchanger Stress and Life Model Validation}

Stress and life prediction tests, described in Table A-1, are based on the premise that due to the large size and cost of a full-scale IHX, finite element models will be used extensively in design and life prediction models. These tests are intended to generate steady-state and transient temperatures within the core for precisely controlled temperature, pressure, and flow inlet conditions. Most IHX designs utilize strain relief features to isolate the core from strain introduced by ducting and support structures, thus life testing requires rigorous consideration and simulation of the IHX boundary conditions and core symmetry. An appropriate test article should include the full size core and realistic boundary conditions up to the point of isolation. The 3-meter-diameter test vessel is sized to accommodate very large IHX cores. In cases where the physical size of the test article demands more than the 2-MW capacity of the HTGL, the best option is to test at full dimensional scale, full temperature and pressure, and reduced mass flow rate. The imposed transient stresses may be reduced, but quantitative measurements with model validation can be employed to interpret the results.

Table A-1. Test objectives and methodology for IHX stress and life model evaluation.

\begin{tabular}{|l|l|l|l|}
\hline \multicolumn{1}{|c|}{ Description } & \multicolumn{1}{c|}{ Purpose } & \multicolumn{1}{c|}{ Test } \\
\hline location
\end{tabular}




\begin{tabular}{|c|l|l|l|l|}
\hline 1.3 & $\begin{array}{l}\text { Transient strain } \\
\text { measurements }\end{array}$ & Additional FEA model validation. & $\begin{array}{l}\text { Same as 1.2. Strain gauges to } \\
\text { be applied to the secondary } \\
\text { inlet side, due to the more } \\
\text { moderate temperatures. }\end{array}$ & $\begin{array}{l}\text { Test bay } \\
\# 1\end{array}$ \\
\hline 1.4 & $\begin{array}{l}\text { Core time } \\
\text { constant } \\
\text { measurement }\end{array}$ & $\begin{array}{l}\text { FEA models of the system piping } \\
\text { and structure rely upon accurate } \\
\text { understanding of the IHX thermal } \\
\text { response. }\end{array}$ & Same as 1.2 & $\begin{array}{l}\text { Test bay } \\
\text { S1 }\end{array}$ \\
\hline
\end{tabular}




\section{A-2.2 Intermediate Heat Exchanger Durability Testing}

Durability testing of IHX designs is outlined in Table A-2. Destructive testing will be employed to understand the failure modes of advanced compact IHX designs. This testing, employing exaggerated and repetitive thermal cycling, serves to bound the life of the core. Data gathered during cyclic testing will also be used to validate FEA predictions.

Table A-2. Objectives and methodology for IHX durability testing.

\begin{tabular}{|c|c|c|c|c|}
\hline & Description & Purpose & Applicable HTGL features & Location \\
\hline $\begin{aligned} 2.0 \\
3 \\
3\end{aligned}$ & $\begin{array}{l}\text { THX } \\
\text { Durability } \\
\text { Testing, }\end{array}$ & $\begin{array}{l}\text { The simulation of anticipated } \\
\text { NGNP maneuvers, faults and } \\
\text { failure modes. }\end{array}$ & $\begin{array}{l}\text { Six-degree-of-freedom control } \\
\text { system to simulate equal of } \\
\text { faster temp and pressure } \\
\text { transitions than hat projected } \\
\text { for the NGNP. Data sample } \\
\text { rates } 200 \text { channels Isecond }\end{array}$ & 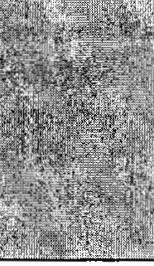 \\
\hline 2.1 & $\begin{array}{l}\text { Simulate } \\
\text { reactor \& } \\
\text { engine trip } \\
\text { failure mode }\end{array}$ & Impose fault mode & & $\begin{array}{l}\text { Test bay } \\
\# 1\end{array}$ \\
\hline 2.2 & $\begin{array}{l}\text { Simulate the } \\
\text { primary fluid } \\
\text { circulator trip } \\
\text { failure mode }\end{array}$ & $\begin{array}{l}\text { This simulation results in a rapid } \\
\text { IHX quench. Cessation of } \\
\text { primary flow and heat input is } \\
\text { followed by continued engine } \\
\text { flow with rapidly dropping } \\
\text { temperature and pressure. IHX } \\
\text { fluid and surface temps to be } \\
\text { measured through cycle. } \\
\text { Nominally } 200 \text { of these faults } \\
\text { are projected over the } 20 \text {-year } \\
\text { period. An IHX and the HTGL } \\
\text { should be capable of } \\
\text { demonstrating all } 200 \text { in a } \\
\text { qualifying test. }\end{array}$ & $\begin{array}{l}\text { The rig tolerates repetitive } \\
\text { cycles of simultaneous cut of } \\
\text { electric power to the heater and } \\
\text { primary circulator without } \\
\text { damage to the electric elements. } \\
\text { The secondary loop utilizes } \\
\text { inventory blow-down to } \\
\text { simulate the engine spool-down. }\end{array}$ & $\begin{array}{l}\text { Test bay } \\
\# 1\end{array}$ \\
\hline 2.3 & $\begin{array}{l}\text { Perform } \\
\text { precision } \\
\text { repetitive } \\
\text { transient } \\
\text { cycles }\end{array}$ & $\begin{array}{l}\text { To properly assess the mode of } \\
\text { IHX failure, it is critical to } \\
\text { perform repetitive thermal and or } \\
\text { pressure cycling on the test } \\
\text { article. To most accurately } \\
\text { correlate cumulative damage } \\
\text { rules with specific failure modes, } \\
\text { it is important to duplicate the } \\
\text { strain range, implying the need } \\
\text { for precise temperature, } \\
\text { pressure, and time control. }\end{array}$ & $\begin{array}{l}\text { The HTGL is equipped with } \\
\text { primary and secondary mass } \\
\text { flow control, primary and } \\
\text { secondary pressure control, and } \\
\text { primary and secondary } \\
\text { temperature control. An } \\
\text { interactive central control and } \\
\text { monitor system will be } \\
\text { programmed to automate } \\
\text { repetitive control of these } \\
\text { control variables. This type of } \\
\text { testing may result in IHX } \\
\text { failure, resulting in the breach o } \\
\text { the IHX pressure boundary. The }\end{array}$ & $\begin{array}{l}\text { Test bay } \\
\# 1\end{array}$ \\
\hline
\end{tabular}




\begin{tabular}{|l|l|l|}
\hline & & $\begin{array}{l}\text { HTGL containment boundary is } \\
\text { designed to tolerate and since } \\
\text { IHX failures, and execute } \\
\text { appropriate safety measures. }\end{array}$ \\
\hline
\end{tabular}




\section{A-2.3 Intermediate Heat Exchanger Performance Validation}

Performance testing of IHX designs is described in Table A-3. These tests require accurate and precise control over the IHX inlet temperature profile. Thermal effectiveness, flow resistance (pressure drop), and leakage will be measured. This testing typically is performed before and after IHX durability tests to assess IHX degradation.

Table A-3. Objectives and methodology for IHX performance testing.

\begin{tabular}{|c|c|c|c|c|}
\hline & Description & Purpose & $\begin{array}{c}\text { Applicable HTGL } \\
\text { features } \\
\end{array}$ & Location \\
\hline 3.0 & $\begin{array}{l}\text { Intermediate Heat } \\
\text { Exchanger (IHX) } \\
\text { performance testing }\end{array}$ & $\begin{array}{l}\text { Steady-state validation of thermal } \\
\text { effectiveness and pressure loss }\end{array}$ & $\begin{array}{l}\text { Full scale IHX, with } \\
\text { precise match of gas } \\
\text { properties. } \\
\text { Dimensional } \\
\text { similitude to be } \\
\text { applied if necessary }\end{array}$ & \\
\hline 3.1 & $\begin{array}{l}\text { Measure thermal } \\
\text { effectiveness }\end{array}$ & $\begin{array}{l}\text { End-to-end thermal performance, } \\
\text { dissection of losses and inefficiencies } \\
\text { under a range of flowing conditions. }\end{array}$ & $\begin{array}{l}\text { The facility provided } \\
\text { complete temp profile } \\
\text { survey via temp rakes } \\
\text { at inlet and exit. Also } \\
\text { accurate mass flow } \\
\text { measurements of both } \\
\text { fluids. }\end{array}$ & $\begin{array}{l}\text { Test bay } \\
\# 1\end{array}$ \\
\hline 3.2 & $\begin{array}{l}\text { Characterize IHX } \\
\text { pressure drop }\end{array}$ & $\begin{array}{l}\text { End-to-end flow resistance, } \\
\text { dissection of losses and inefficiencies } \\
\text { under a range of flowing conditions. }\end{array}$ & $\begin{array}{l}\text { The facility is } \\
\text { equipped with total } \\
\text { pressure rakes to } \\
\text { measure the pressure } \\
\text { profile entering the } \\
\text { IHX }\end{array}$ & $\begin{array}{l}\text { Test bay } \\
\# 1\end{array}$ \\
\hline 3.3 & $\begin{array}{l}\text { Characterize IHX } \\
\text { primary flow blow- } \\
\text { by }\end{array}$ & $\begin{array}{l}\text { Identify potential inefficiencies for } \\
\text { IHX. This loss mechanism is likely to } \\
\text { be a challenge to IHX OEMs. } \\
\text { Typically this test is performed } \\
\text { before and after Durability Testing } \\
(2.0) \text {. }\end{array}$ & $\begin{array}{l}\text { Performance } \\
\text { degradation is } \\
\text { inferred from changes } \\
\text { in thermal } \\
\text { effectiveness. } \\
\text { Monitor temps in } \\
\text { vicinity of seals, to } \\
\text { provided qualitative } \\
\text { view of degradation. }\end{array}$ & $\begin{array}{l}\text { Test bay } \\
\# 1\end{array}$ \\
\hline 3.4 & $\begin{array}{l}\text { Characterize IHX } \\
\text { secondary flow } \\
\text { blow-by }\end{array}$ & $\begin{array}{l}\text { Identify potential inefficiencies for } \\
\text { IHX }\end{array}$ & Same as 3.3 & $\begin{array}{l}\text { Test bay } \\
\# 1\end{array}$ \\
\hline
\end{tabular}




\begin{tabular}{|c|c|c|c|c|}
\hline 3.5 & $\begin{array}{l}\text { Characterize IHX } \\
\text { leakage between } \\
\text { primary \& } \\
\text { secondary fluids }\end{array}$ & $\begin{array}{l}\text { Identify potential inefficiencies for } \\
\text { IHX. This loss mechanism is likely to } \\
\text { be a challenge to IHX OEMs. } \\
\text { Typically this test is performed } \\
\text { before and after Durability Testing } \\
(2.0) \text {. }\end{array}$ & $\begin{array}{l}\text { Test is best conducted } \\
\text { under hot flowing } \\
\text { conditions. For } \\
\text { secondary to primary, } \\
\text { the facility will } \\
\text { monitor the partial } \\
\text { pressure of the } \\
\text { secondary fluid } \\
\text { constituents in the } \\
\text { primary stream. }\end{array}$ & $\begin{array}{l}\text { Test bay } \\
\# 1\end{array}$ \\
\hline
\end{tabular}




\section{A-2.4 Materials Testing}

Table A-4 describes anticipated materials testing to be performed in the HGTL. Dedicated materials test compartments will be located in both the primary and secondary loops. Compartments will be designed to accommodate up to 10 test specimens, each specimen measuring roughly 20 millimeters in diameter and 50 millimeters in length. These compartments are designed to deliver flowing gas at 50 to $75 \mathrm{~m} / \mathrm{s}$ (while monitoring gas impurity levels) and include the capability to impose stress on the samples during extended test periods. A materials test sheet (MTS) will be provided in each of the following sections:

- High-temperature $\left(800\right.$ to $\left.900^{\circ} \mathrm{C}\right)$ primary zone

- Mid-temperature $\left(500\right.$ to $\left.800^{\circ} \mathrm{C}\right)$ primary zone

- High-temperature $\left(800\right.$ to $\left.900^{\circ} \mathrm{C}\right)$ secondary zone

- $\quad$ Mid-temperature $\left(500\right.$ to $\left.700^{\circ} \mathrm{C}\right)$ secondary zone

Table A-4. Test objectives and methodology for IHX materials studies.

\begin{tabular}{|c|c|c|c|c|}
\hline & Description & Purpose & HTGL Applicable features & Location \\
\hline 4.0 & Materials studies & $\begin{array}{l}\text { Unique NGNP long } \\
\text { term exposure } \\
\text { issues }\end{array}$ & Materials test sections & 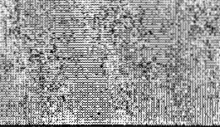 \\
\hline 4.1 & $\begin{array}{l}\text { Long term He } \\
\text { exposure analysis }\end{array}$ & $\begin{array}{l}\text { Simulate temp, } \\
\text { pressure, and } \\
\text { velocity expected in } \\
\text { NGNP } \\
\text { environments. }\end{array}$ & $\begin{array}{l}\text { Dedicated materials test } \\
\text { compartments will be located } \\
\text { in the primary and secondary } \\
\text { loops. The materials test } \\
\text { compartments are designed to } \\
\text { experience moderate gas } \\
\text { velocity at temps and pressures } \\
\text { expected in the NGNP. }\end{array}$ & $\begin{array}{l}\text { Materials test } \\
\text { sections }\end{array}$ \\
\hline 4.2 & $\begin{array}{l}\text { Corrosion in } \mathrm{He} \\
\text { environment, } \\
\text { contaminated with } \\
\text { trace elements found } \\
\text { in a typical HTR }\end{array}$ & same as 4.1 & same as 4.1 & $\begin{array}{l}\text { Materials test } \\
\text { sections }\end{array}$ \\
\hline 4.3 & $\begin{array}{l}\text { The effect of velocity } \\
\text { on corrosion in a } \\
\text { typical HTR } \\
\text { environment }\end{array}$ & same as 4.1 & same as 4.1 & $\begin{array}{l}\text { Materials test } \\
\text { sections }\end{array}$ \\
\hline 4.4 & $\begin{array}{l}\text { Erosion due to } \\
\text { graphite and } \\
\text { insulation materials, } \\
\text { typical of the HTR } \\
\text { environment }\end{array}$ & same as 4.1 & same as 4.1 & $\begin{array}{l}\text { Materials test } \\
\text { sections }\end{array}$ \\
\hline
\end{tabular}




\begin{tabular}{|l|l|l|l|l|}
\hline 4.5 & $\begin{array}{l}\text { Corrosion of metal } \\
\text { candidates in molten } \\
\text { fluoride environment }\end{array}$ & $\begin{array}{l}\text { Hot corrosion } \\
\text { research }\end{array}$ & $\begin{array}{l}\text { Test Bay \#3 will be equipped } \\
\text { with feed and return piping for } \\
800 \text { to } 900^{\circ} \mathrm{C} \text {. This Test Bay is } \\
\text { isolated from the primary loop } \\
\text { and other Test Bays and is } \\
\text { equipped with special } \\
\text { containment and safety } \\
\text { features. }\end{array}$ & Test Bay \#3 \\
\hline 4.6 & $\begin{array}{l}\text { Corrosion of metals } \\
\text { in aqueous H2SO4 }\end{array}$ & $\begin{array}{l}\text { Hot corrosion } \\
\text { research }\end{array}$ & same as 4.5 & Test Bay \#3 \\
\hline
\end{tabular}




\section{A-2.5 Other HTR Component Qualification Tests}

In the course of discussions with various researchers from Sandia National Laboratory Albuquerque, University of Nevada Las Vegas, AREVA, and PBMR, certain components have been found to represent high technical risk, including these components of interest:

- Circulators and shaft seals

- High temperature valves, stem sealing, and valve seat galling

- Insulation performance at high temperatures and saturated in helium

- Turbomachinery tip seals at high temperature and velocity.

These tests, outlined in Table A-5, will last for hundreds or thousands of hours and therefore must be tolerant of (1) perturbations in temperature or pressure as required by other testing in the primary loop. and (2) having the system shut down intermittently for a day at a time to install or remove other tests. As research and development expand in the NGNP mission, more testing needs will emerge. It is an ongoing objective of the HTGL development plan to understand these needs and expand the features of the test rig where applicable.

Table A-5. Test objectives and methodology for other critical HTR components qualification.

\begin{tabular}{|c|c|c|c|c|}
\hline & Description & Purpose & $\begin{array}{c}\text { Applicable HTGL } \\
\text { features }\end{array}$ & Location \\
\hline 5.0 & $\begin{array}{l}\text { Other critical } \\
\text { Him } \\
\text { components } \\
\text { qualificalion } \\
\text { tests }\end{array}$ & 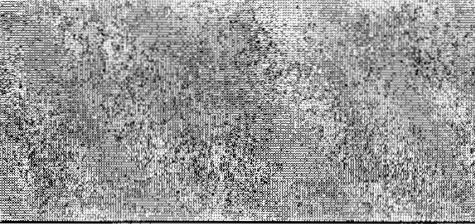 & 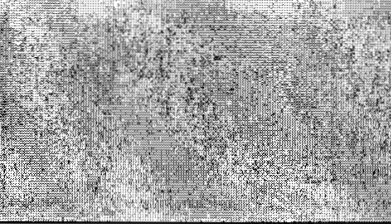 & 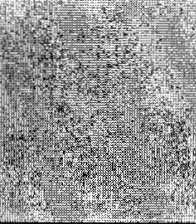 \\
\hline 5.1 & $\begin{array}{l}\text { High } \\
\text { Temperature } \\
\left(500^{\circ} \mathrm{C}\right) \\
\text { circulator } \\
\text { compressors }\end{array}$ & $\begin{array}{l}\text { No commercial industrial or } \\
\text { aerospace compressors systems } \\
\text { have been qualified for HTR } \\
\text { environments. Moreover, the } \\
\text { combined temperature, } \\
\text { pressure, and component tip } \\
\text { speeds add to the technical and } \\
\text { economic challenges. }\end{array}$ & $\begin{array}{l}\text { Though the test loop } \\
\text { maintains integral low } \\
\text { temperature circulators } \\
\text { for normal operation, the } \\
\text { Primary Loop is designed } \\
\text { to accommodate a much } \\
\text { larger hot-circulator test } \\
\text { article. Test Bay\# } 3 \text { may } \\
\text { deliver } 300 \text { to } 900^{\circ} \mathrm{C} \\
\text { helium to the test } \\
\text { circulator. }\end{array}$ & Test Bay \#2 \\
\hline 5.2 & $\begin{array}{l}\text { High } \\
\text { Temperature } \\
\left(500-900^{\circ} \mathrm{C}\right) \\
\text { valves } \\
\end{array}$ & OEM qualification test & $\begin{array}{l}\text { Accessible piping, temp- } \\
\text { controlled He feed. }\end{array}$ & Test Bay \#2 \\
\hline 5.3 & $\begin{array}{l}\text { Helium sealing } \\
\text { methods }\end{array}$ & $\begin{array}{l}\text { Evaluate and characterize } \\
\text { practical high temperature }\end{array}$ & same as 5.2 & Test Bay \#2 \\
\hline
\end{tabular}




\begin{tabular}{|l|l|l|l|}
\hline & sealing methods. & & \\
\hline
\end{tabular}

\section{A-3. REFERENCES}

1. Lecomte, M., 2005, The Areva Near Term HTR Concept and Its Longer Term Development Perspective, ICONE13-50387, May 16 - 202005.

2. Development of the Intermediate Heat Exchanger (IHX) for Antares, 2006, Proceedings of ICAPP, Paper 6457, Reno NV, June 4-8, 2006.

3. Tennenbaum, J., 2006, South Africa's PBMR: World's Most Versatile Nuclear System, EIR Science \& Technology, pp. 34-47, February 10, 2006.

4. Nash, J., 2000, Analysis and Testing of Ingersoll-Rand Recuperator for WR21 ICR Engine, Presented at the American Society of Metals, St. Louis, MO, October 2000. 


\section{Appendix B}

\section{Survey of Existing High-Temperature Gas Loops}




\section{Appendix B}

\section{Survey of Existing High-Temperature Gas Loops}

B-1. INTRODUCTION

High-temperature helium test loops are currently operating or under construction in France, Japan, China, and the Republic of South Africa. Also, pioneering research was performed over the past few decades in Germany. A brief summary of those test rigs and capabilities is provided in the following sections.

\section{B-1.1 German EVA II (also called ADAM II) and KVK Loop}

The German government sponsored critical component tests in a continuously running single primary gas (helium) circuit. The principal objective of the German project was to utilize a nuclear powered heat source to transform their ample coal reserves to petroleum products for the transportation industry. The helium heated in the reactor was intended to drive a Fisher-Tropsch process.

This test facility was commissioned for the evaluation of primary gas components. During its operation from 1981 to 1986, some of the critical specifications and milestones are as follows:

- Electrical heating element... $10 \mathrm{MW}$

- Flow rate $. .4 .0 \mathrm{~kg} / \mathrm{s}$

- $\quad$ Pressure 4.0 MPa

- $\quad T_{M a x}$ $.950^{\circ} \mathrm{C}$

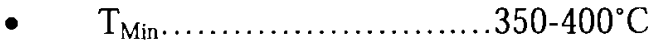

- Operated for a total of 13,000 hours, 7,750 of which was at $900^{\circ} \mathrm{C}$

- $\quad$ Side-by-side design of component pressure vessels allowed proof of coaxial flow principle.

A method of controlling the wall temperature of the large pressure vessel was tested. An inner coaxial shell was employed to bathe the interior of the vessel wall with the cooler circuit flow. Problems were encountered under low flow rates dominated by natural convection and buoyancy effects. An asymmetric temperature distribution of nominally $150^{\circ} \mathrm{C}$ caused severe distortion of several centimeters in the large pressure vessel, and eventual thermal buckling. This condition was not encountered at higher flow rates. As an aside, current intermediate heat exchanger (IHX) developers plan to incorporate similar design features within the IHX pressure vessel. The large HTGL test vessel will allow testing of various annular shell and baffling arrangements.

The German KVA test loop was arranged to test the operation of components of the loop under continuous running conditions. Components included hot gas ducts, hot gas valves, steam generator, electrical and natural gas heaters, blowers, He purification system, and the $\mathrm{He} / \mathrm{He}$ heat exchanger. Some of the remarkable milestones and accomplishments are highlighted below. 
Tests on $\mathrm{He} / \mathrm{He}$ heat exchanger were performed for the following durations:

- 10-MW U-tube $\mathrm{h} / \mathrm{x}$

- $\quad$ 10-MW helical tube $\mathrm{h} / \mathrm{x} \ldots \ldots . . .300 \mathrm{~h}$

- $\mathrm{T}$ $.950^{\circ} \mathrm{C}$

- $\mathrm{T}_{\mathrm{M} x}$ $1,000^{\circ} \mathrm{C}$

- $\quad \mathrm{P}$ $4.0 \mathrm{MPa}$

- $\quad \mathrm{P}_{\mathrm{Max}}$ $4.6 \mathrm{MPa}$

- Flow rate $3.0 \mathrm{~kg} / \mathrm{s}$

- Flow rate - max $.3 .3 \mathrm{~kg} / \mathrm{s}$.

\section{B-1.2 Japanese HENDEL (Helium Engineering Demonstration Loop)}

Japan's Helium Engineering Demonstration Loop (HENDEL) apparatus was developed principally to evaluate components for the Sulfur-Iodine (SI) cycle. Of particular interest was the emphasis on testing of novel heat exchangers. The general capabilities are provided below:

- Heater source power.........400 kW

- Max Temperature. $.880^{\circ} \mathrm{C}$

- $\quad$ Pressure .4.0 MPa

- $\quad$ Flow rate $.0 .1 \mathrm{~kg} / \mathrm{s}$

Hydrogen production was achieved through decomposition of liquid sulfuric acid with two heat exchangers arranged in series. Some of the early accomplishments are summarized as follows:

- $\quad$ First stage heat exchanger provided decomposition of liquid $\mathrm{H}_{2} \mathrm{SO}_{4}$ (for hydrogen production) at about $850^{\circ} \mathrm{C}$ (liquid-to-gas heat exchange)

- $\quad$ Second stage gas-to-gas heat exchanger heated gaseous $\mathrm{SO}_{3}$ at about $500^{\circ} \mathrm{C}$

- $\quad$ Plate-type and cylinder-type ceramic heat exchangers were tested

- $\quad \mathrm{SiC}$ ceramics were found to have high thermal conductivity, good corrosion resistance, and high mechanical strength to withstand static pressure differences between fluids.

A summary of the two IHX ratings is provided below:

- $\quad$ Liquid $\mathrm{H}_{2} \mathrm{SO}_{4}$ heat exchange:

- $\mathrm{T}_{\mathrm{Max}}$ $688^{\circ} \mathrm{C}$ 
- Heat exchange.......127 kW

- $\quad$ Heat transfer area....9 $\mathrm{m}^{2}$

- $\quad$ Gaseous $\mathrm{SO}_{3}$ heat exchanger:

$\begin{array}{ll}\text { - } & T_{\text {Max }} \ldots \ldots \ldots \ldots \ldots \ldots . \ldots 80^{\circ} \mathrm{C} \\ \text { - } & \text { Heat exchange........ } 100 \mathrm{~kW} \\ \text { - } & \text { Heat transfer area.....6 m } \mathrm{m}^{2} .\end{array}$

\section{B-1.3 The Republic of South Africa Helium Test Facility (HTF)}

The South African HTF is under construction in support of the Pebble Bed Modular Reactor (PBMR) direct helium cycle gas turbine generator ${ }^{1,2}$. Its stated mission is to test critical control and safety component systems of PBMR power plant. The PBMR power plant does not currently utilize an IHX, hence no tests are planned in this area. Their focused objectives are directed towards the qualification of their unique gas turbine cycle components. High temperature valves, gas sealing devices, and the lower temperature recuperator $\left(510^{\circ} \mathrm{C}\right)$ are incorporated into the test loop. The test loop will include multiple test bays utilizing a common, controllable heat source to provide concurrent parallel testing of component systems. General specifications are summarized below:

$\cdot$

$T_{M a x}$ $660^{\circ} \mathrm{C}$

•

$P_{\text {Ma }}$ 9.0 MPa

- Flow rate $2.0 \mathrm{~kg} / \mathrm{s}$

\section{B-1.4 French CEA HELITE}

The French Atomic Energy Commission (CEA) helium test loop has been under development since May 2005. This is a multi-phase program, initially emphasizing critical component tests supporting the AREVA power generation concepts ${ }^{3,4}$. In addition to high temperature testing, the experiments emphasize helium gas chemistry and purity control. The CEA has provided early support to the INL effort in the areas of helium purification, a circulator option by Air Technologies and other operational and logistics support. The CEA hosted INL engineers in a productive visit in March 2006. After an initial exchange of information, INL and CEA have worked independently on their respective projects. A follow-up meeting has been discussed to develop a cooperative technology exchange agreement.

Phase 1 - Primary Loop - (to be commissioned in 2008)

- $\quad$ Power - $100 \mathrm{kWe}$

- Helium max temp $-850^{\circ} \mathrm{C}$

- $\quad$ Flow rate $-0.04 \mathrm{~kg} / \mathrm{s}$

- $\quad$ Pressure $-4.5 \mathrm{MPa}$

Phase 2 - Primary and secondary loop (to be commissioned in 2009/2010) 
- $\quad$ Power - $1 \mathrm{MWe}$

- $\quad$ Helium $\max$ temp $-950^{\circ} \mathrm{C}$

- $\quad$ Flow rate $-0.4 \mathrm{~kg} / \mathrm{s}$

- $\quad$ Pressure - $7 \mathrm{MPa}$

\section{B-2. REFERENCES}

${ }^{1}$ Slabber, J., Technical Description of the PBMR Demonstration Power Plant, Document Number 016956, Revision 4, February 2, 2006.

${ }^{2}$ Van Vuuren, M., J., Helium Test Facility (HTF) Overview, Pages 1-15.

${ }^{3}$ Lecomte, M., 2005, The Areva Near Term HTR Concept and Its Longer Term Development Perspective, ICONE13-50387, May 16 - 202005.

${ }^{4}$ Development of the Intermediate Heat Exchanger (IHX) for Antares, 2006, Proceedings of ICAPP, Paper 6457, Reno NV, June 4-8, 2006. 


\section{Appendix C}

\section{Specifications for System Analysis}




\section{Appendix C}

\section{Specifications for System Analysis \\ C-1. INTRODUCTION}

As described in Section 4.1.1, steady-state analysis has been carried out for the configuration illustrated in Figure C-1, based on INL specifications and on representative assumptions for component performance. Relevant inputs are summarized in Table C-1 below.

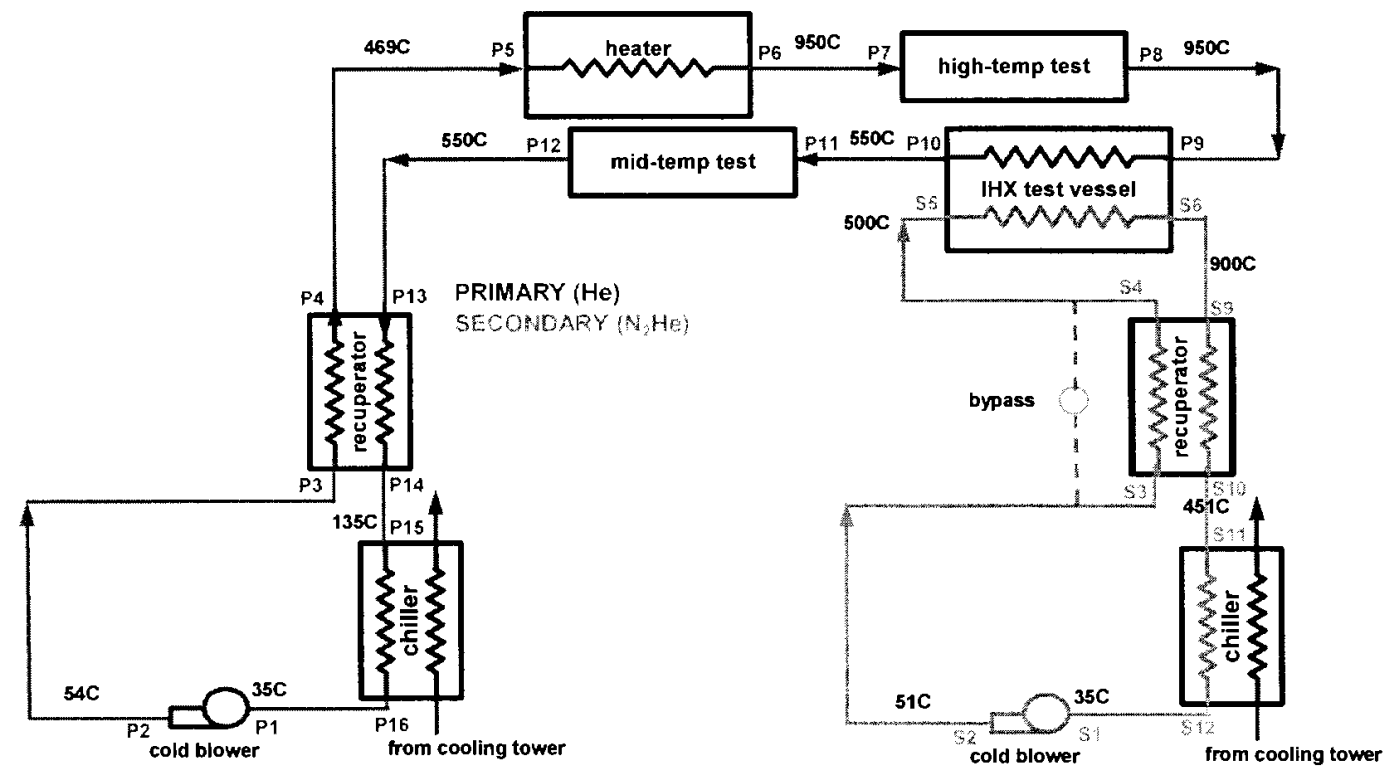

Figure C-1. Simplified schematic diagram based roughly on indirect gas turbine cycle configuration. Temperatures are representative as discussed in text.

Primary (helium) flow is consistent with a heat supply rate of roughly $2 \mathrm{MW}$, with secondary $\left(\mathrm{N}_{2}\right.$ $\mathrm{He})$ flow chosen to give balanced thermal capacitance $\left(\mathrm{mc}_{\mathrm{p}}\right)$ for the hot and cold streams. This specification roughly maximizes IHX thermodynamic performance, making it a representative choice for a practical system.

Spreadsheet-based software tools have been developed for the purposes of piping aerodynamic and thermal analysis, following standard correlations for pressure loss and heat transfer in fully-developed turbulent flow ${ }^{1}$ and applying standard loss coefficients for pipe fittings as multiples of dynamic pressure ${ }^{2}$. These tools have been customized for application to $\mathrm{N}_{2}$-He gas mixtures, for which evaluation of transport properties (viscosity and thermal conductivity) is fairly involved. Transport properties were calculated as outlined by Hirschfelder et al. $^{3}$ and pressure-loss allowances for piping runs were factored into the evaluation of circulator pressure ratio appearing in Section 4.1.1 in the main body of the report. 
Table C-2 summarizes piping pressure loss and various aerodynamic parameters for the network of Figure C-1. Run lengths are taken directly from the mechanical layout developed in Section 4.1.4. Station nomenclature (first column of Table C-2) corresponds to Figure C-1.

Table C-1. Component specifications for preliminary analysis.

\begin{tabular}{||l|c||}
\hline IHX THERMAL PERFORMANCE & \\
primary & \\
composition & pure He \\
massflow & $0.80 \mathrm{~kg} / \mathrm{s}$ \\
$\mathrm{T}_{\mathrm{H}}$ & $950 \mathrm{C}$ \\
$\mathrm{T}_{\mathrm{C}}$ & $550 \mathrm{C}$ \\
secondary & \\
\hline composition & $\mathrm{N}_{2} \mathrm{He}(80: 20)$ \\
massflow & $2.12 \mathrm{~kg} / \mathrm{s}$ \\
$\mathrm{T}_{\mathrm{H}}$ & $900 \mathrm{C}$ \\
$\mathrm{T}_{\mathrm{C}}$ & $500 \mathrm{C}$ \\
\hline PRESSURE LOSSES & \\
primary & \\
IHX test article & $1.5 \%$ \\
recuperator (either leg) & $1.6 \%$ \\
chiller & $2.0 \%$ \\
heater & $2.0 \%$ \\
high-temp test section & $0.25 \%$ \\
mid-temp test section & $0.25 \%$ \\
piping & Table 5 \\
secondary & \\
IHX test articie & $2.5 \%$ \\
recuperator (either leg) & $2.0 \%$ \\
chiller & $1.5 \%$ \\
heater & $1.5 \%$ \\
heat rej'n & $1.0 \%$ \\
piping & Table 5 \\
\hline OTHER & $6000 \mathrm{kPa}$ \\
primary-loop pressure & $5500 \mathrm{kPa}$ \\
secondary-loop pressure & $20 \mathrm{C}$ \\
ambient temp & $15 \mathrm{C}$ \\
chiller approach temp & $70 \%$ \\
blower isentropic effy & \\
\hline
\end{tabular}


Table C-2. Piping pressure loss and other aerodynamic parameters of interest. Values shown in red are total $\Delta \mathrm{P} / \mathrm{P}$ for primary and secondary loop piping including straight runs and fittings.

\begin{tabular}{|c|c|c|c|c|c|c|c|c|c|c|c|c|c|c|}
\hline \multicolumn{15}{|c|}{ fitting loss coeffs (\# of dynamic heads lost in fitting) } \\
\hline$\% \mathrm{He}$ & 100 & & $\mathrm{~K}_{90}$ & \multicolumn{11}{|l|}{0.25} \\
\hline massflow(kg/s) & 0.80 & & $K_{45}$ & \multicolumn{11}{|l|}{0.10} \\
\hline pressure(kPa) & 6000 & & $\mathbf{K}_{\mathrm{TEE}}$ & \multicolumn{11}{|l|}{0.50} \\
\hline & & & $\mathrm{K}_{\text {VALVE }}$ & \multicolumn{11}{|l|}{1.00} \\
\hline secondary & & & $k_{s}(m m)$ & \multicolumn{11}{|l|}{0.045} \\
\hline$\% \mathrm{He}$ & 20 & & & & & & & & & & & & & \\
\hline massflow $(\mathrm{kg} / \mathrm{s})$ & 2.12 & & & & & & & & & & & & & \\
\hline pressure(kPa) & 5500 & & & & & & & & & & & & & \\
\hline \multicolumn{15}{|c|}{ (\# of fittings) } \\
\hline PRIMARY & $\begin{array}{l}\text { Tt } \\
\text { C }\end{array}$ & $\begin{array}{l}\text { LTOT }_{\text {Tot }} \\
\mathrm{m}\end{array}$ & $\begin{array}{l}\text { D } \\
\text { in }\end{array}$ & $N_{90}$ & $\mathbf{N}_{45}$ & $\mathbf{N}_{\text {TEE }}$ & $\mathbf{N}_{\text {VAL }}$ & Mach & $\begin{array}{c}\mathrm{u} \\
\mathrm{m} / \mathrm{s}\end{array}$ & $\begin{array}{l}\text { PDYN } \\
\mathrm{kPa}\end{array}$ & $\Delta \mathrm{p} / \mathbf{p}_{\text {STRT }}$ & $\Delta p / P_{\text {fiT }}$ & $\Delta p^{\prime} / p_{\text {Tот }}$ & $\begin{array}{c}\mathbf{h} \\
W / m^{2} K\end{array}$ \\
\hline p2/p3 & 65 & 2.90 & 2.50 & 3 & 0 & 0 & 1 & 0.027 & 29.6 & 3.7 & $0.05 \%$ & $0.11 \%$ & $0.16 \%$ & 2575 \\
\hline p4/p5 & 469 & 3.92 & 2.50 & 3 & 0 & 0 & 1 & 0.041 & 65.0 & 8.2 & $0.16 \%$ & $0.24 \%$ & $0.40 \%$ & 2869 \\
\hline p6/p9 & 950 & 12.80 & 3.00 & 2 & 2 & 0 & 0 & 0.036 & 74.3 & 6.5 & $0.34 \%$ & $0.08 \%$ & $0.42 \%$ & 2212 \\
\hline p10/p13 & 500 & 10.56 & 3.00 & 3 & 2 & 0 & 1 & 0.029 & 47.0 & 4.1 & $0.18 \%$ & $0.13 \%$ & $0.31 \%$ & 2078 \\
\hline p14/p15 & 96 & 1.09 & 2.50 & 3 & 1 & 1 & 1 & 0.029 & 32.3 & 4.1 & $0.02 \%$ & $0.16 \%$ & $0.18 \%$ & 2607 \\
\hline p16/p1 & 35 & 2.86 & 2.50 & 5 & 0 & 1 & 1 & 0.026 & 27.0 & 3.4 & $0.05 \%$ & $0.16 \%$ & $0.20 \%$ & 2541 \\
\hline \multicolumn{15}{|c|}{$0.87 \%$} \\
\hline SECONDARY & $\begin{array}{l}\mathrm{Tt} \\
\mathrm{C}\end{array}$ & $\begin{array}{c}\text { LTOT }_{\text {Tot }} \\
\mathrm{m}\end{array}$ & $\begin{array}{l}\text { D } \\
\text { in }\end{array}$ & $\mathbf{N}_{90}$ & $\mathbf{N}_{46}$ & $\overline{\mathbf{N}_{\text {TEE }}}$ & $\mathbf{N}_{\text {VAL VE }}$ & Mach & $\begin{array}{c}\mathrm{u} \\
\mathrm{m} / \mathrm{s}\end{array}$ & $\begin{array}{l}\text { PDYN } \\
\mathrm{kPa}\end{array}$ & $\Delta \mathrm{p} / \mathrm{p}_{\text {STRT }}$ & $\Delta p / p_{\text {fIT }}$ & $\Delta \mathbf{p} \mathbf{p}_{\text {TOT }}$ & $\begin{array}{c}\mathbf{h} \\
W / m^{2} K\end{array}$ \\
\hline $52 / s 3$ & 65 & 3.69 & 3.00 & 4 & 0 & 0 & 1 & 0.032 & 18.7 & 4.3 & $0.07 \%$ & $0.16 \%$ & $0.23 \%$ & 1898 \\
\hline$\$ 4 / s 5$ & 450 & 7.79 & 3.50 & 4 & 0 & 0 & 1 & 0.035 & 29.3 & 5.0 & $0.14 \%$ & $0.18 \%$ & $0.32 \%$ & 1603 \\
\hline $56 / 59$ & 900 & 7.77 & 3.50 & 4 & 0 & 0 & 1 & 0.045 & 47.6 & 8.1 & $0.23 \%$ & $0.30 \%$ & $0.52 \%$ & 1803 \\
\hline s10/s11 & 515 & 2.74 & 3.50 & 3 & 0 & 0 & 2 & 0.036 & 32.0 & 5.5 & $0.05 \%$ & $0.27 \%$ & $0.33 \%$ & 1630 \\
\hline $\mathrm{s} 12 / \mathrm{s} 1$ & 35 & 1.65 & 3.00 & 3 & 0 & 0 & 2 & 0.031 & 17.0 & 4.0 & $0.03 \%$ & $0.20 \%$ & $0.23 \%$ & 1880 \\
\hline
\end{tabular}

\section{C-2. REFERENCES}

1. Incropera, F.P. and DeWitt, D.P., 1996, Introduction to Heat Transfer, $3^{\text {rd }}$ edition, Wiley, 1996.

2. Miller, D.S., Internal Flow Systems, $2^{\text {nd }}$ edition, Gulf Publishing, 1990.

3. Hirschfelder, J.O., Curtiss, C.F., and Bird, R.B., 1964, Molecular Theory of Gases and Liquids, Wiley. 


\section{Appendix D}

\section{Original Specifications for HTGL Provided by INL}




\section{Appendix D}

\section{Original Specifications for HTGL Provided by INL \\ D-1. INTRODUCTION}

\section{D-1.1 Scope}

This document contains the requirements for a conceptual design of a high temperature test loop to characterize the performance of components such as heat exchangers and valves used to transfer energy from a Very High Temperature Reactor (VHTR) to end uses such as a high temperature gas turbine or a thermochemical hydrogen production plant. The test loop will be sized to accommodate components fabricated using designs and techniques representative of commercial scale systems. This test loop will fill the niche between fundamental materials R\&D, coupon testing, computer modeling and integrated system demonstration.

\section{D-1.2 Deliverables}

Physical deliverables at the end of this stage of the project are as follows:

- Conceptual design description consisting of the system design requirements and a brief description of the design layout, major components, decision processes, and recommended control parameters.

- $\quad$ Piping \& instrumentation diagram

- $\quad$ Preliminary integrated system layout (3-D model)

- 3-D layout drawings of major components

- Envelope drawings for the vessels or other engineered components

- Layout conceptual instrumentation diagrams

- $\quad$ Specification of major components: circulator(s), valves, piping, heat sources, heat sinks, controls and recommended potential vendors

- Summary of utilities requirements

- $\quad$ Preliminary thermodynamic analysis of entire system including heat loss to the surroundings

- $\quad$ Scoping calculations of required piping thicknesses to meet ASME B31.3 Code requirements

- $\quad$ Preliminary piping stress analysis including thermal stresses

- $\quad$ Equipment cost estimate.

\section{D-2. FUNCTIONAL AND PERFORMANCE REQUIREMENTS}

\section{D-2.1 Test Loop Functional Overview}

The test loop is intended to provide an environment prototypical of the process conditions in the primary and secondary loops of a VHTR and its accompanying power or hydrogen generation plants. The environment consists of flowing, high temperature, high pressure nonflammable gas. The testing will evaluate the performance of various materials and equipment items in conditions similar to their intended service, but without the difficulties of operating a VHTR or hydrogen plant to achieve them. The expected general process arrangement is illustrated in Figure D-1. 


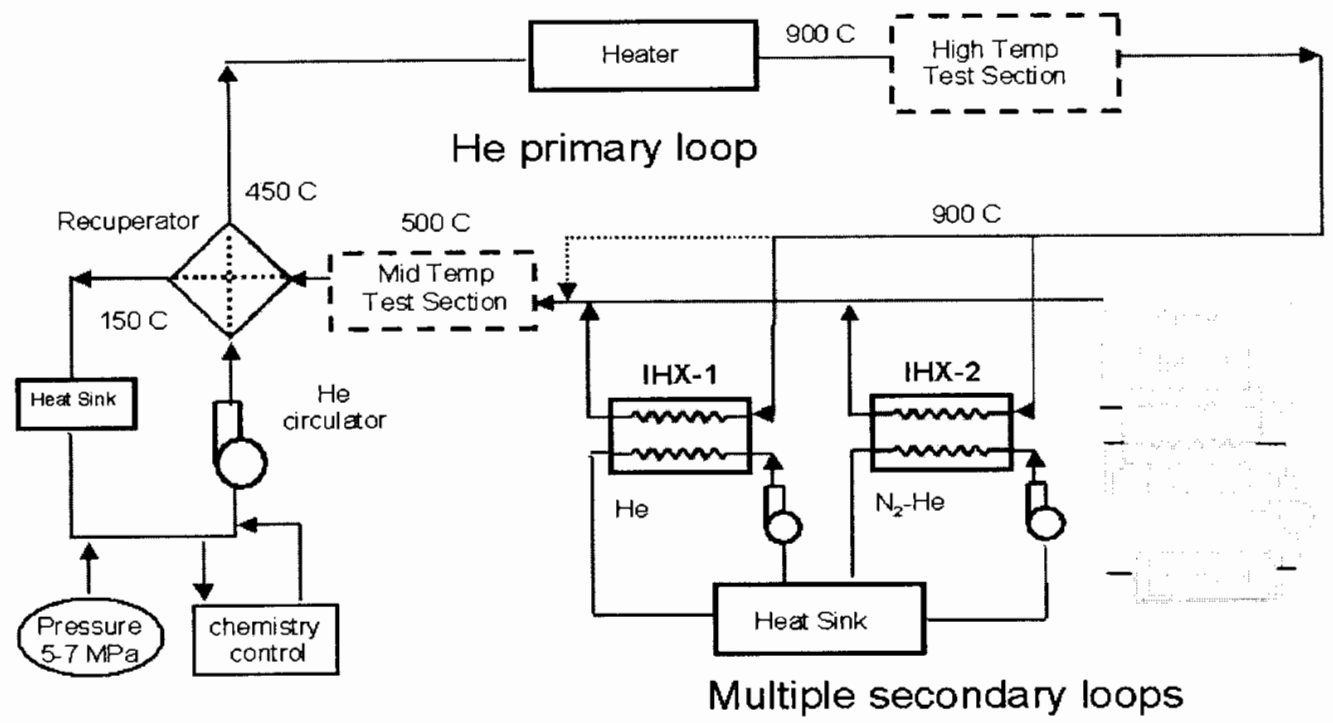

Figure D-1. Schematic flow sheet of the test loop with three test stations (IHX 1-3).

The items to be tested will include heat exchangers, valves, piping, instrumentation, and related items. The basic form of a test will be to flow hot gas through a test item for a specified period then to remove and examine the item for signs of degradation. If necessary such as for heat exchanger testing, the capability of simulating a cooler secondary loop will be available. The flow rate and temperature of gas through the test item will be regulated or varied as needed for the test. The properties and performance measures expected to be tested include the following:

- Short term structural integrity

- Long term creep

- Thermal shock resistance

- Differential thermal expansion accommodation

- Mechanical shock resistance

- $\quad$ Effects of rapid depressurization

- Corrosion characteristics or fouling

- $\quad$ Long term/high cycle degradation of performance

- $\quad$ Pressure drop

- Overall heat transfer coefficient of heat exchangers

- Actuation torque of valves at high temperature and rated flow

- $\quad$ Sealing characteristics of valves at high temperature and rated pressure

- $\quad$ Performance of various joining techniques.

The test loop shall allow various test components to be individually installed and removed from a number of test stations. Because different tests might require different conditions, each test station will have the ability to adjust within reasonable limits the temperature and flow rate of hot gas supplied to the station from the main loop. The anticipated duration of each test will be anywhere from 1-1000 hours. This variety of durations makes it necessary that test items can be safely and conveniently installed or removed from a test station while the rest of the loop runs without disruption. For long term-operation, the test must be able to operate unattended, although operator attendance during normal working hours can be assumed. 


\section{D-2.2 General System Performance Requirements}

Table D-General HGTL System Performance Requirements.

\begin{tabular}{|c|c|c|c|}
\hline & Primary Loop & $\begin{array}{l}\text { Test Stations - } \\
\text { Primary Side } \\
\end{array}$ & Secondary Loops \\
\hline Gas composition & Helium & Helium & $\mathrm{He}, \mathrm{He} / \mathrm{N}_{2}$, air, $\mathrm{O}_{2}$ \\
\hline $\begin{array}{l}\text { Normal operating } \\
\text { pressures }\end{array}$ & 0.2 and $8 \mathrm{MPa}$ & 0.2 and $7.5 \mathrm{MPa}$ & $0.1-7 \mathrm{MPa}$ \\
\hline $\begin{array}{l}\text { Maximum operating } \\
\text { pressure }\end{array}$ & $8 \mathrm{MPa}$ & $8 \mathrm{MPa}$ & $8 \mathrm{MPa}$ \\
\hline $\begin{array}{l}\text { Maximum gas } \\
\text { temperature }\end{array}$ & $\begin{array}{l}900^{\circ} \mathrm{C} \text { (later increased } \\
\text { to } 950^{\circ} \mathrm{C} \text { ) }\end{array}$ & $\begin{array}{l}900^{\circ} \mathrm{C} \text { (later } \\
\text { increased to } 950^{\circ} \mathrm{C} \text { ) }\end{array}$ & $900^{\circ} \mathrm{C}$ \\
\hline $\begin{array}{l}\text { Design return temp to } \\
\text { heater }\end{array}$ & $450^{\circ} \mathrm{C}$ & & \\
\hline Gas flow rate & $0.16 \mathrm{~kg} / \mathrm{sec}$ & & \\
\hline Operating heat flux & $\begin{array}{l}0-500 \mathrm{~kW} \text { normal, can } \\
\text { be higher for heatup }\end{array}$ & & $0-500 \mathrm{~kW}$ \\
\hline Heating & $\begin{array}{l}\text { Ambient to } 900^{\circ} \mathrm{C} \text {; rate } \\
\text { to be determined }\end{array}$ & $\begin{array}{l}\text { Ambient to } 900^{\circ} \mathrm{C} \text {; } \\
\text { rate to be determined; } \\
\text { same for cooling. } \\
\text { Ability to cycle } \\
\text { nonstop between } \\
\text { heating and cooling }\end{array}$ & \\
\hline
\end{tabular}

\section{D-2.3 Design Life}

Design for a service life of 15 years with normal maintenance and some equipment replacement ( $<25 \%$ of total capital investment). Assume 2000 hours/year of heated operation.

\section{D-2.4 Plant Operator Interfaces}

The test stations and any equipment in them will in general be operated from a computer console with all equipment controlled remotely. This assures operator safety during testing of novel equipment and may be accomplished via pneumatic or electrical actuators or manually operated valves with adequate physical shielding to isolate the operator from the test system. The test loop itself, when simply circulating hot gases or being prepared for operation, may be operated either remotely via computer control or with manually operated instruments and equipment.

\section{D-2.5 Safety Significance Category and Quality Requirements of Conceptual Design}

The safety significance of the conceptual design is "Consumer Grade." No output documents are quality records, however all output documents must receive a technical peer review by a person other than the main author, and be approved by the Project/Lead Engineer or his/her designee. 


\section{D-3. SUBSYSTEM REQUIREMENTS}

\section{D-3.1 Primary Loop}

\section{D-3.1.1 Primary Loop Heater}

The primary loop heating shall be either natural gas firing or electrical resistance. The heating may take place in multiple stages if advantageous. Because of the severe service of this component, maintenance of and the ability to replace heating elements shall be addressed in the conceptual design.

Control of the primary heater shall maintain the primary flow temperature within $10^{\circ} \mathrm{C}$ of the setpoint. The heater must provide stable safe operation with net test item loads of 0-500 $\mathrm{kW}$. Because of heat losses to the primary loop cooler and the room, the demand on the heater will not be zero even if there is no test load on-line. The system should be insulated to reduce his heat loss should be a practical minimum for operator safety, personnel comfort, and reduced effect on the building's heating ventilation and air conditioning (HVAC) system.

Provide startup heating sufficient to bring the circulating gas to operating temperature in no more than two hours, and quicker is better. As long as the gas temperature is hot and stable enough for testing, the entire mass of the system need not be at full temperature. Estimate the heatup time of the system from ambient temperature to $900^{\circ} \mathrm{C}$.

Any special needs of the heater for a safe and stable shutdown must be identified for inclusion in future operating instructions. In particular, any issues connected with a sudden emergency shutdown of the system without operator attention must be factored into the hardware design.

\section{D-3.1.2 Primary Loop Circulator}

This device is intended only for circulating gas around the loop and is not the source of the system pressure. The circulator shall be an oil-free type that does not introduce either lubricants or external air into the system. In concert with pulsation dampeners if used, it shall provide non-pulsing flow with maximum pulse amplitude less than $1 \%$ of the total absolute pressure.

The circulator must be able to operate at atmospheric pressure for initial temperature-only testing of new equipment as well as at $8 \mathrm{MPa}$ for full-conditions testing. Because approximately the same volumetric flow is needed at both conditions two circulators may be necessary, one for each pressure.

\section{D-3.1.3 Filter}

To collect scale, aerosols, or debris from the circulator or from the test items, a filter should be provided in the primary loop.

\section{D-3.1.4 Primary loop cooling and heat recovery}

Because the circulator and filter are expected to be relatively low temperature devices it might be necessary to drop the primary flow temperature several hundred degrees $C$ below the component test temperature. If this is done, a recuperator as shown in the schematic flow sheet may be used to minimize heat losses. A compact plate/fin compact heat exchanger is suggested but not required for this application. A primary loop cooler will also be necessary if such a cooling and reheat circuit is used. That cooler shall reject its heat to the system heat sink described as part of the support facilities. 


\section{D-3.2 Test stations}

\section{D-3.2.1 Physical arrangement}

The system shall have at least four test stations where separate tests can be performed on individual items or sets of smaller items. Each station must be able to accommodate a 300 -pound test item that has external dimensions up to $30 \times 30 \times 60$ inches installed in either vertical or horizontal positions. To provide the greatest flexibility in how the test item itself can be configured, all piping and instrumentation connections to the test item must originate from just one vertical plane (for instance, the back or side wall of the test station) or optionally from overhead with at least 96 -inch clearance from the floor. Each station will provide enough open access that a small forklift can be used to help install the test item.

The final design report shall provide detailed drawings and design descriptions for the interfaces between the unspecified test articles and the test stations.

\section{D-3.2.2 Isolation and containment}

Each test station shall provide physical shielding or containment so that if a test item should unexpectedly leak nearby personnel or equipment are not harmed by jets of hot gas. This is to include possible leaks from the primary and secondary loop connections even if no test item is installed at that test station. Any such shielding or containment must still allow visual inspection of the test item for leaks either directly or by an installed video camera. If a test item might fail in a way that creates a projectile hazard, containment of that problem will be an additional part of designing and setting up that test.

To allow installation, inspection, or removal of test items while the whole system is running, each test station will have lock out capability on the connections to the primary and secondary gas loops and on any energy sources for the test item such as electrical or pneumatic power to valves. The presence of a test item in the test station or adjacent ones must not interfere with installing or removing lock out devices.

\section{D-3.2.3 Control of test conditions and data collection}

Each test station shall have instrumentation and controls to allow testing at different conditions at each station. These controls will act on the gas drawn from the primary loop to regulate flow, temperature, and pressure as needed with the capability of providing ramped or cyclic variations of each of these. These changes can be accomplished with control valves and a heat exchanger. Because the primary loop circulator will generate only a modest pressure rise, if reduced pressure operation is needed at a test station while the primary loop is at full pressure, that gas will either have to be vented to the exhaust stack with compensatory makeup provided by the primary loop pressure maintenance system or it will have to be recompressed with the system charge compressor. Consequently, a reduced primary/hot flow capacity at the test station is acceptable when operating at reduced pressure.

Each test station will have data collection capability. The pressure and flow of the primary and secondary side flows, as well as the feed and supply temperatures and the pressure drop of each across the test unit, must at a minimum be recorded. In addition, the test station must provide additional data collection points for twelve thermocouples, twelve strain gauges, and six 4-20 mA instrument outputs all to be provided as part of the test item. The data logging interval for these variables must individually selectable by the operator to cover the range of one second to one hour. 


\section{D-3.2.4 Utilities for the test item}

The test station shall have tie-ins available to supply basic utilities to the test item. These shall include power (120/240 VAC, low voltage instrument power), instrument air, and cooling water (if used elsewhere) sufficient for $500 \mathrm{~kW}$ removal.

\section{D-3.3 Secondary Loops}

\section{D-3.3.1 Secondary Loop Circulators}

This device is intended only for circulating gas around the loop and is not the source of the system pressure. The circulator shall be an oil-free type that does not introduce either lubricants or external air into the system. In concert with pulsation dampeners if used, it shall provide non-pulsing flow with a maximum pulse amplitude less than $1 \%$ of the total absolute pressure.

The circulator must be able to operate at atmospheric pressure for initial temperature-only testing of new equipment as well as at $8 \mathrm{MPa}$ for full-conditions testing. Because approximately the same volumetric flow is needed at both conditions two circulators may be necessary, one for each pressure.

\section{D-3.4 Support systems}

\section{D-3.4.1 Vacuum Pump}

To allow removal of air from the system before filling it with other gases a vacuum pump capable of evacuating the primary loop to 50 millitorr in one hour shall be provided. Two or more evacuation and refill cycles might be used to remove air or previous gases from the loops. Switching valves and appropriate piping shall be provided to allow the vacuum pump to connect to any of the secondary loops as well as the primary loop, including any test items. The vacuum pump system must not permit oil to enter the primary or secondary loops even during upset conditions.

\section{D-3.4.2 Gas supply, pressurization, and depressurization}

The primary and secondary loops shall be filled with gases from conventional laboratory cylinders if the total volume is small enough or from a tube trailer(s) for larger amounts. With a design pressure of $8 \mathrm{MPa}$ or about $1200 \mathrm{psia}$, the cylinders themselves can provide the pressurization needed. However, to obtain the best usage of gases, a staged filling of the system may used. Partly empty cylinders would be used to provide the initial pressurization from atmospheric pressure to one or more levels of intermediate pressure, with full bottles only used at the end to reach full pressure. Alternatively, the use of a charge compressor to pump the contents of partly depleted low-pressure bottles up to the design pressure should be considered.

Pressures in the primary and secondary loops shall be controlled by venting or adding gas of the proper composition. This control must work during initial pressurization, gas heatup, and hot gas circulation.

\section{D-3.4.3 Chemistry Control System}

The basic composition of the circulating gases will be established by evacuating and filling the process loops with the desired gases from high-pressure bottles, most likely high purity helium or helium/nitrogen mixes. Once the gases are circulating, minor composition adjustments might be made for specific tests. The gases to added might include $\mathrm{N}_{2}$ to adjust thermal conductivity or density; air or $\mathrm{O}_{2}$ to 
create an oxidizing atmosphere; $\mathrm{H}_{2}$ or $\mathrm{CH}_{4}$ to create a reducing atmosphere; or $\mathrm{H}_{2} \mathrm{O}, \mathrm{CO}_{2}, \mathrm{SO}_{2}$, or $\mathrm{H}_{2} \mathrm{~S}$ for corrosion tests (especially in the secondary loops). The amounts of these species to be added or removed will be small, corresponding to $1-1000 \mathrm{ppm}$ when diluted in the loop gas, so reactivity of the mixture will not be an issue (though hazards of the undiluted gases must still be considered). The system design shall include provisions for the following:

- $\quad$ Adding known small amounts of other gases to the system from laboratory cylinders

- Adding a known small amount of water or water vapor

- $\quad$ Removing trace residual oxygen with a getter material to be specified

- Capturing gases on a bed of absorptive material such as activated carbon, zeolite, or lime.

The final gas composition must be monitored. The conceptual design shall include locations for and descriptions of gas sampling and conditioning systems for feeding either a sample container for offline analysis or an on-line instrument such as a mass spectrometer or gas chromatograph, which should also be described.

\section{D-3.4.4 Gas vent system}

Vented gas from the primary and secondary loops shall be routed to an exhaust stack capable of handling large volumes of $900^{\circ} \mathrm{C}$ inert gas. The pressure relief devices in this system shall also be routed to that stack or other safe location.

\section{D-3.4.5 System heat sink}

In order to test the performance of heat exchangers and to reduce the gas temperature prior to the primary circulator, considerable thermal energy must be continuously removed from the system. Comparison of an evaporative cooling tower versus a fan driven convection system is needed. The evaporative cooling tower may be smaller, cheaper, and use less electricity; however, it requires freeze protection, periodic biocide treatment, and other maintenance so the life cycle cost may be greater. However, an air cooler may have better turndown performance. It is allowable to use different heat sinks (for instance two air coolers, or an air cooler and cooling tower) if different services are best accommodated that way. If an air cooler is used, the consequences for building ventilation of discharging that heat to the room or alternatively discharging that quantity of heated air from the room must be considered. An air cooler, if it is large, may have to be installed outside.

The expected system cooling rate during shut down with this heat sink (sized for process purposes) shall be calculated. If more than a few hours of cooling are needed to work on the high-maintenance parts of the system, additional cooling capacity might be necessary.

\section{D-4. ENGINEERING DESIGN REQUIREMENTS}

\section{D-4.1 Codes and Standards}

For conceptual design many of the analyses and design features required by the listed Codes will not have been completed, however the conceptual design should take these Codes into account so that final design can be developed directly from the conceptual design. 


\section{D-4.2 Civil and Structural}

Structures used to support equipment shall be designed for the loads they will encounter in normal handling and service (including transportation) and for seismic loads in accordance with American Society of Mechanical Engineers (ASME) B31.3. Pipe supports shall be in accordance with ASME B31.3. Tubing 1" OD or less may be supported using engineering judgment and rules of thumb.

\section{D-4.3 Mechanical}

\section{D-4.3.1 Pressure Vessels}

Any pressure vessels used by the system shall comply with the ASME Boiler and Pressure Vessel Code Section VIII, Div. 1, or Div. 2. Exceptions are vessels that fall below pressure and size limits as delineated in the Code.

\section{D-4.3.2 Pipe and Tubing}

Pipe shall be designed and in accordance with ASME B31.3, Normal Service Conditions, with the following exceptions:

- $\quad$ Lines with pipe wall temperatures exceeding the limits of the ASME B31.3 Code. Such lines shall be qualified by an engineering analysis showing similar factors of safety as the B31.3 Code.

- Lines utilizing experimental materials not listed under the ASME B31.3 Code. Such lines shall be qualified by an engineering analysis showing similar factors of safety as the B31.3 Code.

- The components being tested in the test sections. Protection from failure for such items shall be provided by engineered features (e.g., surrounding protective structures) and/or specific engineering analyses.

- Low service utility lines, defined as carrying non-flammable non-hazardous materials at low temperature $\left(<200^{\circ} \mathrm{F}\right)$ and pressure $(<150 \mathrm{psig})$ need not be in accordance with ASME B31.3 requirements, but all components in such lines shall be rated for the design pressure of the line. Flexible elements (bellows, braided flex hose, etc.) need not be specified in accordance with ASME B31.3, but must be rated by the manufacturer for the intended service as evidenced by published catalog information or specific certification.

- $\quad$ Tubing 1-inch outer dimension (OD) or less is not required to be in accordance with ASME B31.3 requirements. However, pressure design (minimum wall thickness) shall be in accordance with ASME B31.3. Tubing connections may be made by compression fittings or welding.

\section{D-4.4 Electrical Power}

Electrical power design shall be in accordance with the National Electric Code.

\section{D-4.5 Instrumentation and Control}

Instrumentation and control equipment shall be approved for installation and use in the environmental conditions specified. The control system shall be capable of controlling all process functions necessary for stand-alone operation of the system. In addition, it shall detect hazardous off- 
normal conditions and automatically place the entire system and all test items into a safe mode. The instrument readings that triggered that situation and those during the safety testing of the system shall be recorded for later analysis.

The following guidance is provided regarding specification of instruments throughout the system.

1. Pressure. Standard pressure transducers are expected to be applicable. The transducers may be placed on a pigtail to reduce temperature and the dry process gas obviates condensation concerns.

2. Temperature. Standard thermocouples in protective thermowells or with thick walled sheaths are expected to serve well. Ensure thermowell walls are not so thick as to create a large thermal lag problem.

3. Flow. Pitot tube type will probably be used but other types should be investigated. Because of the high temperature, pitot tubes for these measurements may not be off the shelf. It will probably be possible to take flow measurements in cooler sections to eliminate this concern.

\section{D-4.6 Other Requirements}

The equipment shall be laid out in an open arrangement that provides easy access for maintenance to instruments, control valves, rotating equipment, and the high-temperature heaters.

\section{D-4.7 Natural Phenomena and Operating Environment}

The major process equipment shall be analyzed for seismic stability in accordance with Uniform Building Code provisions, seismic zone $2 \mathrm{~B}$, and importance factor of 1.5 . Tubing and low service utility lines need not be considered in the seismic analysis. humidity.

The design ambient conditions for the system are $40-90^{\circ} \mathrm{F}$ temperature and $0-80 \%$ relative 


\section{Appendix E}

\section{Transient Maneuvers - Specification for HTGL}




\section{Appendix E}

\section{Transient Maneuvers - Specification for HTGL}

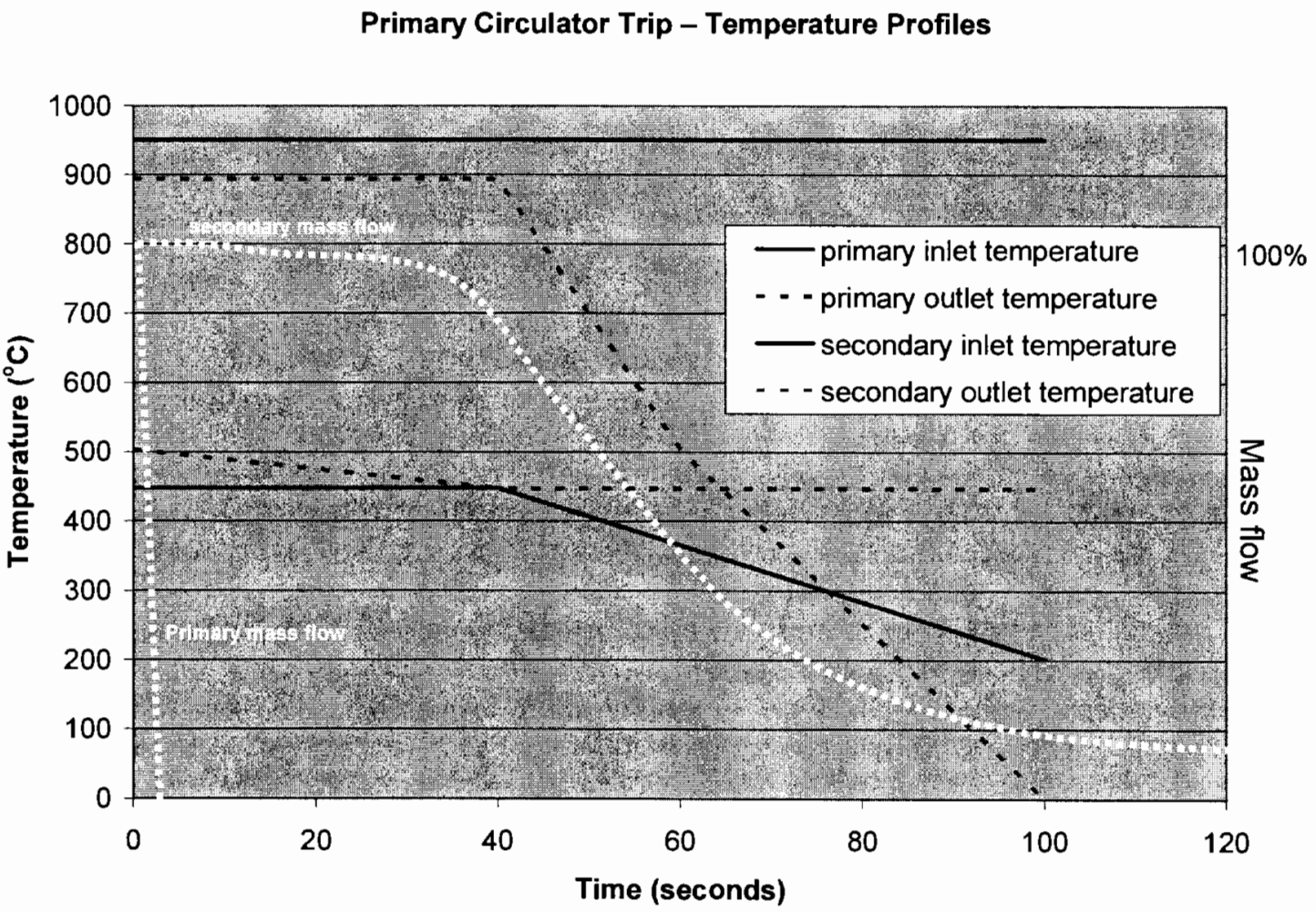

Figure E-1. The primary circulator trip results in rapid cessation of primary flow, with continuing secondary flow. The secondary flow tends to quench the hot core, creating elevated thermal stress and potential cracking after repeated cycles. 


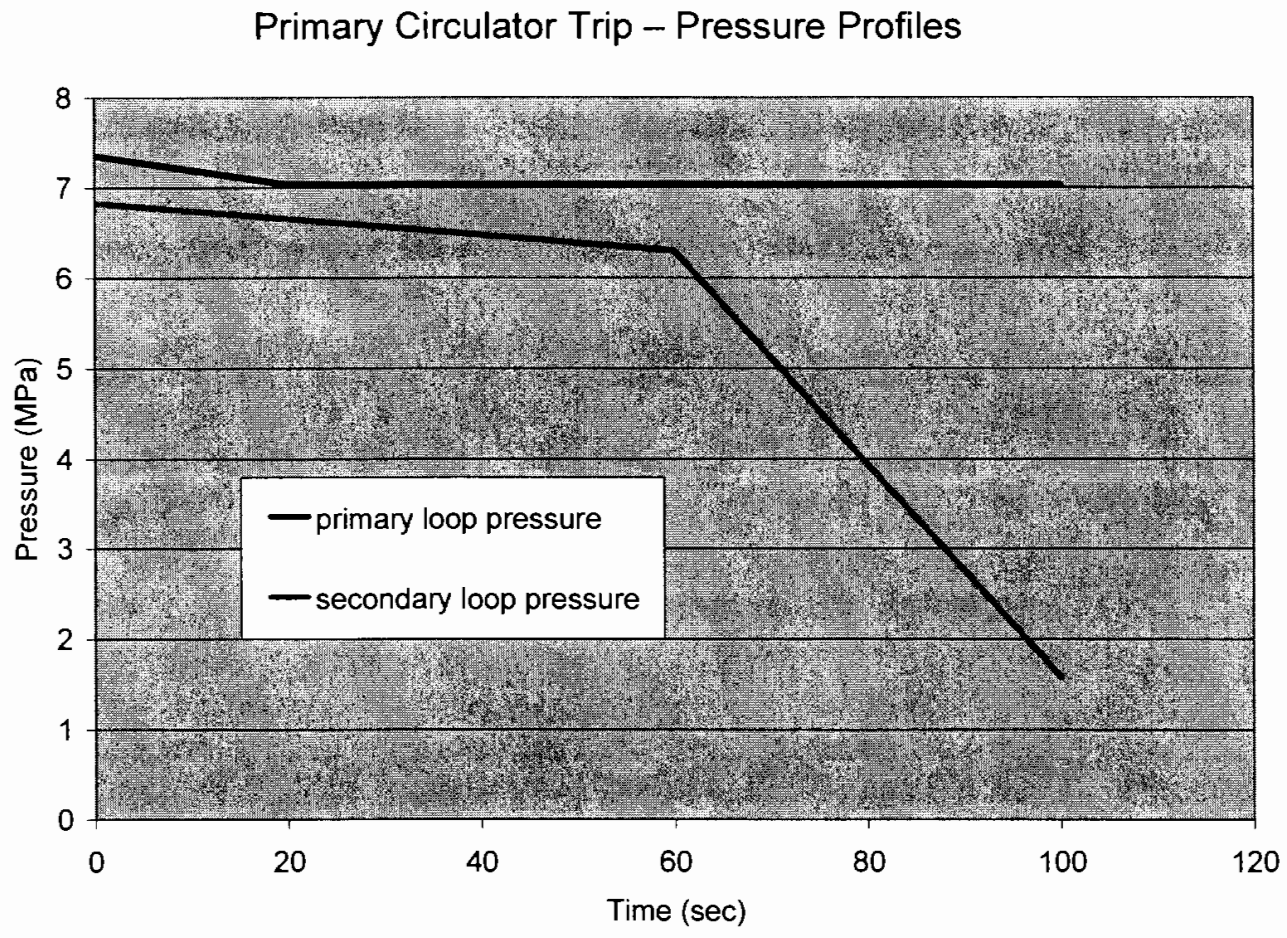

Figure E-2. Pressure transient for primary circulator trip.

\section{Engine Fault - Loss of Secondary Flow Rate Temperature Profiles}

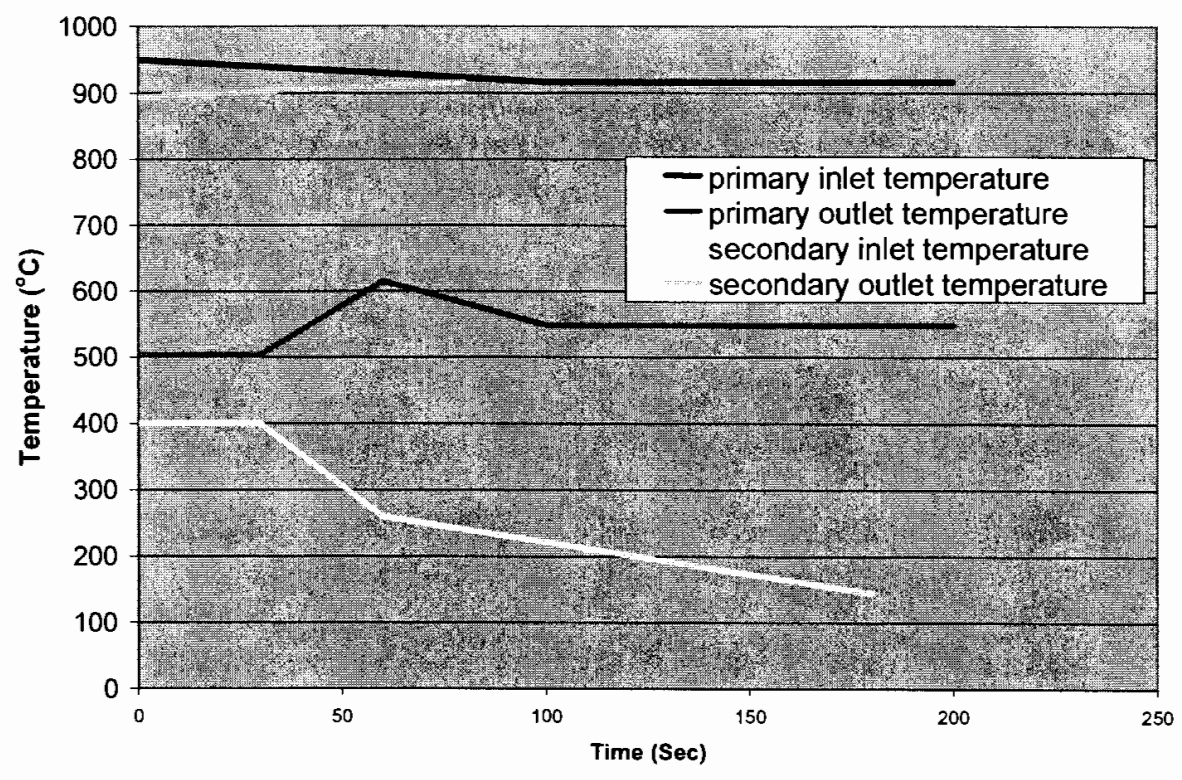

Figure E-3. Gas turbine faults result in a loss of secondary flow, followed by a reactor shutdown sequence. 


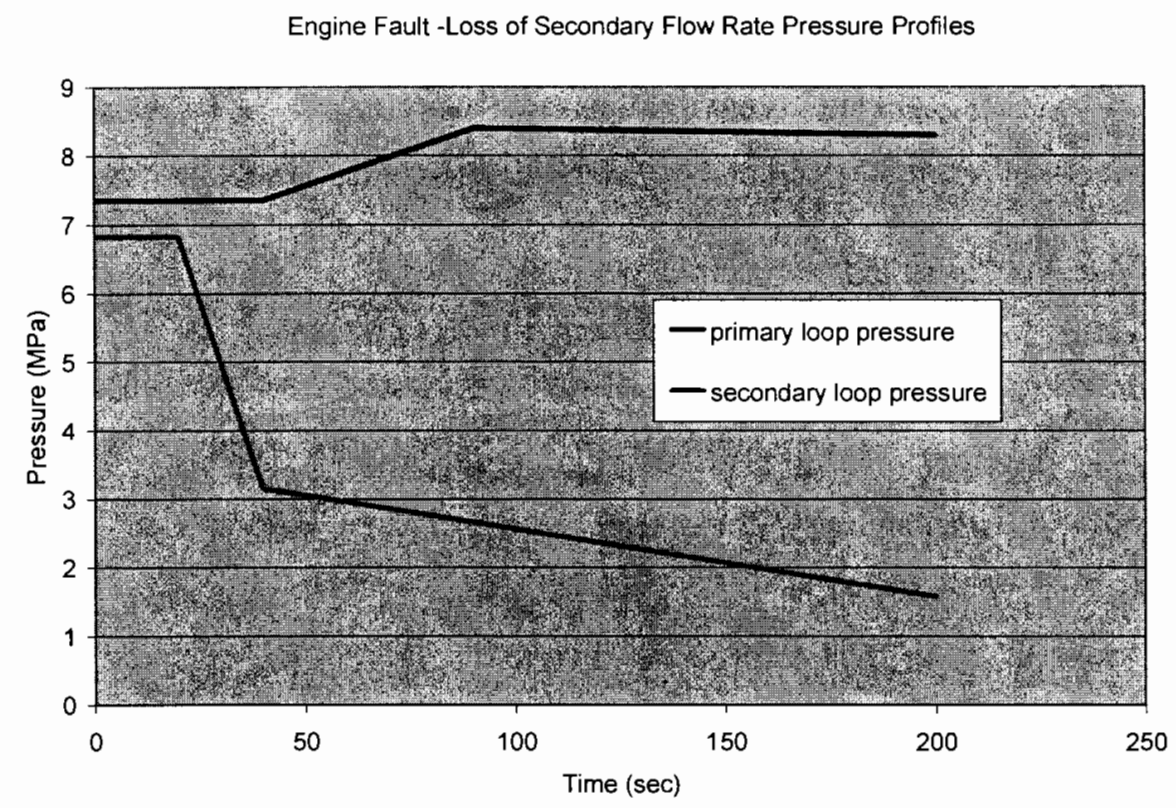

Figure E-4. Secondary pressure drops rapidly as engine pressure ratio diminishes. Primary loop pressure rises inversely proportional to the gas temperature. 


\section{Appendix F}

\section{Transient Thermal Analysis of Heater-Discharge Duct}




\section{Appendix F}

\section{Transient Thermal Analysis of Heater-Discharge Duct}

IHX test requirements call for simulation of temperature transients corresponding to various maneuver and failure scenarios, for which relevant time scales are on the order of seconds. Because thermal lag introduced by test-loop piping poses a potential corrupting influence on these tests, it is desirable to minimize its importance.

An analysis is developed to predict the piping thermal response between the heater discharge and IHX inlet (stations P6 to P9 of Figure F-1), although the method could be applied equally to other insulated piping runs. For the heater-discharge pipe, it is shown that thermal lag is essentially negligible relative to time scales for imposed thermal transients.

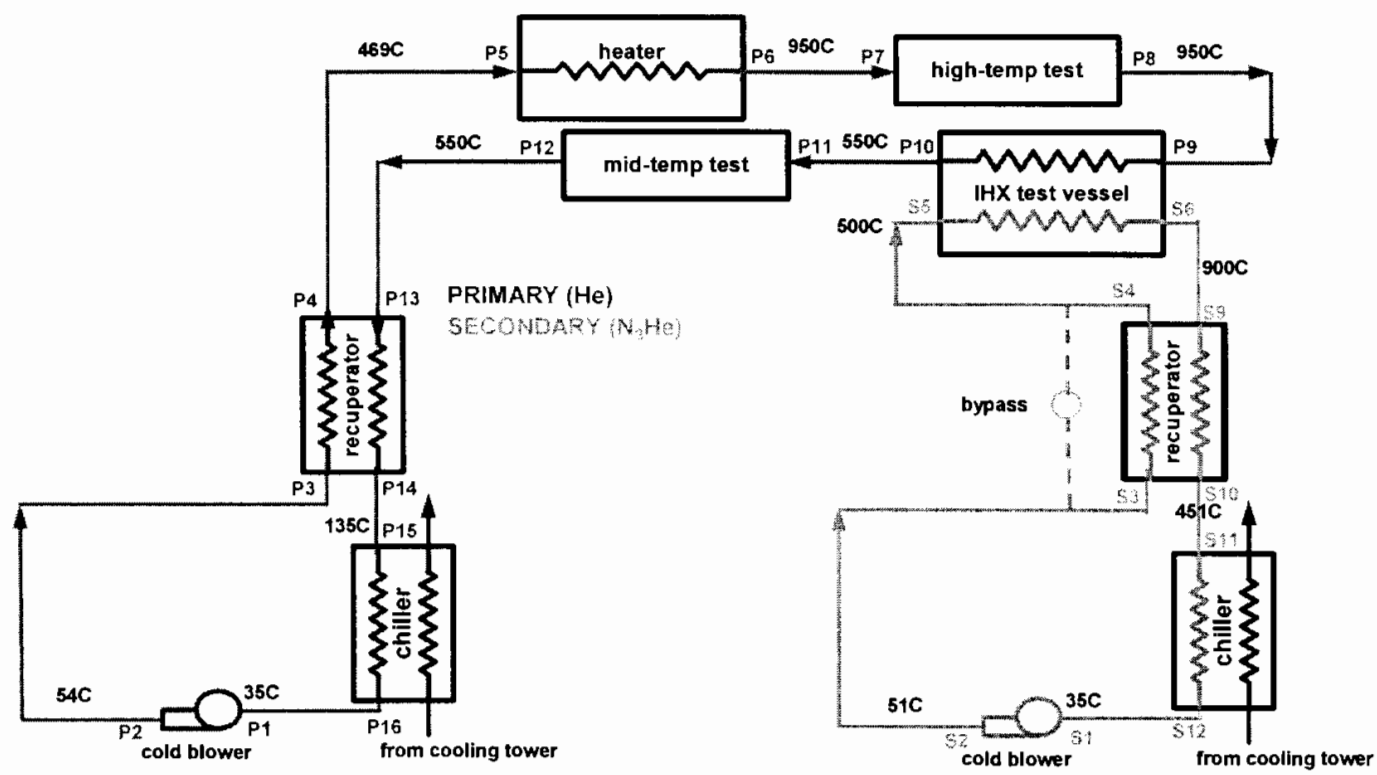

Figure F-1. Simplified schematic diagram based roughly on indirect gas turbine cycle configuration.

A rough estimate is developed for the thermal time constant across a long insulated pipe, by considering the response of the discharge temperature to a step change at the inlet. The pipe insulation strategy is that developed in the main body of this report (see Section 4.1.7). Simplifying for discussion purposes, the structure consists of a thin sheet-metal flow liner surrounded by external insulation. Steady conditions are assumed prior to the step change, i.e. the gas and liner temperature are initially equal aside from any small difference arising from steady conduction.

We consider first the worst-case (slowest response) scenario in which the wall temperature remains fixed, as would apply in the limit of high thermal inertia of the flow liner. As a further simplification, a uniform heat-transfer coefficient is prescribed, strictly appropriate for fully-developed temperature and velocity profiles. The steady-state solution reached under these conditions is sketched qualitatively below for $0<\mathrm{x}<\mathrm{L}$, and governed by the equation following: 


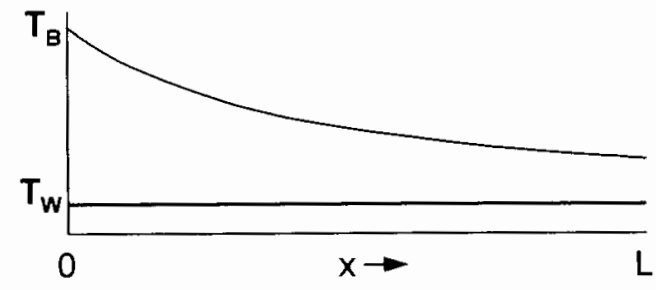

energy balance: $\quad \dot{m} c_{p} \frac{d T_{G}}{d x}=q=-\frac{h A}{L}\left(T_{G}-T_{W}\right)$

solution: $\quad \frac{T_{G}(x)-T_{W}}{T_{G}(0)-T_{W}}=e^{-4\left(\frac{x}{D}\right) \frac{\mathrm{Nu}}{\operatorname{Re} \operatorname{Pr}}}$

In the equations above, $\mathrm{T}_{\mathrm{G}}$ is the bulk gas temperature, and $\mathrm{T}_{\mathrm{W}}$ is the wall (liner) temperature which is presumed constant. Nusselt, Reynolds, and Prandtl numbers ( $\mathrm{Nu}, \mathrm{Re}, \mathrm{Pr})$ are defined following the usual conventions.

It is further noted that the steady solution above is established for $t>t_{\text {trans }}$, the time required for the gas to transit the pipe. For cases of interest $t_{\text {trans }}$ is negligible compared with the time scale for imposed thermal transients.

The above relation establishes the minimum change in discharge bulk gas temperature following a step change at the inlet. In the 'short-pipe' limit $(\mathrm{x} / \mathrm{L} \rightarrow 0)$ the full $\Delta \mathrm{T}$ is experienced at the discharge irrespective of wall thermal response. For 'long' pipes $(\mathrm{x} / \mathrm{L} \rightarrow \infty)$ the gas equilibrates with the wall, and overall transient response is governed by the wall time constant. Inserting representative values above for the heater-discharge pipe, we find

$\frac{T_{G}(L)-T_{W}}{T_{G}(0)-T_{W}}=0.19$

According to this result, the gas approaches the wall temperature for the 'long' heater-discharge pipe, making the wall thermal response the controlling factor.

An estimate of the time constant for liner thermal response is based on the idealized 'infinite slab' model in Figure F-2. It is noted that the heat transfer coefficient differs dramatically on the inner (flowing gas) and outer (insulated) surfaces of the liner, supporting the adiabatic boundary condition applied in the model. 

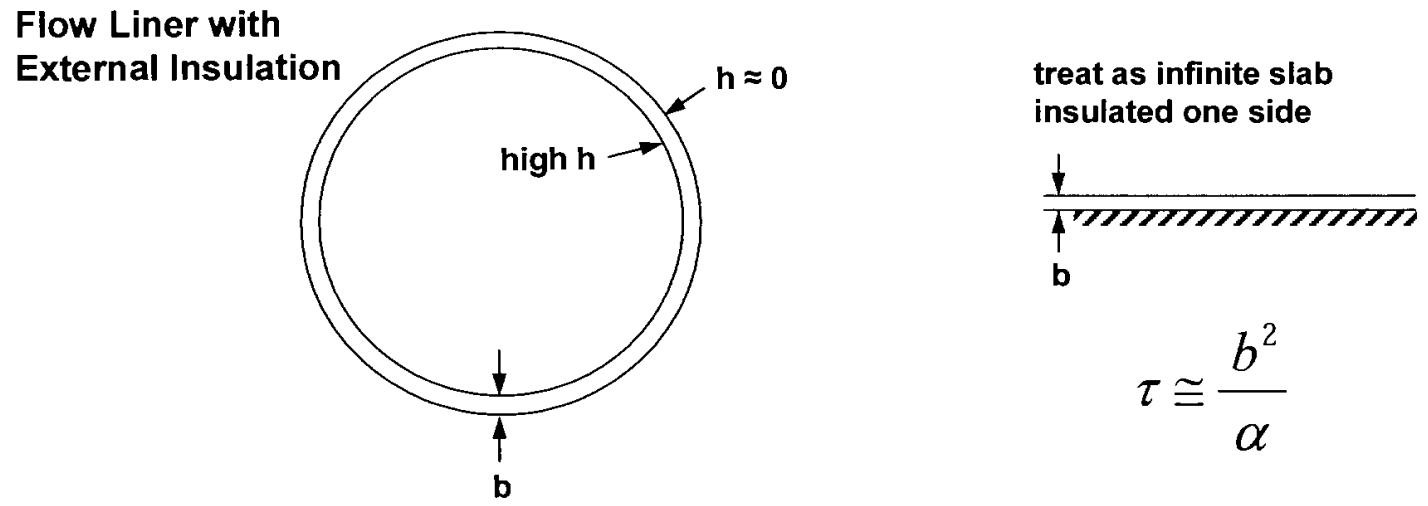

Figure. F-2. Flow liner and the 'infinite slab' approximation used in the thermal analysis.

For an infinite slab of thickness $b$, the thermal time constant can be roughly estimated as $b^{2} / \alpha$, where $\alpha$ is the thermal diffusivity of the material. Referring to numerical results generated from an analytical solution for this problem this estimate is conservative, the actual time constant being closer to one-third this value. ${ }^{1}$

For the heater-discharge pipe, assigning liner thickness $b=1.6 \mathrm{~mm}$ (see Section 4.1 .7 of the main body of this report) and assuming stainless steel construction, a response time of around $0.2 \mathrm{~s}$ is found $(\tau$ $\left.=0.3 b^{2} / \alpha\right)$. Because this value is much shorter than the time scale for imposed thermal transients, the corrupting influence of the heater-discharge pipe can safely be ignored.

As a cautionary note, the analysis above does not consider thermal response of the hightemperature test section (stations P7 to P8), for which details are thus far undetermined. This issue should be revisited in the eventual design process for this section.

\section{REFERENCES}

1. Carslaw, H.S., and Jaeger, J.C., 1959, Conduction of Heat in Solids, $2^{\text {nd }}$ edition, Oxford University Press. 


\section{Appendix G}

\section{Piping and Interface Diagram}




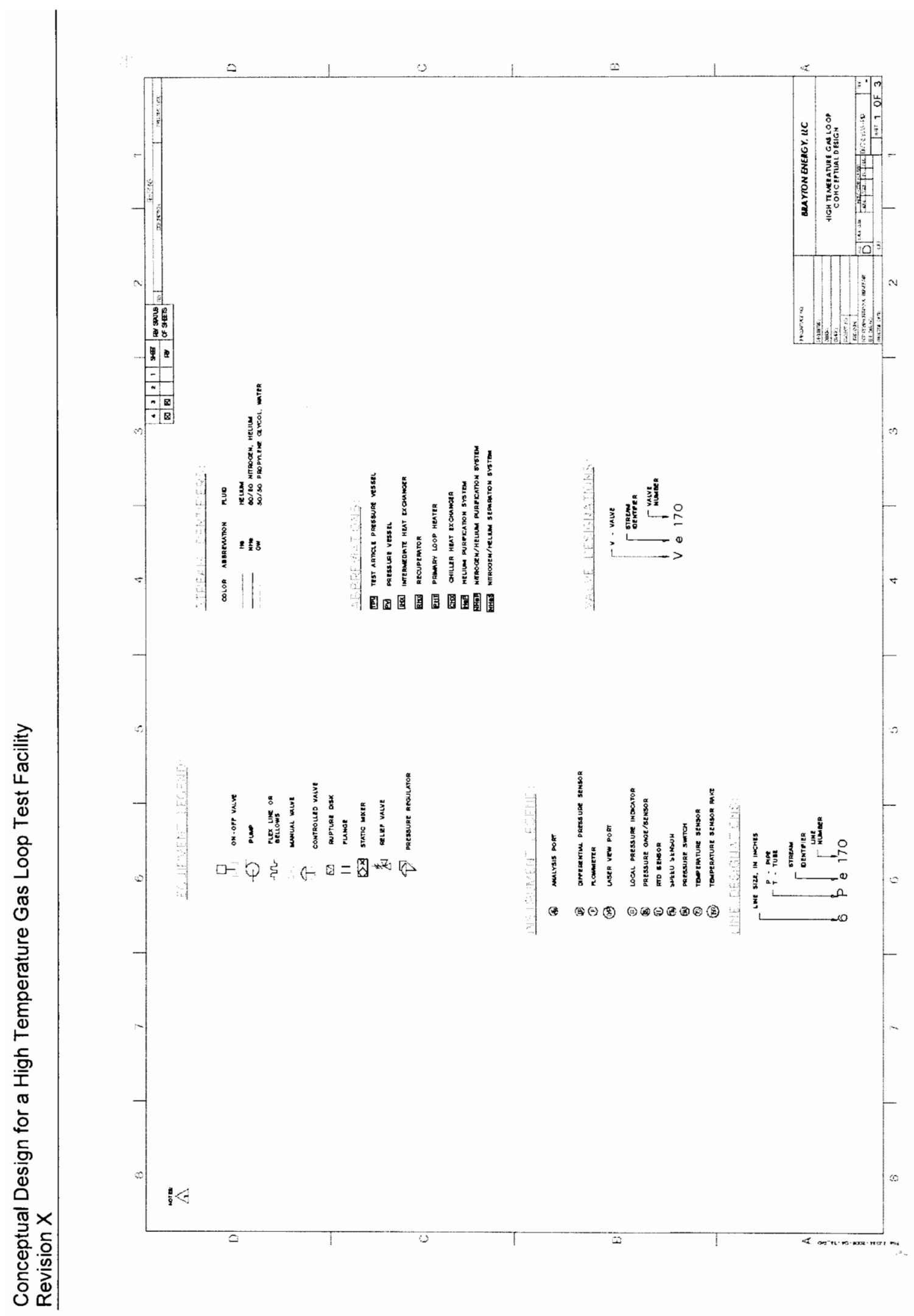




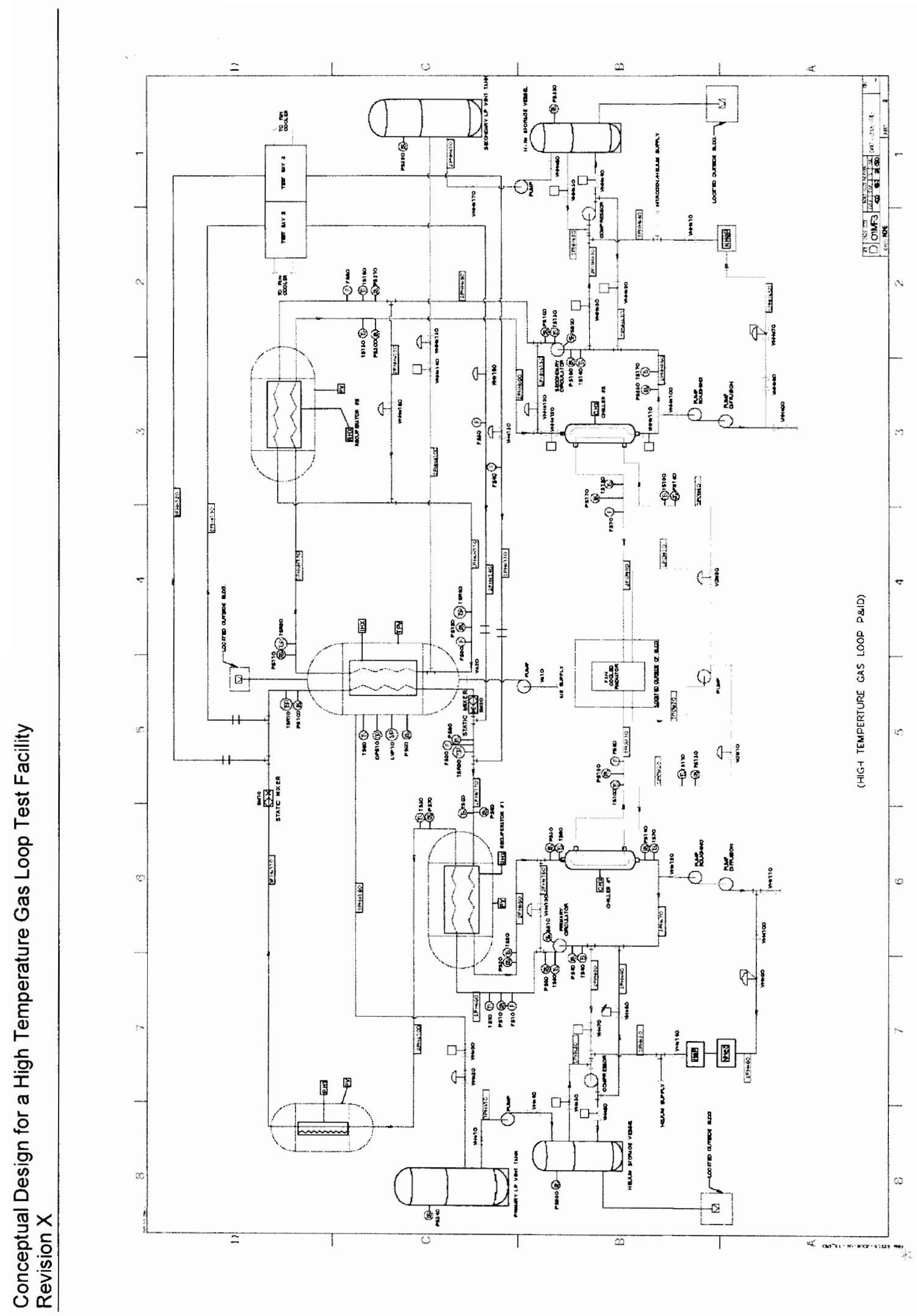


Conceptual Design for a High Temperature Gas Loop Test Facility

Revision X

Table G-1. Preliminary instrumentation list for Piping and Interface Diagrams (P\&ID). The P/N designations as shown on the P\&ID above indicate the sensor location.

\begin{tabular}{|c|c|c|}
\hline P/N & Instrument & Quantity \\
\hline SM10 & Static mixer, Test article PV primary inlet & 1 \\
\hline SM20 & Static mixer, Test article PV primary outlet & 1 \\
\hline TSR10 & Temperature sensor rake, Test article PV primary inlet & 1 \\
\hline PS100 & Pressure sensor, Test article PV primary inlet & 1 \\
\hline TS80 & Temperature sensor, Test article PV & 3 \\
\hline DPS10 & Differential pressure sensor, Test article PV & 1 \\
\hline LPV10 & Laser port view, Test article PV & 1 \\
\hline PS90 & Pressure sensor, Test article PV & 1 \\
\hline PS80 & Pressure sensor, Test article PV primary outlet & 1 \\
\hline FS20 & Flow meter, Test article PV primary outlet & 1 \\
\hline TSR30 & Temperature sensor rake, assembly, Test article PV primary outlet & 1 \\
\hline TS90 & Temperature sensor, Recuperator \#1 hot side inlet & 3 \\
\hline PS60 & Pressure sensor, Recuperator \#1 hot side inlet & 1 \\
\hline TS20 & Temperature sensor, Recuperator \#1 hot side outlet & 3 \\
\hline PS20 & Pressure sensor, Recuperator \#1 hot side outlet & 1 \\
\hline PS230 & Pressure sensor, Primary inventory storage tank & 1 \\
\hline PS240 & Pressure sensor, Primary LP vent tank & 1 \\
\hline TS40 & Temperature sensor, Primary circulator inlet & 3 \\
\hline PS40 & Pressure sensor, Primary circulator inlet & 1 \\
\hline TS30 & Temperature sensor, Primary circulator outlet & 3 \\
\hline PS30 & Pressure sensor, Primary circulator outlet & 1 \\
\hline SS10 & Speed sensor, primary circulator & 1 \\
\hline FS10 & Flow meter, primary circulator outlet & 1 \\
\hline TS160 & Temperature sensor, Recuperator \#2 cold side inlet & 3 \\
\hline PS210 & Pressure sensor, Recuperator \#2 cold side inlet & 1 \\
\hline TSR40 & Temperature sensor rake, assembly, TPV secondary inlet & 1 \\
\hline PS120 & Pressure sensor, TPV secondary inlet & 1 \\
\hline TSR20 & Temperature sensor rake, assembly, Test article PV secondary outlet & 1 \\
\hline PS110 & Pressure sensor, TPV secondary outlet & 1 \\
\hline PS70 & Pressure sensor, Recuperator \#1 cold side outlet & 1 \\
\hline TS50 & Temperature sensor, Recuperator \#1 cold side outlet & 3 \\
\hline TS140 & Temperature sensor, Secondary circulator inlet & 3 \\
\hline PS180 & Pressure sensor, Secondary circulator inlet & 1 \\
\hline TS150 & Temperature sensor, Secondary circulator outlet & 3 \\
\hline PS190 & Pressure sensor, Secondary circulator outlet & 1 \\
\hline SS20 & Speed sensor, secondary circulator & 1 \\
\hline PS230 & Pressure sensor, Secondary inventory storage tank & 1 \\
\hline PS220 & Pressure sensor, Secondary LP vent tank & 1 \\
\hline TS150 & Temperature sensor, Chiller \#2 hot side inlet & 3 \\
\hline PS200 & Pressure sensor, Chiller \#2 hot side inlet & 1 \\
\hline TS170 & Temperature sensor, Chiller \#2 hot side outlet & 3 \\
\hline PS250 & Pressure sensor, Chiller \#2 hot side outlet & 1 \\
\hline FS60 & Flow meter, Recuperator \#2 cold side inlet & 1 \\
\hline TS10 & Temperature sensor, Recuperator \#1 cold side inlet & 3 \\
\hline PS10 & Pressure sensor, Recuperator \#1 cold side inlet & 1 \\
\hline
\end{tabular}


Conceptual Design for a High Temperature Gas Loop Test Facility

Revision $\mathrm{X}$

\begin{tabular}{|l|l|c|} 
FS10 & Flow meter, recuperator \#1 cold side inlet & 1 \\
\hline TS60 & Temperature sensor, Chiller \#1 hot side inlet & 3 \\
\hline PS50 & Pressure sensor, Chiller \#1 hot side inlet & 1 \\
\hline FS70 & Flow meter, chiller \#2 cold side outlet & 1 \\
\hline TS70 & Temperature sensor, Chiller \#1 hot side outlet & 3 \\
\hline PS140 & Pressure sensor, Chiller \#1 hot side outlet & 1 \\
\hline FS30 & Flow meter, recup. 2 cold side outlet & 1 \\
\hline PS170 & Pressure sensor, chiller \#2, cold side outlet & 1 \\
\hline TS120 & Temperature sensor, chiller \#2, cold side outlet & 3 \\
\hline TS130 & Temperature sensor, chiller \#2, cold side inlet & 3 \\
\hline PS160 & Pressure sensor, chiller \#2, cold side inlet & 1 \\
\hline TS100 & Temperature sensor, chiller \#1, cold side outlet & 3 \\
\hline PS130 & Pressure sensor, chiller \#1, cold side outlet & 1 \\
\hline FS60 & Flow meter, chiller \#1 cold side outlet & 1 \\
\hline FS50 & Flow meter, test bay 2, primary return & 1 \\
\hline FS40 & Flow meter, test bay 3, primary return & 1 \\
\hline
\end{tabular}




\section{Appendix $\mathrm{H}$}

\section{Sulfur-lodine Equipment Schematic}




\section{Appendix $\mathrm{H}$}

\section{Sulfur-lodine Equipment Schematic}

The following schematic provides a simplified view of the equipment required to support future sulfur-iodine experiments (Figure H-1). This equipment might occupy Test Bay 2 of the HTGL. After a preliminary assessment, the test bay area and the adjoining area shown in Section 4.1.4 in the main body of this report appear adequate to house the necessary equipment.

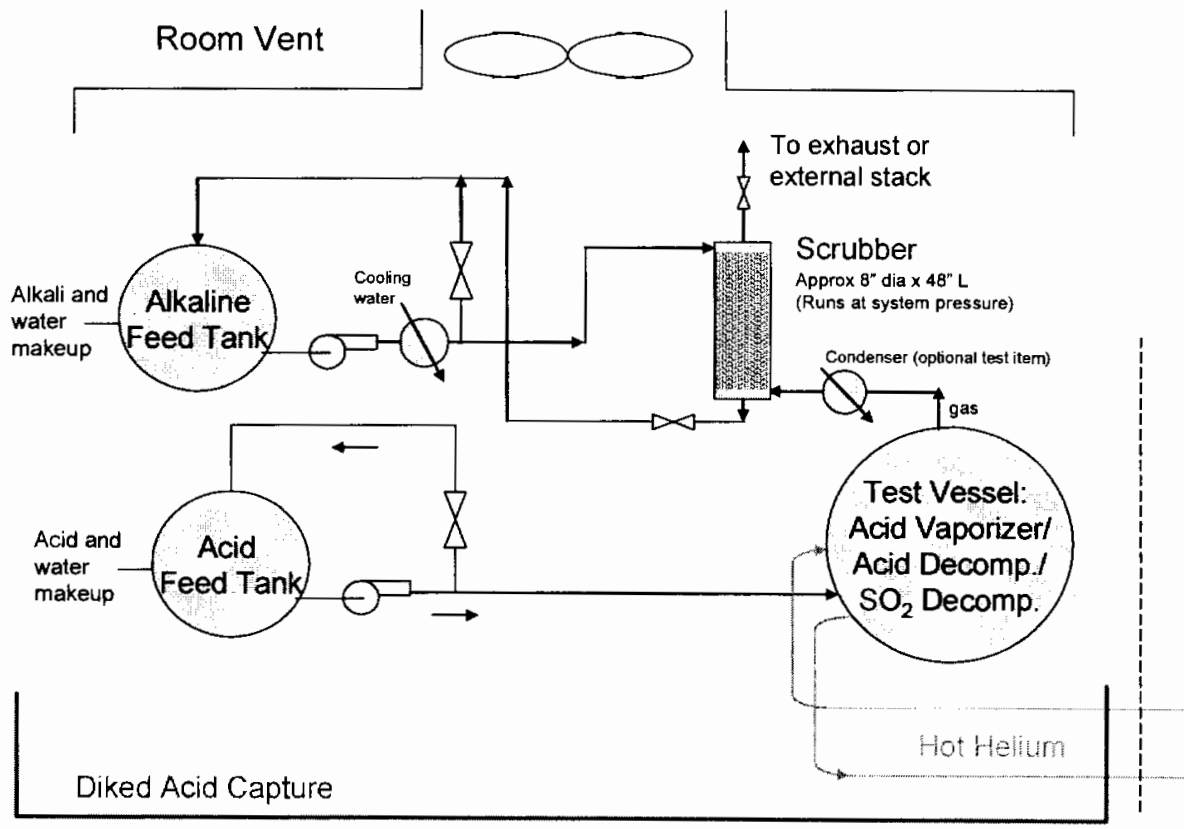

Figure H-1. Schematic diagram indicating equipment and flow for a sulfur-iodine process for hydrogen production. 


\section{Appendix I}

\section{Pressure Vessel Design and Analysis}




\section{Appendix I}

\section{Pressure Vessel Design and Analysis}

Component Sizing Parameters

A 3-meter-diameter primary test vessel represents a current maximum size with regard to an optimization between the following:

- Component cost

- $\quad$ Maximizing allowable test article size

- $\quad$ Space for insulation

- On-site lifting requirements

- Transportation feasibility.

Vendor Identification, Budgetary Cost Estimate, and Lead Time

Budgetary pricing guidelines were obtained from Steel Pro, in Rockland, Maine, and are applicable to vessels in the 1 to 3 -meter-diameter range. The guidelines are based on the following assumptions:

- Inclusion of one 150-millimeter ANSI B16.5 Class 600 flanged connection

- Inclusion of one 203-millimeter ANSI B16.5 Class 600 flanged connection

- Inclusion of one man-way for access inside the vessel as required per ASME Code

- $\quad$ Construction of grade 304/304L stainless steel.

The estimated cost for the 3-meter-diameter vessel, as shown below, is $\$ 570,000$. While more expensive than carbon steel, ( $\$ 1.10$ CS vs. $\$ 1.50$ SS, Spring 2006) the material cost differential is significantly offset by elimination of post-weld heat treating and painting/maintenance costs.

Vendor Specification and Performance

The containment vessel specification for the 3-meter-diameter vessel includes general information at this time:

- 3.0-meter-diameter vessel, total mass: 27,533 kilograms.

- $\quad$ Top bell mass: 21,274 kilograms

- $\quad$ Material, 304/304L SS

- Max. outside touch temperature: $150^{\circ} \mathrm{C}$

Installation 
The 3.0-meter-diameter vessel shown in Figure I-1 shows the proposed containment vessel configuration. The vessel is vertically oriented with ducting penetrating the lower portion only, allowing unencumbered removal of the top bell portion for test article access. Primary and secondary flow is provided for the test article by four, upward facing flanges. This arrangement provides a flexible interface for those test articles requiring closed direct-ducting of primary and secondary inlet and outlet flow, while also permitting the open-plenum approach currently in use with some plate-fin and printed-circuit IHX designs.

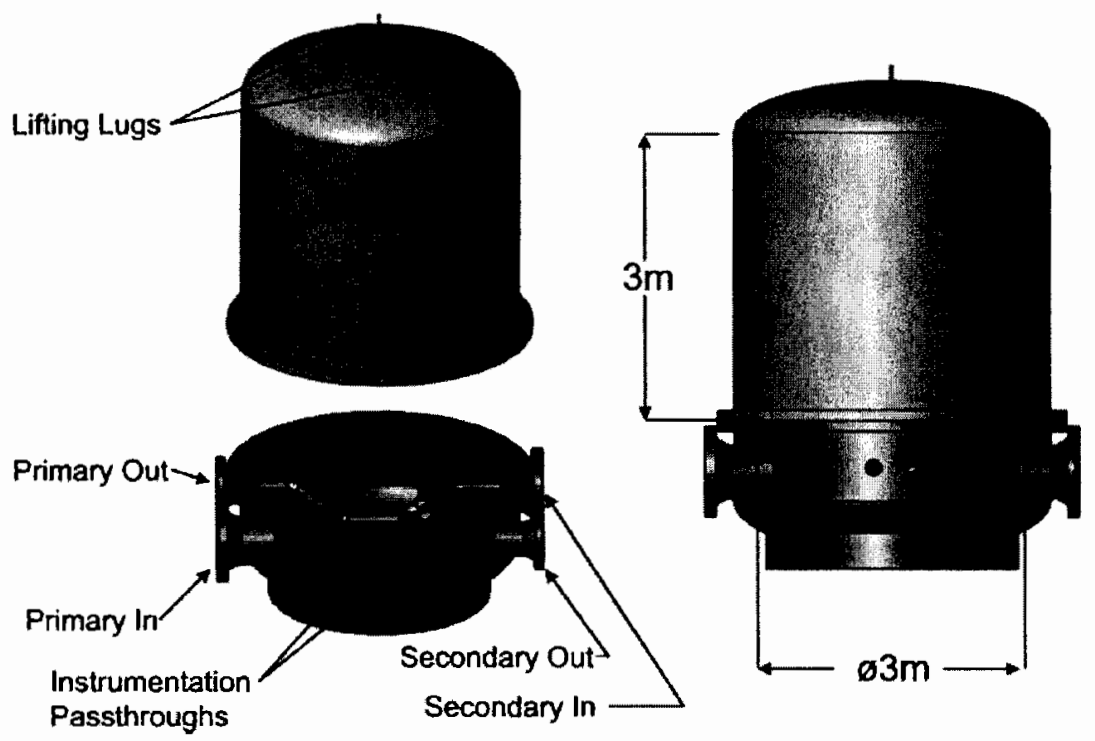

Figure I-1. Bay 1 test vessel annotated to show pass-throughs for instrumentation, as well as flange locations for primary and secondary gas interfaces. A removable bell allows unencumbered access for installation and removal of test equipment. The working volume is 3-meters in diameter by 3 -meters tall.

A similar design and cost analysis has been performed for the pressure vessel intended to contain the electric heater core. A standard inside diameter of 60 inches was selected for this application. The insulation thickness surrounding the electrical heater elements is therefore 429 millimeters (16.9 inches). This thickness yields a surface temperature in the range of $72^{\circ} \mathrm{C}\left(160^{\circ} \mathrm{F}\right)$. Table $\mathrm{I}-1$ summarizes the cost analysis for the heater pressure vessel. This cost is added to the cost roll-up for the electric heater for inclusion in the overall cost summary provided in Section 5.

Table I-1. Pressure vessel cost factors for primary heat-source.

\begin{tabular}{|c|c|c|}
\hline Cost Factor & Dimension & Magnitude \\
\hline Inner Diameter & meter & 1.54 \\
\hline Max Wall Temp & ${ }^{\circ} \mathrm{C}$ & 94 \\
\hline Internal Pressure & $\mathrm{MPa}$ & 7.0 \\
\hline Cylindrical Length & meter & 3.44 \\
\hline Outer Diameter & meter & 1.61 \\
\hline Cyl Wall Thickness & mm & 33.5 \\
\hline
\end{tabular}




\begin{tabular}{|c|c|c|}
\hline$\sigma_{\text {Allowable }}$ & $\mathrm{MPa}$ & 138 \\
\hline Mass & $\mathrm{kg}$ & 5904 \\
\hline Relative complexity (ref: test vessel) & & 1 \\
\hline Estimated Fully Burdened Cost & $\$ 122,000$ \\
\hline
\end{tabular}




\section{Appendix $J$}

\section{Circulator Vendor Data}


Conceptual Design for a High Temperature Gas Loop Test Facility

INL/EXT-06-11648

Revision 0

August 2006 


\section{AAARTECHOLOGIES}

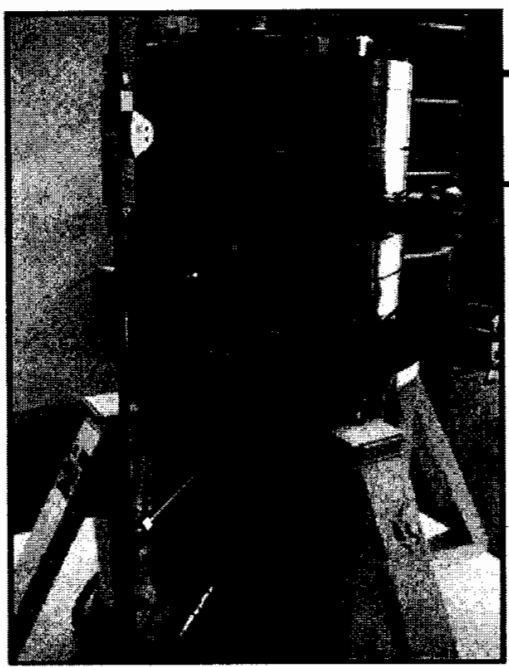

Helium Circulator for testing loop

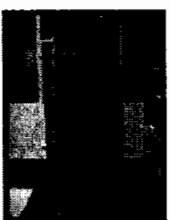

Motor driver

AT ACFS RECTENRRATTVE COWOESSSOR

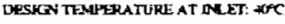

DNET PRESSLRE 109 BARS MAX

MOTCR RATED POWER EO HW

MOTOR TYPE: MAHRSED SYNCHRONGWIS MOTOR

GREASE LUURLCA TID REARRMGS

Figure J-1. Photograph of Air Technologies helium circulator.

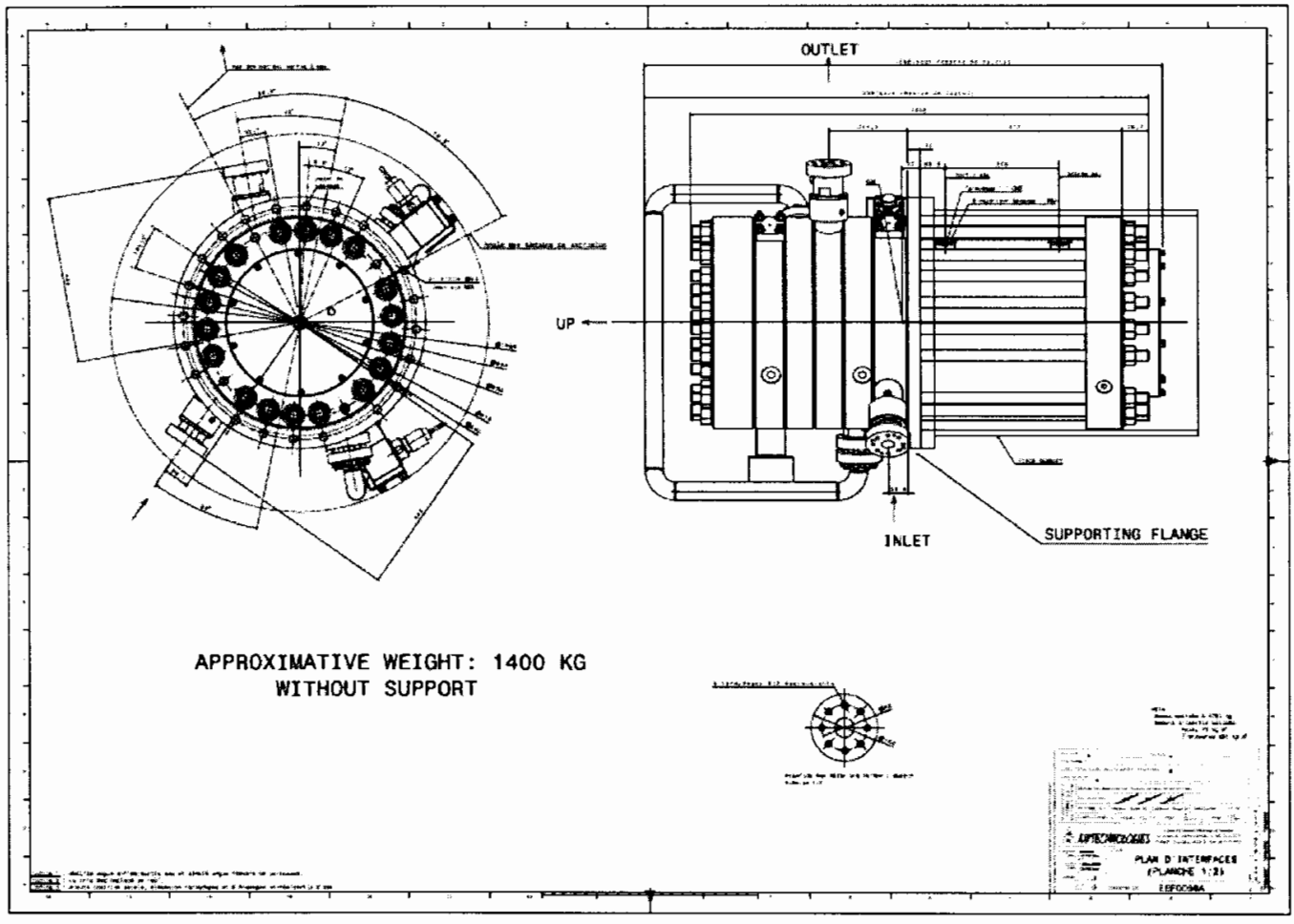

Figure J-2. Drawing of Air Technologies helium circulator. 


\section{AAARTECHNOLOGES}

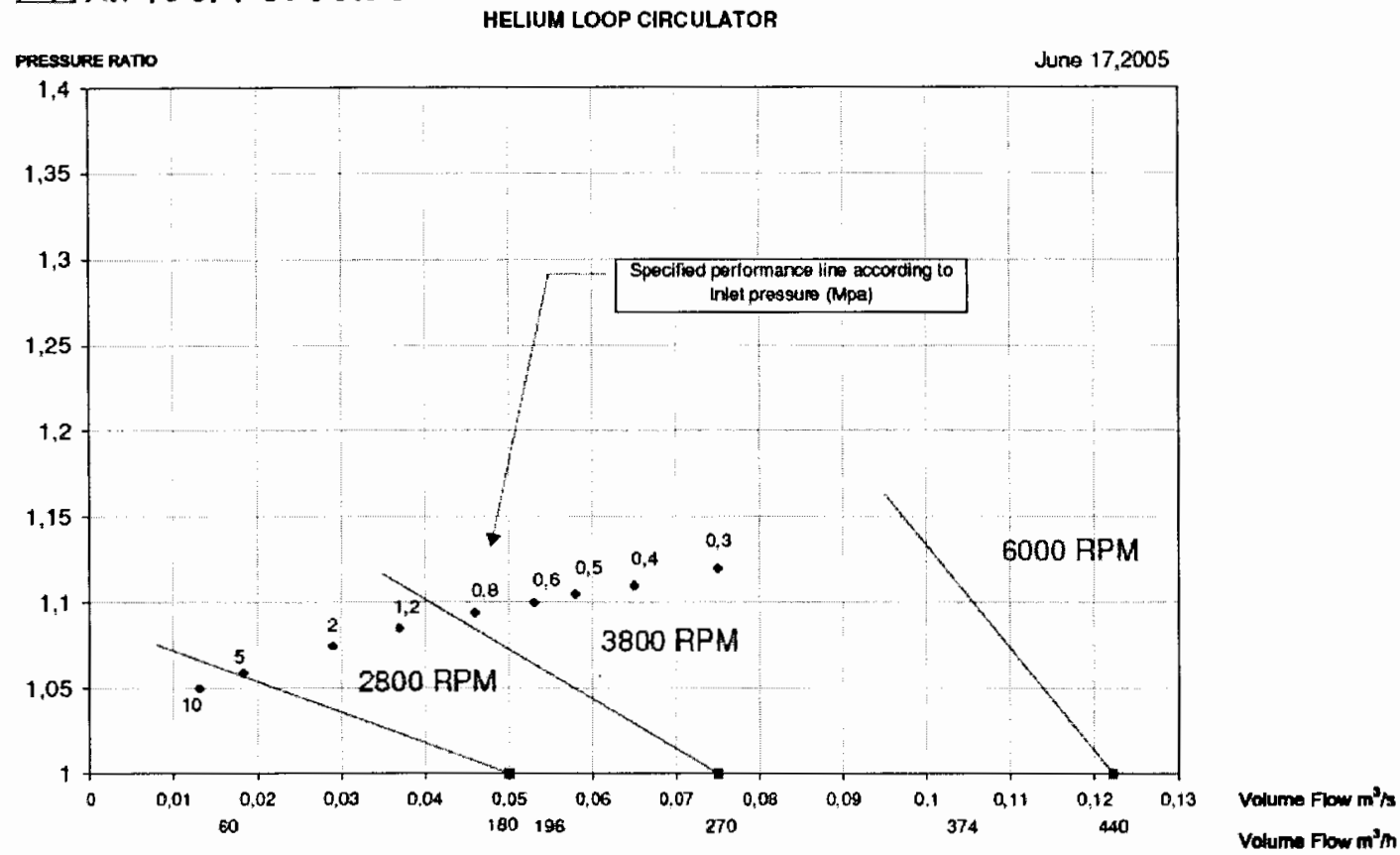

Figure J-3. Performance data for Air Technologies helium circulator.

Table J-1. Performance data from Barber-Nichols Corporation.

\begin{tabular}{|c|c|c|c|c|c|}
\hline \multicolumn{2}{|c|}{ PLMP } & \multicolumn{2}{|c|}{ MUTOR } & \multicolumn{2}{|c|}{ BEARLNGS } \\
\hline FUID & GN 2 & HP & 35 & TYPE & 9205 \\
\hline FLDW RATE & 538 ACFM & VLTAGE & $200 v$ & HSG FIT & $.0021 / .0033 \mathrm{~L}$ \\
\hline HEAD RISE & $2400 \mathrm{FT}$ & $\mathrm{Hz}$ & 9000 & SHAFT FIT & $.0001 \mathrm{~L} / .0004 \mathrm{~T}$ \\
\hline SPEED & 9000 RPM & PHASE & $3 \emptyset$ & PRELDAD & $20-30<B$ \\
\hline TEMER, & $-233 \mathrm{TO}+142^{\circ} \mathrm{F}$ & MEG & RELLAND & LUBE & SRI II GREASE \\
\hline PRES, e +142 & 98 PSI & EFF & $85 \%$ & IMPELLER FIT & $.0002 \mathrm{~L} / .0007 \mathrm{~T}$ \\
\hline PRES, -233 & 35 PSI & & & & \\
\hline
\end{tabular}

- $\quad$ Capable engineering firm specializing in custom turbomachinery

- $\quad$ Responded to our RFQ and offered a two-stage centrifugal compressor with variable speed permanent magnetic motor

- $\quad$ Need to investigate further. 


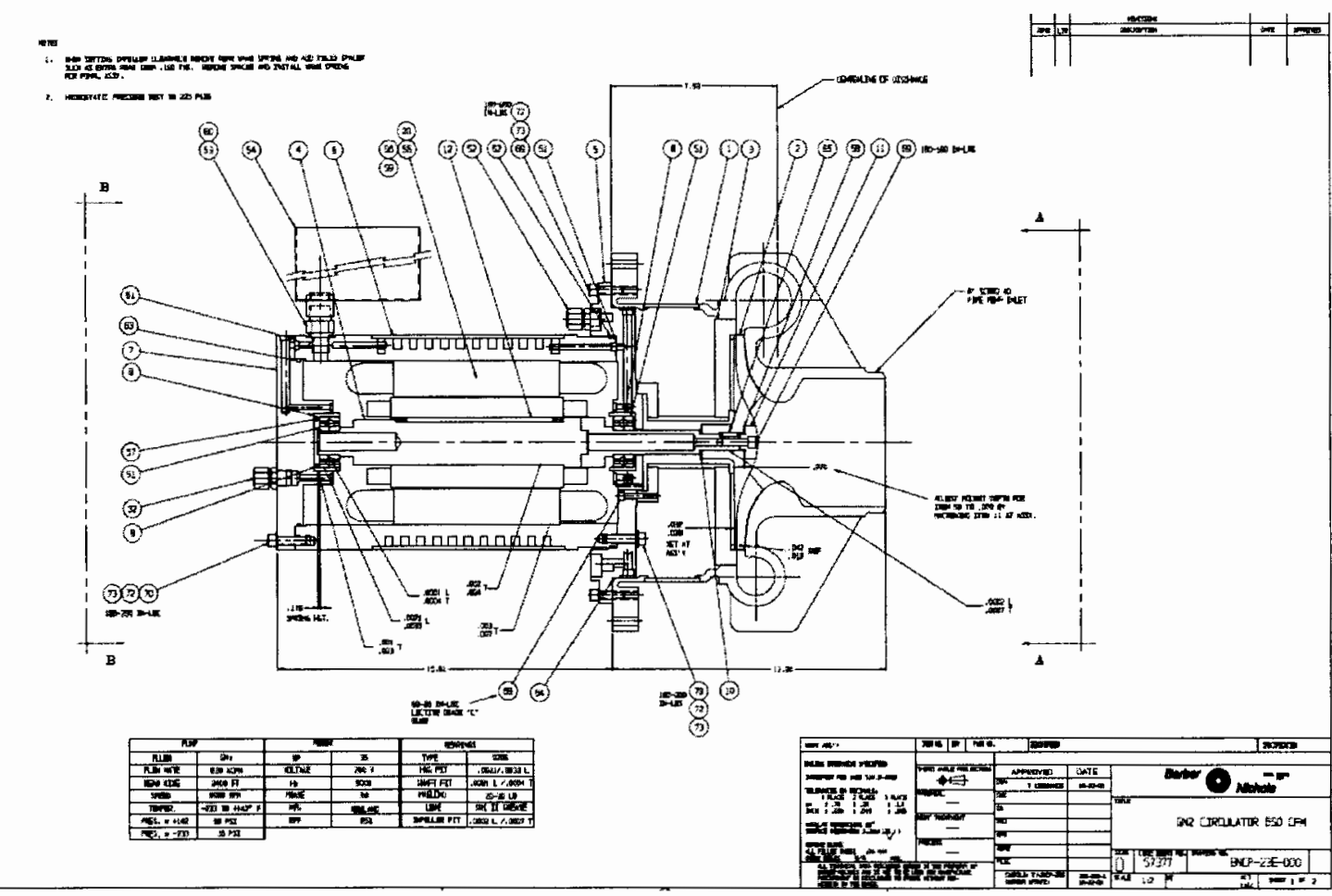

Figure J-4. Barber-Nichols high-speed centrifugal compressor. Two units required per circulator.

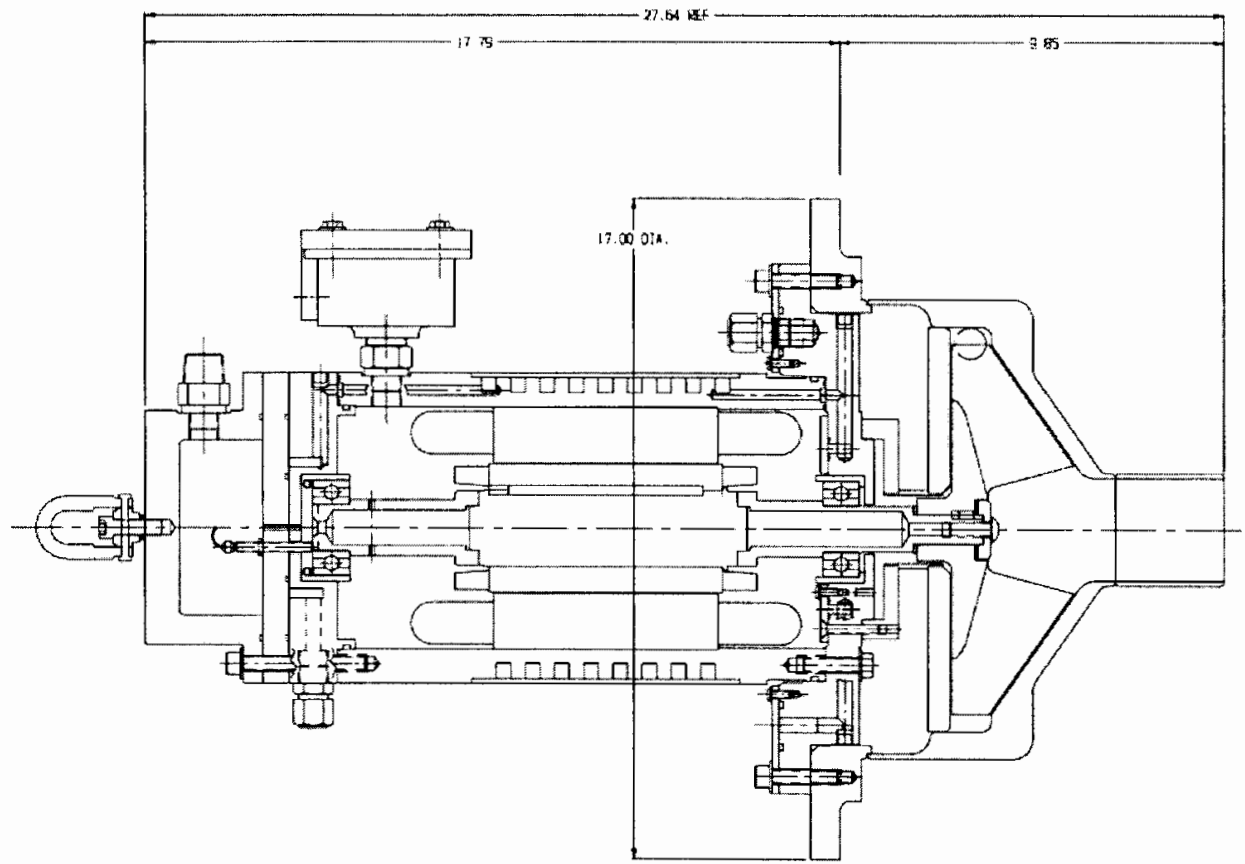

Figure J-5. Barber-Nichols variable-speed permanent-magnet motor centrifugal compressor. 


\section{RIX 2J SERIES}

\section{OIL-FREE OR OIL-LUBRICATED GAS COMPRESSORS FOR HIGH-PRESSURE SERVICE TO 7,000 PSIG}

RIX 2 S compressurs feature heavy dity crosshead construction with tho ienikal. th-Hne cwilinders and full water cooling. The guid

citinchers are cast into the crantcase for strength and ngldity. RIX $2 J J 5$ model is fabricated with Leaver amponents and of ers a center maln beanting for additional harsepower and nod load capactr:

CONSTRLCTION

Crankcaw: Pressure lubricated with shaft-miounied Cerotor on purmp and full flow oul fiter

Brarings Spherical roller naln beartros Sleeve type center matn and comecting rod bearings Bronze wrist pin bushing needle bearings optional.

Dustance Pheces: Extra-kong dual compartment and netallic slingers arallable.
COMPRESSION AREA

Typiral Oll-Free Units

Cyinktrs: Iron or bonize

castings with statnless thers as

required Mlachined steet for high pressure with wer or dry trom or sainless liners.

Pustow Rings and Packings: A wide selection of designs and materials are avallable, including Morgandle, Aavolyn. France and C. Lee Cook prochicts Higlpressune stages (over 2000 psig) commonty tise flanting pisions for maxtmum seding, long life anct quick replacement.

Parking Loxer Vented and for purged packings avalkble as required.

PistonRads:Stalnless steel or Tungsten coated for liong life Extrationg distance pleces.

\section{SPECIFICATIONS}

Horsepower Range $2 J 5$ to $150 \mathrm{BHP}$ 2JIS to 250 BHF

Displacement

Up to 360 CFM 2-3 5tage

Up to 180 CFM (4 Stage)

Cylinders: 1 to 1 Stages

Dlameters from

$y=10 \%$

Sroke

5 inches

Speed:

250-720 RPM

Typhal Gases

Oxygen, Hydrogen.

Argon, Nitrogen. Helium,

Natural Gax, Breathing Air

PACKACINC
AVAILABLE FROM:

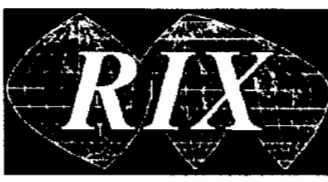

RIX INDUSTRIES 4900 Industrial Way Benicia, CA 94510 USA 707-747-5900 Phone 707-747-9200 Fax www.rixindustries.com

Figure J-6. Specifications for RIX piston-driven compressors. 


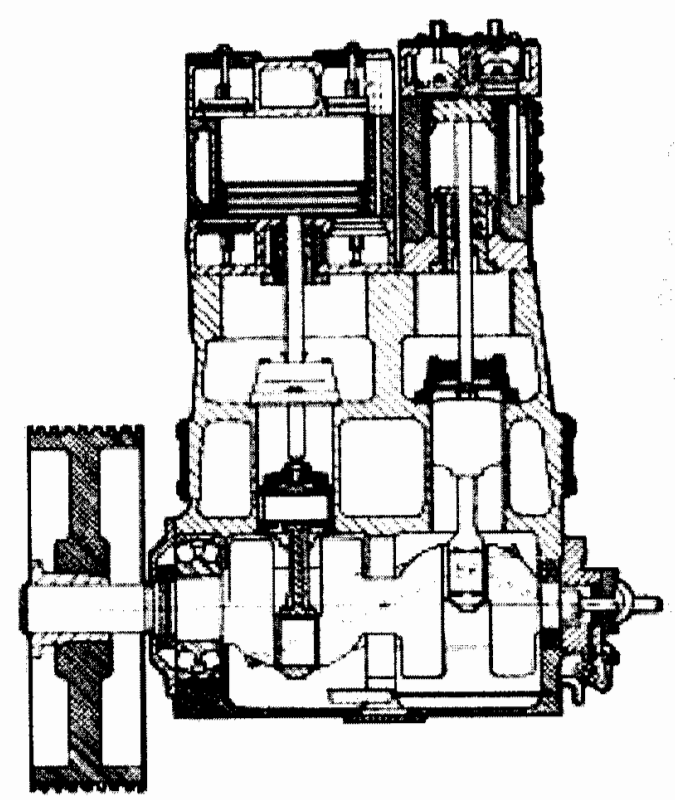

$2 J S 2$

Two-Stage Compressor

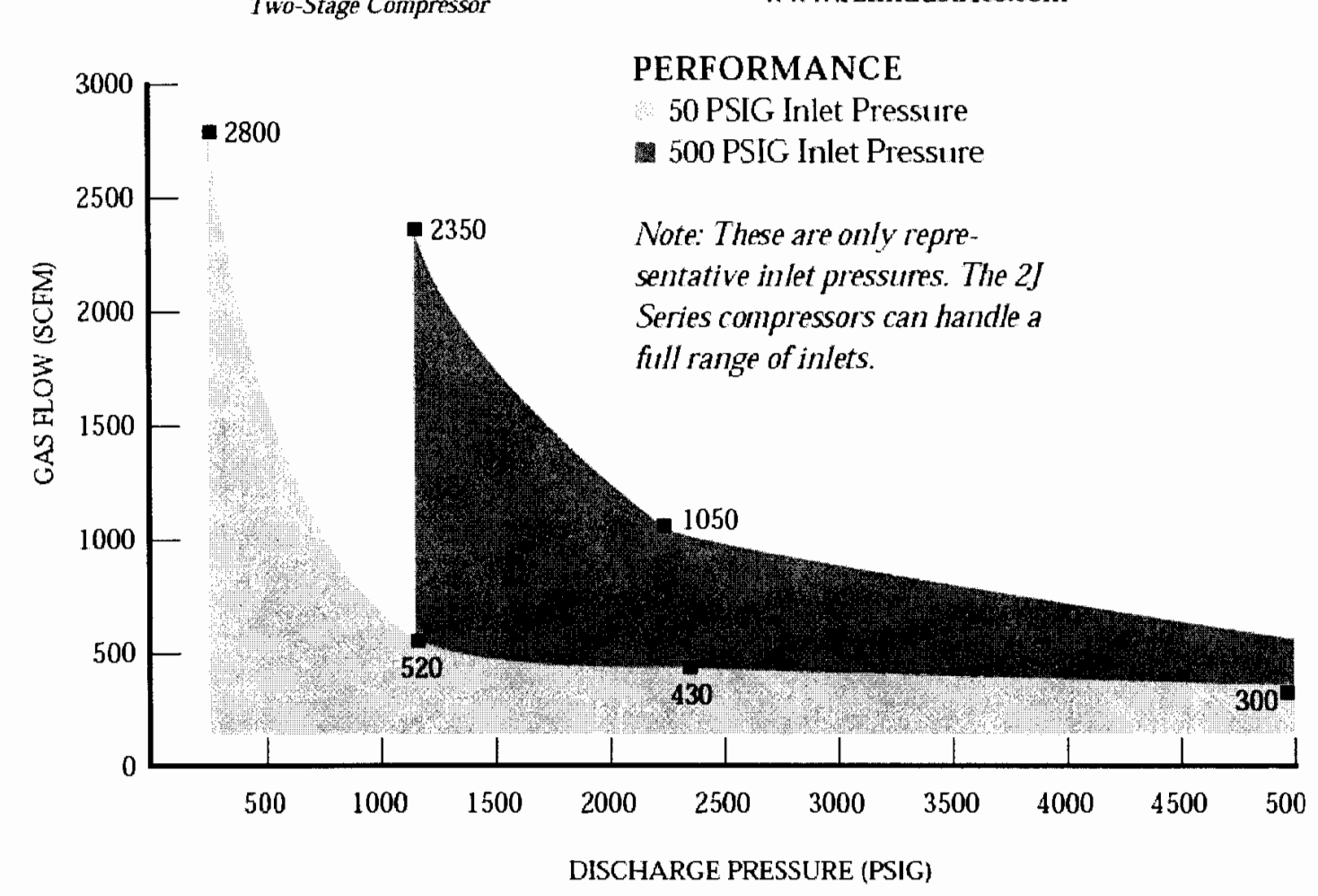

Recommended for our application

- Two stage

- Double acting opposed

- Concerns about our high mean pressure

- Engineering required

AVAILABLE FROM:

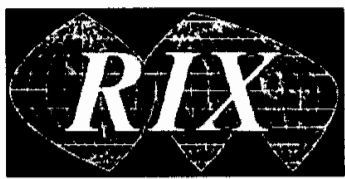

RIX INDUSTRIES

4900 Industrial Way

Benicia, CA 94510 USA

707-747-5900 Phone

707-747-9200 Fax

www.rixindustries.com

Figure J-7. Performance data for RIX piston-driven compressors. 

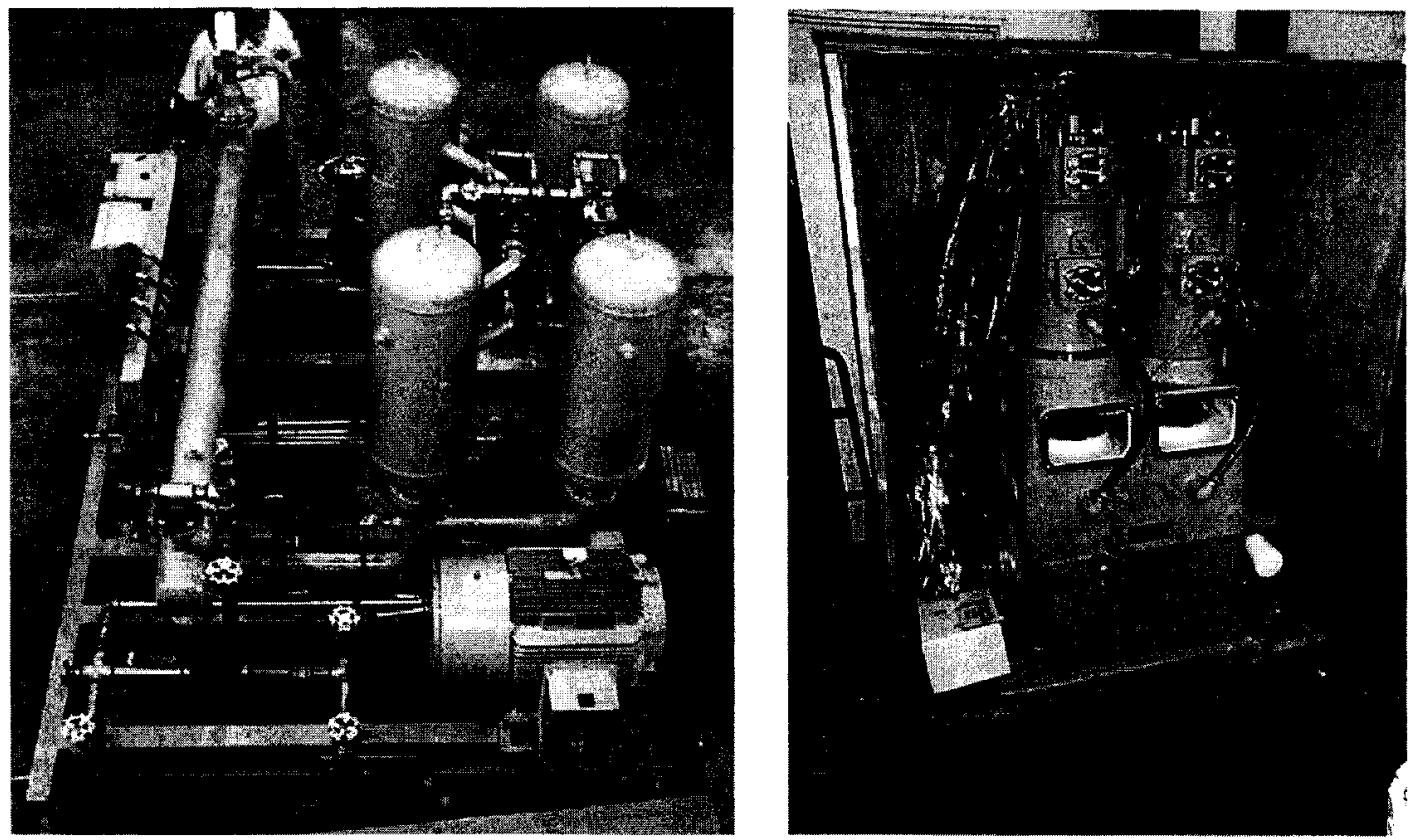

Figure J-8. Photographs of RIX piston-driven compressor. 


\section{Appendix K}

\section{Heat Exchanger Analysis Model Used in Sizing Multi-Pass Cross-Flow Heat Exchangers}




\section{Appendix K}

\section{Heat Exchanger Analysis Model Used in Sizing Multi-pass Cross-flow Heat Exchangers}

The attached model was written in MathCAD and used to analyze heat exchangers for the HTGL project. This model is a general-purpose tube-shell analysis, suitable to derive the thermal performance and pressure drop of multi-pass cross flow arrangements. The model contains empirical surface data and correlations from Kays and London, Compact Heat Exchangers, Second Addition, McGraw-Hill, 1955. The model was applied to the following designs for the HTGL project:

- $\quad$ Secondary recuperator - reference design for the multi-pass cross flow (both sides $\mathrm{He}-\mathrm{N}_{2}$ mix)

- $\quad$ Secondary gas-gap recuperator - modified version of the reference design, including the additional gas-gap containing either helium or argon

- $\quad$ Primary cooler - water in the cross flow shell, helium in the tubes

- $\quad$ Secondary cooler - water in the cross flow shell, $\mathrm{He}-\mathrm{N}_{2}$ mix in the tubes

The MathCAD model, configured for one of the above cases, follows: 
INL Chiller Sizing

\section{Multi-pass Tube Fin Heat Exchanger}

Operating condition, air side:

$$
\begin{array}{ll}
\text { medot }_{\mathbf{a}}:=2.1 \frac{\mathrm{kg}}{\mathrm{s}} & \text { AirSideFluid }:=\longdiv { 8 0 \% \mathrm { N } 2 2 0 \% \mathrm { He } = } \\
\text { Lunnidity }:=0.015 \frac{\mathrm{kg}}{\mathrm{kg}} & \text { RelativeHumidity }:=95 \% \\
\mathrm{~T}_{\mathrm{a}_{-} \text {in }}:=(900+273.15) \cdot \mathrm{K} & \mathrm{f}_{-} \mathrm{a}:=0.01 \\
\mathrm{P}_{\mathrm{c}}:=5.5 \mathrm{MPa} &
\end{array}
$$

Operating conditions, finned side: $\quad 80 \%$ N2 / $20 \%$ He mixture

$$
\begin{aligned}
& \operatorname{mdot}_{\mathbf{w}}:=\operatorname{mdot}_{\mathbf{a}} \\
& \mathrm{T}_{\mathbf{w}_{-} \text {in }}:=(65+273.15) \cdot \mathrm{K}
\end{aligned}
$$

Chiller surface: $7.75-5 / 8$ (finned circular tubes, see Fig. 10-92)

\section{Material Characteristics:}

Stainless Steel (347)

$$
\operatorname{kmat}(\mathrm{T}):=\| \begin{aligned}
& \mathrm{t} \leftarrow \frac{\mathrm{T}}{\mathrm{R}}-459.7 \\
& \frac{(12.4-9.4) \cdot \frac{\mathrm{BTU}}{\mathrm{R} \cdot \mathrm{hr} \cdot \mathrm{ft}}}{(932-212) \cdot \mathrm{R}} \cdot(\mathrm{t} \cdot \mathrm{R})+8.52 \cdot \frac{\mathrm{BTU}}{\mathrm{R} \cdot \mathrm{lur} \cdot \mathrm{ft}}
\end{aligned}
$$

\section{Surface Characteristics:}

Water-side:
$r_{\mathbf{h}_{-}} \mathbf{a}:=\frac{0.0154 \mathrm{ft}}{4}$
flow passage hydraulic radius
$\alpha_{w}:=140 \frac{\mathrm{ft}^{2}}{\mathrm{ft}^{3}}$
total water-side transfer area/total volume
fin_ratio $:=0.892$
fin area/total area 
INL Chiller Sizing

$$
\sigma_{\mathrm{w}}:=0.538
$$

$\delta:=0.018 \mathrm{in}$

fin_ $1:=\frac{0.92 \mathrm{in}-0.38 \mathrm{in}}{2}$

Air-side:

$\mathrm{OD}_{\text {tube }}:=0.38 \mathrm{in}$

Wall $_{\text {thk }}:=0.010 \mathrm{in}$

ID $_{\text {tube }}:=O D_{\text {hibe }}-2 \cdot$ Wall thk $_{\text {the }}$

AOD_tube $:=\frac{\pi}{4} \cdot O D_{\text {rube }}{ }^{2}$

A ID_tube $:=\frac{\pi}{4} \cdot \mathrm{D}_{\text {tube }}{ }^{2}$

A tube_frontal $:=0.975 \mathrm{in} \cdot 0 . \mathrm{sin}$

Atube_freeflow $:=$ AD_tube

Peri ${ }_{\text {tube inside }}:=\pi \cdot \mathrm{ID}_{\text {tube }}$

$\sigma_{\mathrm{a}}:=\frac{\text { Aube_freeflow }}{\text { Atube_frontal }}$

$a_{\mathbf{a}}:=\frac{\text { Peri }_{\text {tube_inside }}}{\text { A tube_trontal }}$

$r_{h_{-} w}:=\frac{A_{\text {hube_freeflow }}}{\text { Peri thbe_iuside }}$

Core Dimensions:

Corew $:=10$ in

CoreH $:=(0 \mathrm{ft}+11 \mathrm{in})$

Coret $:=12 \cdot 0.8 \mathrm{in}+0.8 \mathrm{in}$

$A_{\text {fr_w }}:=\operatorname{CoreH} \cdot$ Corew

$A_{\text {freeflow_w }}:=\sigma_{a} \cdot A_{\text {fr_w }}$

$\rho_{\text {tube_w }}:=\frac{1}{0.975 \text { in }}$ free-flow area/frontal area

fin metal thickness

fin length (one-half distance between tubes) free-flow/frontal area

water-side transfer area/total volume

water-side flow-passage hydraulic radius 
INL Chiller Sizing

$$
\begin{aligned}
& P_{\text {tube_L }}:=\frac{1}{0.8 \text { in }} \quad \text { tubes per inch (length) }
\end{aligned}
$$

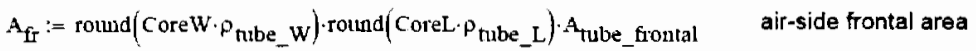

$$
\begin{aligned}
& A_{\text {freeflow }}:=\operatorname{round}\left(\text { Core } W \cdot \rho_{\text {tube_}} W\right) \cdot \text { round }\left(\text { CoreL } \cdot \rho_{\text {tube_L }}\right) \cdot A_{\text {tube_freetlow }} \\
& \mathrm{W}:=\mathrm{CoreW} \cdot \mathrm{CoreH} \cdot \mathrm{CoreL} \quad \text { total heat exchanger volume }
\end{aligned}
$$

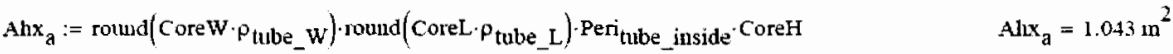

$$
\begin{aligned}
& \operatorname{Alnx}_{\mathrm{W}}:=a_{\mathrm{W}} \cdot \mathrm{V} \quad \operatorname{Ahx}_{\mathrm{W}}=8.61: \mathrm{nI}^{2}
\end{aligned}
$$

\section{Fluid Properties:}

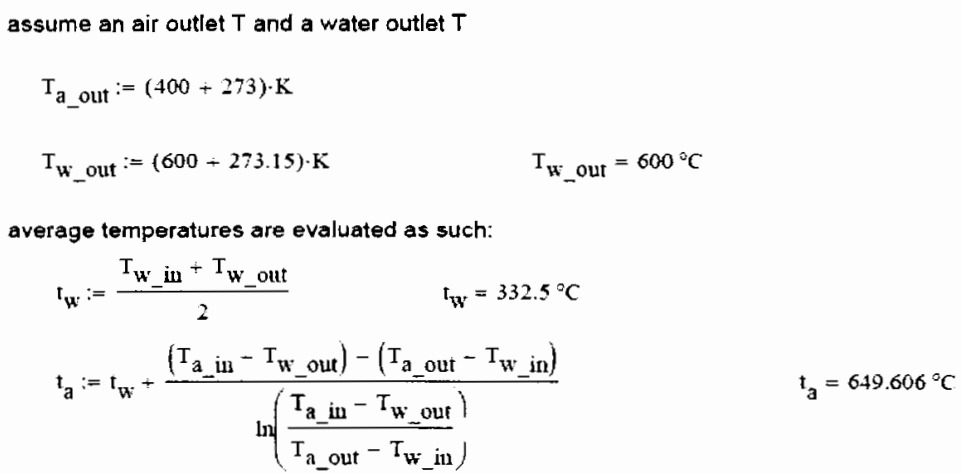

\section{Air Properties:}

๑
$\mu_{\mathrm{a}}\left(\mathrm{t}_{\mathrm{a}}\right)=4.265+10^{-5} \frac{\mathrm{kg}}{\mathrm{s} \cdot \mathrm{ml}}$
$\operatorname{Pr}_{a}\left(t_{a}\right)=0.448$
$\mathrm{CP}_{\mathrm{a}}\left(\mathrm{t}_{\mathrm{a}}\right)=1.963 \times 10^{3} \frac{\mathrm{m}^{2}}{\mathrm{k} \cdot \mathrm{s}^{2}}$
$\mathrm{K}_{\mathrm{a}}\left(\mathrm{ta}_{\mathrm{a}}\right)=0.187 \frac{1}{\mathrm{~K} \cdot \mathrm{s} \cdot \mathrm{m}} \mathrm{J}$ 
INL Chiller Sizing

Water Properties:

同

$\kappa_{w}\left(t_{w}\right)=0.139 \frac{\mathrm{in} \cdot \mathrm{kg}}{\mathrm{k} \cdot \mathrm{s}^{3}}$

$\mu_{w}\left(t_{w}\right)=3.265 \times 10^{-5} \frac{\mathrm{kg}}{\mathrm{s} \cdot \mathrm{m}}$

$C p_{w}\left(t_{w}\right)=1.913 \times 10^{3} \frac{\mathrm{m}^{2}}{\mathrm{~K} \cdot \mathrm{s}^{2}}$

$\operatorname{Pr}_{w}\left(L_{w}\right)=0.45$

$\rho_{w}\left(t_{w}\right)=13.911 \frac{\mathrm{kg}}{\mathrm{m}^{3}}$

\section{Reynolds Numbers:}

Air side:

$G_{\mathbf{a}}:=\frac{\text { mdot }_{\mathbf{a}}}{\text { A freeflow }_{\text {few }}}$

$\mathrm{G}_{\mathrm{a}}=245.988 \frac{\mathrm{kg}}{\mathrm{s} \cdot \mathrm{m}^{2}}$

$v a(t):=\frac{\text { indot }_{a}}{\rho_{a}(t) \cdot A_{\text {freetlow }}}$

$v_{a}:=v a\left(t_{a}\right)$

$v_{a}=26.942 \frac{\mathrm{m}}{\mathrm{s}}$

$\operatorname{Rea}(t):=\frac{4 \cdot \mathrm{J}_{\mathrm{L}_{\_} \mathrm{a}} \cdot \mathrm{G}_{\mathrm{a}}}{\mu_{\mathrm{a}}(t)}$

$\operatorname{Re}_{\mathrm{a}}:=\operatorname{Rea}\left({ }_{\mathrm{a}} \mathrm{a}\right)$

$\operatorname{Re}_{\mathrm{a}}=2.7 \times 10^{4}$

Water side:
$G_{W}:=\frac{\operatorname{midot}_{w}}{A_{f_{-}{ }_{W}} \cdot \sigma_{W}}$
$G_{w}=55.002 \frac{\mathrm{kg}}{\mathrm{s} \cdot \mathrm{m}^{2}}$
$v w(t):=\frac{\operatorname{mdot}_{w}}{\rho_{w}(t) \cdot A_{\text {freeflow_w }}}$
$v_{w}:=v w\left(t_{w}\right)$
$v_{w}=16.301 \frac{\mathrm{m}}{\mathrm{s}}$

page 5 of 15 
INL Chiller Sizing

$\operatorname{Rew}(t):=\frac{4 \cdot r_{h_{-} w} \cdot G_{w}}{\mu_{w}(t)}$

$\operatorname{Re}_{w}:=\operatorname{Rew}\left(t_{w}\right)$

$\operatorname{Re}_{\mathrm{u}}=1.54 \times 10^{4}$

St and $f:$

๑ Reference:UNet-store250perfiperf_model_filesiTube-FinCF-7.34.xncd(R)

From Fig. 10-83 for surface CF7.34 at Re

$$
\begin{aligned}
& f_{w}:=\operatorname{ffitCF}_{3} 36\left(\mathrm{Re}_{\mathrm{w}}\right) \quad \mathrm{f}_{\mathrm{w}}=0.035
\end{aligned}
$$

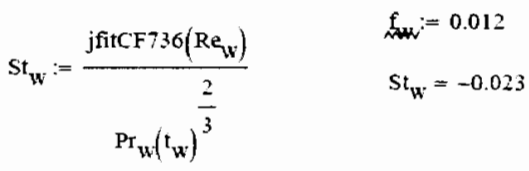

jfitCF $736\left(\operatorname{Re}_{w}\right)=-0.014$

$S t=0.005$

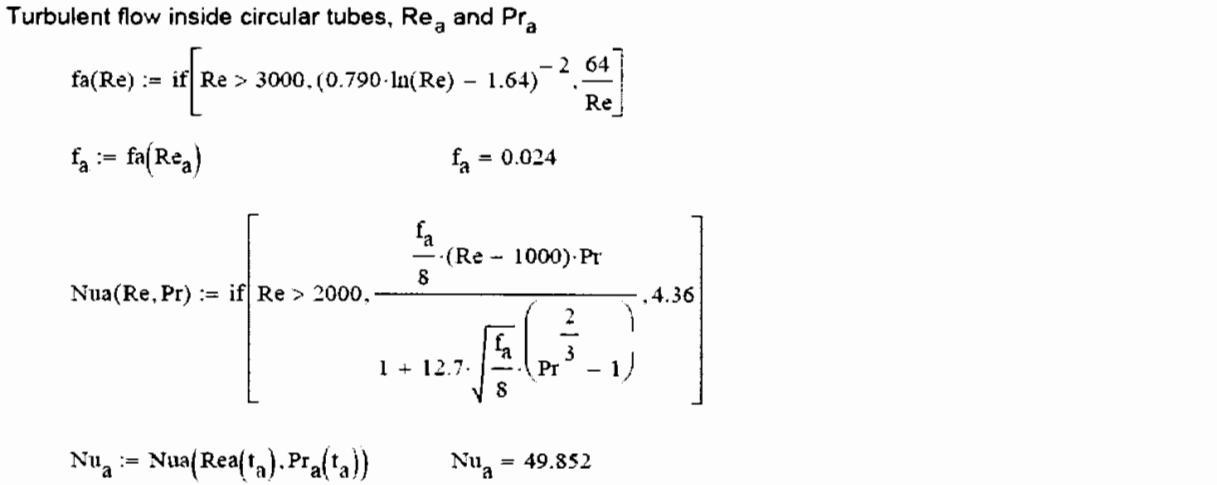

Heat Transfer Coefficients:

page 6 of 15 
INL Chiller Sizing

$$
\begin{aligned}
& \mathrm{h}_{\mathrm{a}}:=\frac{\mathrm{Nu}_{\mathrm{a}} \cdot \mathrm{k}_{\mathbf{a}}\left(\mathrm{l}_{\mathrm{a}}\right)}{4 \cdot \mathrm{r}_{\mathrm{h}_{-} \mathrm{a}}} \quad \mathrm{l}_{\mathrm{a}}=1.983 \times 10^{3} \frac{\mathrm{L}}{\mathrm{k} \cdot \mathrm{m}^{2}} \mathrm{~W} \\
& \mathrm{~J}_{w}:=S t_{w} \cdot G_{w} \cdot C P_{w}\left(t_{w}\right) \quad h_{w}=526.154 \frac{w}{\mathrm{~m}^{2} \cdot K}
\end{aligned}
$$

Fin Effectiveness:

$$
\begin{aligned}
& \mathrm{m}_{\mathrm{w}}:=\sqrt{\frac{2 \cdot \mathrm{h}_{\mathrm{w}}}{\operatorname{kmat}\left(\mathrm{t}_{\mathrm{w}}\right)^{-\delta}}} \\
& \mathrm{niw}_{\mathrm{w}}=345.402 \frac{1}{\mathrm{~m}} \\
& \mathrm{n}_{\mathrm{w}} \cdot \operatorname{fin} \_1=2.369 \\
& \eta_{f_{-} w}:=\frac{\tanh \left(m_{w} \cdot f i m_{-} l\right)}{m_{w} \cdot f\left(i_{-} I\right.} \quad \eta_{f_{-} w}=0.415
\end{aligned}
$$

Overall Surface Effectiveness:

$$
\eta_{O_{-} w}:=1-\text { fin_ratio }\left(1-\eta_{f_{-} w}\right) \quad \eta_{o_{-} w}=0.478
$$

Overall Heat Transfer U (Based on Air-Side Area):

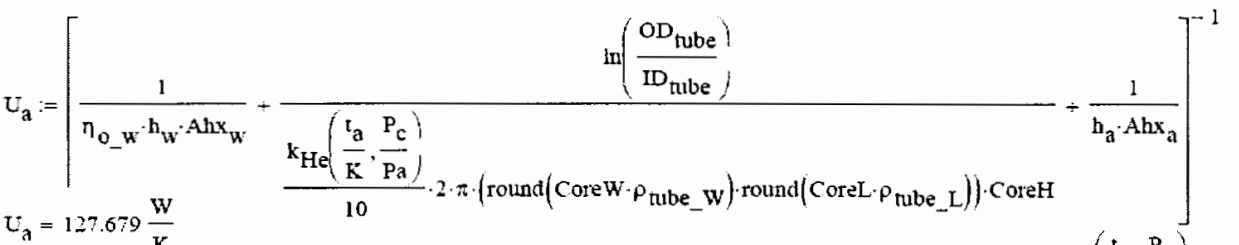

$$
\begin{aligned}
& v_{\mathrm{a}}=127.679 \frac{\mathrm{W}}{\mathrm{K}} \quad 10 \quad \mathrm{k}_{\mathrm{He}}\left(\frac{\mathrm{ta}_{\mathrm{a}}}{\mathrm{K}} \frac{\mathrm{P}_{\mathrm{c}}}{\mathrm{Pa}_{\mathrm{a}}}\right)=0.344 \frac{\mathrm{m} \cdot \mathrm{kg}}{\mathrm{K} \cdot \mathrm{s}^{3}}
\end{aligned}
$$

$$
\begin{array}{ll}
\mathrm{C}_{\mathrm{a}}:=\operatorname{mdot}_{\mathrm{a}} \cdot \mathrm{C}_{\mathrm{a}}\left(\mathrm{t}_{\mathrm{a}}\right) & \mathrm{C}_{\mathrm{a}}=4.122 \times 10^{3} \frac{\mathrm{W}}{\mathrm{K}} \\
\mathrm{C}_{\mathrm{w}}:=\operatorname{tudot} \mathrm{t}_{\mathrm{w}} \cdot \mathrm{Cp}_{\mathrm{w}}\left(\mathrm{t}_{\mathrm{w}}\right) & \mathrm{C}_{\mathrm{w}}=4.018 \times 10^{3} \frac{\mathrm{W}}{\mathrm{K}} \\
\mathrm{N}_{\mathrm{tu}}:=\frac{\mathrm{U}_{\mathrm{a}}}{\min \left(\mathrm{C}_{\mathrm{a}} \cdot \mathrm{C}_{\mathrm{w}}\right)} & \mathrm{N}_{\mathrm{ru}}=0.032 \\
\mathrm{CRR}:=\frac{\min \left(\mathrm{C}_{\mathrm{a}} \cdot \mathrm{C}_{\mathrm{w}}\right)}{\max \left(\mathrm{C}_{\mathrm{a}}, \mathrm{C}_{\mathrm{w}}\right)} & \mathrm{CRR}=0.975
\end{array}
$$

$\Theta$ Reference:iNet-store250iperfper_model_filesixflow_Cmax_mixed.xmcd(R) 


\section{INL Chiller Sizing}

$\varepsilon_{m}=x_{1}$ flow_Cmax_mixed $\left(C_{\mathbf{a}}, C_{\mathbf{w}}, N_{\mathrm{tu}}\right)$

$\mathrm{NP}:=3$

$\varepsilon_{\mathrm{MP}_{-} C F}(\varepsilon, N P):=\frac{\left(\frac{1-\varepsilon \cdot \mathrm{CRR}}{1-\varepsilon}\right)^{N P}-1}{\left(\frac{1-\varepsilon \cdot C R R}{1-\varepsilon}\right)^{N P}-C R R}$ $\varepsilon=3.1 \%$

$$
\varepsilon_{\mathrm{MP} C F}(\varepsilon, N P)=8.7 \%
$$

\section{Outlet Temperatures:}

$$
\begin{aligned}
& \text { Tanaub: }=T_{a_{-} \text {in }}-\frac{\min \left(C_{a}, C_{w}\right)}{C_{a}} \cdot \varepsilon_{M P_{-} C F}(\varepsilon, N P) \cdot\left(T_{a_{-}} \text {in }-T_{w_{-} \text {in }}\right) \\
& \mathrm{T}_{\mathrm{a}_{-} \text {out }}=829.1{ }^{\circ} \mathrm{C}
\end{aligned}
$$

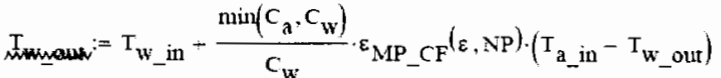

$$
\begin{aligned}
& \mathrm{T}_{\mathrm{w}_{\text {out }}}=91.1^{\circ} \mathrm{C}
\end{aligned}
$$

\section{Pressure Drops:}

$$
\begin{aligned}
& \text { Ploss }_{a}=\frac{\sigma_{a}{ }^{2}}{2 \cdot \rho_{a}\left(T_{a_{-} \text {in }}\right) \cdot P_{c}}\left[\left(1+\sigma_{a}{ }^{2}\right) \cdot\left(\frac{\rho_{a}\left(T_{a_{-} \text {in }}\right)}{\rho_{a}\left(T_{a_{-} \text {out }}\right)}-1\right)-f_{a} \cdot \frac{v \cdot a_{a}}{A_{f r} \cdot \sigma_{a}} \cdot\left(\frac{\rho_{a}\left(T_{a_{i} \text { in }}\right)}{\rho_{a}\left(t_{a}\right)}\right)\right] \\
& \text { Ploss }_{\mathrm{a}}=0.178 \%
\end{aligned}
$$

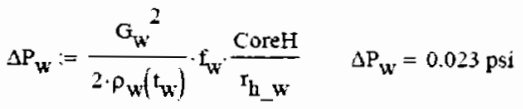

$$
\begin{aligned}
& \text { Ploss }_{W}:=\frac{\Delta \mathrm{P}_{\mathrm{w}}}{\mathrm{P}_{\mathrm{c}}} \quad \text { Ploss }_{\mathrm{w}}=2.9 \times 10^{-3} \%
\end{aligned}
$$




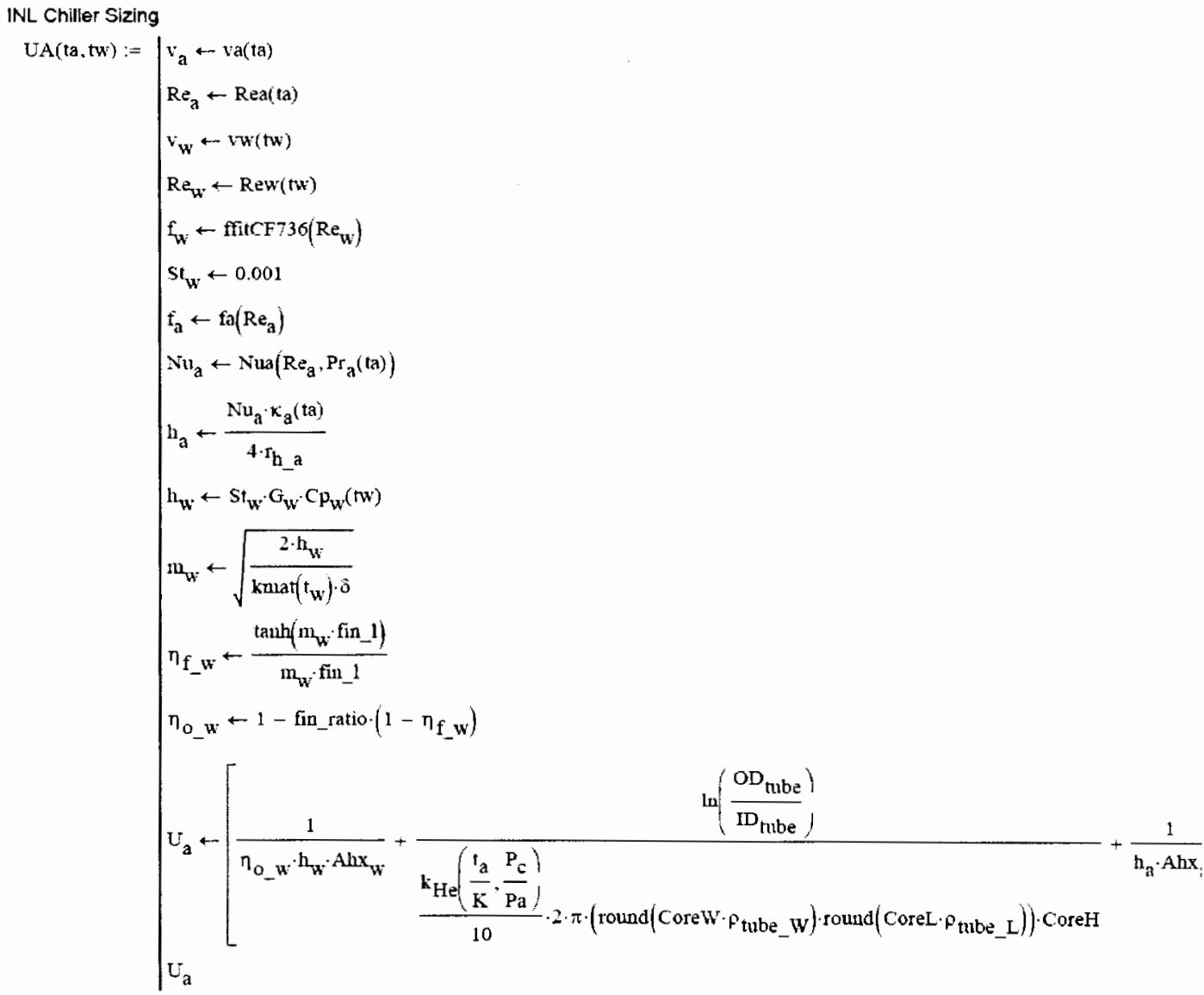




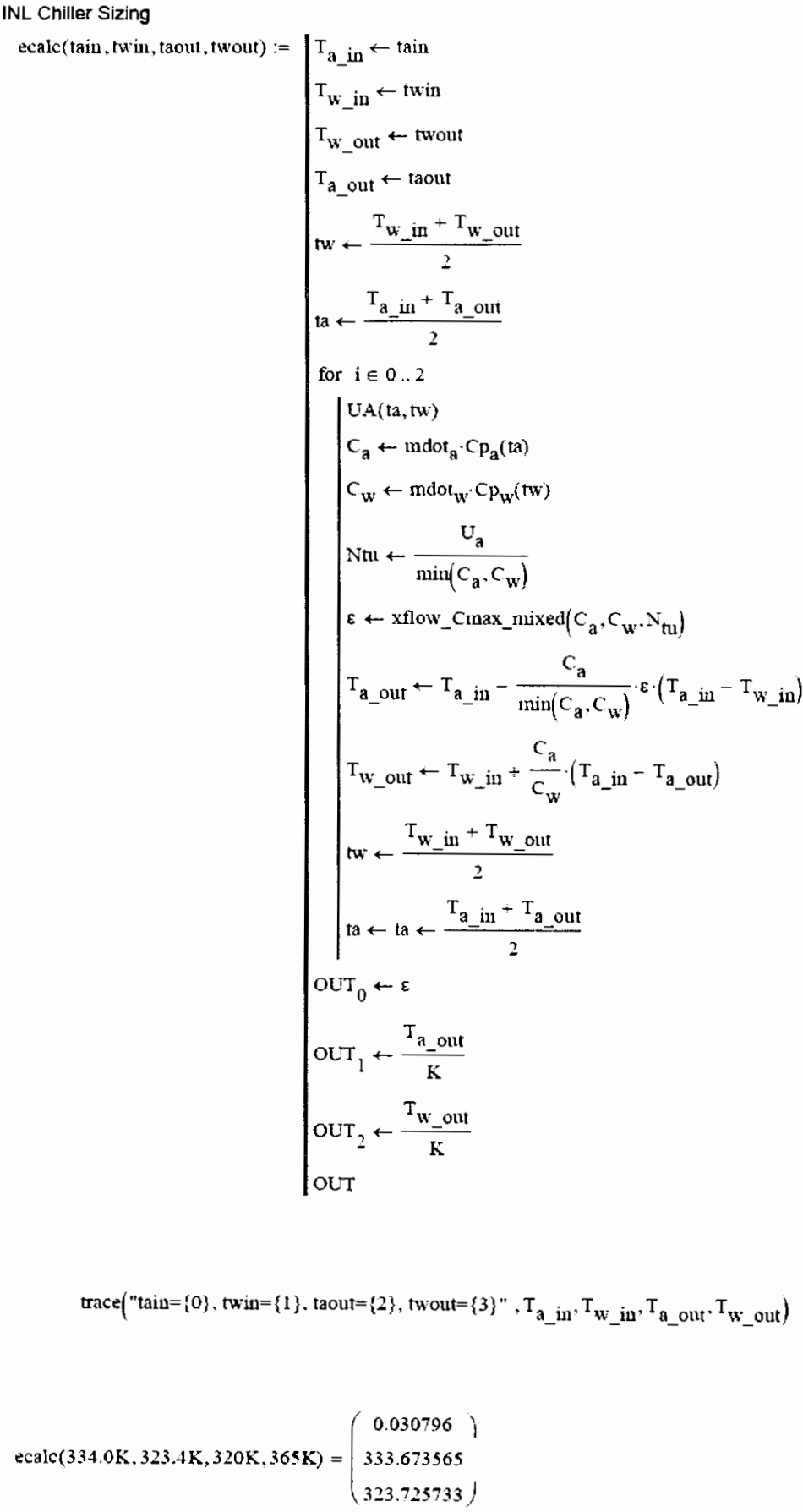


INL Chiller Sizing

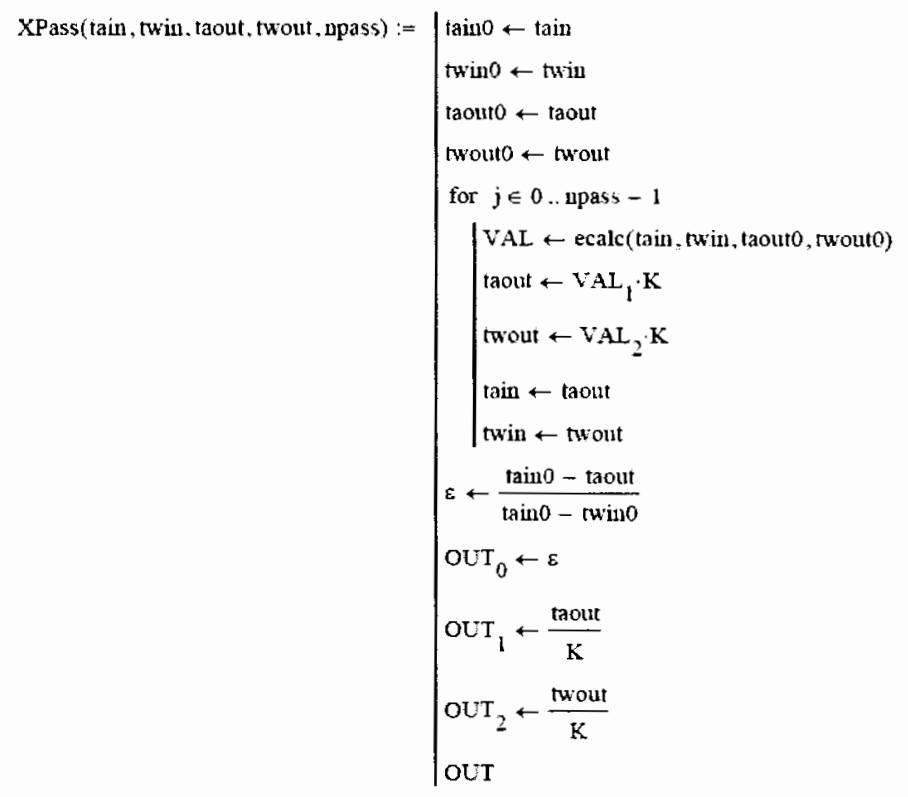

trace $\left(\right.$ tain $=\{0\}$, twin $=\{1\}$, taout $=\{2\}$, twout $=\{3\}^{\prime \prime}$, tain, twin, taout , twout $)$

$$
\begin{aligned}
& \varepsilon_{m}:=\operatorname{ecalc}\left(\mathrm{T}_{\mathrm{a}_{-} \text {in }} \cdot \mathrm{T}_{\mathrm{w}_{-} \text {inl }} \cdot \mathrm{T}_{\mathrm{a}_{-} \text {out }}, \mathrm{T}_{\mathrm{w}_{-} \text {out }}\right) \quad \varepsilon_{0}=3.1 \% \\
& \text { upass }:=12 \\
& E_{\text {MP_CF }}\left(\varepsilon_{0} \cdot \text { npass }\right)=27.7 \% \\
& T_{a_{-} \text {out_MP }}:=T_{a_{-} \text {in }}-\frac{\min \left(C_{a}, C_{w}\right)}{C_{a}} \cdot \varepsilon_{M P \_} C F\left(\varepsilon_{0} \cdot \text { npass }\right) \cdot\left(T_{a_{-} \text {in }}-T_{w_{-}} \text {in }\right) \\
& T_{w_{-} \text {out_MP }}:=T_{w_{-} \text {ill }}+\frac{\min \left(C_{a}, C_{w j}\right)}{C_{w}} \cdot \varepsilon_{M P} M_{-}\left(\varepsilon_{0} \cdot \text { npass }\right) \cdot\left(T_{a_{-} \text {in }}-T_{w_{-} \text {in }}\right) \\
& \operatorname{Vdot}_{w}:=\frac{\operatorname{mdot}_{w}}{\rho_{W}\left(\frac{T_{W_{-} \text {in }}+T_{w_{2} \text { out_MPP }}}{2}\right)} \\
& \varepsilon_{M P}:=\varepsilon_{M P} C F\left(\varepsilon_{0}, \text { npass }\right) \\
& \text { Ploss } a \text {-npass }=2.14 \% \\
& T_{\text {a_out_MP }}=674.8^{\circ} \mathrm{C} \\
& T_{w_{-} \text {out_MP }}=296.1^{\circ} \mathrm{C}
\end{aligned}
$$


INL Chiller Sizing

$\Delta \mathrm{P}_{\mathrm{w}_{-} \mathrm{MP}}:=$ npass $\Delta \mathrm{P}_{\mathrm{W}} \quad \Delta \mathrm{P}_{\mathrm{w}_{-} \mathrm{MP}}=0.278 \mathrm{psi}$

$\varepsilon_{\mathrm{MP}}=27.7 \%$

$T_{a_{-} \text {in }}=900^{\circ} \mathrm{C} \quad T_{w_{-} \text {in }}=65^{\circ} \mathrm{C}$

$T_{\text {a_out_MP }}=674.8^{\circ} \mathrm{C} \quad T_{w_{\text {_out_MP }}}=296.1^{\circ} \mathrm{C}$ 


\section{Appendix L}

\section{Primary and Secondary Cooler Analysis and Quotations}




\section{Appendix L}

\section{Primary and Secondary Cooler Analysis and quotations}

Table L-1. Independent sizing analysis for primary and secondary coolers.

\begin{tabular}{|c|c|c|c|}
\hline \multicolumn{4}{|c|}{ INL HTGL Coolers - Performance and Sizing Analysis } \\
\hline & $\begin{array}{c}\text { Primary } \\
\text { cooler }\end{array}$ & $\begin{array}{c}\text { Secondary } \\
\text { cooler }\end{array}$ & Notes \\
\hline Type & Tube-shell & Tube-shell & \\
\hline Alloy & AISI 316 & AISI 316 & \\
\hline Max operating pressure, $\mathrm{MPa}$ & 8 & 8 & max condition \\
\hline Design pressure, MPa & 6 & 5.5 & $\begin{array}{l}\text { Sizing spec, (higher pressure results in } \\
\text { similar performance, but lower pressure } \\
\text { drop) }\end{array}$ \\
\hline Liquid/glycol/ $\mathrm{H}_{2} \mathrm{O}$ mix & $38 \%$ & $38 \%$ & good to $-12 \mathrm{~F}$ ambient (check?) \\
\hline Liquid flow rate, $\mathrm{kg} / \mathrm{s}$ & 1.15 & 1.2 & \\
\hline GPM & 18 & 19 & Review fan cooler capacity and specs \\
\hline Gas, $\% \mathrm{He}$, balance $\mathrm{N}_{2}$ & $100 \%$ & $20 \%$ & \\
\hline Gas flow rate, $\mathrm{kg} / \mathrm{s}$ & 1.0 & 2.7 & \\
\hline Shell, fin density FPI: liquid *1 & 7.34 & 7.34 & $\begin{array}{l}* 1-\mathrm{f} \& \mathrm{~J} \text { data from Kays and London, } \\
\text { Surface CF }-7.34\end{array}$ \\
\hline Tube ID fin density FPI: gas & 0 & 0 & \\
\hline number of liquid passes & 3 & 7 & \\
\hline number of gas passes & 1 & 1 & \\
\hline Tube diameter, OD, Inches & 0.375 & 0.375 & \\
\hline Tube wall thickness, in & 0.012 & 0.012 & assuming on $11 \mathrm{ksi}$ hoop stress \\
\hline Tube stack number or rows,y & 85.0 & 75.0 & 0.816666667 \\
\hline $\begin{array}{l}\text { Number of tube rows, } z \text {, width- } \\
\text { wise }\end{array}$ & 3.0 & 2.0 & \\
\hline Total number of tubes & 255 & 150 & \\
\hline Total tube bundle weight, $\mathrm{kg}$ & 34.4 & 23.6 & \\
\hline Effectiveness & 0.707 & 0.72 & \\
\hline Gas side pressure drop $\Delta P / P$ & $0.13 \%$ & $0.78 \%$ & may be able to reduce circulator lift \\
\hline Liquid side pressure drop, psig & $<10$ & $<10$ & $\begin{array}{l}\text { Water pressure drop is very low, } \\
\text { suggesting a better surface should be } \\
\text { available. }\end{array}$ \\
\hline $\mathrm{Cmin} / \mathrm{C} \max$ & 0.86 & 0.9 & \\
\hline Gas inlet temp, ${ }^{\circ} \mathrm{C}$ & 99 & 93 & Spec \\
\hline Gas exit temp, ${ }^{\circ} \mathrm{C}$ & 50.7 & 50.5 & hot day conditions \\
\hline Liquid in, ${ }^{\circ} \mathrm{C}$ & 40 & 40 & Spec \\
\hline Liquid out, ${ }^{\circ} \mathrm{C}$ & 95.9 & 87 & $\begin{array}{l}\text { Conservative, may consider lowering to } \\
\text { reduce size }\end{array}$ \\
\hline Dimensions & & & \\
\hline
\end{tabular}




\begin{tabular}{|l|l|l|l|}
\hline Tube length, $\left(\mathrm{x}^{*} \mathrm{n}\right)$ in & $\mathbf{7 2}$ & $\mathbf{8 4}$ & \\
\hline No of vessels & 2 & 1 & \\
\hline Frontal circle diameter, in & $\mathbf{1 1 . 5}$ & $\mathbf{1 2 . 2}$ & \\
\hline Head thickness (cylinder), in & 0.4624 & 0.4916 & \\
\hline
\end{tabular}

\section{FOUR-PASS ASME TEMA-C}
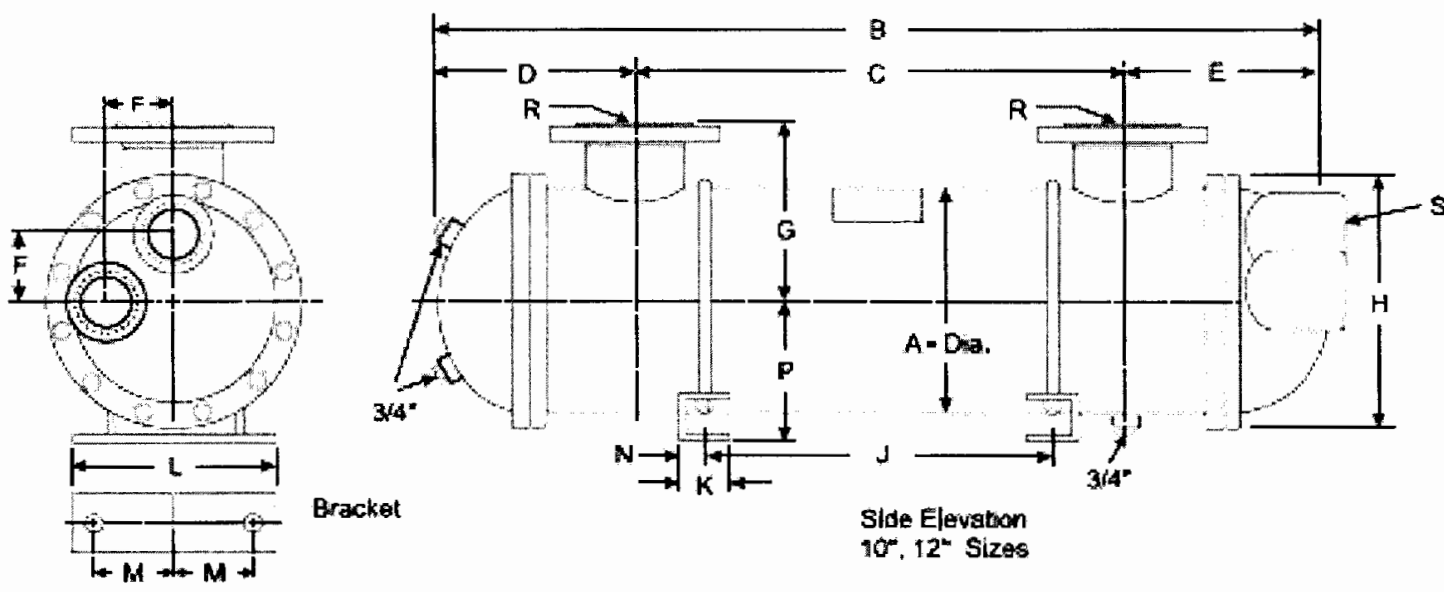

Side Elevation

10\%, $12^{4}$ Sizes

Figure L-1. Elevation drawing of a typical cooler.

Table L-2. General installation diagram for primary and secondary coolers.

\begin{tabular}{|l|l|l|}
\hline & Primary (2 each) & Secondary (one does the job) \\
\hline A & 12.75 in & 12.75 in \\
\hline Head Wall thickness & 0.75 in & 0.5 in \\
\hline E2 & 72 in & 84 in \\
\hline Tube diameter & 0.375 in & 0.375 in \\
\hline Number of tubes & $255(128$ per vessel) & 150 \\
\hline
\end{tabular}




\section{API Heat Transfer}

API Basco

2777 Walden Avenue

Buffalo, NY 14225

QUOTATION

716-684-6700 Fax: 716-684-2129

mailto:/sales@apiheattransfer.com

Company: Brayton Energy, LLC

Phone: (603) 601-0450

Fax:

Attn: Jim Kesselli
Quote Number: DW0625470

Revision. 1

Quote Date: 8 Aug 2006

Quoted By: Daryl Werth

Reference:

In response to your inquiry, we are pleased to submit this quotation for your approval.

\begin{tabular}{|c|c|c|c|c|c|}
\hline $\begin{array}{c}\text { Item } \\
\#\end{array}$ & Qty & Description & $\begin{array}{c}\text { Weight, } \\
\text { Lbs }\end{array}$ & $\begin{array}{l}\text { Price Each } \\
\text { (\$US) }\end{array}$ & Total (\$US) \\
\hline 01 & 1 & $\begin{array}{l}\mathrm{HX}-1 \\
\text { Basco size } 10-228 \text { type }-\mathrm{E}-\text { per the } \\
\text { specification sheet dated 8/8/2006 }\end{array}$ & 0 & $\$ 21,580.00$ & $\$ 21,580.00$ \\
\hline 02 & 1 & $\begin{array}{l}\text { HX - } 2 \\
\text { Basco size 10-174 type -E- per the } \\
\text { specification sheet dated } 8 / 8 / 2006\end{array}$ & 0 & $\$ 19,160.00$ & $\$ 19,160.00$ \\
\hline
\end{tabular}

Rep Contact:

\section{API Heat Transfer}

Company: API Basco

2777 Walden Avenue

Buffalo, NY 14225

Phone: 716-684-6700

Title: Application Engineer

Fax: $716-684-2129$

Phone: $716-684-6700 \times: 287$

E-Mail: dwerth@apiheattransfer.com

Figure L-2. Price quote for primary and secondary coolers. 


\section{API Heat Transfer}

\section{Basco/Whitlock Shell and Tube Heat Exchanger}

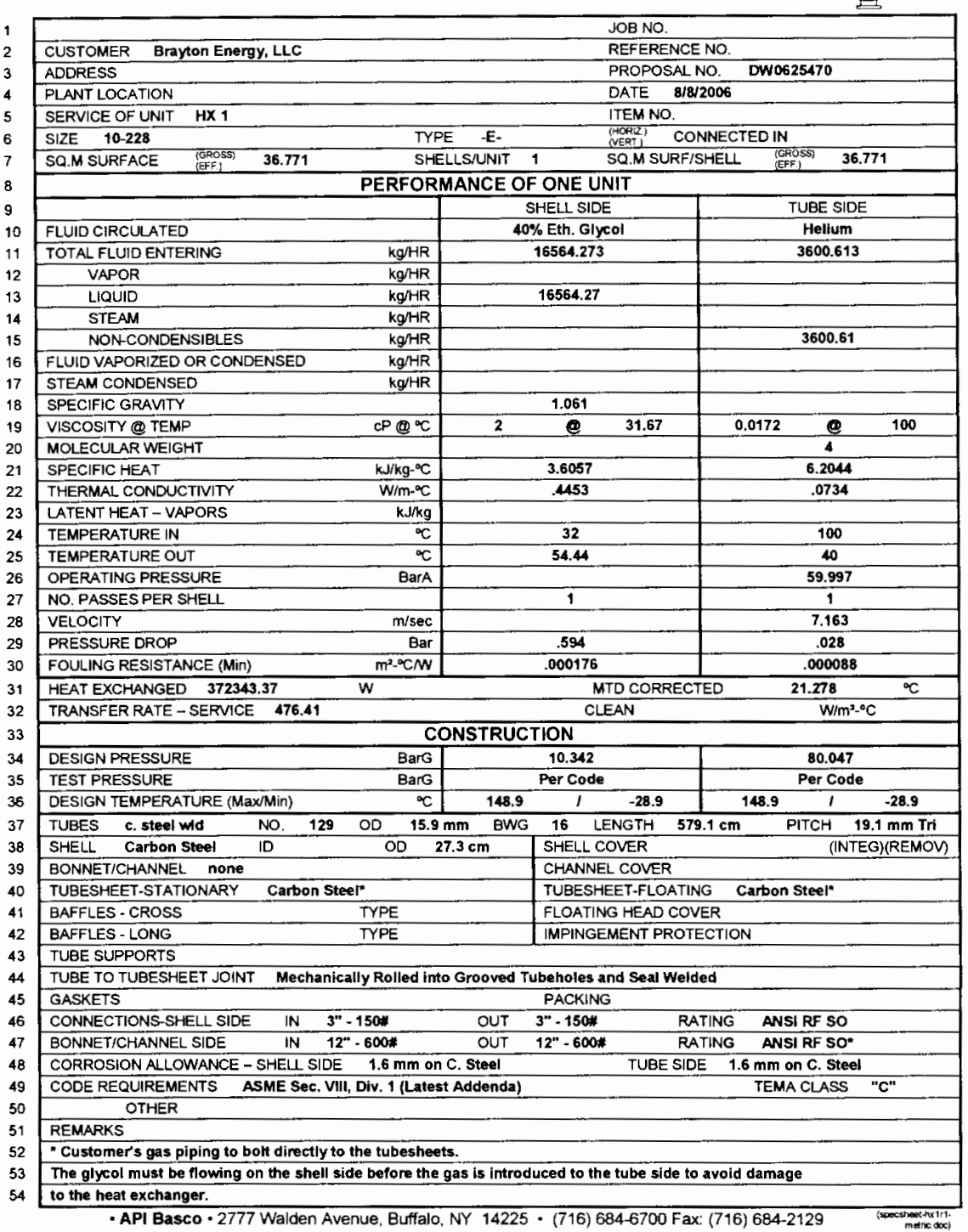

- mum apiheattransfer.com

Figure L-3. Specifications for Basco Shell and Tube Heat Exchanger. 
API Heat Transfer

Basco/Whitlock Shell and Tube Heat Exchanger

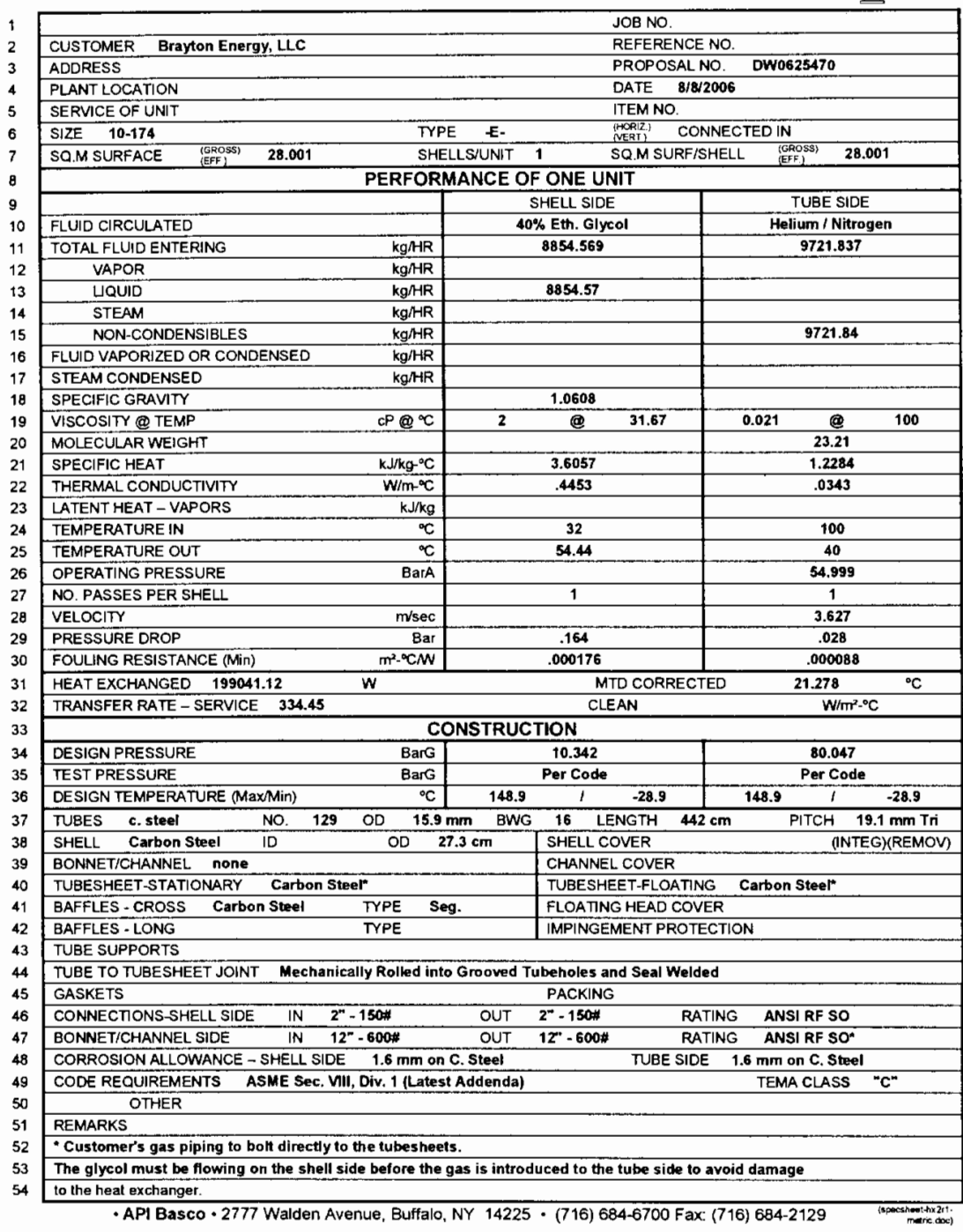

- unw apiheatranster com

Figure L-4. Specifications for Basco Shell and Tube Heat Exchanger. 


\section{Appendix M}

Fan-cooled Radiators - Specifications, Cost Quotes, and Installation Details 


\section{Price- FOB Tulsa OK USA}

Description Unit price USD qty Total Price USD

Air Cooled Heat Exchangers

$\$ 88,100 \quad 1 \quad \$ 88,100$

(1 bay, 2 bundles, 2 fans per unit) Ex Works

FOB Tulsa OK.

Terms: $\quad$ SPX Terms \& Conditions (Available upon request)

Price Basis: $\quad$ Budget $+/-10 \%$

Quotation Validity: 30 days

Material Delivery: Within 16-20 weeks from Approval of Basic Engineering Documents

Payment: Down Payment and Progress Payments based on engineering and material deliverables, net 30 days, essentially as follows:

- $15 \%$ Upon Submittal of Basic Engineering Documents (GA, FL)

- 35\% Upon Receipt of Tube and Fin Materials at Shop

- $50 \%$ Payments against bill of lading

Figure M-1. SPX Cooling Technologies Cost Estimate and Lead Time.

\section{Vendor Specification and Performance}

A statement of air cooler design conditions and the design selection by the vendor are shown below in Figure M-2. 


\begin{tabular}{|r|c|c|c|}
\hline ACHE DESIGN CONDITION & & Primery & Secondary \\
\hline Fluid & & $50 \%$ PGi50\% Water & $50 \%$ PG50\% water \\
\hline Total Fluid Flow & Lbsith & 9.571 & 48,413 \\
\hline Inlet Temperature & ${ }^{\circ} \mathrm{F}$ & 213.8 & 255.2 \\
\hline Outlet Temperature & ${ }^{\circ} \mathrm{F}$ & 104 & 104 \\
\hline Design heat duty & MM Buhr & 0.978 & 6.851 \\
\hline Inlet Air Dry Bulb Temperature & ${ }^{\circ} \mathrm{F}$ & 95 & 95 \\
\hline Tube side pressure drop & psi & 5.6 & 6.1 \\
\hline Site Elevation & $\mathrm{ft}$ & 4000 & 4000 \\
\hline
\end{tabular}

\begin{tabular}{|c|c|c|}
\hline ACHE DESIGN SELECTION & & \\
\hline Number of Bays per unit & - & 1 \\
\hline Plot Arrangement & $\begin{array}{l}\mathrm{ft} \\
\mathrm{ft}\end{array}$ & $\begin{array}{l}32^{\prime \prime} 0^{\prime \prime} \\
10^{\prime} 9^{\prime \prime}\end{array}$ \\
\hline $\begin{array}{r}\text { Drive Equipment } \\
\text { Number of Drive motor } \\
\text { Fan Diameter (Forced Draft) } \\
\text { Motor Size }\end{array}$ & $\begin{array}{c}- \\
\mathrm{ft} \\
\mathrm{HP}\end{array}$ & $\begin{array}{c}2 \\
9 \\
25 \\
\end{array}$ \\
\hline $\begin{array}{l}\text { Sound Pressure Level @ } 3 \mathrm{ft} \text { from ACE } \\
\text { Perimeter }\end{array}$ & $\mathrm{DB}(\mathrm{A})$ & 85 \\
\hline $\begin{array}{l}\text { Total Design Fan Power @ Fan shaft } \\
\text { (N) Fans Full) }\end{array}$ & $\mathrm{HP}$ & 42 \\
\hline
\end{tabular}

Figure M-2. SPX Design Conditions and Selection.

\section{Installation}

Figure M3 shows the configuration for two bundled heat exchangers. 


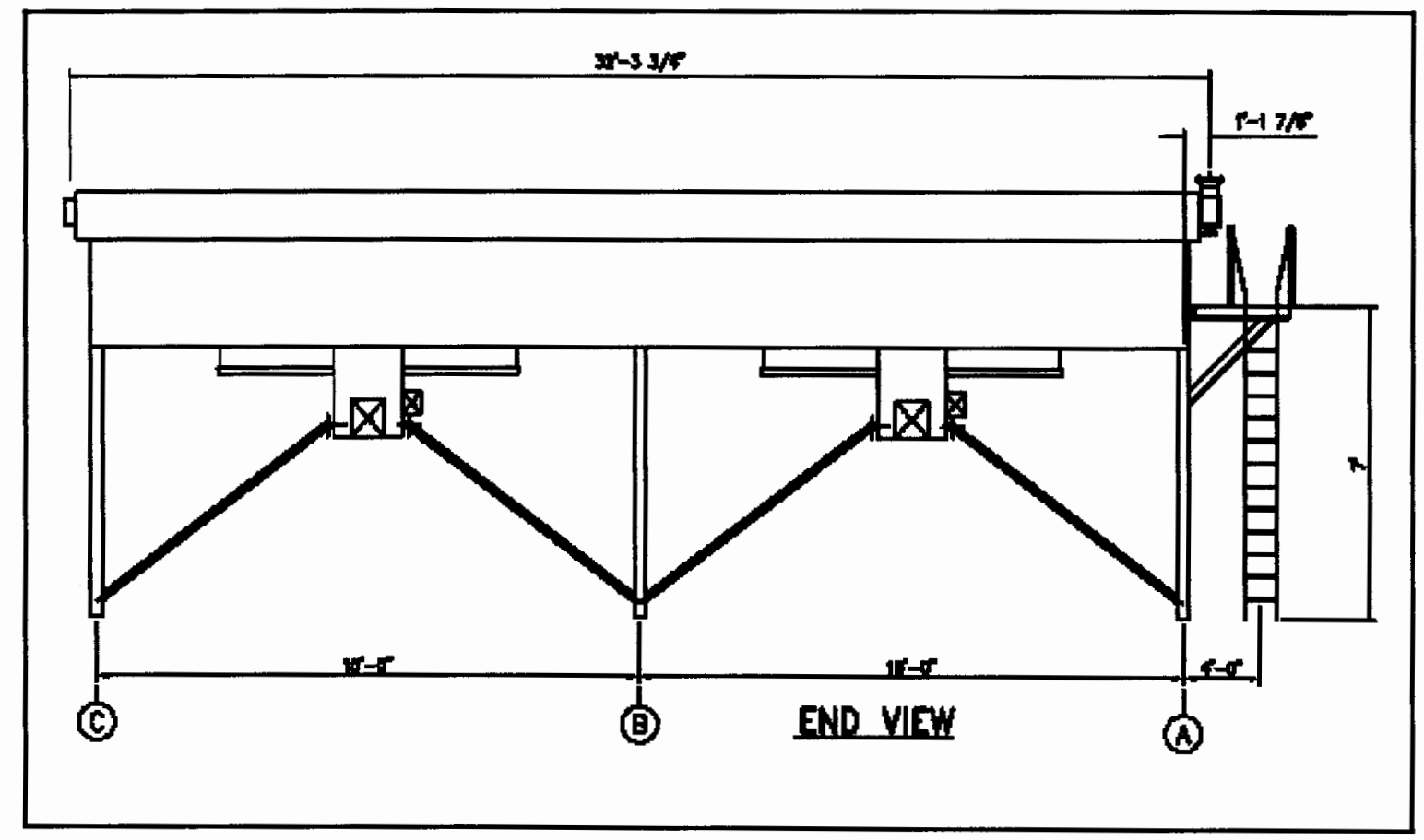

Figure M-3. Elevation View, Air-Cooled Heat Exchanger (ACHE). 